\title{
Automation of the Superpave mix design process for the West Virginia Division of Highways
}

\author{
Martin Felix Padula \\ West Virginia University
}

Follow this and additional works at: https://researchrepository.wvu.edu/etd

\section{Recommended Citation}

Padula, Martin Felix, "Automation of the Superpave mix design process for the West Virginia Division of Highways" (2002). Graduate Theses, Dissertations, and Problem Reports. 1288.

https://researchrepository.wvu.edu/etd/1288

This Thesis is protected by copyright and/or related rights. It has been brought to you by the The Research Repository @ WVU with permission from the rights-holder(s). You are free to use this Thesis in any way that is permitted by the copyright and related rights legislation that applies to your use. For other uses you must obtain permission from the rights-holder(s) directly, unless additional rights are indicated by a Creative Commons license in the record and/ or on the work itself. This Thesis has been accepted for inclusion in WVU Graduate Theses, Dissertations, and Problem Reports collection by an authorized administrator of The Research Repository @ WVU. For more information, please contact researchrepository@mail.wvu.edu. 


\title{
AUTOMATION OF THE SUPERPAVE MIX DESIGN PROCESS FOR THE WEST VIRGINIA DIVISION OF HIGHWAYS
}

\author{
MARTIN PADULA
}

Thesis submitted to the College of Engineering and Mineral Resources at West Virginia University in partial fulfillment of the requirements for the degree of

\author{
Master of Science \\ In \\ Civil and Environmental Engineering \\ Dr. John P. Zaniewski, Chair \\ Dr. Ronald W. Eck, \\ Mr. Michael Blankenship \\ Department of Civil and Environmental Engineering \\ Morgantown, West Virginia \\ 2002
}

Keywords: Superpave, Asphalt, Steel Slag, Computer Programming 


\section{ABSTRACT \\ AUTOMATION OF THE SUPERPAVE MIX DESIGN PROCESS FOR THE WEST VIRGINIA DIVISION OF HIGHWAYS \\ MARTIN PADULA}

During the fifty years between 1940 and 1990, the nation's bituminous roadways were predominantly designed using either the Marshall or Hveem method. The Superior $\underline{\text { Performing Asphalt Pavements (Superpave) }}{ }^{\mathrm{TM}}$ method was later developed to address the issues of increased traffic volumes and heavier loads on the nation's roadways. This new mix design process relies on volumetric calculations and graphs, which are cumbersome to perform by hand. There is no current public domain Superpave software package available which is independent of any commercial laboratory product and available to an asphalt mix designer. A component of this research project consisted of creating a generic Superpave mix design program that can be utilized by anyone, regardless of the laboratory equipment used for testing.

The goal of this research is to create a fully functional software package to automate the entire Superpave mix design process. The program was then used to design asphalt mixes made of steel slag obtained from International Mill Service, Inc. (IMS) as the only aggregate type. Steel slag aggregate offers a cost effective alternative to conventional aggregates used in asphalt mixes. Various mix designs were created, using only steel slag, in an attempt to meet all volumetric requirements. The steel slag mix performance was then evaluated with respect to rutting. These results were compared to mixes created with limestone and other natural aggregates to determine performance of the software and feasibility of slag utilization. After numerous aggregates structures and binder trials, no acceptable mix design could be created comprised of IMS steel slag. 


\section{ACKNOWLEDGEMENTS}

I would like to thank Dr. John Zaniewski for his unceasing support and assistance throughout the research and thesis writing process. I am grateful that he made me work harder than I ever thought was possible, in the process making me a stronger person and better engineer. Without his guidance and encouragement, I never would have been able to accomplish so much.

I would also like to thank Dr. Ronald Eck and Mr. Michael Blankenship for being on my thesis committee. The time and effort they put into revising and correcting my thesis, while adding helpful comments about improving the text, made the document a much more complete and polished work.

Also deserving of much thanks are my parents, Donald and Ann Padula. Without their constant love and support, my success would never have been possible.

A special thanks goes to Jennifer Morris, fellow graduate student, friend, and constant source of encouragement and strength. She helped me deal with the challenges that each day presented and encouraged me not to give up on my goals.

Keith Lesch, Christian Duvall, Karl Leslie and Vincent Medved also provided expert advice in the computer programming, for their time and energy, I am extremely grateful.

Thanks also goes to Andy Kincell, Carlos Reyes, David Diaz, Sean Rafferty, and Sri Harsha Nallamothu, their help in the West Virginia University Asphalt Laboratory is appreciated. 


\section{TABLE OF CONTENTS}

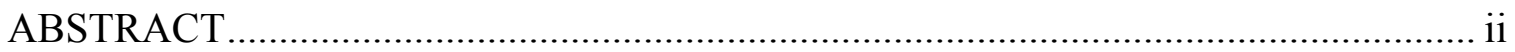

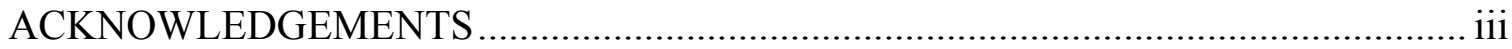

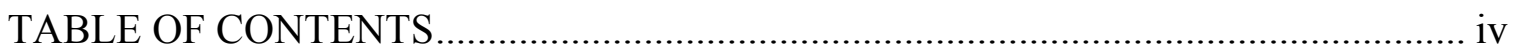

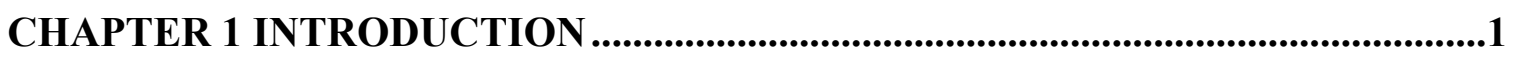

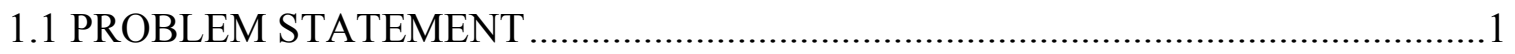

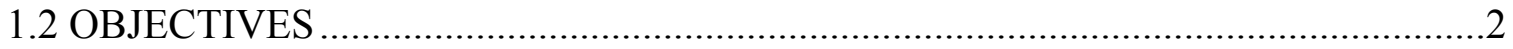

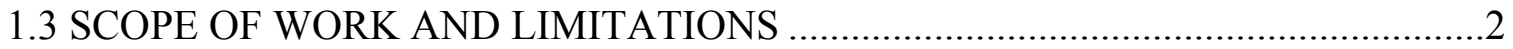

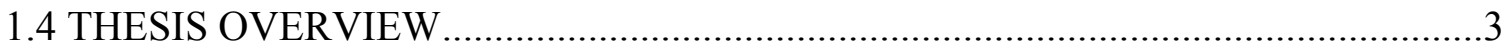

CHAPTER 2 LITERATURE REVIEW ....................................................................

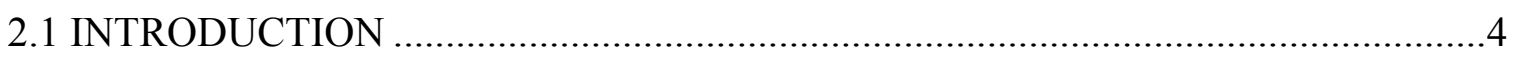

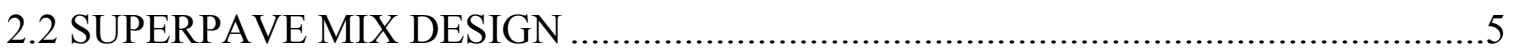

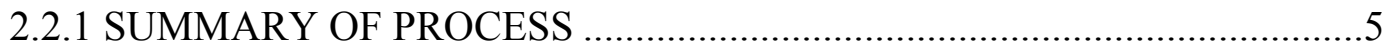

2.2.2 MIX COMPOSITION INFORMATION …………...................................

2.2.3 AGGREGATE CONSENSUS PROPERTIES ...............................................

2.2.4 DAS ASPHALT CONTENT ESTIMATING ………..............................11

2.2.5 MAXIMUM THEORETICAL SPECIFIC GRAVITY TESTING................14

2.2.6 GYRATORY COMPACTOR SAMPLES ……………………................16

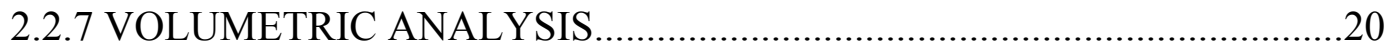

2.2.8 VOLUMETRIC ANALYSIS ADJUSTMENTS …....................................24

2.2.9 DETERMINING OPTIMUM ASPHALT CONTENT ………….................26

2.2.10 FINAL TESTS TO EVALUATE ACCEPTABILITY …………………......29

2.2.11 ASPHALT PAVEMENT ANALYZER ……………….............................

2.2.12 AVAILABLE SUPERPAVE SOFTWARE …………...............................32

2.3 STEEL SLAG AS AN HMA AGGREGATE ALTERNATIVE...................................33

2.4 MICROSOFT EXCEL AS A SOFTWARE DEVELPMENT TOOL ...........................35

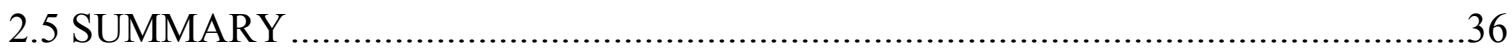

CHAPTER 3 RESEARCH METHODOLOGY ..........................................................37

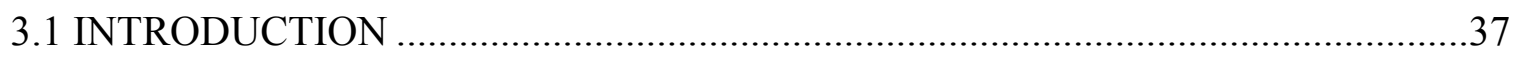

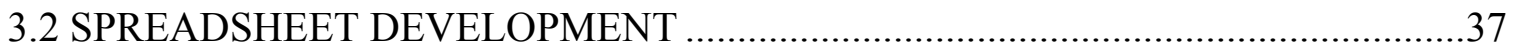

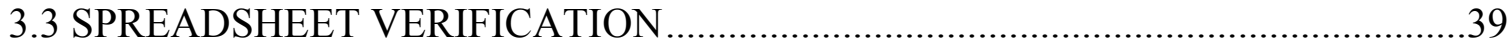

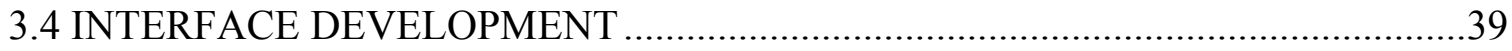




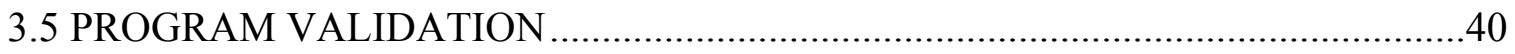

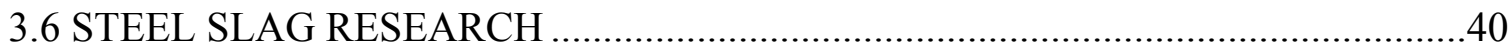

CHAPTER 4 PROGRAM STRUCTURE AND VALIDATION...................................41

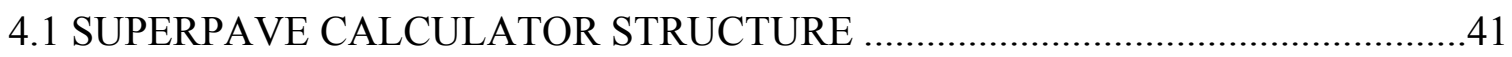

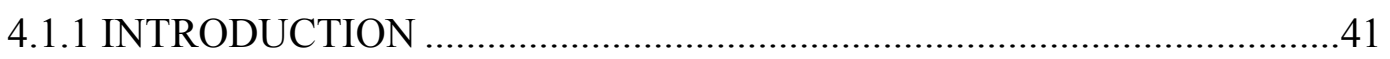

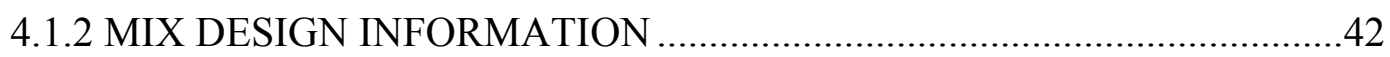

4.1.3 DESIGN AGGREGATE STRUCTURE DETERMINATION .....................42

4.1.4 DESIGN AGGREGATE STRUCTURE VOLUMETRICS..........................44

4.1.5 VOLUMETRICS USING FOUR DIFFERENT ASPHALT CONTENTS..44

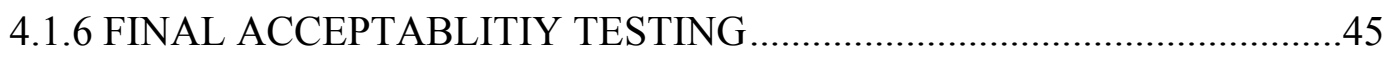

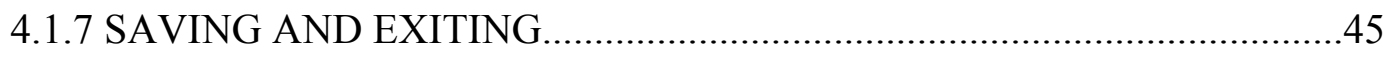

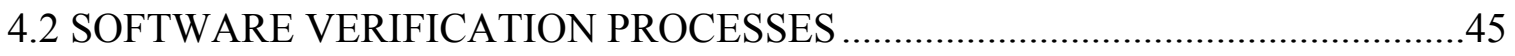

4.3 PROGRAM FUNCTIONALITY VALIDATION.....................................................

4.4 ACCEPTABILITY OF SUPERPAVE CALCULATOR RESULTS ...........................46

4.5 LABORATORY VALIDATION OF SOFTWARE..................................................47

CHAPTER 5 MIX DESIGN OF STEEL SLAG ASPHALT …...................................53

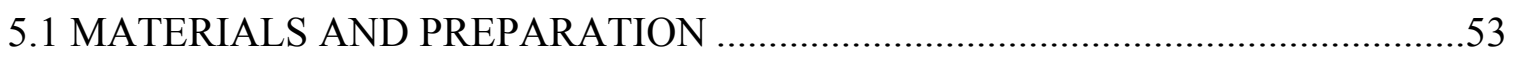

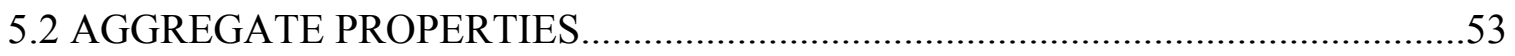

5.3 INITIAL MIX DESIGN TRIALS USING STEEL SLAG .........................................54

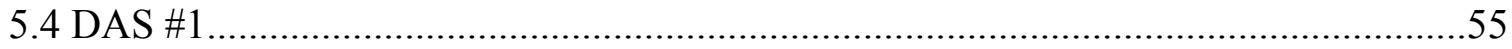

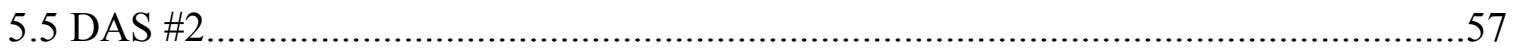

5.6 DAS FROM LITERATURE TO DETERMINE OPTIMUM BINDER

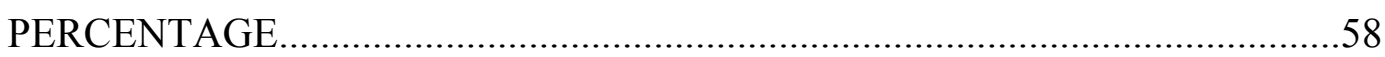

5.7 EVALUATION OF RUT SUSCEPTIBILITY AND CONCLUSIONS ......................60

CHAPTER 6 CONCLUSIONS/RECOMMENDATIONS..............................................61

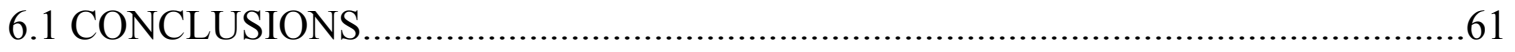

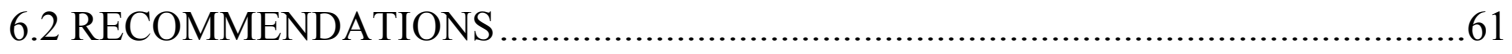

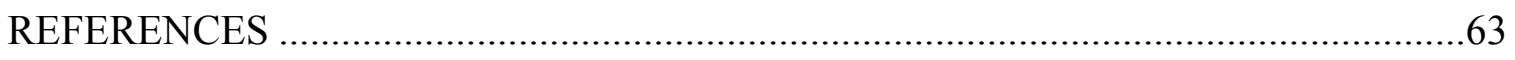

APPENDIX A SCREEN SHOTS FROM SUPERPAVE CALCULATOR ……………....66

APPENDIX B SUPERPPAVE CALCULATOR USER'S MANUAL ............................108

APPENDIX C SLAG AGGREGATE EVALUATION LABORATORY RESULTS...120

VITA 


\section{LIST OF FIGURES}

Figure 2.1 Superpave Mix Design Summary Sheet.................................................... 6

Figure 2.2 Flat/Elongated Test Dimensional Labels..................................................... 10

Figure 2.3 Superpave Gyratory Compactor ................................................................. 17

Figure 2.4 VTM v/s Asphalt Content (Interpolation Graph) ……………...................... 27

Figure 2.5 VMA v/s Asphalt Content (Interpolation Graph)............................................ 27

Figure 2.6 VFA v/s Asphalt Content (Interpolation Graph) ............................................ 28

Figure $2.7 \% \mathrm{G}_{\mathrm{mm}, \mathrm{Nini}} \mathrm{V} / \mathrm{s}$ Asphalt Content (Interpolation Graph)..................................... 28

Figure 2.8 D/b Ratio v/s Asphalt Content (Interpolation Graph) ...................................... 28

Figure 4.1 Structure of User Interface for Superpave Calculator ..................................... 43

Figure 4.2 Actual Job Mix Formula Sheet for Superpave Mix Design ........................... 51

Figure 5.1 Interpolation of VTM v/s Percent Binder.................................................... 56

Figure 5.2 Interpolation of VMA v/s Percent Binder .................................................. 56

Figure 5.3 Interpolation of VFA v/s Percent Binder...................................................... 57

Figure A.1 Introduction to Superpave Calculator............................................................. 67

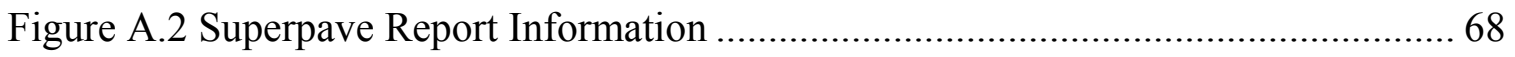

Figure A.3 Superpave Calculator Worksheet Choices .................................................... 69

Figure A.4 Mix Information Worksheet............................................................... 70

Figure A.5 Calculated Aggregate Consensus Properties Worksheet................................ 71

Figure A.6 Aggregate Data Worksheet.............................................................................. 72

Figure A.7 Aggregate Gradation Chart.................................................................. 73

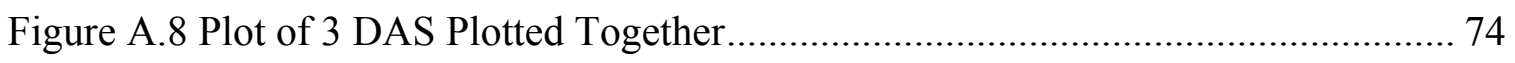

Figure A.9 Asphalt Content Estimator for Design Aggregate Structure ........................... 75

Figure A.10 Weigh-Out Sheets for Design Aggregate Structure Volumetrics.................. 76

Figure A.11 Sample Rice Weigh-Out Sheet, Cumulative Sieve Weights ......................... 77

Figure A.12 Sample Rice Weigh-Out Sheet, Individual Sieve Weights .......................... 78

Figure A.13 Sample Pill Weigh-Out Sheet, Cumulative Sieve Weights1 ........................ 79

Figure A.14 Sample Pill Weigh-Out Sheet, Individual Sieve Weights ............................ 80

Figure A.15 Data Entry Form for Rice and Pill Tests for Each DAS.............................. 81

Figure A.16 DAS Pill and Rice Test Analysis Worksheet .............................................. 82

Figure A.17 Adjusted Volumetrics for Design Aggregate Structures .............................. 83

Figure A.18 Percent Binder Estimates for User Defined DAS (If Needed) ...................... 84

Figure A.19 Final DAS and Percent Binder Estimate Confirmation................................. 85 
Figure A.20 Weigh-Out Sheets for Percent Binder Trial Volumetrics.............................. 86

Figure A.21 Sample Rice Weigh-Out Sheet for Cumulative Sieve Weights ................... 87

Figure A.22 Sample Rice Weigh-Out Sheet for Individual Sieve Weights....................... 88

Figure A.23 Sample Pill Weigh-Out Sheet for Cumulative Sieve Weights ..................... 89

Figure A.24 Sample Pill Weigh-Out Sheet for Individual Sieve Weights ....................... 90

Figure A.25 Final Volumetric Information Entry Worksheet .......................................... 91

Figure A.26 Percent Binder Trials Volumetric Analysis.................................................. 92

Figure A.27 Graphs of Mix Properties v/s Asphalt Content............................................ 93

Figure A.28 Chart of Interpolated Final Volumetrics.................................................... 94

Figure A.29 Weigh-Out Sheets for Optimum Asphalt Content Volumetrics ................... 95

Figure A.30 Rice Weigh-Out Sheet - Cum. Sieve Weights for Final Volumetrics ......... 96

Figure A.31 Rice Weigh-Out Sheet - Individual Sieve Weights for Final Volumetrics .. 97

Figure A.32 Pill Weigh-Out Sheet - Cumulative Sieve Weights for Final Volumetrics.. 98

Figure A.33 Pill Weigh-Out Sheet - Individual Sieve Weights for Final Volumetrics .... 99

Figure A.34 Volumetric Data Entry Worksheet for Optimum Asphalt Content ............ 100

Figure A.35 Volumetric Data Analysis for Optimum Asphalt Content ........................ 101

Figure A.36 Agg. Weigh-Out and Data Entry Worksheets for Tensile Strength Ratio.. 102

Figure A.37 Aggregate Weigh-Out Sheet for TSR Pill, Cumulative Sieve Weights .... 103

Figure A.38 Aggregate Weigh-Out Sheet for TSR Pill, Individual Sieve Weights ....... 104

Figure A.39 Exit Screen for Superpave Calculator .......................................................... 105

Figure A.40 Sample Job Mix Formula Print Out (Produced Using Trial Data) ............. 106

Figure A.41Sample Weigh-Out Sheet Print-Out (Using Trial Data).............................. 107

Figure C.1 Blended Gradation for Trials 1-4 (64\% \#57 Slag \& 36\% \#10 Slag) ............ 121

Figure C.2 Blended Gradation for Trial 5 (72\% \#57 Slag \& 28\% \#10 Slag) ................. 122

Figure C.3 Blended Gradation for Trials 6 \& 6.1 (Gradation from Literature).............. 123

\section{LIST OF TABLES}

Table 2.1 Control Points for Each Nominal Maximum Aggregate Size ............................ 8

Table 2.2 WVDOH Superpave Aggregate Consensus Property Requirements 2002 ...... 11

Table 2.3 Total Rice Sample Mass for Each Maximum Aggregate Size ........................... 15

Table 2.4 Number of Compaction Gyrations based on ESAL Data .................................. 18

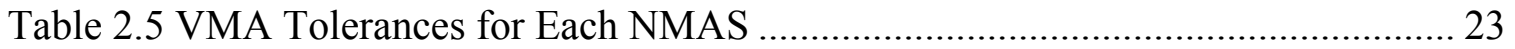

Table 2.6 VFA Tolerances for Traffic ESALs........................................................... 23 
Table $2.7 \% \mathrm{G}_{\mathrm{mm} \text {,Nini }}$ Tolerances for Traffic ESALs ....................................................... 24

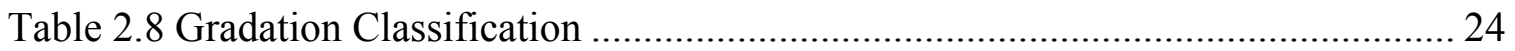

Table 2.9 Theoretical Data to Illustrate Mix Properties Interpolation Method ................ 27

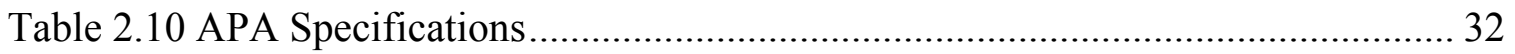

Table 4.1 Data Used for Validation of Superpave Calculator .......................................... 48

Table 4.2 Comparison of Actual and Theoretical DAS Analysis...................................... 49

Table 4.3 Comparison of Optimum Binder Percentage Analysis and Final Test Results 50

Table 5.1 Dry Sieve Gradation Analysis Results......................................................... 53

Table 5.2 Calculated Steel Slag Specific Gravity and Absorption Values ....................... 54

Table 5.3 Trial 1Volumetric Summary …………………....................................... 54

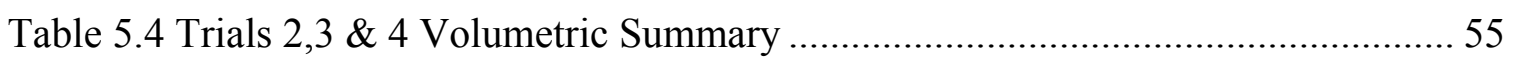

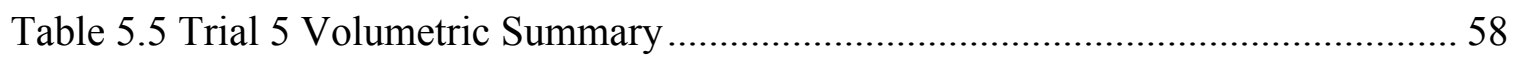

Table 5.6 Steel Slag Gradation from Literature Review............................................... 59

Table 5.7 Trial 6 Average Volumetric Summary …………………………………….... 59

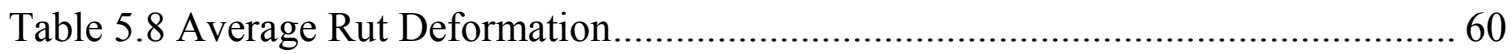

Table C.1 Estimated Binder Percentages from Aggregate Data................................... 124

Table C.2 Bulk Specific Gravity and Absorption of 3/4" Slag........................................ 125

Table C.3 Bulk Specific Gravity and Absorption of 1/2" Slag...................................... 126

Table C.4 Bulk Specific Gravity and Absorption of 3/8" Slag...................................... 127

Table C.5 Bulk Specific Gravity and Absorption of \#4 Slag ......................................... 128

Table C.6 Summary of Bulk Specific Gravity and Absorption for Coarse Steel Slag ... 129

Table C.7 Fine Steel Slag Aggregate Bulk Specific Gravity and Absorption................ 130

Table C.8 Trial 1 Volumetric Data .......................................................................... 131

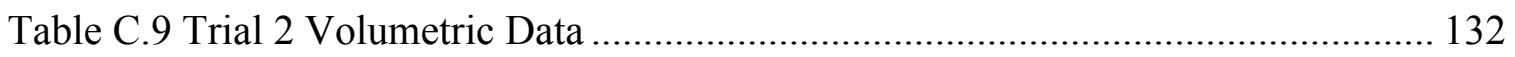

Table C.10 Trial 3 Volumetric Data ……………………..................................... 133

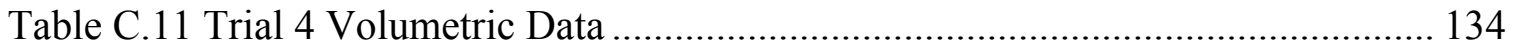

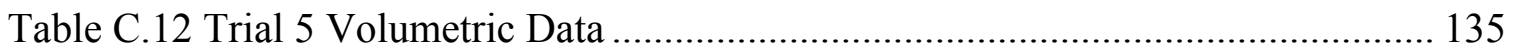

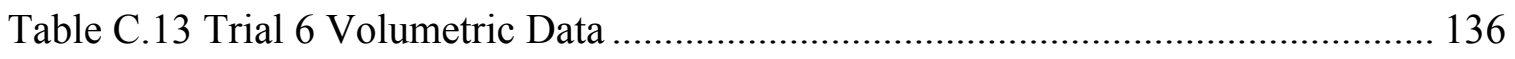

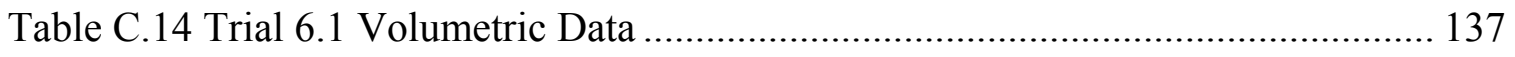

Table C.15 Trial 1 Pill and Rice Test Data and Calculations ........................................ 138

Table C.16 Trial 2 Pill and Rice Test Data and Calculations ....................................... 139

Table C.17 Trial 3 Pill and Rice Test Data and Calculations ......................................... 140

Table C.18 Trial 4 Pill and Rice Test Data and Calculations ......................................... 141 
Table C.19 Trial 5 Pill and Rice Test Data and Calculations .................................... 142

Table C.20 Trial 6 Pill and Rice Test Data and Calculations ...................................... 143

Table C.21 Trial 6.1 Pill and Rice Test Data and Calculations .................................... 144

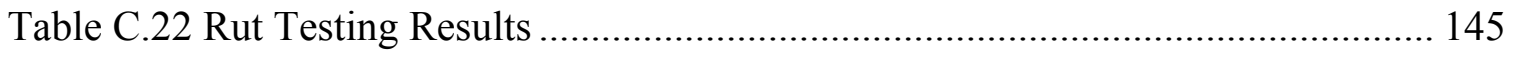




\section{CHAPTER 1 INTRODUCTION}

During the fifty years between 1940 and 1990, the nation's bituminous roadways were predominantly designed using either the Marshall or Hveem method. In the mid 1990 's, the Superior Performing Asphalt Pavements (Superpave) ${ }^{\mathrm{TM}}$ method was developed to address the issues of increased traffic volumes and heavier loads on the nation's roadways. This new mix design process relies on volumetric calculations and graphs, which are cumbersome to perform by hand. Various companies have created Superpave mix design software which directly interfaces with their laboratory equipment. However, there is not a public domain Superpave software package independent of any commercial laboratory product and available to any asphalt mix designer. There is a need for a generic Superpave mix design program that can be utilized by anyone, regardless of the laboratory equipment used for testing.

Steel slag has been used as a Hot Mix Asphalt (HMA) aggregate in many steel producing states since the mid-1960's. Slag has been blended with gravel and crushed stone aggregates to provide a mix with excellent stability and stripping resistance. An investigation of a mix with steel slag as the only aggregate is needed to determine if a mix design for West Virginia roadways is possible.

\subsection{PROBLEM STATEMENT}

The major benefit of the Superpave mix design procedure is the creation of a superior bituminous pavement that will resist rutting and deformation. The drawback to the process is the intensive and involved nature of the analysis. The entire mix design procedure requires over thirty equations, all of which are interconnected and dependent on the aggregate and binder properties. There is currently no public domain software on the market allowing the mix design process to proceed from aggregate stockpile data to a complete mix design. This lack of Superpave software yields non-uniformity in the mix design submissions, hand calculations and graphs and variability in the mix design format submitted to the highway agency.

Due to the presence of the steel industry in Southwest Pennsylvania and North West Virginia, steel slag has been used in a limited capacity for past Marshall mix 
designs. Because of the development of the Superpave mix design process, information on a Superpave mix consisting of only steel slag would be valuable. Since no empirical data is available on mix designs consisting solely of steel slag as the aggregate, research and testing is required.

\subsection{OBJECTIVES}

The objective of this research was to create a software package that would automate the entire Superpave mix design procedure, then validate the program by creating a mix comprised solely of steel slag aggregate. The goal of the project was to create a "user-friendly" program in Excel that can be used by any mix designer and be easily updated as needed. The program produces printed output in a format compatible with the requirements of the WVDOH. The slag research was intended to determine if a mix design comprising only inexpensive steel slag aggregate was able to meet all necessary criteria and display superior rutting resistance.

\subsection{SCOPE OF WORK AND LIMITATIONS}

In this research work, software to automate the Superpave mix design method was developed and mixes were created using only locally produced steel slag as the aggregate. The Superpave mix design procedures of the West Virginia Division of Highways (WVDOH) were followed along with the Materials Procedure (MP) dealing with bituminous pavements. The gyratory compactor was used to make the Asphalt Pavement Analyzer (APA) samples to determine the bulk specific gravity and evaluate rut susceptibility.

The Superpave mix design process requires evaluation of aggregate characteristics, including gradations, prior to the determination of binder content. Once the aggregate characteristics are determined, the Superpave analysis process is used to estimate binder contents, then asphalt concrete samples are prepared and tested. The software developed during this research focuses on the Superpave analysis. Therefore, the assumption was made that the designer would complete the aggregate evaluation prior to using the software. The software does not allow for the analysis of aggregate characteristics. 
In the mix design process, the user is only allowed to use up to four sources of aggregates per mix design. Generally, it is not feasible for a contractor to use more than four stockpiles in a mix of asphalt concrete, so this should not be a limitation on the application of the program.

The experimental design used for this research work provides a comparison between the mixes created using the software versus those produced by an independent contractor. International Mill Service, Inc. (IMS), located in Weirton, WV provided the steel slag used for the research. The asphalt used was PG 64-22 from Marathon-Ashland. The work was limited to Superpave mixes created in West Virginia and was also limited to laboratory testing. Field evaluation could not be performed since the WVDOH has not constructed any mixes designed using the Superpave Calculator software package.

\subsection{THESIS OVERVIEW}

This thesis is organized into six chapters and three appendices. After the introductory chapter, Chapter 2 presents a summary of literature review. Superpave mix design procedures are outlined with standard test procedures and required WVDOH specifications. An explanation of the determination of maximum theoretical specific gravity, bulk specific gravity, tensile strength ratio and volumetric calculations are included in the literature review. The method of rut testing with the Asphalt Pavement Analyzer (APA), as specified by the device manufacturer, is also explained. The research methodology and procedures for spreadsheet development and verification, along with interface creation and validation is presented in Chapter 3. Chapter 4 presents the software verification process and structure. Chapter 5 provides an overview of the steel slag mix design and testing. Chapter 6 completes the thesis with the conclusions and recommendations.

Appendix A presents the Superpave Calculator program screen captures along with sample print-outs. The user's manual for the Superpave Calculator comprises Appendix B. Appendix C includes all of the calculated data and computed values throughout the steel slag research and testing. 


\section{CHAPTER 2 LITERATURE REVIEW}

\subsection{INTRODUCTION}

The first recorded instance of roads utilizing bituminous pavement techniques dates back to ancient Babylon between 625 and 604 BC. These roadways were nothing more than soil and stone cart paths covered with a layer of tar, or asphalt binder, from a nearby well, called the Fountain of Is, which helped to improve the integrity and useful life of the surface (Baird, 2000). The layer of asphalt waterproofed the roadway, which made it less susceptible to rutting during the muddy times and it also helped to control the dust during the dry periods.

The first roadway paved with bituminous hot mix asphalt (HMA) in the United States was Pennsylvania Avenue in Washington DC in 1876 (Rock Binder's Inc., 2002). A group of army engineers used natural asphalt from Trinidad Lake, located on Island of Trinidad, to pave the road in front of the White House. The surface lasted for 11 years, enduring variable weather conditions and heavy traffic.

By the 1940's, scientists and engineers better understood the nature of HMA paving and the Marshall and Hveem mix design methods were coming into prominence. For the next fifty years, the majority of the roadways built in the United States used one of these two methods, but in the late 1980's, the Strategic Highway Research Program was initiated to develop a better mix design approach. In the mid 1990's, the Superior $\underline{\text { Performing Asphalt Pavements (Superpave) }}{ }^{\mathrm{TM}}$ method was developed to address the issues of increased traffic volumes and heavier loads on the nation's roadways. The 2000 Superpave Implementation survey shows that almost every state in the US is at some stage of Superpave implementation (FHWA, 2000). This trend necessitates utilizing modern technology for a streamlined, cost-effective approach to the development of asphalt mix designs.

The Superpave mix design method is described in this chapter. The analytical procedure requires the execution of a series of equations for the volumetric analysis and estimated optimum percent binder. The Microsoft Excel spreadsheet program is well suited for the required analysis and the features implemented during the research are 
briefly presented in this chapter. For software verification, research on steel slag as a viable coarse and fine aggregate alternative was explored and numerous design aggregate structures and binder percentages were tried. A brief review of literature concerning steel slag as an HMA aggregate is also included in this chapter.

\subsection{SUPERPAVE MIX DESIGN}

The Superpave mix design process encompasses a number of tests and procedures which, when properly implemented, provide the information needed to design asphalt concrete. The design process is performed to ensure that seven main objectives are met and the final product meets the criteria for acceptable quality and performance in the following areas (Roberts, et al., 1996):

- Resistance to Permanent Deformation - Pavement should not distort or displace when subjected to traffic

- Fatigue Resistance - Pavement should not crack when subjected to repeated loads

- Resistance to Low Temperature Cracking - Roadways created with the proper binder selection have minimized problems

- Durability - The mix must contain sufficient asphalt cement to ensure an adequate film thickness around the aggregates, which minimizes cement aging during service

- Resistance to Moisture Induced Damage - Proper aggregates must be selected to prevent loss of adhesion between the aggregate surface and the asphalt binder

- Skid Resistance - The mix must be designed to provide sufficient resistance to skidding during normal turning and breaking movements

- Workability - The mix must be capable of being placed and compacted with reasonable effort

An outlined structure of the entire mix design process is presented in Figure 2.1. A more in-depth explanation of each step, including the science and assumptions behind the entire mix design procedure, is also included.

\subsubsection{SUMMARY OF PROCESS}

The entire Superpave mix design process, outlined in Sections 2.2.2 through 2.2.11 is concisely summarized in Figure 2.1, "Superpave Mix Design Steps" from a Superpave Asphalt Mixture Design Workshop (Zaniewski, 2002). 


\section{Superpave Mix Design Steps}

- Determine design aggregate structure

- Evaluate stockpiles

- Test for source properties

- Test for consensus properties-

Property

Dividing Sieve

Fine aggregate angularity

P $2.36 \mathrm{~mm}$

Sand equivalency

P $4.75 \mathrm{~mm}$

Flat and elongated

R $9.5 \mathrm{~mm}$

Coarse aggregate angularity

R $4.75 \mathrm{~mm}$

- Gradation

- Specific gravities, $\mathrm{G}_{\mathrm{sb}}, \mathrm{G}_{\mathrm{sa}}$

- Determine 3 blends that meet aggregate criteria

- Gradation - within control points, outside restricted zone

- Compute blended consensus properties

- Estimate asphalt content for each blend

- Make samples, mixing and compacting at temperatures specified by binder supplier

- Two samples compacted to $\mathrm{N}_{\text {des }}$

- Two $\mathrm{G}_{\mathrm{mm}}$ samples

○ Compute volumetrics, $\mathrm{G}_{\mathrm{mm}}, \mathrm{G}_{\mathrm{mb}}, \mathrm{oG}_{\mathrm{mm}}$, VTM, VMA, VFA, D/b, $\% \mathrm{G}_{\mathrm{mm}, \mathrm{Nini}}$

- Adjust volumetrics for 4\% VTM

- Select best design aggregate structure

- Determine optimum asphalt content

- Using best design aggregate structure and $P_{b \text {,est }}$, compact two samples to $N_{\text {des }}$ and two $G_{m m}$ samples at four asphalt contents

- $\mathrm{P}_{\mathrm{b}, \mathrm{est}}-0.5 \%$

- $\mathrm{P}_{\mathrm{b}, \mathrm{est}}$

- $\mathrm{P}_{\mathrm{b}, \mathrm{est}}+0.5 \%$

- $\mathrm{P}_{\mathrm{b}, \mathrm{est}}+1.0 \%$

○ Compute volumetrics, $\mathrm{G}_{\mathrm{mm}}, \mathrm{G}_{\mathrm{mb}}, \% \mathrm{G}_{\mathrm{mm}}, \mathrm{VTM}, \mathrm{VMA}, \mathrm{VFA}, \mathrm{D} / \mathrm{b}, \% \mathrm{G}_{\mathrm{mm}, \text { Nini }}$

- Plot volumetrics v/s percent asphalt

- Select optimum asphalt content at $\mathrm{P}_{\mathrm{b} \text {, opt }}$ - corresponds to 4\% VTM and check volumetric criteria

- Compact two samples at $\mathrm{P}_{\mathrm{b} \text {, opt }}$ and check $\% \mathrm{G}_{\mathrm{mm}, \mathrm{Nmax}}<98 \%$

- Evaluate moisture sensitivity

- Compact six samples to $7 \%$ air, $95 \mathrm{~mm}$ tall

○ Condition three samples

- Measure split tensile strength of all samples

○ Check TSR $>80 \%$

Figure 2.1 Superpave Mix Design Summary Sheet 


\subsubsection{COMPOSITION INFORMATION}

When the West Virginia Division of Highways (WVDOH) determines that a new roadway is needed, or an existing road needs repaved, a list of mix guidelines is presented to a design laboratory. Mix design details, such as the 20-year design equivalent single axle loads (ESAL's), whether the mix will be a skid design, and the depth from the surface are provided. These are important factors in outlining the limits, tolerances, and controls for the mix design. The ESAL's determine the Fine Aggregate Angularity (FAA), the Flat/Elongated (F/E), and the Sand Equivalency (SE) limits, and also the Voids Filled with Asphalt (VFA) requirements and the needed gyrations for Percent of Theoretical Maximum Specific Gravity $\left(\% \mathrm{G}_{\mathrm{mm}, \mathrm{Nmax}}\right)$. The temperature range of the region controls the binder grade and specific gravity for the mix design. For example, a PG 64-22 binder is indicative of a geographic area having a seven-day average maximum pavement design temperature of $64^{\circ} \mathrm{C}$ and a minimum pavement temperature of $-22^{\circ} \mathrm{C}$. The specific gravity of the binder, while falling between 0.900 and 1.100 , is dependent on the binder type and producer and may vary slightly between suppliers. A function of the design layer surface of a bituminous roadway, the Nominal Maximum Aggregate Size (NMAS) also establishes limits and tolerances. The NMAS is defined as, "One sieve size larger than the first sieve to retain more than 10 percent of the material" (Roberts, et al., 1996). From this NMAS designation, the blended gradation control points, as well as the antiquated restricted zone, discussed in Section 2.2.3, are set forth.

\subsubsection{AGGREGATE CONSENSUS PROPERTIES}

Once the mix composition information is established, the aggregate gradation, source properties, and specific gravity are determined for each stockpile, either by physically testing each aggregate or relying on supplier provided data. The aggregates are blended to create a Design Aggregate Structure (DAS) and then a graph of the blend is analyzed to determine if the control points are violated. Each NMAS has specific control points, which the blend must be between to be considered acceptable. The control points for each NMAS are presented in Table 2.1 (WVDOT, 2000). 
Table 2.1 Control Points for Each Nominal Maximum Aggregate Size

\begin{tabular}{|c|c|c|c|c|c|c|c|c|c|c|c|c|}
\hline \multicolumn{13}{|c|}{ Nominal Maximum Aggregate Size Control Points - Limits on Percent Passing Each Sieve } \\
\hline SIEVE & \multicolumn{2}{|c|}{$37.5 \mathrm{~mm}$} & \multicolumn{2}{|c|}{$25 \mathrm{~mm}$} & \multicolumn{2}{|c|}{$19 \mathrm{~mm}$} & \multicolumn{2}{|c|}{$12.5 \mathrm{~mm}$} & \multicolumn{2}{|c|}{$9.5 \mathrm{~mm}$} & \multicolumn{2}{|c|}{$4.75 \mathrm{~mm}$} \\
\hline (mm) & Lower & Upper & Lower & Upper & Lower & Upper & Lower & Upper & Lower & Upper & Lower & Upper \\
\hline 50 & 100 & - & - & - & - & - & - & - & - & - & - & - \\
\hline 37.5 & 90 & 100 & 100 & 100 & - & - & - & - & - & - & - & - \\
\hline 25 & - & 90 & 90 & 100 & 100 & 100 & - & - & - & - & - & - \\
\hline 19 & - & - & - & 90 & 90 & 100 & 100 & 100 & - & - & - & - \\
\hline 12.5 & - & - & - & - & - & 90 & 90 & 100 & 100 & 100 & - & - \\
\hline 9.5 & - & - & - & - & - & - & - & 90 & 85 & 100 & 100 & 100 \\
\hline 4.75 & - & - & - & - & - & - & - & - & - & 80 & 90 & 100 \\
\hline 2.36 & 15 & 36 & 19 & 45 & 20 & 50 & 28 & 58 & 30 & 55 & - & 90 \\
\hline 1.18 & - & - & - & - & - & - & - & - & - & - & 40 & 65 \\
\hline 0.6 & - & - & - & - & - & - & - & - & - & - & - & - \\
\hline 0.3 & - & - & - & - & - & - & - & - & - & - & - & - \\
\hline 0.15 & - & - & - & - & - & - & - & - & - & - & - & - \\
\hline 0.075 & 1 & 6 & 1 & 7 & 2 & 8 & 2 & 10 & 2 & 9 & 3 & 11 \\
\hline Pan & - & - & - & - & - & - & - & - & - & - & - & - \\
\hline
\end{tabular}


In mixes created before 2002, an important requirement to be considered was the restricted zone, which lies along the maximum density line between the intermediate sieve size-either 4.75 or $2.36 \mathrm{~mm}$ depending on the NMAS of the mix-and the $0.3 \mathrm{~mm}$ sieve. It was believed that blends passing through this zone would lead to excessive rutting or "tender" mixes. Through empirical data over years of testing, it has been determined that a high quality mix can be created that passes through the restricted zone and thus the zone is no longer used to limit aggregate blends (WVDOH, 2000).

Each DAS blend is evaluated for acceptability with respect to fine aggregate angularity, coarse aggregate angularity, flat/elongated ratio, and the sand equivalency test. As required by Superpave, the consensus properties for the design aggregate blends are determined as:

- Coarse Aggregate Angularity (ASTM D 5821) -testing materials retained on $4.75 \mathrm{~mm}$ sieve.

- Fine Aggregate angularity (AASHTO T304) - testing materials passing the $2.36 \mathrm{~mm}$ sieve.

- Flat \& Elongated particles (ASTM D4791) - testing materials retained on $9.5 \mathrm{~mm}$ sieve.

- Sand Equivalent (AASHTO T176) -testing materials passing the $4.75 \mathrm{~mm}$ sieve.

A stockpile is not considered in the blended consensus property calculation if less than $10 \%$ of the stockpile applies to the property standard. For example, if less than 10 percent of a stockpile is retained on the $4.75 \mathrm{~mm}$ sieve, the coarse aggregate angularity is not considered for that stockpile.

In West Virginia, a slight modification to the fine aggregate angularity test has been implemented and is specified in MP 401.02.28 as follows in Note 12:

Note 12: "Fine aggregates sizes that are coarse graded and have only a small amount of minus $600 \mathrm{~mm}$ (No. 30) material often cannot be individually tested using (the method described in AASHTO T304). Such aggregates must be blended with the other fine aggregates of the mixture to the specified mix design proportions before testing can be conducted." (WVDOT, 2000) 
Equation 2.1 is used for blending the aggregate consensus properties:

$$
X=\frac{x_{1} P_{1} p_{1}+x_{2} P_{2} p_{2}+\ldots}{P_{1} p_{1}+P_{2} p_{2}+\ldots}
$$

where:

$\mathrm{X}=$ Blended consensus property;

$\mathrm{x}_{\mathrm{i}}=$ Consensus property for stockpile $\mathrm{i}$;

$\mathrm{P}_{\mathrm{i}}=$ Percent of stockpile $\mathrm{i}$ in the blend; and

$p_{i}=$ Percent of stockpile $i$ which either passes or is retained on the dividing sieve.

The flat and elongated test follows the general procedures of ASTM D 4791, but is modified for Superpave. Under the Superpave guidelines an aggregate particle coarser than $4.75 \mathrm{~mm}$ sieve is flat and elongated if the ratio of the maximum to minimum dimension is greater than 5 (Harman, et al., 1999). Figure 2.2 visually presents the dimensional labels of a typical aggregate, with the length being the maximum dimension and the width as the minimum dimension.

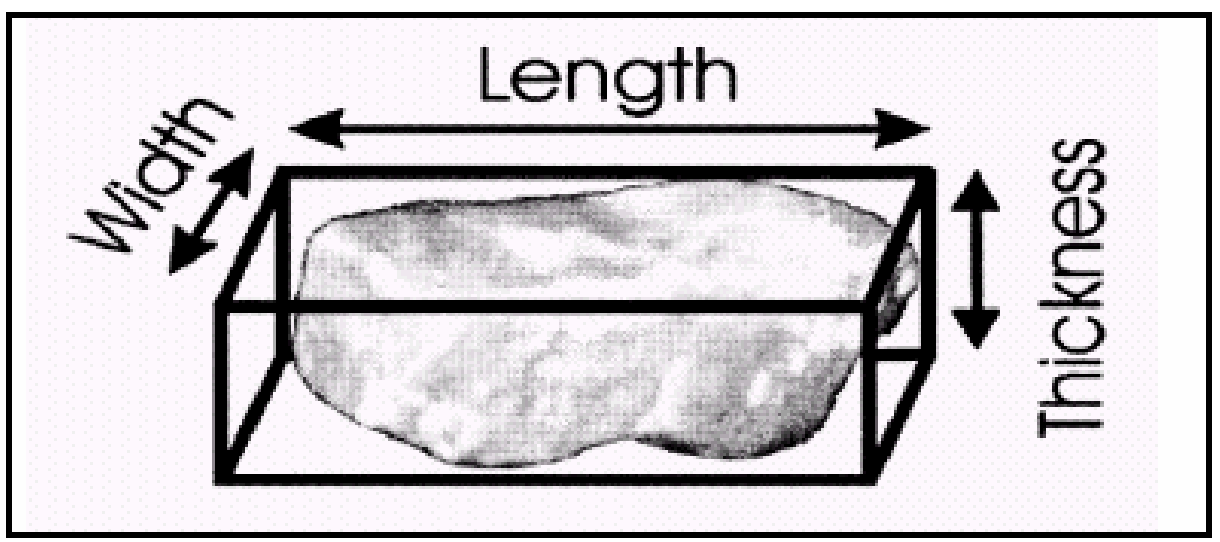

Figure 2.2 Flat/Elongated Test Dimensional Labels

Table 2.2 presents all of the aggregate consensus property requirements as determined by the WVDOH. The values are based solely on the design ESALs and are used when determining if a blended aggregate design structure is acceptable (WVDOT, 2000). These values have changed from the previous DOH specification; Table 2.2 reflects the most recent requirements. 
Each of these criteria are tested for the blended design aggregate structures, and any value that falls outside of these tolerances renders that blend unacceptable. In mixes prior to 2002, when the restricted zone was in effect, it was thought that blends that went underneath of the restricted zone provided a better structure. Now, with the restricted zone no longer an issue, the prevailing logic is to create two DAS coarser than and one DAS finer than the maximum density line on a FHWA 0.45 Power Gradation Chart (Harman, et al., 1999). The FHWA 0.45 Power gradation chart is used to define permissible gradations. This chart uses a unique graphing technique to judge the cumulative particle size distribution of a blend. The ordinate (y-axis) of the chart is percent passing. The abscissa (x-axis) is an arithmetic scale of sieve size opening in microns, raised to the 0.45 power (Harman, et al., 1999).

Table 2.2 WVDOH Superpave Aggregate Consensus Property Requirements 2002

\begin{tabular}{|c|c|c|c|c|c|c|}
\hline \multirow{2}{*}{$\begin{array}{l}\text { Design } \\
\text { ESALs } \\
\text { (millions) }\end{array}$} & \multicolumn{2}{|c|}{$\begin{array}{l}\text { Coarse Aggregate } \\
\text { angularity (\%min)* }\end{array}$} & \multicolumn{2}{|c|}{$\begin{array}{c}\text { Fine aggregate } \\
\text { angularity }(\% \mathrm{~min})\end{array}$} & \multirow{2}{*}{$\begin{array}{c}\begin{array}{c}\text { Sand } \\
\text { equivalent }\end{array} \\
\text { Percent } \\
\text { minimum }\end{array}$} & \multirow{2}{*}{$\begin{array}{c}\begin{array}{c}\text { Flat \& } \\
\text { elongated }\end{array} \\
\begin{array}{c}\text { Percent } \\
\text { minimum }\end{array}\end{array}$} \\
\hline & $\begin{array}{l}\leq 100 \mathrm{~mm} \\
\text { from } \\
\text { surface }\end{array}$ & $\begin{array}{l}>100 \mathrm{~mm} \\
\text { from } \\
\text { surface }\end{array}$ & $\begin{array}{l}100 \mathrm{~mm} \\
\text { from } \\
\text { surface }\end{array}$ & $\begin{array}{l}>100 \mathrm{~mm} \\
\text { from } \\
\text { surface }\end{array}$ & & \\
\hline$<0.3$ & $55 /-$ & - & - & - & 40 & - \\
\hline 0.3 to $<3$ & 75/- & 50/- & 40 & 40 & 40 & 10 \\
\hline 3 to $<10$ & $85 / 80$ & $60 /-$ & 45 & 40 & 40 & 10 \\
\hline 10 to $<20$ & $90 / 95$ & $80 / 75$ & 45 & 40 & 45 & 10 \\
\hline 10 to $<30$ & $95 / 90$ & $80 / 75$ & 45 & 40 & 45 & 10 \\
\hline 30 & $100 / 100$ & $100 / 100$ & 45 & 45 & 50 & 10 \\
\hline
\end{tabular}

After the three DAS are determined, trial mixes are created and tested to determine an optimum design aggregate structure, which provides a basis for the remainder of the mix design process.

\subsubsection{DAS ASPHALT CONTENT ESTIMATING}

Once three blends are created with consensus properties and control points within tolerances, each design aggregate structure's specific gravities are calculated to facilitate an asphalt content (AC) estimation. Two specific gravities are required for calculation of AC, the apparent specific gravity $\left(\mathrm{G}_{\mathrm{sa}}\right)$ and the bulk specific gravity $\left(\mathrm{G}_{\mathrm{sb}}\right)$. By definition, the specific gravity of an aggregate is the ratio of the weight of the unit volume of the 
material to the weight of an equal volume of water (Roberts, et al., 1996). The apparent specific gravity includes only the volume of the aggregate particle, while the bulk specific gravity includes the overall volume of the particle, as well as the volume of the pores that become filled with water after a 24-hour soaking. The specific gravities of the blend are calculated using Equation 2.2:

$$
G_{s b}=\frac{P_{1}+P_{2}+\ldots+P_{n}}{\frac{P_{1}}{G_{1}}+\frac{P_{2}}{G_{2}}+\ldots+\frac{P_{n}}{G_{n}}}
$$

where,

$\mathrm{G}_{\mathrm{sb}}=$ Blended specific gravity of aggregate;

$\mathrm{P}_{\mathrm{n}}=$ Percent of aggregate $n$ in the blend; and

$\mathrm{G}_{\mathrm{n}}=$ Specific gravity of aggregate $n$.

The asphalt content estimating process is repeated for each DAS. This repetition is necessary because the blends vary enough that one $\mathrm{AC}$ would not produce the required $4.0 \%$ air voids necessary for each structure. After the blended $\mathrm{G}_{\mathrm{sb}}$ and $\mathrm{G}_{\mathrm{sa}}$ are calculated, the effective specific gravity $\left(\mathrm{G}_{\mathrm{se}}\right)$ is calculated by using an estimated absorption factor (F) of 0.8 and target air voids of 4.0\% (Harman, et al., 1999). $\mathrm{G}_{\mathrm{se}}$ is estimated according to Equation 2.3 (WVDOH, 2000):

$$
G_{s e}=G_{s b}+F\left(G_{s a}-G_{s b}\right)
$$

where,

$\mathrm{G}_{\mathrm{se}}=$ Effective specific gravity of aggregate;

$\mathrm{G}_{\mathrm{sb}}=$ Bulk specific gravity of aggregate;

$\mathrm{F}=$ factor for absorption; and

$\mathrm{G}_{\mathrm{sa}}=$ Apparent specific gravity of aggregate.

The volume of absorbed binder is then calculated according to Equation 2.4

$$
V_{b a}=\frac{P_{s}\left(1-V_{a}\right)}{\frac{P_{b}}{G_{b}}+\frac{P_{s}}{G_{s e}}}\left(\frac{1}{G_{s b}}-\frac{1}{G_{s e}}\right)
$$


where,

$\mathrm{V}_{\mathrm{ba}}=$ Volume of absorbed binder;

$\mathrm{P}_{\mathrm{s}}=$ Percent of aggregate;

$\mathrm{V}_{\mathrm{a}}=$ Volume of air voids $(4.00 \%)$.

$\mathrm{P}_{\mathrm{b}}=$ Initial Estimate for asphalt binder content, percent by weight of mix;

$\mathrm{G}_{\mathrm{b}}=$ Specific gravity of binder; and

$\mathrm{P}_{\mathrm{s}}=$ Percent of aggregate;

$\mathrm{G}_{\mathrm{se}}=$ Effective specific gravity of aggregate; and

$\mathrm{G}_{\mathrm{sb}}=$ Bulk specific gravity of aggregate.

The estimated volume of effective binder $\left(\mathrm{V}_{\mathrm{be}}\right)$ is calculated according to Equation 2.5:

$$
V_{b e}=0.176-0.0675 \log \left(S_{n}\right)
$$

where,

$\mathrm{V}_{\mathrm{be}}=$ Volume of effective binder; and

$\mathrm{S}_{\mathrm{n}}=$ Nominal maximum sieve size of aggregate blend.

The estimated weight of stone $\left(\mathrm{W}_{\mathrm{s}}\right)$ is estimated with Equation 2.6 as:

$$
W_{s}=\frac{P_{s}\left(1-V_{a}\right)}{\left(\frac{P_{b}}{G_{b}}+\frac{P_{s}}{G_{s e}}\right)}
$$

where,

$\mathrm{W}_{\mathrm{s}}=$ Weight of aggregate $(\mathrm{g})$;

$\mathrm{P}_{\mathrm{s}}=$ Percent of aggregate;

$\mathrm{V}_{\mathrm{a}}=$ Volume of air voids $(4.00 \%)$;

$\mathrm{P}_{\mathrm{b}}=$ Initial Estimate for asphalt binder content, percent by weight of mix;

$\mathrm{G}_{\mathrm{b}}=$ Specific gravity of binder; and 
$\mathrm{G}_{\mathrm{se}}=$ Effective specific gravity of aggregate.

Finally, the estimated percent binder can be calculated, combining Equations 2.3 2.6 into Equation 2.7:

$$
P_{b \text { Trial }}=\frac{G_{b}\left(V_{b e}+V_{b a}\right)}{\left(G_{b}\left(V_{b e}+V_{b a}\right)\right)+W_{s}}
$$

where,

$\mathrm{P}_{\mathrm{b} T r i a l}=$ Percent (by weight) of binder for the initial trial;

$\mathrm{G}_{\mathrm{b}}=$ Specific gravity of binder;

$\mathrm{V}_{\mathrm{be}}=$ Volume of effective binder.

$\mathrm{V}_{\mathrm{ba}}=$ Volume of absorbed binder; and

$\mathrm{W}_{\mathrm{s}}=$ Weight of aggregate $(\mathrm{g})$.

The value for user defined percent binder $\left(\mathrm{P}_{\mathrm{b}}\right)$ in Equation 2.4 and $\mathrm{P}_{\mathrm{b} \text { Trial }}$ in Equation 2.7 must be equal, and Equations 2.4-2.7 are iterated until equality is achieved. The asphalt content for each DAS, once determined, is used for two gyratory compaction samples and two maximum theoretical specific gravity tests, then used to calculate an optimum asphalt content.

\subsubsection{MAXIMUM THEORETICAL SPECIFIC GRAVITY TESTING}

Once three design aggregate structures and their respective estimated percent binders are calculated, they are tested to determine which provides the best aggregate structure. To determine the properties of each DAS, the Rice test is used, in conjunction with the gyratory compactor, to determine the actual percentage of air voids, and the maximum and bulk specific gravities.

The maximum theoretical specific gravity test, developed by James Rice, referred to as the "Rice Test", is used to determine the maximum specific gravity $\left(\mathrm{G}_{\mathrm{mm}}\right)$ of a sample. $G_{m m}$ is defined as, "The ratio of the weight in air of a unit volume of an uncompacted bituminous paving mixture at a stated temperature to the weight of an equal volume of gas-free distilled water at a stated temperature" (AASHTO T 209-99, 2000). AASHTO standard T209-99 covers the procedures and calculations for determining $\mathrm{G}_{\mathrm{mm}}$. 
The methodology of this procedure is the same for all samples, but the maximum aggregate size (MAS) of the blend determines the total mass of the sample to be used for testing and is illustrated in Table 2.3. The maximum aggregate size is defined by Superpave as, "One sieve size larger than the nominal maximum aggregate size" (Roberts, et al., 1996).

Table 2.3 Total Rice Sample Mass for Each Maximum Aggregate Size

\begin{tabular}{|c|c|}
\hline $\begin{array}{c}\text { MAXIMUM } \\
\text { AGGREGATE } \\
\text { SIZE }(\mathrm{mm})\end{array}$ & $\begin{array}{c}\text { RICE } \\
\text { SAMPLE } \\
\text { MASS }(\mathrm{g})\end{array}$ \\
\hline 50 & 6000 \\
\hline 37.5 & 4000 \\
\hline 25 & 2500 \\
\hline 19 & 2000 \\
\hline 12.5 & 1500 \\
\hline 9.5 & 1000 \\
\hline 4.75 & 500 \\
\hline
\end{tabular}

Once the needed sample mass is determined, the necessary amount of aggregate retained on each sieve size is weighed, and heated at $155 \pm 5^{\circ} \mathrm{C}$ for a minimum of two hours. An amount of asphalt binder is also heated in the oven until it flows easily and mixing effort is minimal. The aggregate blend and the specified mass of asphalt cement are mixed together until the binder covers the aggregate with an even film thickness. The bituminous mixture is placed back into the oven to cure at $135 \pm 5^{\circ} \mathrm{C}$ for 2 hours, with stirring every 30 minutes to allow absorption of binder into the aggregates. After the specified reheating time, the sample is removed from the oven and placed on a table, where it is rapidly cooled and the aggregates are separated into individual particles no larger than $1 / 4$-inch in diameter. This loose conglomeration of asphalt-covered aggregates is weighed, placed in a bowl, or pycnometer, then covered with water and placed in a vacuum chamber at $15 \mathrm{~mm} \mathrm{Hg}(3.7 \pm 0.3 \mathrm{kPa})$ for $15 \pm 2 \mathrm{~min}$. Once all of the trapped gases are removed from the mixture, the sample is suspended in a tank of water and weighed (AASHTO T 209-99, 2000). These masses are then entered into Equation 2.8 and the $\mathrm{G}_{\mathrm{mm}}$ is obtained. 


$$
G_{m m}=\frac{A}{A-(B-C)}
$$

where,

$\mathrm{G}_{\mathrm{mm}}=$ Maximum theoretical specific gravity;

$\mathrm{A}=$ Sample weight $(\mathrm{g})$;

$\mathrm{B}=\mathrm{Bowl}+$ sample in water weight $(\mathrm{g}) ;$ and

$\mathrm{C}=$ Bowl in water (Calibration) weight $(\mathrm{g})$.

Two Rice tests are performed for each DAS and the average is used for further volumetric analysis.

\subsubsection{GYRATORY COMPACTOR SAMPLES}

For the Superpave mix design process, samples are compacted using the gyratory compactor presented in Figure 2.3. The compacted samples, or "pills" are used to determine the percent air (VTM) and bulk specific gravity $\left(\mathrm{G}_{\mathrm{mb}}\right) . \mathrm{G}_{\mathrm{mb}}$ is defined as, "The ratio of the weight in air of a unit volume of a compacted specimen of HMA (including permeable voids) at a stated temperature to the weight of an equal volume of gas-free distilled water at a stated temperature" (Roberts, et al., 1996).

The bulk specific gravity $\left(\mathrm{G}_{\mathrm{mb}}\right)$ is calculated as:

$$
G_{m b}=\frac{A}{B-C}
$$

where,

$\mathrm{G}_{\mathrm{mb}}=$ Bulk specific gravity of the pill;

$\mathrm{A}=$ Dry weight of pill, (g);

$\mathrm{B}=$ Wet weight of saturated surface dry (SSD) pill, (g); and

$\mathrm{C}=$ Submerged weight of pill, $(\mathrm{g})$.

$$
V T M=\left(1-\frac{G_{m b}}{G_{m m}}\right) 100
$$


where,

$\mathrm{VTM}=$ Actual percent of air content of the mix, also known as voids in total mix;

$\mathrm{G}_{\mathrm{mb}}=$ Bulk specific gravity of the pill; and

$\mathrm{G}_{\mathrm{mm}}=$ Theoretical maximum specific gravity of the sample.

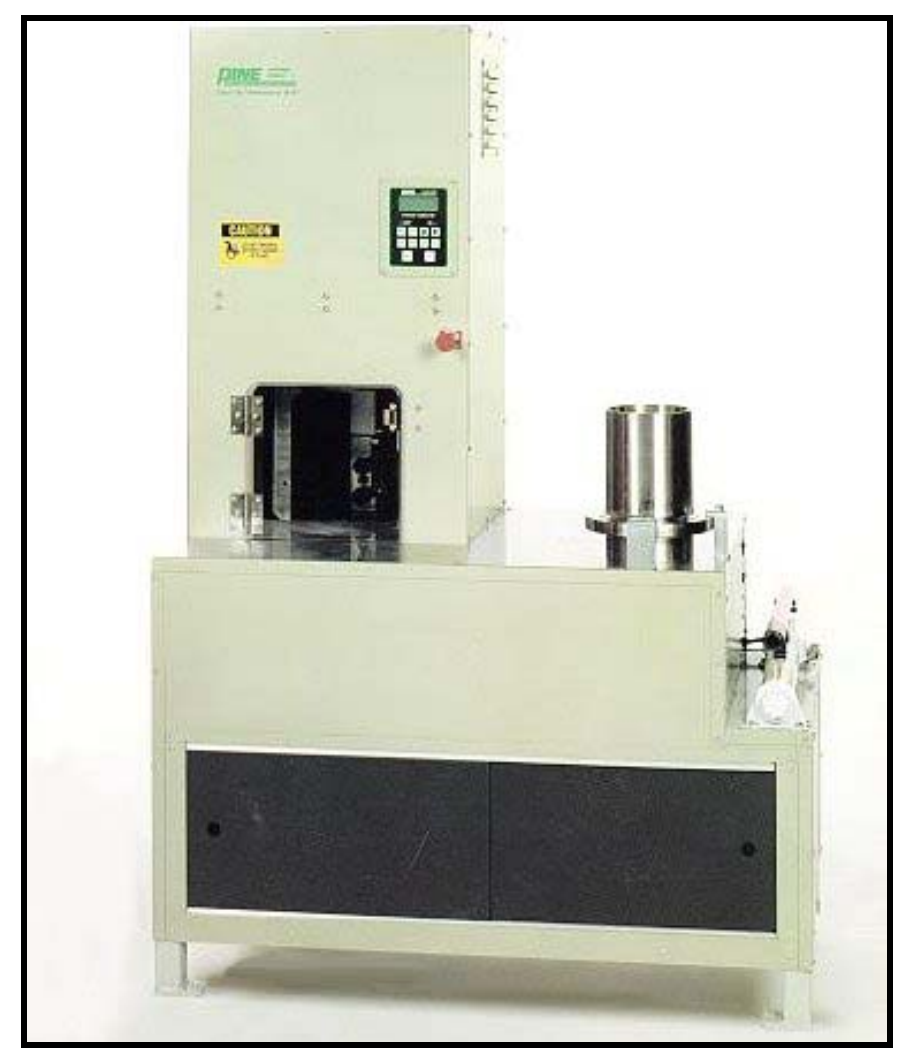

Figure 2.3 Superpave Gyratory Compactor

When the Strategic Highway Research Program was charged with the development of a superior mix design process, one of the main goals was to develop a laboratory compaction method that can consistently produce specimens representative of in-service pavements. The compactive effort of the gyratory compactor is controlled by three parameters: vertical pressure, angle of compaction, and number of gyrations. The AASHTO provisional standard TP 4-00 covers the compaction of cylindrical specimens of hot-mix asphalt (HMA) using the Superpave gyratory compactor and AASHTO standard T 166-00 outlines the testing methodology of the cylinders. This standard 
specifies the compaction criteria of the Superpave gyratory Compactor and states, "The ram shall apply and maintain a pressure of $600 \pm 18 \mathrm{kPa}$ perpendicular to the cylindrical axis of the specimen during compaction. The compactor shall tilt the specimen at an angle of $1.25 \pm 0.02^{\circ}$ and rotate the specimen molds at a rate of $30.0 \pm 0.5$ gyrations per minute throughout compaction.” (AASHTO T P4, 2000)

Superpave requirements specify that the number of initial, design, and maximum gyrations depend on the traffic ESALs, as presented in Table 2.4 (WVDOT, 2000). The number of gyrations for design, $\mathrm{N}_{\mathrm{d}}$, was selected to produce a density of $4.0 \% \mathrm{VTM}$ in the mix, which is equivalent to the expected density in the field after construction. An initial compactive effort, $\mathrm{N}_{\mathrm{i}}$, was defined to identify "tender" mixes, which are difficult to compact in the field because the mix lacks the internal friction required to prevent the excessive deformation (Roberts, et al., 1996). The maximum Superpave compactive effort, $\mathrm{N}_{\max }$ was selected to ensure the material does not over compact under traffic. $\mathrm{N}_{\max }$ and $\mathrm{N}_{\mathrm{i}}$ are a function of $\mathrm{N}_{\mathrm{d}}$ :

$$
\begin{aligned}
& N_{i}=\left(N_{d}\right)^{0.45} \\
& N_{\text {max }}=\left(N_{d}\right)^{1.10}
\end{aligned}
$$

where,

$\mathrm{N}_{\mathrm{i}}=$ Initial number of gyrations;

$\mathrm{N}_{\mathrm{d}}=$ Design number of gyrations; and

$\mathrm{N}_{\max }=$ maximum number of gyrations .

Table 2.4 Number of Compaction Gyrations based on ESAL Data

\begin{tabular}{|c|c|c|c|}
\hline $\begin{array}{c}\text { ESALs } \\
\text { (millions) }\end{array}$ & $\mathrm{N}_{\mathrm{i}}$ & $\mathrm{N}_{\mathrm{d}}$ & $\mathrm{N}_{\max }$ \\
\hline$<0.3$ & 6 & 50 & 75 \\
\hline $0.3<3$ & 7 & 75 & 115 \\
\hline $3<30$ & 8 & 100 & 160 \\
\hline$\geq 30$ & 9 & 125 & 205 \\
\hline
\end{tabular}

The gyratory compaction samples are created by first determining a total mass and weights retained on each sieve, then weighing the aggregates. The aggregates and 
binder must be heated, mixed together, and then cured to allow for binder absorption, stirring every 30 minutes. The aggregate and binder blend is then compacted in a gyratory compactor to a determined number of rotations. In order to determine the proper sample mass for each pill, either the actual $\mathrm{G}_{\mathrm{mm}}$, from Equation 2.8, or the theoretical $\mathrm{G}_{\mathrm{mm}}$ from Equation 2.13 is used. The theoretical volume of a cylinder in Equation 2.14, and the blended aggregate and binder properties are used in Equation 2.15 to estimate a mass that will have $4 \%$ air content at $115 \mathrm{~mm}$ in height. If the maximum theoretical specific gravity test has already been performed, then $\mathrm{G}_{\mathrm{mm}}$ is calculated according to Equation 2.8, otherwise it can be estimated using Equation 2.13.

$$
G_{m m}=\frac{1}{\frac{1-P_{b}}{G_{s e}}+\frac{P_{b}}{G_{b}}}
$$

where,

$\mathrm{G}_{\mathrm{mm}}=$ Theoretical maximum specific gravity;

$\mathrm{P}_{\mathrm{b}}=$ Asphalt content, percent by weight of mix;

$\mathrm{G}_{\mathrm{se}}=$ Effective specific gravity of aggregate blend; and

$\mathrm{G}_{\mathrm{b}}=$ Specific gravity of asphalt cement.

$$
V_{\text {pill }}=\left[\left(\frac{\pi}{4} d^{2} h\right)\left(1-V_{\text {surf. }}\right)\right]\left(1-V_{a}\right)
$$

where,

$\mathrm{V}_{\text {pill }}=$ Total volume of the pill, minus all air voids $\left(\mathrm{mm}^{3}\right)$;

$\mathrm{d}=$ Diameter of gyratory compaction cylinder, $150 \mathrm{~mm}$;

$\mathrm{h}=$ Height of gyratory compaction cylinder, $115 \mathrm{~mm}$;

$\mathrm{V}_{\text {surf. }}=$ Volume of surface voids on the pill; and

$\mathrm{V}_{\mathrm{a}}=$ Optimum value of air voids in sample, target is $4.0 \%$. 
The volume of surface voids on the pill ( $\left.\mathrm{V}_{\text {surf. }}\right)$ is estimated to be $3.0 \%$ from empirical testing conducted in the West Virginia University Asphalt Technology Laboratory.

$$
W_{\text {pill }}=\left(V_{c y l}\right) G_{m m}
$$

where,

$\mathrm{W}_{\text {pill }}=$ Total theoretical weight of gyratory compactor sample pill (g);

$\mathrm{V}_{\mathrm{cyl}}=$ Total volume of cylindrical pill, minus all air voids; and

$\mathrm{G}_{\mathrm{mm}}=$ Theoretical maximum specific gravity.

After the theoretical weight of the pill is calculated, the aggregate is weighed, heated, mixed with the calculated percentage of heated binder, reheated then compacted. The reheated sample is placed into a mold, $150 \mathrm{~mm}$ in diameter and $300 \mathrm{~mm}$ tall $\mathrm{It}$ is then compacted to a specific number of gyrations, which, theoretically yields a sample exactly $115 \mathrm{~mm}$ tall. The compacted pill is removed from the mold and allowed to cool, weighed to within $0.1 \mathrm{~g}$, then submerged in a tank of water for 3 to 5 minutes and weighed to the same tolerance. The wet pill is towel dried to the Saturated Surface Dry (SSD) condition and weighed. These weights are used to calculate the $\mathrm{G}_{\mathrm{mb}}$ using Equation 2.9, and VTM is computed using Equation 2.10.

Two pills are created for each DAS, and the average $G_{m b}, G_{m m}$ and percent air (VTM) are used for further volumetric analysis.

\subsubsection{VOLUMETRIC ANALYSIS}

The bulk specific gravity and maximum specific gravity from the tests are used to evaluate the volumetric properties of the mix using Equations 2.16 to 2.24 (Roberts, et al., 1996).

$$
\% G_{m m, N d e s}=\frac{G_{m b}}{G_{m m}}
$$




$$
\begin{aligned}
& G_{s e}=\frac{1-P_{b}}{\frac{1}{G_{m m}}-\frac{P_{b}}{G_{b}}} \\
& P_{b a}=100\left(\frac{G_{s e}-G_{s b}}{G_{s b}\left(G_{s e}\right)} G_{b}\right) \\
& P_{b e}=P_{b}-P_{b a}\left(1-P_{b}\right) \\
& \frac{d}{B}=\frac{\left(\frac{\% P_{\# 200}}{100}\right)}{P_{b e}} \\
& \% G_{m m, N i n i}=\% G_{m m, N d e s} \frac{h_{d e s}}{h_{i n i}} \\
& V T M=1-\frac{G_{m b}}{G_{m m}} \\
& V M A=100\left(1-\frac{G_{m b}\left(1-P_{b}\right)}{G_{s b}}\right) \\
& V F A=100\left(\frac{V M A-V T M}{V M A}\right)
\end{aligned}
$$

where,

$\% \mathrm{G}_{\mathrm{mm}, \mathrm{Ndes}}=$ Percent of maximum specific gravity at design number of revolutions;

$\mathrm{G}_{\mathrm{mb}}=$ Bulk specific gravity;

$\mathrm{G}_{\mathrm{mm}}=$ Maximum specific gravity;

$\mathrm{G}_{\mathrm{se}}=$ Effective specific gravity of aggregate;

$\mathrm{P}_{\mathrm{b}}=$ Percent binder;

$\mathrm{G}_{\mathrm{b}}=$ Specific gravity of the binder;

$\mathrm{P}_{\mathrm{ba}}=$ Percent binder absorbed;

$\mathrm{G}_{\mathrm{sb}}=$ Bulk specific gravity of aggregate; 
$\mathrm{P}_{\mathrm{be}}=$ Effective percent binder

$\% \mathrm{P}_{\# 200}=$ Percent of the aggregate blend passing the \#200 sieve;

$\% \mathrm{G}_{\mathrm{mm}, \mathrm{Nini}}=$ Percent of maximum specific gravity at initial number of revolutions;

$\mathrm{h}_{\text {des }}=$ Height at the design number of revolutions;

$\mathrm{h}_{\mathrm{ini}}=$ Height at the initial number of revolutions;

$\mathrm{VTM}=$ Air voids in compacted mixture;

$\mathrm{VMA}=$ Volume of voids in mineral aggregates; and

$\mathrm{VFA}=$ Voids filled with asphalt

For DAS evaluation only, these volumetric properties are used to determine whether the HMA mixture is acceptable. If the VTM is not equal to the target of 4 percent, then it must be mathematically adjusted to 4 percent air and all volumetrics must be adjusted accordingly.

Of all the possible volumetric properties, five have AASHTO tolerances, which must be met (Roberts, et al., 1996):

1. Air Voids in Compacted Mixture (VTM) - The total volume of the small pockets of air between the coated aggregate particles throughout a compacted paving mixture, the target is $4.0 \%$. Tolerance is $3.0 \%-5.0 \%$. See Equation 2.22 .

2. Volume of Voids in the Mineral Aggregate (VMA) - The volume of intragranular void space between the aggregate particles of a compacted paving mixture that includes the air voids and volume of the asphalt not absorbed into the aggregates. The tolerances on VMA depend on NMAS and are presented in Table 2.5 (Roberts, et al., 1996). 
Table 2.5 VMA Tolerances for Each NMAS

\begin{tabular}{|c|c|}
\hline $\begin{array}{c}\text { NOMINAL } \\
\text { MAXIMUM } \\
\text { AGGREGATE SIZE } \\
(\mathrm{mm})\end{array}$ & $\begin{array}{c}\text { MINIMUM } \\
\text { VMA } \\
(\%)\end{array}$ \\
\hline 37.5 & $11 \%$ \\
\hline 25 & $12 \%$ \\
\hline 19 & $13 \%$ \\
\hline 12.5 & $14 \%$ \\
\hline 9.5 & $15 \%$ \\
\hline
\end{tabular}

3. Voids filled with Asphalt Cement (VFA) - The percent of the volume of the VMA that is filled with asphalt cement. The tolerances for VFA are dependent on the estimated traffic and are presented in Table 2.6.

Table 2.6 VFA Tolerances for Traffic ESALs

\begin{tabular}{|c|c|c|}
\hline Traffic & \multicolumn{2}{|c|}{ VFA Percent } \\
\hline ESALs (millions) & Minimum & Maximum \\
\hline$<0.3$ & 70 & 80 \\
\hline $0.3<3$ & 65 & 78 \\
\hline $3<10$ & 65 & 75 \\
\hline $10<30$ & 65 & 75 \\
\hline$\geq 30$ & 65 & 75 \\
\hline
\end{tabular}

The values in Table 2.5 are the nationally accepted tolerances for VFA percentage. In West Virginia, some slight modifications have been included to prevent troubling issues and are specified in MP 401.02.28 (WVDOT, 2000).

Note 3: "For a $9.5 \mathrm{~mm}$ NMAS mixture, the specified VFA range shall be $73 \%$ to $76 \%$ for design traffic levels $\geq 3$ million ESALs."

Note 4: "For 25 mm NMAS mixture, the specified lower limit of VFA shall be $64 \%$ for design traffic levels $<0.3$ million ESALS."

Note 5: "For $37.5 \mathrm{~mm}$ NMAS mixtures, the specified lower limit of the VFA range shall be $64 \%$ for all design traffic levels."

4. Percent of Maximum Specific Gravity at the Initial Number of Revolutions $\left(\mathrm{G}_{\mathrm{mm}, \mathrm{Nini}}\right)$ - Refers to the percent of maximum specific gravity obtained at $\mathrm{N}_{\mathrm{ini}}$, which can not be measured, only estimated using the height ratio factors. See Equations 2.16 and 2.21. The criteria for $\% \mathrm{G}_{\mathrm{mm} \text {,Nini }}$ are dependent on the estimated traffic and are presented in Table 2.7. 
Table $2.7 \% \mathrm{G}_{\mathrm{mm}, \text { Nini }}$ Tolerances for Traffic ESALs

\begin{tabular}{|c|c|}
\hline $\begin{array}{c}\text { Traffic } \\
\text { ESALs (millions) }\end{array}$ & $\begin{array}{c}\text { Percent of Theoretical } \\
\text { Gmm at } \mathrm{N}_{\text {initial }}\end{array}$ \\
\hline$<0.3$ & $\leq 91.5$ \\
\hline $0.3<3$ & $\leq 90.5$ \\
\hline $3<10$ & $\leq 89.0$ \\
\hline $10<30$ & $\leq 89.0$ \\
\hline$\geq 30$ & $\leq 89.0$ \\
\hline
\end{tabular}

5. Dust to Binder Ratio $(\mathrm{D} / \mathrm{b})$ - The ratio of the amount of the blended aggregate passing the \#200 sieve to the effective binder content of the mix. The value for $\mathrm{D} / \mathrm{b}$ must be between $0.6-1.2$ for coarse graded blends and between $0.8-1.6$ for fine graded mixes. According to the Materials Procedure:

"The combined aggregate gradation shall be classified as coarse graded when it passes below the Primary Control Sieve (PCS) control point as defined in Table 2.8. All other gradations shall be classified as fine graded."

Table 2.8 Gradation Classification

\begin{tabular}{|c|c|c|c|c|c|}
\hline \multicolumn{6}{|c|}{ PCS Control Point for Mixture Nominal Maximum Aggregate Size } \\
(\% Passing) \\
\hline Nominal Maximum Aggregate Size & $37.5 \mathrm{~mm}$ & $25.0 \mathrm{~mm}$ & $19.0 \mathrm{~mm}$ & $12.5 \mathrm{~mm}$ & $9.5 \mathrm{~mm}$ \\
\hline Primary Control Sieve & $9.5 \mathrm{~mm}$ & $4.75 \mathrm{~mm}$ & $4.75 \mathrm{~mm}$ & $2.36 \mathrm{~mm}$ & $2.36 \mathrm{~mm}$ \\
\hline PCS Control Point & 47 & 40 & 47 & 39 & 47 \\
\hline
\end{tabular}

\subsubsection{VOLUMETRIC ANALYSIS ADJUSTMENTS}

In theory, both pills at each DAS would have exactly $4.0 \%$ air and the compacted heights would be $115.0 \mathrm{~mm}$, but this is rarely the case; therefore a series of equations are used to adjust the volumetric properties to a target VTM of 4.0\%. Equations 2.25-2.30 are used to adjust the values (Harman, et al., 1999).

$$
\begin{aligned}
& P_{b, e s t}=P_{b, \text { trial }}-(0.4 \times(4.00 \%-V T M)) \\
& V M A_{\text {est }}=V M A+C \times(4.00 \%-V T M) \\
& V F A_{\text {est }}=100\left(\frac{V M A_{\text {est }}-4.00 \%}{V M A_{\text {est }}}\right)
\end{aligned}
$$




$$
\begin{aligned}
& \% G m m_{\text {est }, \text { Nini }}=\% G m m_{\text {Nini }}-(4.00 \%-V T M) \\
& P_{b e, e s t}=-\left(G_{b} * P_{s}\right)\left(\frac{\left(G_{s e}-G_{s b}\right)}{G_{s e}\left(G_{s b}\right)}\right)+P_{b, e s t} \\
& \frac{d}{B}{ }_{e s t}=\frac{\% P_{\# 200}}{P_{b e, e s t}}
\end{aligned}
$$

where,

$\mathrm{P}_{\mathrm{b}, \mathrm{est}}=$ Estimated percent binder needed to achieve $4.0 \%$ air;

$\mathrm{P}_{\mathrm{b}, \text { trial }}=$ Percent binder used in the initial trials;

$\mathrm{VTM}=$ Air voids in compacted mixture;

$\mathrm{VMA}_{\text {est }}=$ Estimated air voids in compacted mixture, from trial volumetric data;

$\mathrm{VMA}=$ Volume of voids in mineral aggregates;

$\mathrm{C}=$ Correction factor,

If $\operatorname{VTM}<4.0 \%, C=0.1$,

If $\mathrm{VTM}>4.0 \%, \mathrm{C}=0.2$;

$\mathrm{VFA}=$ Voids filled with asphalt;

$\mathrm{VFA}_{\text {est }}=$ Estimated voids filled with asphalt, from trial volumetric data;

$\% \mathrm{G}_{\mathrm{mm} \text { est,Nini }}=$ Estimated percent of maximum specific gravity at the initial number of revolutions;

$\% \mathrm{G}_{\mathrm{mm} \text {,Nini }}=$ Percent of maximum specific gravity at initial number of revolutions;

$\mathrm{P}_{\mathrm{b}, \mathrm{est}}=$ Estimated percent binder, from trial volumetric data;

$\mathrm{P}_{\mathrm{b}}=$ Percent binder;

$\mathrm{G}_{\mathrm{b}}=$ Specific gravity of the binder;

$\mathrm{P}_{\mathrm{s}}=$ Percent stone;

$\mathrm{G}_{\mathrm{sb}}=$ Bulk specific gravity; 
$\mathrm{G}_{\mathrm{se}}=$ Effective specific gravity;

$\mathrm{P}_{\mathrm{be}}=$ Effective percent binder;

$\mathrm{D} / \mathrm{b}_{\text {est }}=$ Estimated dust to binder ratio, from trial volumetric data;

$\mathrm{D} / \mathrm{b}=$ Dust to binder ratio; and

$\% \mathrm{P}_{\# 200}=$ Percent of the aggregate blend passing the $\# 200$ sieve.

The calculated adjusted volumetric properties are then compared to the acceptable limits presented in Section 2.3.4. The adjusted values are analyzed by the technician, who determines which design aggregate structure presents the best overall possibility for a superior HMA pavement. If no DAS yields a viable option for an acceptable structure, three different DASs are chosen and the Rice test and pill compaction procedures are repeated until a structure is determined. Once the design aggregate structure is found, the next procedures are performed to determine the asphalt content that will produce $4.0 \%$ VTM, while meeting all required properties.

\subsubsection{DETERMINING OPTIMUM ASPHALT CONTENT}

Once the design aggregate structure is selected, the optimum asphalt cement percent must be determined. Two maximum theoretical gravity tests are performed and two gyratory compaction samples are created at four asphalt contents:

- $\mathrm{P}_{\mathrm{b}, \mathrm{est}}-0.5 \%$

- $\mathrm{P}_{\mathrm{b}, \mathrm{est}}$

- $\mathrm{P}_{\mathrm{b}, \mathrm{est}}+0.5 \%$

- $\mathrm{P}_{\mathrm{b} \text {,est }}+1.0 \%$

The laboratory procedures are the same as those outlined in Sections 2.2.3 and 2.2.4, and volumetric properties are calculated as detailed in Section 2.2.5. Table 2.9 presents an example of the computed volumetric properties, including, VTM, VMA, $\mathrm{VFA}, \mathrm{D} / \mathrm{b}$ and $\% \mathrm{G}_{\mathrm{mm} \text {,Nini. }}$. Each of these parameters is plotted against percent binder as shown on Figures 2.4 to 2.8. The optimum binder percentage is determined as the percent binder corresponding to 4.0\% VTM, as shown on Figure 2.4. This percent binder is used to determine the other volumetric properties and those values are compared with the limits set forth in Section 2.2.5 to determine if the asphalt content and DAS are 
acceptable. If the criteria are not satisfied, a new design aggregate structure must be evaluated.

Table 2.9 Theoretical Data to Illustrate Mix Properties Interpolation Method

\begin{tabular}{|c|c|c|c|c|}
\hline $\mathrm{P}_{\mathrm{b}}$ & $4.5 \%$ & $5.0 \%$ & $5.5 \%$ & $6.0 \%$ \\
\hline $\mathrm{VTM}$ & $6.0 \%$ & $4.6 \%$ & $2.9 \%$ & $1.9 \%$ \\
\hline $\mathrm{VMA}$ & $15.7 \%$ & $15.3 \%$ & $15.2 \%$ & $15.4 \%$ \\
\hline $\mathrm{VFA}$ & $61.3 \%$ & $70.0 \%$ & $79.0 \%$ & $85.0 \%$ \\
\hline $\mathrm{D} / \mathrm{b}$ & 1.7 & 1.5 & 1.2 & 1.1 \\
\hline $\mathrm{oG}_{\mathrm{mm}, \mathrm{Nini}}$ & $84.5 \%$ & $86.0 \%$ & $87.2 \%$ & $87.9 \%$ \\
\hline
\end{tabular}

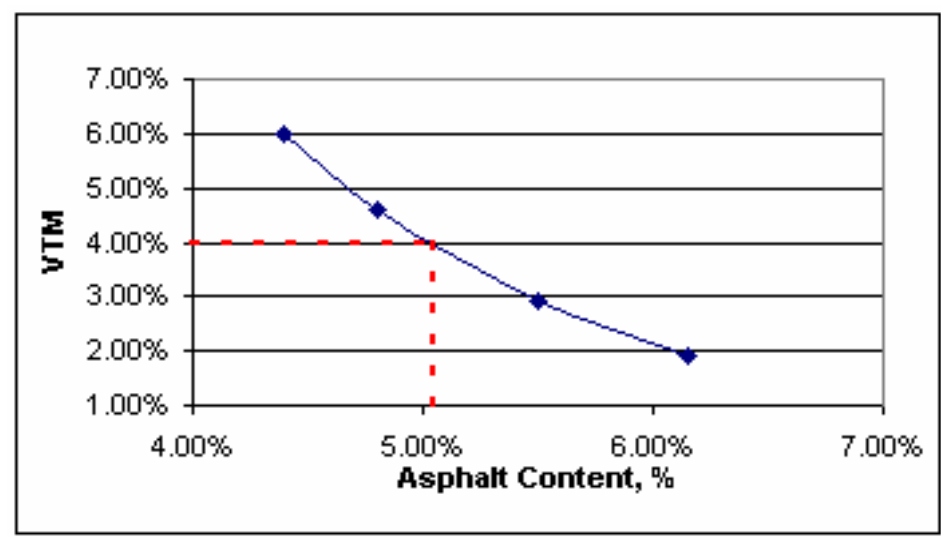

Figure 2.4 VTM v/s Asphalt Content (Interpolation Graph)

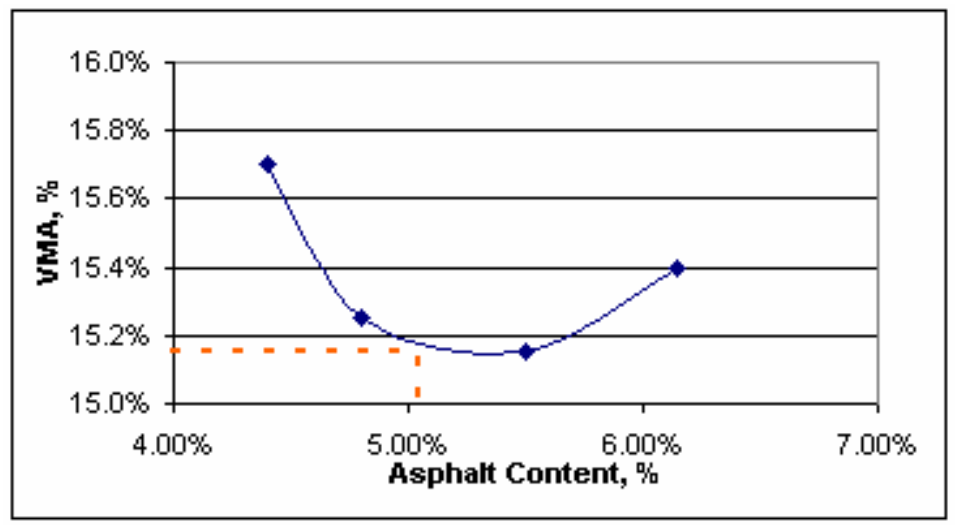

Figure 2.5 VMA v/s Asphalt Content (Interpolation Graph) 


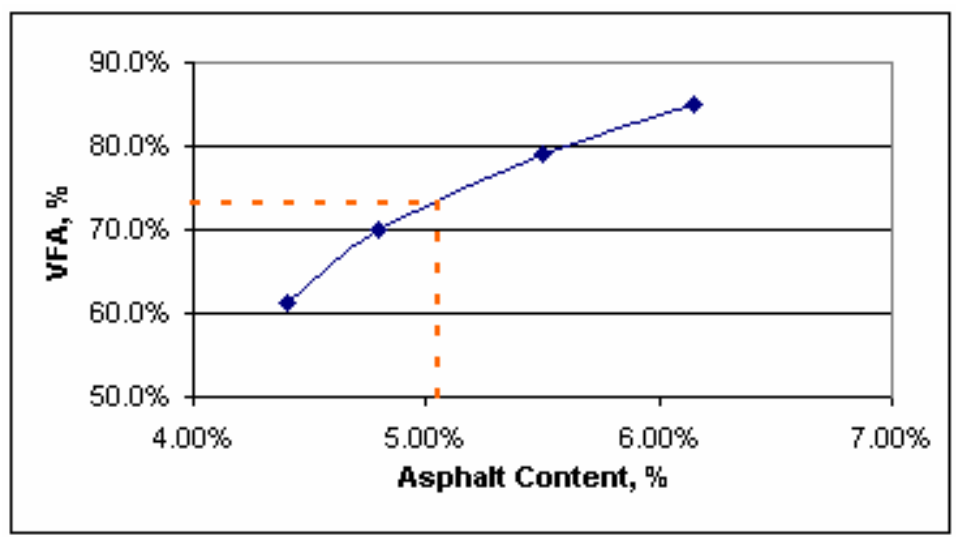

Figure 2.6 VFA v/s Asphalt Content (Interpolation Graph)

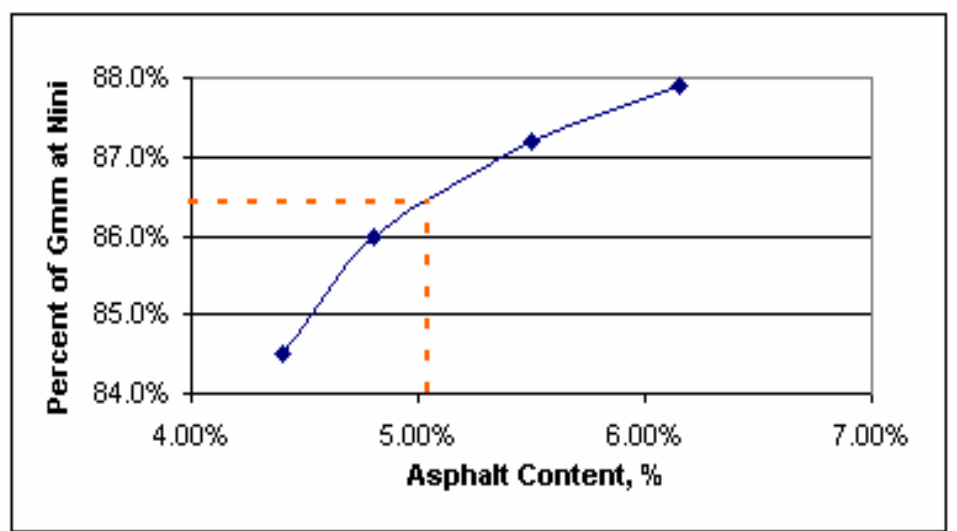

Figure $2.7 \% \mathrm{G}_{\mathrm{mm}, \mathrm{Nini}} \mathrm{v} / \mathrm{s}$ Asphalt Content (Interpolation Graph)

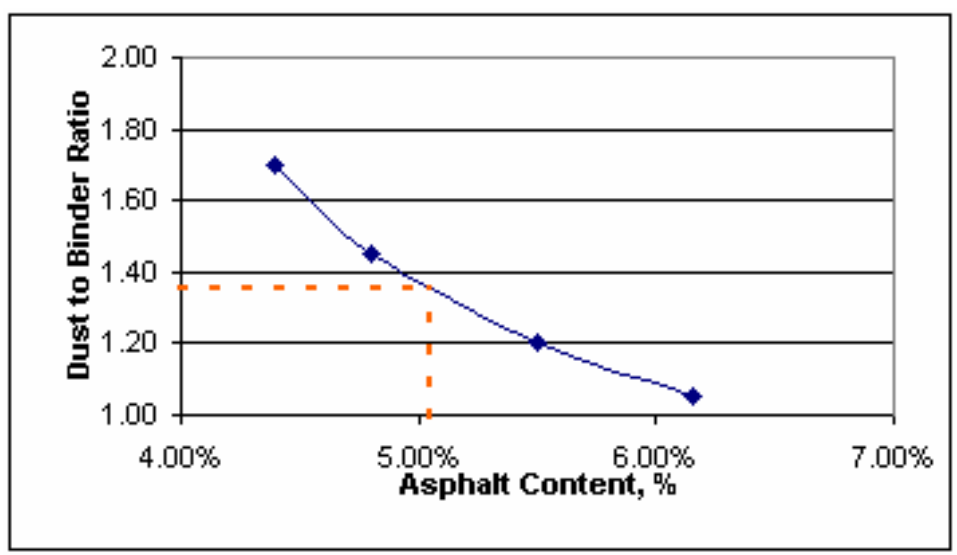

Figure $2.8 \mathrm{D} / \mathrm{b}$ Ratio v/s Asphalt Content (Interpolation Graph)

The percent binder at $4.0 \% \mathrm{VTM}$, and the corresponding volumetric properties, can be interpolated using Equations 2.31 and 2.32. Although Figures 2.4 to 2.8 show 
curved relationships, linear interpolation is adequate for the precision needed for this analysis.

$$
\begin{aligned}
& P_{b, \text { opt }, \text { est }}=P_{b, \text { below }}-\left[\frac{V T M_{\text {below }}-4.00 \%}{V T M_{\text {below }}-V T M_{\text {above }}} \times\left(P_{b, \text { below }}-P_{b, \text { above }}\right)\right] \\
& X_{\text {opt est }}=X_{\text {below }}-\left[\frac{P_{b, \text { below }}-P_{b, \text { opt }, \text { est }}}{P_{b, \text { below }}-P_{b, \text { above }}} \times\left(X_{\text {below }}-X_{\text {above }}\right)\right]
\end{aligned}
$$

where,

$\mathrm{P}_{\mathrm{b}, \mathrm{opt}, \mathrm{est}}=$ Interpolated percent binder needed to achieve $4.0 \%$ air;

$\mathrm{X}_{\text {opt,est }}=$ Volumetric property to be adjusted to $4.0 \%$ VTM, mathematically;

$\mathrm{P}_{\mathrm{b} \text {,below }}=$ Percent binder which yields a VTM immediately below 4\%;

$\mathrm{P}_{\mathrm{b}, \text { above }}=$ Percent binder which yields a VTM immediately above 4\%;

$\mathrm{VTM}_{\text {below }}=\mathrm{VTM}$ value at $\mathrm{P}_{\mathrm{b}}$ which is immediately below $4 \%$;

$\mathrm{VTM}_{\mathrm{above}}=\mathrm{VTM}$ value at $\mathrm{P}_{\mathrm{b}}$ which is immediately above $4 \%$;

$\mathrm{X}_{\text {below }}=$ Volumetric property at $\mathrm{P}_{\mathrm{b}}$ which is immediately below $4 \%$; and

$X_{\text {above }}=$ Volumetric property at $P_{b}$ which is immediately above $4 \%$.

\subsubsection{FINAL TESTS TO EVALUATE ACCEPTABILITY}

Two more Rice tests and compaction samples are created at the interpolated optimum binder percentage and are prepared in the same manner as presented in Sections 2.2.4 and 2.2.5. The samples are compacted to $\mathrm{N}_{\max }$ and Equation 2.33 is used to calculate $\% \mathrm{G}_{\mathrm{mm}, \mathrm{Nmax}}$, which is then compared with a maximum value of $98.0 \%$ (WVDOT, 2000). The air voids of samples compacted with $\mathrm{N}_{\max }$ revolutions is required to be at least 2 percent; mixtures with less than 2\% VTM are believed to be more susceptible to rutting (Roberts, et al., 1996). The percent $\% \mathrm{G}_{\mathrm{mm}, \mathrm{Nmax}}$ provides an estimate of the ultimate field density, which insures that the mixture does not densify excessively, leading to low in-place voids. 
$\% G_{m m, N \text { max }}=\frac{G_{m b, N \max }}{G_{m m}}$

where,

$\% \mathrm{G}_{\mathrm{mm}, \mathrm{Nmax}}=$ Percent of maximum specific gravity at the design number of revolutions (See Table 2.4);

$\mathrm{G}_{\mathrm{mb}, \mathrm{Nmax}}=$ Bulk specific gravity of the pill compacted to $\mathrm{N}_{\max }$ revolutions; and

$\mathrm{G}_{\mathrm{mm}}=$ Maximum specific gravity from the Rice test.

Values of $\% \mathrm{G}_{\mathrm{mm} \text {, Nmax }}$ that are greater than $98.0 \%$ are deemed unacceptable and the mix design process returns to the beginning, where a new DAS is selected and all of the subsequent steps are repeated.

The final test of HMA mix design acceptability is the evaluation of moisture susceptibility. Over a period of time, the effects of moisture on an asphalt roadway can lead to a phenomenon called "stripping". Stripping produces a loss of strength in the asphalt by weakening the bond between the asphalt cement and the aggregates (Roberts, et al., 1996). This loss of strength can be gradual, as the roadway slowly exhibits signs of rutting, or it can be sudden where the roadway shows signs of distress as the asphalt cement peels off of the aggregates. The moisture sensitivity of the design mixture is evaluated by performing the AASHTO T-283 test on the design aggregate blend at the optimum asphalt content. Modifying Equations 2.14 and 2.15 for $7.0 \% \mathrm{VTM}$ and $\mathrm{h}_{\text {des }}$ of $95 \mathrm{~mm}$, six compaction samples are prepared, as detailed in Section 2.2.5, and the specimens are compacted. The gyratory compactor is set to a height control mode and the compaction continues until the required height is achieved. Three compacted pills are subjected to partial vacuum saturation, followed by an optional freeze cycle, then a 24hour conditioning cycle at $60^{\circ} \mathrm{C}$; three pills are not conditioned. The unconditioned samples are soaked in a water bath at $60^{\circ} \mathrm{C}$ for 60 minutes to equilibrate the temperatures. The conditioned and unconditioned specimens are tested to determine indirect tensile strengths. The moisture sensitivity is determined as a ratio of the tensile strengths of the conditioned subset divided by the tensile strengths of the control subset. The minimum acceptable value of tensile strength ratio (TSR) allowable is $80 \%$. If the minimum is not 
met, a new design is required which incorporates an antistrip agent. According to MP 401.02.28, "A Division approved antistripping additive, such as hydrated lime conforming to the requirements of AASHTO M303, or a liquid antistripping additive, may be added to the mixture if needed. If such an additive is used, the process is restarted at the DAS selection and all design testing must be conducted with the additive in the mixture (WVDOT, 2000)." The use of AASHTO T-283 is not required to design a Superpave mix, but the West Virginia DOH requires the test to ensure rut resistance (WVDOH, 2000).

\subsubsection{ASPHALT PAVEMENT ANALYZER}

The evaluation of the mix for rut resistance is not part of the Superpave mix design, but can be used with any design method to evaluate asphalt performance. After a mix design is deemed acceptable by passing all required tests, and meeting all necessary criteria, it can be tested for susceptibility to rutting. Ruts are defined as depressions, which occur in the pavement's wheel path, caused by traffic compaction or displacement of unstable material. A negligible amount of rutting can be expected to occur on a HMA surface due to the continued densification under traffic after initial compaction during construction. Much of the rutting that occurred before the advent of the Superpave method can be attributed to an improper mix design. Some common mistakes made when designing the HMA mixes include the selection of high asphalt content, use of excessive filler material (material passing \#200 sieve), or use of too many rounded particles in aggregates. In recent years, the potential for rutting on the nation's highways has increased due to higher traffic volumes and the increased use of radial tires that typically exhibit higher inflation pressures (Roberts, et al., 1996). One of the most common types of laboratory equipment that predicts field-rutting potential is the Asphalt Pavement Analyzer (APA). The APA is the commercial version of the Georgia Loaded Wheel Tester (GLWT) and was first manufactured in 1996 by Pavement Technology, Inc. The APA is a multi-functional Loaded Wheel Tester (LWT) that can be used for evaluating rutting, fatigue cracking, and moisture susceptibility of hot and cold asphalt mixes. 
The standard method followed to determine rutting susceptibility using APA is developed by APAC Materials Services in an ASTM format. Rutting susceptibility of mixes is assessed by placing cylindrical samples under repetitive wheel loads and measuring the amount of permanent deformation under loading. Six samples at a time can be tested in APA under controlled temperature, and in dry or submerged-in-water conditions. The rut depth is measured after the desired number of cycles (usually 8000) of load application. Table 2.9 shows the test parameters specified in the APAC procedure. After the cycles are completed, the cylinders are removed from the APA and the rut depths are measured relative to the surface of the pill. These rut values are then compared with each other and previous empirical data to determine the rutting potential of the mix when laid on a roadway. If the results show a high tendency towards rutting, the mix may have to be redesigned using a different design aggregate structure to minimize the effects of rutting.

Table 2.10 APA Specifications

\begin{tabular}{|c|c|}
\hline Factors & $\begin{array}{c}\text { Range specified in } \\
\text { APAC procedure }\end{array}$ \\
\hline Air void content & $7 \pm 1 \%$ \\
\hline Test temperature & $\begin{array}{c}\text { Based on average high } \\
\text { pavement temperature }\end{array}$ \\
\hline Wheel load & $100 \pm 5 \mathrm{lb}$ \\
\hline Hose pressure & $100 \pm 5 \mathrm{psi}$ \\
\hline Specimen type & Beams, cylinders \\
\hline Compaction & $\begin{array}{c}\text { Rolling, vibratory, and } \\
\text { gyratory }\end{array}$ \\
\hline
\end{tabular}

\subsubsection{AVAILABLE SUPERPAVE SOFTWARE}

Equipment vendors, such as Pine Instrument Co., have developed Superpave analysis software that is provided with their equipment (Pine, 1998). The American Association of State Highway and Transportation Officials (AASHTO) contracted the University of Maryland to develop a generic Superpave analysis software package, which was released in 2000. However, this software is not currently supported or marketed by AASHTO (AASHTO, 2002). The literature review during the research failed to locate any public domain software. 


\subsection{STEEL SLAG AS AN HMA AGgREGATE ALTERNATIVE}

It is unknown exactly when steel slags were first used as a roadway construction material, but an ancient Roman road, created with slag, dates back to 200AD (Lee, 1974). Steel slag is a by-product of open-hearth, basic oxygen, and electric arc steel making processes and industrial blast furnaces. Steel slags have been used in highway construction in the United States and Canada since the turn of the century (Ciesielski, 1996). Today, there are many types of slag produced in the United States including ferrous slags, chrome slags and copper slags, of which ferrous slags are most abundant in the north-central West Virginia region. Ferrous slags can further be divided into three subcategories: air-cooled blast furnace slag, expanded blast furnace slag, and granulated blast furnace slag. The region's most abundant slag type is air-cooled blast furnace slag, which is produced by pouring the molten slag into a pit or onto a slag bank until cool, at which time it is removed, crushed and screened (McGannon, 1971).

Steel slag is described as:

Steel slag consists of crushed angular particles with rough irregular surfaces. It is essentially free from flat or elongated pieces and has a rougher surface texture than gravels and crushed stones. It is highly resistant to weathering, as are other types of iron blast furnace slags. Freezing and thawing effects together with sulfate soundness losses are reported to be exceptionally low (Noureldin, 1990).

Several studies have been initiated in recent years to determine the acceptability of using steel slag in hot mix asphalt production. Southern Ontario, Canada began using great amounts of slag in HMA in the early 1970's and considerable data has been collected on the performance of various roadways (Ali, et al., 1992). Steel slag has a high bulk specific gravity when compared with most natural aggregates used in HMA mix designs. Slag specific gravity values typically range from 3.2 to 3.6, while the average specific gravity for natural HMA aggregates is approximately 2.6. The hardness, as measured on Moh's hardness scale for slag is between 6 and 7, compared with limestone's rating of 3 to 4. Los Angeles abrasion testing has shown slag to be extremely resistant to degradation, making it a useful material in a surface coarse. Steel slag is $100 \%$ crushed and angular, with a gradation that usually requires no blending. Mixes made with slag have very high stabilities, satisfactory flows and excellent stripping 
resistance. Slag mixes also have good heat retention and compatibility, and, when used as a surface coarse, have good wear and skid resistance (Ali, et al., 1992). HMA mixes made with steel slag also demonstrate longer heat retention after mixing and ease of compaction without "shoving" in front of the roller (Ramirez, 1992). It has been empirically determined that the absorption of steel slag is higher than most natural aggregates, especially among the fine aggregates, which, in one regard, is a disadvantage of this material, but it also beneficially produces lower drying costs (Hanson and Lynn, 1995).

The three main disadvantages in using steel slag as an aggregate include: variation in characteristics, extremely high unit weight, and its expansive nature. The characteristic variations are due to the fact that this material is only a by-product of the steel making process, and quality control is not a priority. Even though gradation and screening properties are fairly consistent, the specific gravity and absorption may greatly differ from plant to plant, or even within the same plant. Since the specific gravity of slag is much greater than natural aggregates, it requires more tonnage to produce a specific volume of an HMA mixture. This extra weight per mixture, combined with weight restrictions on the roadways and tonnage limits on trucks, limits slag mixtures as a viable economical alternative to natural HMA mixtures over great distances. Another drawback to using slag involves its expansive nature, which is due to the hydration of calcium and magnesium oxides. The calcium hydrates rapidly to cause extensive volume changes in a short period of time, while the magnesium oxide hydrates more slowly and may not show signs of expansion for several years (Hegmon and Ryan, 1984). This phenomenon can be controlled by one or any combination of three ways, which include: suitable aging in stockpiles, treatment of aggregates with spent acids, or complete coating of particles with asphalt binder to prevent the intrusion of water (Noureldin, 1990).

If steel slag is to be utilized as an aggregate in hot mix asphalt, quality control should be of paramount importance to insure the most uniform by-product possible. The stockpiles should be small and carefully monitored to ensure uniformity; they should be free of large particles, and they should be allowed to adequately age. Research from the Canadian Technical Asphalt Association suggests these five steps to ensure the quality and uniformity of steel slag stockpiles (Emery, 1984): 
1. Avoid contamination by refractories and rubbish in the processing areas.

2. Weather the slag for a minimum of one month before screening.

3. Monitor free lime content.

4. Rescreen any agglomerated or crusted stockpiled slag.

5. Pay special attention to $\mathrm{AC}$ content and mix adequately.

It is clearly demonstrated that if the slag producer is within a reasonable distance and the slag piles are properly maintained and cured, HMA production with steel slag is definitely a viable option. It is more complicated to ensure the uniformity and consistency of slag aggregates, but if done properly, a pavement with superior performance and a longer life can be expected.

\subsection{MICROSOFT EXCEL AS A SOFTWARE DEVELPMENT TOOL}

Microsoft Excel is a powerful tool for analyzing and presenting information (Jacobson, 1997). It is ideally suited for spreadsheet data entry, computations and graphing technology, making this a powerful tool to use when performing a Superpave mix design. The actual data entry into Excel for a mix design can be confusing, with the formulas in certain cells and the output in others. Using Excel's built-in macro function, this problem is eliminated by allowing the user to enter data only in specified fields. Visual Basic for Applications (VBA) first appeared in Excel in Version 5; the use transformed the approach of user interface with the supporting workbooks. Using VBA, the programmer is able to present the user with electronic forms that only allow data entry in certain text boxes and return calculated values in other specified locations (Masters, 1999). This method of user interface minimizes the user-related error while maximizing efficiency. When a userform is implemented, the program's user has no choice but to enter data in only the provided cells for input, thus eliminating the possibility of erasing an important formula or entering an improper data type into a field. VBA in Excel allows the programmer to create a macro to automate all necessary tasks, which is easily shared among users, and can be modified by authorized personnel at any time. The use of VBA requires the programmer to be familiar with the visual basic programming language, and understand Excel's macro features (Schneider, 1999). 


\subsection{SUMMARY}

The Superpave mix design process presented has been used by the West Virginia Division of Transportation and its contractors for the past five years. The entire Superpave process, including the equations and supporting theory, was detailed in the literature review. An explanation of the laboratory testing procedures for maximum theoretical specific gravity and bulk specific gravity, supported by the departmental specification is also included. Also described was a brief overview of the Asphalt Pavement Analyzer, including the theory behind the development and test methodology. The variations between some national standards and the current WV specifications have also been presented, which provide a wider margin of error in some instances and a tighter standard in others. The criteria for both have been presented here.

The literature review of the steel slag research and its benefits and disadvantages was presented to introduce the concept of using slag as a possible superior alternative to natural aggregates in HMA. A brief introduction to Microsoft Excel and the Visual Basic for Applications macro tool were also included. 


\section{CHAPTER 3 RESEARCH METHODOLOGY}

\subsection{INTRODUCTION}

In this research, software was developed to automate the aggregate analysis and Superpave mix design process for West Virginia state specifications. The software was then tested using steel slag as the aggregate for an entire mix design. Mixes were prepared at varying asphalt contents until the target of 4.0\% VTM was achieved; the rut susceptibility was then tested and compared with acceptable limits. The software validation was achieved by inputting the mix design parameters from previous WVDOT paving contracts and comparing the actual values with the theoretical program output. The following sections of this chapter explain the software development process and the laboratory-testing program conducted in the Asphalt Technology Laboratory of West Virginia University. A flowchart outline of the Superpave mix design process is presented in Figure 3.1, detailing all of the necessary steps to complete an entire design. This outline was used as a guideline in the development of the spreadsheet and the software. The program screen captures are presented in Appendix A, the Superpave Calculator user's manual comprises Appendix B and the steel slag mix design data is presented in Appendix C.

\subsection{SPREADSHEET DEVELOPMENT}

All of the necessary equations to perform a complete Superpave mix design are presented in Section 2.2. Throughout the design process, many of these calculations must be repeated numerous times. An Excel spreadsheet, which contained each of these equations, was created to streamline the mix design process. The program was designed so that the data input boxes and output fields were identified and the formula cells were protected. Final results were returned in specific, labeled locations along with an indication of whether the results were within specification limits. After all formulas and charts were built into the workbook, the functionality of the program was tested. 


\section{Superpaue Mix Design Process Flow Chart}

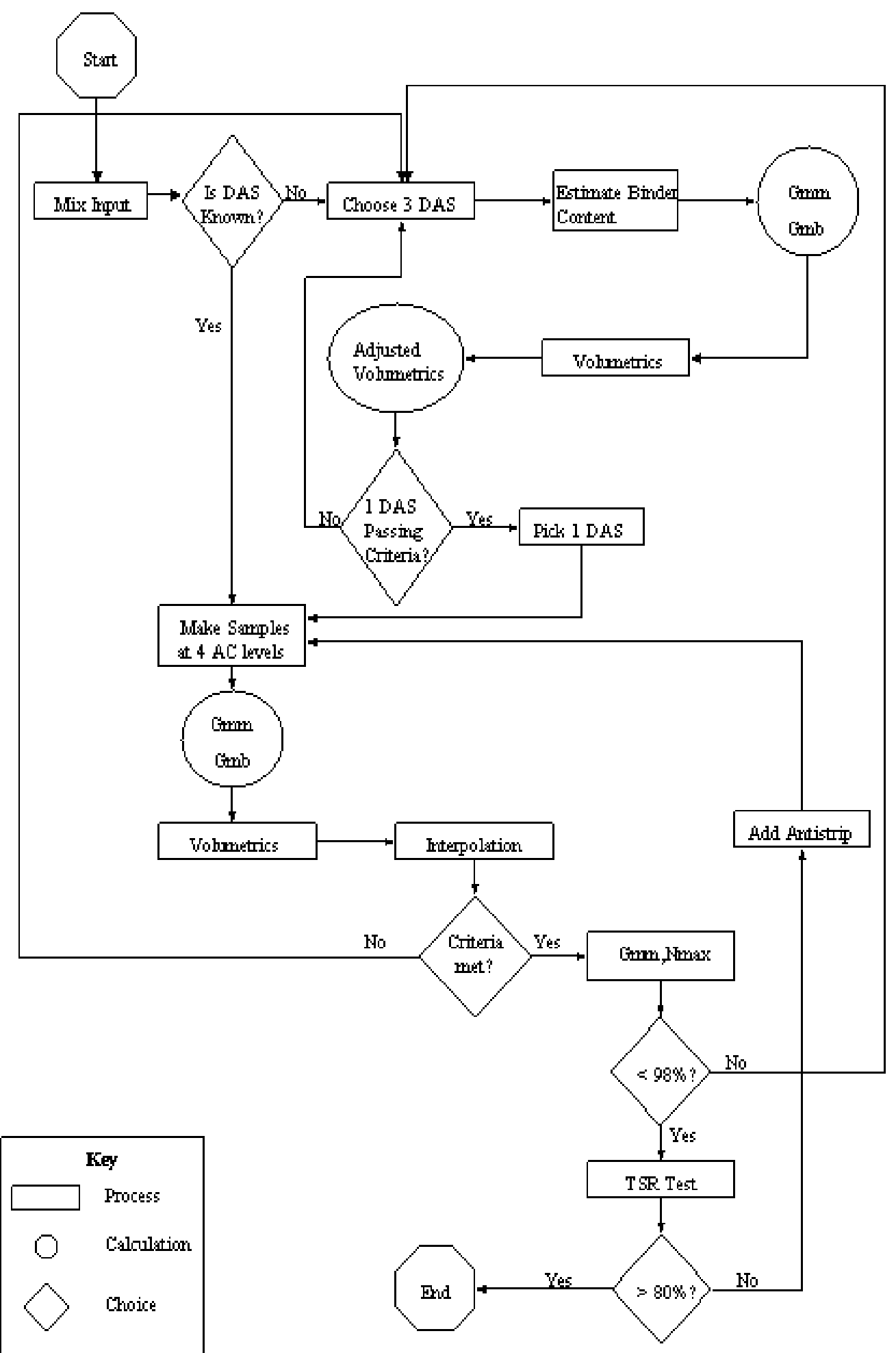

Figure 3.1 Superpave Mix Design Process Flow Chart 


\subsection{SPREADSHEET VERIFICATION}

Several different mixes were created using a developmental spreadsheet to verify the accuracy of the equations and identify any formulas that were entered incorrectly. Numerous mix designs were created in the WVU Asphalt Technology Lab, and the workbook was further refined and programming errors were identified and corrected. This spreadsheet worked very well for development, but was not practical for implementation by others. The cells were not protected and each step of the process was on a different worksheet. An interface was required that would remove any interaction with the formulas and limit the user to inputting data and viewing results.

\subsection{INTERFACE DEVELOPMENT}

Two different software packages were evaluated to create a functional user interface; Visual Basic 6.0 and Visual Basic for Applications (VBA). The interfaces created with VB 6.0 did not directly link to the Excel workbook and all formulas were built into each user form. The necessity of repeating each of the formulas in every VB 6.0 user form proved that VBA was a much more practical alternative. A series of user interface forms was created in VBA, with designated input boxes and areas identified for calculated results and acceptability. As presented in Chapter 4, the program was created using a "hub-and-spoke" design instead of a linear procedure. The reasoning behind the hub utilization is that at any time during the mix design process, the user may need to return to an earlier page to change inputs, or view calculated results. In a linear program, this process may require cumbersome movement through numerous sheets. The hub design allows the user to always return to the main page and proceed further, eliminating unnecessary steps. The design also allows the computer to only load the necessary user forms, instead of all of them, which optimizes the memory and reduces processing time. Unique user forms are displayed in Appendix A and described in Appendix B. Their structure limits the data entry of the user, allowing only reasonable and appropriate inputs. The formulas are hidden and all supporting worksheets remained active, but unseen to the user. After the user interface development, the program was again tested for formula validity and operational functionality. 


\subsection{PROGRAM VALIDATION}

The newly created "Superpave Calculator", with user interface forms and supporting Excel workbook, was tested in the WVU Asphalt Technology Laboratory and with previous WVDOT mix designs. A complete validation example is presented in Chapter Four. Various WVU mix designs utilized the software for limestone and steel slag aggregate mixes, comparing the calculated results to the actual values. Throughout the validation procedures, any programming errors were identified and corrected and functionality and ease of use were maximized.

\subsection{STEEL SLAG RESEARCH}

Based on interest expressed by International Mill Service, Inc. (IMS), the Asphalt Technology Laboratory agreed to develop a Superpave mix design using 100\% steel slag as the aggregate. Due to the density and surface characteristics of slag, the testing and mix design process for slags are more complicated than for conventional aggregates. It was during the development of the slag mix design that the prototype Superpave analysis spreadsheet was created. The methodology applied to the development of the steel slag mix design was to:

1. obtain samples from the supplier,

2. perform the aggregate evaluation test to characterize the material, as described in Chapter 2.2.2-2.2.8,

3. perform the analysis prescribed in the Superpave mix design method to determine the optimum asphalt content, as described in Chapter 2.2.9-2.2.10 and

4. test the designed mix with the Asphalt Pavement Analyzer, described in Chapter 2.2.11.

All of the results of the steel slag research comprise Chapter 5 and Appendix C. 


\section{CHAPTER 4 PROGRAM STRUCTURE AND VALIDATION}

\subsection{SUPERPAVE CALCULATOR STRUCTURE}

\subsubsection{INTRODUCTION}

The Superpave Calculator software was developed using a hub-and-spoke form for the entire mix design process, as presented in Figure 4.1. The process begins at the top left of the figure and proceeds clockwise until the Superpave mix design procedure is completed. There are four main components to the software, which are connected to the Main Choices Page at the central hub:

- The steps that are within 9 o'clock and 12 o'clock on Figure 4.1 receive the input about the report criteria and aggregate data.

- The right side of the hub diagram, between 12 o'clock and 4 o'clock is used for the design aggregate structure (DAS) determination. If no acceptable DAS is found after performing the five steps, the process returns to the option at 12 o'clock and the steps are repeated.

- The bottom left portion of the diagram, between 5 o'clock and 7 o'clock is used for calculation of the optimum binder percentage once a DAS has been determined.

- The left side of the hub diagram, between 8 o'clock and 9 o'clock, shows the final tests performed once an optimum binder percentage is determined. Mixes that do not meet the $\% \mathrm{G}_{\mathrm{mm}, \mathrm{Nmax}}$ criteria must be redesigned with a new DAS; those that fail the TSR test require antistrip and the binder percentage calculations are repeated.

The Superpave Calculator can run on any computer that is adequate for Excel 97 or a later version. The process for installing the software is presented in Appendix B. The installation process will create a shortcut button on the Excel toolbar. Clicking on the shortcut button will launch the Superpave Calculator. After launching the application, an option of creating a new mix design or modifying an existing project is presented. If modification is required, a Windows "File Open" box is displayed; the user selects the appropriate existing project and opens it for changes. If a new mix design is to 
be created, the user first enters all of the necessary report data into the appropriate input fields, detailing project number, location data and mix designer. Information about the aggregates and binder, including suppliers, location, type and codes is also required.

\subsubsection{DESIGN INFORMATION}

Once the report information is entered, the user is prompted to enter all necessary mix design information by way of a series of option buttons. Required parameters include: design level, binder type, traffic ESALs, NMAS and specific gravity of the binder. The designer has the option to enter data about temperatures, Recycled Asphalt Pavement (RAP) used in the process, and any helpful comments. The user is then linked to the main choices page, which acts as the "hub" of the program, and is returned here after each successive step is completed. The aggregate data, including gradation, bulk and apparent specific gravity is then entered into the proper fields. The software is designed with a maximum of four separate aggregates allowed for a mix design. Data on the aggregate consensus properties, including fine aggregate angularity, coarse aggregate angularity, sand equivalency and flat-and-elongated ratio is entered in the next step of the process, which is evaluated for acceptability when creating blends.

\subsubsection{DESIGN AGGREGATE STRUCTURE DETERMINATION}

If the user knows the percentage of each aggregate that is used to create the blend, it may be entered during aggregate data entry; otherwise a Design Aggregate Structure (DAS) must be determined. The DAS evaluation begins with selection of three different aggregate blends that meet all necessary criteria. Percentages, which must add to $100 \%$, are entered into the appropriate input boxes, and a graph of the blended gradation is viewed for acceptability. An asphalt content for each of these DAS is then estimated automatically, using a series of equations based on aggregate data. The estimated asphalt contents are then used in experimental tests to determine the maximum theoretical specific gravity $\left(\mathrm{G}_{\mathrm{mm}}\right)$ and the bulk specific gravity $\left(\mathrm{G}_{\mathrm{sb}}\right)$ of each DAS. 


\section{Structure of User Interface for Superpave Calculator}

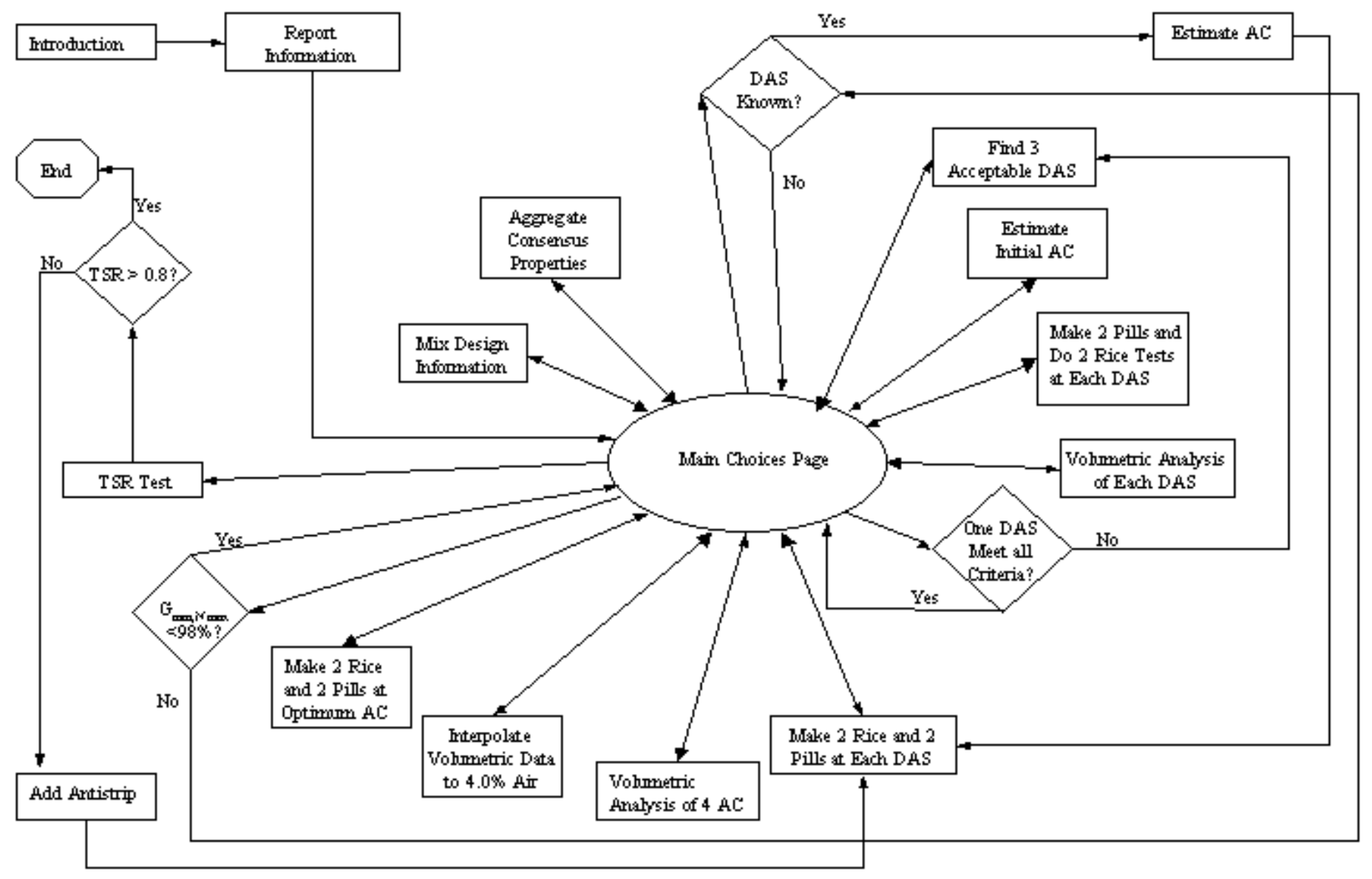

Figure 4.1 Structure of User Interface for Superpave Calculator 


\subsubsection{DESIGN AGGREGATE STRUCTURE VOLUMETRICS}

The weights and heights from the tests are then entered into the proper fields. The calculated volumetric output is presented on a separate user form, which compares the actual values with the acceptable tolerances. These volumetric values are then mathematically adjusted to $4.0 \%$ Voids in the Total Mixture (VTM) and presented for selection of the best aggregate structure. If none of the DASs pass all of the volumetric requirements, the user is returned to the page for the initial step in determining a DAS. The user then needs to select and evaluate three new DASs. Once an acceptable DAS is identified, the optimum asphalt binder percentage is determined.

\subsubsection{VOLUMETRICS USING FOUR DIFFERENT ASPHALT CONTENTS}

The user has the option of accepting the computer calculated optimum binder percentage, or entering a different asphalt content. After finalizing the asphalt percentage, the software creates weigh-out sheets for preparing samples for the volumetric evaluation. Maximum theoretical specific gravity samples are created at:

- $\mathrm{P}_{\mathrm{b}, \mathrm{est}}-0.5 \%$

- $\mathrm{P}_{\mathrm{b}, \mathrm{sst}}$

- $\mathrm{P}_{\mathrm{b}, \mathrm{est}}+0.5 \%$

- $\mathrm{P}_{\mathrm{b}, \mathrm{est}}+1.0 \%$

$\mathrm{P}_{\mathrm{b}, \text { sst }}$ is the estimated optimum binder percentage used for volumetric analysis, as determined during the DAS selection process. After the tests at the four binder percentages are completed, the weights are entered into the appropriate fields and the software performs the calculations. A graph of the asphalt content (AC) versus Voids in the Total Mix (VTM) is created and the interpolated AC value that yields 4.0\% VTM is determined. This AC is then used to interpolate the values for Voids in the Mineral Aggregate (VMA), Voids Filled with Asphalt (VFA), Percent of $\mathrm{G}_{\mathrm{mm}}$ at initial number of revolutions $\left(\mathrm{G}_{\mathrm{mm}, \mathrm{Nini}}\right)$ and the Dust to Binder Ratio $(\mathrm{D} / \mathrm{b})$. If all of the interpolated values are within the mix design limits, the final tests to evaluate acceptability are performed. If the mix fails the mix design limits, the DAS evaluation must be repeated. However, due to the Superpave process, there is a low probability of not finding a suitable asphalt content for a DAS that was selected using the prescribed methodology. 


\subsubsection{FINAL ACCEPTABLITIY TESTING}

Upon determining the optimum binder percentage, two final tests are performed to validate the mix. Two maximum theoretical specific gravity tests are run and two samples are compacted to the maximum number of revolutions, $\mathrm{N}_{\max }$. The volumetric analysis is performed on these results and the $\% \mathrm{G}_{\mathrm{mm}, \mathrm{Nmax}}$ is compared to the maximum value of $98.0 \%$. The Superpave Calculator identifies an acceptable result by turning the field around the computed $\% \mathrm{G}_{\mathrm{mm} \text {,Nmax }}$ green; failure to meet the criteria is indicated by a red field.

If $\% \mathrm{G}_{\mathrm{mm}, \mathrm{Nmax}}$ is within the limits, the program automatically creates weigh-out sheets for six more compaction samples to perform the Tensile Strength Ratio Test. The user compacts the six specimens, conditions three of them and leaves the other three unconditioned. The split tensile test is performed on all six samples and the average of the conditioned values is divided by the average of the unconditioned samples. This ratio must meet a minimum of 80 percent to be within the tolerance; once again the software indicates acceptable values. If all of the test results yield passing values, the user is finished with the Superpave mix design process and may print the results and exit the software.

\subsubsection{SAVING AND EXITING}

At any point along the design process, the user may exit the program by simply pressing the "Exit" button on the main choices page. Exiting brings up the final screen in the series, allowing the user to exit with, or without, saving. Pressing the "Exit and Save" button opens Windows "Save As" box in which the user names the file and places it in the selected folder. The exit page also contains a button which automatically prints out the "West Virginia Division of Highways Job Mix Formula for Superpave Hot-Mix Asphalt", form T400 SP, with all necessary items automatically entered. When exiting the software, the program automatically closes the Excel workbook.

\subsection{SOFTWARE VERIFICATION PROCESSES}

The Superpave Calculator verification process required an independent three-step procedure. Data with known results were entered into all of the data entry boxes. This ensured that each input field was properly linked to the Excel spreadsheet and all 
formulas received the correct data. After the functionality of the software was validated, data sets from existing mix designs from the West Virginia Division of Highways were entered into the program and the theoretical outputs were compared to the calculated WVDOH values. Once the theoretical values were determined to be equivalent to the actual results, the software was implemented in the West Virginia University Asphalt Technology Laboratory, and new mix designs were created. This chapter details the three verification processes, including a data comparison summary.

\subsection{PROGRAM FUNCTIONALITY VALIDATION}

After completion of the data entry forms, userforms, and the Excel spreadsheet, extensive testing was then conducted to verify the proper function of the workbookuserforms program. Data sets with known results were entered into the input fields where the corresponding links to Excel were verified and the calculations were checked. This step was not designed to confirm the software's accuracy in estimation of theoretical binder percentages or calculate a design aggregate structure. The purpose of the validation of functionality was to ensure that every text input corresponded with the proper Excel worksheet cell and the output values were returned correctly. Software accuracy confirmation was conducted with WVDOH data.

\subsection{ACCEPTABILITY OF SUPERPAVE CALCULATOR RESULTS}

Upon completion of the Superpave Calculator program, validation of the methodology and calculations was required. Six data sets from previous WVDOH Superpave mix designs were entered into the software. Three of the designs were full processes and three were determination of optimum asphalt content, given the design aggregate structures (DAS). The results were calculated and compared to the actual values obtained. Of the six mix designs that were entered, the results from the least accurate are presented in Tables 4.1 to 4.3. The average estimated binder percentages for the DAS differed by only $6 \%$ and all volumetric calculations were exactly equal. The source of the difference was traced to the method used by the contractor for estimating binder content. The Superpave Calculator accurately applies the models while the contractor's method used an approximation. From empirical testing, the six percent difference between the actual and theoretical values would not change the final optimum binder percentage; therefore both methods yield acceptable results. All interpolated 
values were consistent with the $\mathrm{DOH}$ estimates. The final volumetrics and necessary test results were also exactly equal to the $\mathrm{DOH}$ values. All input data sets, estimated results and actual values are presented in the following tables, along with the actual and Superpave Calculator T400 SP summary sheets in Figures 4.2 and 4.3.

\subsection{LABORATORY VALIDATION OF SOFTWARE}

To further validate the program, the Superpave Calculator was used for developing mix designs in the Asphalt Technology Laboratory. The majority of the lab testing was performed with steel slag as the only aggregate. However, the software was used to evaluate mix designs prepared for other projects in the Asphalt Technology Laboratory that contained limestone and natural sand. All of the data sets and results for the steel slag evaluation are presented in Appendix C. These results are discussed in Chapter 5. 
Table 4.1 Data Used for Validation of Superpave Calculator

\begin{tabular}{|c|c|c|c|c|c|c|}
\hline \multirow{2}{*}{$\begin{array}{l}\text { Report Number: } \\
\text { HMA Type: }\end{array}$} & \multicolumn{2}{|c|}{1349538} & \multicolumn{2}{|c|}{ Date Accepted: } & \multicolumn{2}{|c|}{ May 6,2002} \\
\hline & \multirow{2}{*}{\multicolumn{2}{|c|}{$\begin{array}{c}9.5 \mathrm{~mm} \text { (Wearing-I) Skid } \\
\text { Producer }\end{array}$}} & \multicolumn{2}{|c|}{ HMA Code: } & \multicolumn{2}{|c|}{ Code } \\
\hline Producer: & & & \multicolumn{2}{|c|}{ Plant Location: } & \multicolumn{2}{|c|}{ Location } \\
\hline Designed By: & \multicolumn{2}{|c|}{$\begin{array}{l}\text { Producer } \\
\text { Designer }\end{array}$} & \multicolumn{2}{|c|}{ Design Lab: } & \multicolumn{2}{|c|}{$\mathrm{Lab}$} \\
\hline Plant Type: & \multicolumn{2}{|c|}{ Batch } & \multirow{2}{*}{\multicolumn{2}{|c|}{\begin{tabular}{|l} 
Plant Make: \\
Design ESALs:
\end{tabular}}} & \multicolumn{2}{|c|}{ Make } \\
\hline Plant Code: & \multicolumn{2}{|l|}{ Code } & & & $3<31$ & Million \\
\hline & \multicolumn{2}{|l|}{ Source } & Code & \multicolumn{2}{|c|}{ Agg. Type } & Agg. Code \\
\hline CA1 & \multicolumn{2}{|l|}{ Source } & Code & \multicolumn{2}{|c|}{ \#8 Limestone } & 1135 \\
\hline FA1 & \multicolumn{2}{|l|}{ Source } & Code & \multicolumn{2}{|c|}{ Limestone } & 1116 \\
\hline FA2 & \multicolumn{2}{|l|}{ Source } & Code & \multicolumn{2}{|c|}{ \#9 Limestone } & 1137 \\
\hline FA3 & \multicolumn{2}{|l|}{ Source } & Code & Lin & estone & 1116 \\
\hline Binder & Supplier & & Code & & & 1091 \\
\hline & $\%$ Binder in & RAP De & sign & & None & \\
\hline & Mean Temp. (F) & Min. T & emp. ( F) & Max & Temp. ( & \\
\hline & 310 & & 285 & & 335 & \\
\hline & Remarks: & & Jone & & & \\
\hline & Agg & egate $\mathrm{G}$ & radations & & & \\
\hline & \#9 Limestone & L.Sa & nd \#1 & L. S & ad \#2 & Skid \\
\hline Sieve & \% Passing & $\% \mathrm{~Pa}$ & assing & $\% \mathrm{P}$ & $\underline{s i n g}$ & \% Passing \\
\hline $\mathbf{5 0 . 0}$ & 100.0 & 10 & 0.0 & & & 100.0 \\
\hline 37.5 & 100.0 & 10 & 0.0 & & & 100.0 \\
\hline 25.0 & 100.0 & 10 & 0.0 & & & 100.0 \\
\hline 19.0 & 100.0 & 10 & 0.0 & & & 100.0 \\
\hline 12.5 & 100.0 & 10 & 0.0 & & & 100.0 \\
\hline 9.5 & 100.0 & 10 & 0.0 & & & 94.0 \\
\hline 4.75 & 75 & 99 & 9.8 & & 0.0 & 2.8 \\
\hline 2.36 & 2.5 & 80 & 0.9 & & .5 & 1.6 \\
\hline 1.18 & 1.5 & 50 & 0.9 & & .0 & 1.5 \\
\hline 0.60 & 1.4 & 32 & 2.9 & & & 1.4 \\
\hline 0.30 & 1.3 & 21 & 1.2 & & & 1.3 \\
\hline 0.075 & 1.2 & 9 & .5 & & & 1.1 \\
\hline Gsb & 2.681 & 2.6 & 623 & & & 2.693 \\
\hline Gsa & 2.740 & 2.7 & 749 & & & 2.729 \\
\hline & & & of Total & end & & \\
\hline Blend ID & \#9 Limestone & & Sand \#1 & & Sand \#2 & Skid \\
\hline Coarse & 14 & & 30 & & 18 & 38 \\
\hline Fine & 10 & & 46 & & 12 & 32 \\
\hline Intermediate & 12 & & 38 & & 15 & 35 \\
\hline
\end{tabular}


Table 4.2 Comparison of Actual and Theoretical DAS Analysis

\begin{tabular}{|c|c|c|c|c|c|c|c|c|}
\hline \multicolumn{9}{|c|}{ Comparison of Actual and Theoretical DAS Analysis } \\
\hline \multicolumn{4}{|c|}{$\begin{array}{l}\text { Actual Initial Percent Binders } \\
\text { for } 3 \text { DAS (From DOT) }\end{array}$} & \multicolumn{4}{|c|}{$\begin{array}{l}\text { Theoretical Initial Percent Binders for } 3 \\
\text { DAS (Using an F-Value of } 0.6 \text { for } \\
\text { Limestone) }\end{array}$} & \multirow{2}{*}{$\begin{array}{l}\text { \%Difference } \\
4.11 \%\end{array}$} \\
\hline \multirow{3}{*}{\multicolumn{2}{|c|}{\begin{tabular}{|c|} 
Coarse \\
Fine \\
Intermediate \\
\end{tabular}}} & \multirow{3}{*}{\multicolumn{2}{|c|}{\begin{tabular}{|l|l|}
\multirow{4}{*}{} & $5.60 \%$ \\
\cline { 2 - 2 } & $5.60 \%$ \\
\cline { 2 - 2 } & $5.60 \%$ \\
\end{tabular}}} & \multirow{3}{*}{\multicolumn{2}{|c|}{\begin{tabular}{|c|} 
Coarse \\
Fine \\
Intermediate \\
\end{tabular}}} & & $5.83 \%$ & \\
\hline & & & & & & & $5.93 \%$ & $5.89 \%$ \\
\hline & & & & & & & $5.88 \%$ & $5.00 \%$ \\
\hline \multicolumn{9}{|c|}{ DAS Volumetric Analysis Using an Estimated Binder Percentage of 5.6\% } \\
\hline \multicolumn{9}{|c|}{ User Input } \\
\hline & \multicolumn{3}{|c|}{ Max. Specific Gravity Data } & \multirow{2}{*}{\multicolumn{5}{|c|}{$\begin{array}{c}\text { Bulk Specific Gravity Data } \\
\text { (All weights in grams, heights in } \mathrm{mm} \text { ) }\end{array}$}} \\
\hline & \multirow{2}{*}{$\begin{array}{l}\text { Sample } \\
\text { Weight } \\
\text { (g) }\end{array}$} & \multirow{2}{*}{$\begin{array}{c}\text { Bowl + Sample } \\
\text { in Water } \\
\text { Weight }(\mathrm{g})\end{array}$} & \multirow{2}{*}{$\begin{array}{l}\text { Calib. } \\
\text { Weight } \\
\text { (g) }\end{array}$} & & & & & \\
\hline & & & & Dry & Wet & SSD & $\mathbf{h}_{\text {ini }}$ & $\mathbf{h}_{\text {des }}$ \\
\hline \multirow{2}{*}{$\begin{array}{c}\text { DAS \#1 } \\
\text { (Coarse) }\end{array}$} & 2055.6 & 2197.3 & 965.7 & 4857.6 & 2821.3 & 4862.9 & 133.6 & 118.5 \\
\hline & 2064.2 & 2202.5 & 965.7 & 4888.6 & 2844.4 & 4892.2 & 133.1 & 118.4 \\
\hline \multirow{2}{*}{$\begin{array}{c}\text { DAS \#2 } \\
\text { (Fine) }\end{array}$} & 2035.6 & 2185.3 & 965.7 & 4851.9 & 2820.5 & 4855.5 & 131.1 & 117.0 \\
\hline & 2029.9 & 2181.2 & 965.7 & 4859.8 & 2831.5 & 4865.4 & 131.3 & 117.0 \\
\hline \multirow{2}{*}{$\begin{array}{c}\text { DAS \#3 } \\
\text { (Interm.) }\end{array}$} & 2015.9 & 2174.4 & 965.7 & 4883.8 & 2842.1 & 4887.3 & 132.4 & 117.7 \\
\hline & 2021.6 & 2176.9 & 965.7 & 4864.0 & 2829.7 & 4867.0 & 132.2 & 117.5 \\
\hline \multicolumn{9}{|c|}{ Volumetric Analysis Summary } \\
\hline & & \multicolumn{3}{|c|}{ WVDOT Values } & & \multicolumn{3}{|c|}{ Superpave Calculator Values } \\
\hline \multicolumn{2}{|c|}{ DAS } & Av. Gmm & Av. Gmb & Av. \% Air & & Av. Gmm & Av. Gmb & Av. \% Air \\
\hline \multicolumn{2}{|c|}{ Coarse } & 2.495 & 2.384 & $4.45 \%$ & & 2.495 & 2.383 & $4.49 \%$ \\
\hline \multicolumn{2}{|c|}{ Fine } & 2.494 & 2.387 & $4.29 \%$ & & 2.493 & 2.387 & $4.25 \%$ \\
\hline \multicolumn{2}{|c|}{ Intermediate } & 2.496 & 2.388 & $4.33 \%$ & & 2.496 & 2.388 & $4.33 \%$ \\
\hline \multicolumn{9}{|c|}{$\begin{array}{c}\text { From the Volumetric Data, the Intermediate Blend is Chosen for } \\
\text { Further Mix Design Analysis }\end{array}$} \\
\hline \multirow{2}{*}{\multicolumn{2}{|c|}{ Percent Binder }} & \multicolumn{3}{|c|}{ WVDOT Value } & & \multirow{2}{*}{\multicolumn{3}{|c|}{\begin{tabular}{|c|} 
Superpave Calculator Value \\
$5.73 \%$ \\
\end{tabular}}} \\
\hline & & & $5.70 \%$ & & & & & \\
\hline \multicolumn{4}{|c|}{ Percent Difference } & & & & & \\
\hline
\end{tabular}


Table 4.3 Comparison of Optimum Binder Percentage Analysis and Final Test Results

\begin{tabular}{|c|c|c|c|c|c|c|c|c|c|}
\hline \multirow{4}{*}{$\mathbf{P}_{\mathbf{b}}$} & \multicolumn{9}{|c|}{ User Input } \\
\hline & \multicolumn{3}{|c|}{ Max. Specific Gravity Data } & \multirow{2}{*}{\multicolumn{6}{|c|}{$\begin{array}{l}\text { Bulk Specific Gravity Data } \\
\text { All weights in grams, heights in mm) }\end{array}$}} \\
\hline & \multirow{2}{*}{$\begin{array}{l}\text { Sample } \\
\text { Weight } \\
\text { (g) }\end{array}$} & \multirow{2}{*}{$\begin{array}{c}\text { Bowl + Sample } \\
\text { in Water } \\
\text { Weight }(\mathrm{g})\end{array}$} & \multirow{2}{*}{$\mid \begin{array}{c}\text { Calib. } \\
\text { Weight }(g)\end{array}$} & & & & & & \\
\hline & & & & Dry & Wet & \multicolumn{2}{|c|}{ SSD } & $\mathbf{h}_{\text {ini }}$ & $\mathbf{h}_{\text {des }}$ \\
\hline \multirow[b]{2}{*}{$5.2 \%$} & & & & & & \multirow{2}{*}{\multicolumn{2}{|c|}{4926.0}} & \multirow{2}{*}{133.4} & \\
\hline & $\frac{2049.3}{20260}$ & & & 4910.9 & $\frac{2854.0}{20221}$ & & & & \\
\hline & & & & & & \multicolumn{2}{|c|}{4894.7} & & \\
\hline \multirow{2}{*}{$5.7 \%$} & 2055.3 & 2195.6 & 965.7 & 4859.6 & 2827.5 & \multicolumn{2}{|c|}{4863.7} & 131.6 & 117.1 \\
\hline & 2061.3 & 2199.1 & 2061.3 & 4881.7 & 2847.3 & \multicolumn{2}{|c|}{4884.7} & 131.7 & 117.2 \\
\hline \multirow{2}{*}{$6.2 \%$} & 20653 & 21953 & 9657 & 48870 & 28617 & \multicolumn{2}{|c|}{4889.0} & 130.9 & 1163 \\
\hline & 2049.9 & 2185.3 & 965.7 & 4908.1 & 2874.4 & \multicolumn{2}{|c|}{4910.6} & 131.8 & 117.0 \\
\hline & \multirow{2}{*}{\multicolumn{3}{|c|}{\begin{tabular}{l|l|l}
2025.9 & 2165.0 & 965.7 \\
2036.9 & 2169.9 & 965.7
\end{tabular}}} & 4852.5 & 2846.6 & 485 & & 129.6 & 115.1 \\
\hline $6.7 \%$ & & & & 4821.8 & 2826.6 & 482 & 3.8 & 129.0 & 114.6 \\
\hline & & & Volumetric $A$ & alysis Sun & mary & & & & \\
\hline & & & WVDOT Va & & Supe & pave & Cal & ulator & - Values \\
\hline & $\mathbf{P}_{\mathbf{b}}$ & Av. Gmm & Av. Gmb & Av. \% Air & Av. G & & Av. $C$ & & v. \% Air \\
\hline & $.2 \%$ & 2.509 & 2.372 & $5.46 \%$ & 2.5 & & 2.3 & & $5.42 \%$ \\
\hline & $.7 \%$ & 2.490 & 2.392 & $3.94 \%$ & $2.4 \mathrm{C}$ & & 2.3 & & $3.98 \%$ \\
\hline & $.2 \%$ & 2.470 & 2.411 & $2.39 \%$ & 2.47 & & 2.4 & & $2.43 \%$ \\
\hline & $.7 \%$ & 2.449 & 2.415 & $1.39 \%$ & 2.4 & & 2.4 & & $1.39 \%$ \\
\hline & & & erpolated Opt & mum Perce & nt Binder & & & & \\
\hline & & WVD & OT Value & & Super & ave & Calc & ulator & Value \\
\hline & & & $5.7 \%$ & & & & $5.7 \%$ & & \\
\hline & & $\% \mathrm{G}_{1}$ & $\mathrm{~mm}, \mathrm{Nmax}$ at $\mathrm{Op}$ & mum Perce & nt Binder & & & & \\
\hline & Max. $\mathrm{S}_{\mathrm{p}}$ & ecific Gra & vity Data & & Ik Specif & c Gr & avity & Data & \\
\hline & Sample & & Calib & (All we & ights in $\mathrm{g}$ & ams, & heig & ats in $r$ & nm) \\
\hline & $(\mathbf{g})$ & Weight (g) & Weight (g) & Dry & Wet & & D & $\mathbf{h}_{\text {ini }}$ & $\mathbf{h}_{\text {des }}$ \\
\hline $\mathbf{P}_{b}$ & & & & & & & & & \\
\hline $57 \%$ & 2055.3 & 2195.6 & 965.7 & 4857.4 & 2857.7 & 48 & 9.4 & 131.6 & 115 \\
\hline $0.17 \mathrm{o}$ & 2061.3 & 2199.1 & 965.7 & 4851.4 & 2857.1 & 48 & 3.3 & 131.2 & 114.7 \\
\hline & & VDOT Va & & & Superp & ave & Calct & lator & Value \\
\hline & & $97.5 \%$ & & & & & $7.5 \%$ & & \\
\hline & & & Tensile : & rength Rati & & & & & \\
\hline & & Wet $\mathrm{T}$ & [ensile Stren & th $(k N)$ & 22.5 & & 22.5 & & 20.8 \\
\hline & & Dry $T$ & ensile Stren & th $(\mathbf{k N})$ & 23.8 & & 22.6 & & 23.8 \\
\hline & & VDOT Va & & & Super & pave & Calc & ulato & Value \\
\hline & & $93.7 \%$ & & & & & 94.0 & & \\
\hline
\end{tabular}


TAUO SH

$03-00$

WEST VIRGINIA DIVISION OF HIGHWAYS

JOB MIX FORMULA FOR SUPERPAVE HOT-MIX ASPHALT

\begin{tabular}{|c|c|c|c|}
\hline Report Number: & 1349538 & Date Accepted: & May 6, 2002 \\
\hline HMA Type: . & $9.5 \mathrm{~mm}$ (Wearing-1) Skid & HMA Code: & \\
\hline Producer: & & Plant Location: & \\
\hline Designed By: & & Design Lab: & \\
\hline Plant Type: & Batch & Plant Make: & \\
\hline Plant Code: & & Design ESALs: & $3<30$ Million \\
\hline
\end{tabular}

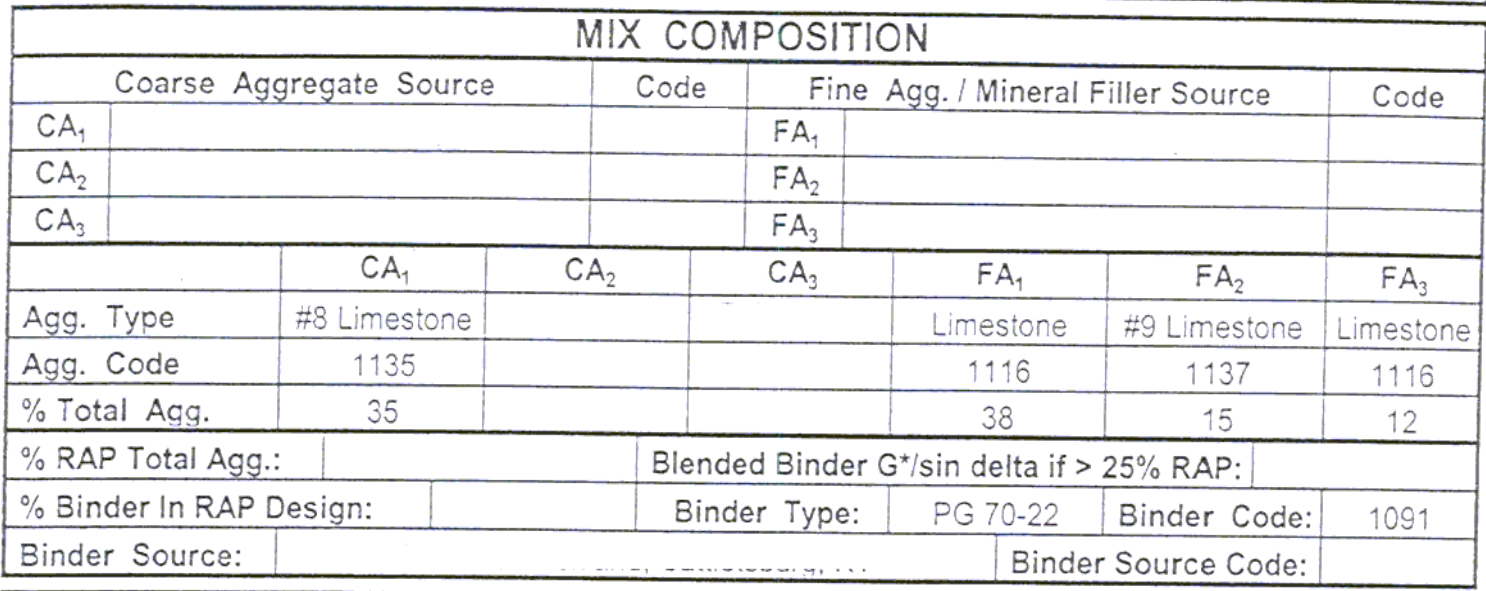

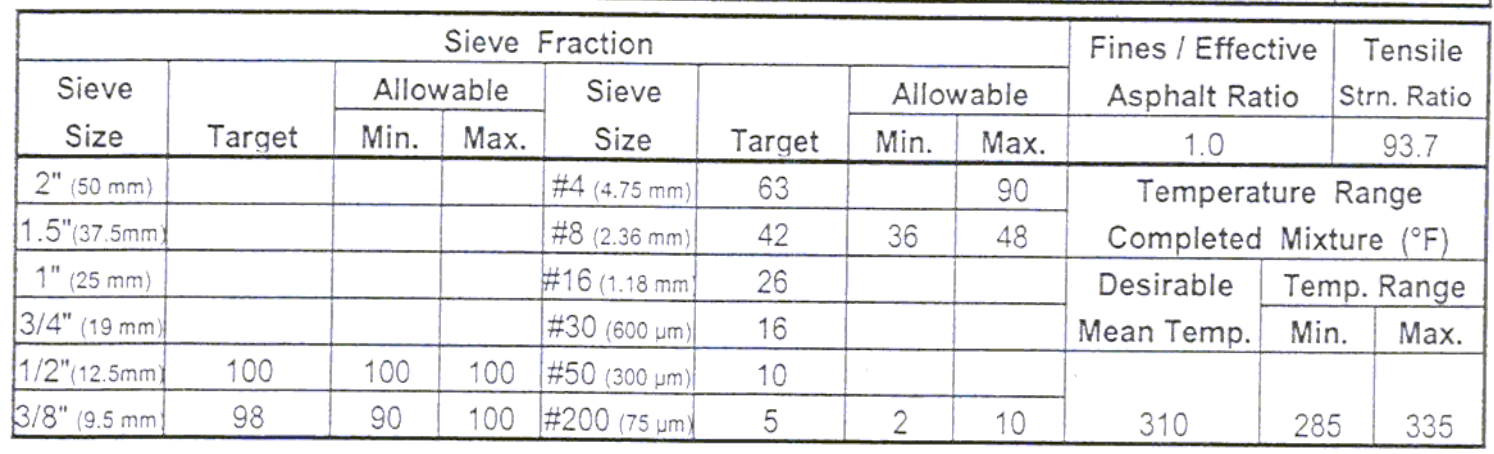

\section{JOB MIX FORMULA VALUES}

\begin{tabular}{|c|c|c|c|c|}
\hline \multicolumn{3}{|c|}{ Job Mix Formula Targets } & \multicolumn{2}{|c|}{ Job Mix Formula Tolerances } \\
\hline Specific gravity stone & Design Property & Accepted Target & Minimum & Maximum \\
\hline bulk (Gsb): 2.658 & Asphalt $(\%)$ & 5.7 & 5.3 & 6.1 \\
\hline \multirow{2}{*}{$\begin{array}{c}\text { Maximum } \\
\text { Density }\left(\mathrm{kg} / \mathrm{m}^{3}\right)\end{array}$} & Air Voids $(\%)$ & 4.0 & 2.8 & 5.2 \\
\hline & VMA $(\%)$ & 15.5 & 14.5 & 16.5 \\
\hline 2491 & VFA $(\%)$ & 74 & 73 & 76 \\
\hline Gyrations@ @ $N_{\text {initi: }}$ & 8 & ons@ $N_{\text {design }}:$ & Gyration & $\max :$ \\
\hline
\end{tabular}

Remarks:

Figure 4.2 Actual Job Mix Formula Sheet for Superpave Mix Design 
$1400 \mathrm{SP}$

03-00

WEST VIRGINIA DIVISION OF HIGHWAYS JOB MIX FORMULA FOR SUPERPAVE HOT-MIX ASPHALT

\begin{tabular}{|lc|lc|}
\hline Report Number: & \multicolumn{1}{l}{ 1349538 } & Date Accepted: & May 6, 2002 \\
\hline HMA Type: & 9.5mm (Wearing-1) Skid & HMA Code: & 13967 \\
\hline Producer: & Producer & Plant Location: & Location \\
\hline Designed By: & Designer & Design Lab: & Lab \\
\hline Plant Type: & Batch & Plant Make: & Make \\
\hline Plant Code: & Code & Design ESALs (Millions): & $3<30$ \\
\hline
\end{tabular}

\section{COMPOSITION}

\begin{tabular}{|c|c|c|c|c|c|c|c|}
\hline \multicolumn{3}{|c|}{ Coarse Aggregate Source } & Code & \multicolumn{3}{|c|}{ Fine Agg. / Mineral Filler Source } & Code \\
\hline $\mathrm{CA}_{1}$ & \multicolumn{2}{|c|}{ Supplier } & Code & $\mathrm{FA}_{1}$ & \multicolumn{2}{|c|}{ Supplier } & Code \\
\hline $\mathrm{CA}_{2}$ & & & & $\mathrm{FA}_{2}$ & \multicolumn{2}{|c|}{ Supplier } & Code \\
\hline \multirow{2}{*}{\multicolumn{2}{|c|}{$\mathrm{CA}_{3}$}} & & & $\mathrm{FA}_{3}$ & \multicolumn{2}{|c|}{ Supplier } & Code \\
\hline & & $\mathrm{CA}_{1}$ & $\mathrm{CA}_{2}$ & & $\mathrm{FA}_{1}$ & $\mathrm{FA}_{2}$ & MIN. FILL \\
\hline \multicolumn{2}{|c|}{ Aggregate Type } & \#8 L-Stone & & & Limestone & \#9 L-Stone & Limestone \\
\hline \multicolumn{2}{|c|}{ Aggregate Code } & 1135 & & & 1116 & 1137 & 1116 \\
\hline \multicolumn{2}{|c|}{$\%$ Total Aggregate } & $35.0 \%$ & & & $38.0 \%$ & $15.0 \%$ & $12.0 \%$ \\
\hline \multicolumn{2}{|c|}{$\%$ RAP Total Agg: } & N/A & \multicolumn{4}{|c|}{$\begin{array}{llll}\text { Blended Binder } \mathrm{G}^{\star} / \text { sin delta if }>25 \% \text { RAP: } & \\
\end{array}$} & N/A \\
\hline \multicolumn{2}{|c|}{$\%$ Binder in RAP Design: } & N/A & \multicolumn{2}{|c|}{ Binder Type: } & PG 70-22 & Binder Code: & 1091 \\
\hline \multicolumn{2}{|c|}{ Binder Source: } & \multicolumn{3}{|c|}{ Binder Supplier } & \multicolumn{2}{|c|}{ Binder Source Code: } & Code \\
\hline
\end{tabular}

\begin{tabular}{|c|c|c|c|c|c|c|c|c|c|c|}
\hline & & & Sieve & raction & & & & \multirow{2}{*}{$\begin{array}{l}\text { Fines/Effective } \\
\text { Asphalt Ratio }\end{array}$} & \multirow{2}{*}{\multicolumn{2}{|c|}{$\begin{array}{c}\text { Tensile } \\
\text { Strn. Ratic }\end{array}$}} \\
\hline \multirow{2}{*}{$\begin{array}{l}\text { Sieve } \\
\text { Size }\end{array}$} & \multirow[b]{2}{*}{ Target } & \multicolumn{2}{|c|}{ Allowable } & \multirow{2}{*}{$\begin{array}{l}\text { Sieve } \\
\text { Size }\end{array}$} & \multirow[b]{2}{*}{ Target } & \multicolumn{2}{|c|}{ Allowable } & & & \\
\hline & & Min. & Max. & & & Min. & Max. & 1.0 & & 4.0 \\
\hline 2" (50mm) & & & & $\# 4(4.75 \mathrm{~mm})$ & & & 80 & \multirow{2}{*}{\multicolumn{3}{|c|}{$\begin{array}{c}\text { Temperature Range } \\
\text { Completed Mixture }\left({ }^{\circ} \mathrm{F}\right)\end{array}$}} \\
\hline $1.5^{\prime \prime}(37.5 \mathrm{~mm})$ & & & & $\# 8 "(2.36 \mathrm{~mm})$ & 42.5 & 30 & 55 & & & \\
\hline 1" $(25 \mathrm{~mm})$ & & & & $\# 16$ (1.18mm) & & & & \multirow{2}{*}{$\begin{array}{c}\text { Desirable } \\
\text { Mean Temp. }\end{array}$} & \multicolumn{2}{|c|}{ Temp. Range } \\
\hline $3 / 4^{\prime \prime}(19 \mathrm{~mm})$ & & & & $\# 30\left(600_{\mu} \mathrm{m}\right)$ & & & & & Min. & Max. \\
\hline $1 / 2 "(12.5 \mathrm{~mm})$ & 100 & 100 & 100 & $\# 50(300 \mu \mathrm{m})$ & & & & & & \\
\hline $3 / 8^{\prime \prime}(9.5 \mathrm{~mm})$ & 92.5 & 85 & 100 & $\# 200(75 \mu \mathrm{m})$ & 5.5 & 2 & 9 & 310 & 285 & 335 \\
\hline
\end{tabular}

JOB MIX FORMULA VALUES

\begin{tabular}{|c|c|c|c|c|c|}
\hline \multicolumn{4}{|c|}{ Job Mix Formula Targets } & \multicolumn{2}{|c|}{ Job Mix Formula Tolerances } \\
\hline \multirow{2}{*}{$\begin{array}{l}\text { Specific gravity stone } \\
\text { bulk (Gsb): } \quad 2.658\end{array}$} & Design Property & \multicolumn{2}{|c|}{ Accepted Target } & Minimum & Maximum \\
\hline & Asphalt (\%) & \multicolumn{2}{|c|}{5.7} & 5.3 & 6.1 \\
\hline \multirow{2}{*}{$\begin{array}{c}\text { Maximum Density } \\
\left(\mathrm{kg} / \mathrm{m}^{3}\right)\end{array}$} & Air Voids (\%) & \multicolumn{2}{|c|}{4.0} & 2.5 & 5.5 \\
\hline & VMA $(\%)$ & \multicolumn{2}{|c|}{16.0} & 15.0 & 17.0 \\
\hline 2490.0 & VFA $(\%)$ & \multicolumn{2}{|c|}{74.5} & 73.0 & 76.0 \\
\hline Gyrations $@ N_{\text {initial: }}$ & Gyra & Q $N_{\text {design: }}$ & 100 & Gyrations @ $\mathrm{N}_{\max }$ : & 160 \\
\hline
\end{tabular}

Remarks: This is a re-creation of an existing mix, to test software accuracy

Figure 4.3 Job Mix Formula Sheet for Superpave Mix Design Created by the Software 


\section{CHAPTER 5 MIX DESIGN OF STEEL SLAG ASPHALT}

\subsection{MATERIALS AND PREPARATION}

The steel slag aggregates used for the entire research project were obtained from International Mill Service, Inc. (IMS), Weirton WV, and consisted of two types: \#57 (coarse) slag and \#10 (fine) slag. Blends of the two aggregate types were used in each mix design, then tested for volumetric analysis and rut susceptibility. The asphalt used for each design trial was PG 64-22 obtained from Marathon, Ashland, OH. Processing the aggregates consisted of sieving, washing, and oven drying. The aggregates were separated with a nest of sieves, consisting of: 1", 3/4" 3/8" \#4, \#8, \#16, \#30, \#50, \#200 and pan. The material retained on each sieve and pan was placed into storage bins.

\subsection{AGGREGATE PROPERTIES}

The sieve analysis of the two steel slag aggregates used in this research is shown in Table 5.1 and a summary of the specific gravities of all aggregates used is presented in Table 5.2. Graphs of each blended gradation are found in Appendix C.

Table 5.1 Dry Sieve Gradation Analysis Results

\begin{tabular}{|c|c|c|c|}
\hline & \multicolumn{2}{|c|}{ Percent Passing (\%) } & \\
\hline Sieve No. & $\begin{array}{c}\text { IMS } \\
\# 57 \text { Slag }\end{array}$ & $\begin{array}{c}\text { IMS } \\
\# 10 \text { Slag }\end{array}$ & $\begin{array}{c}\text { Sieve Size } \\
(\mathrm{mm})\end{array}$ \\
\hline $2 "$ & 100.0 & 100.0 & 50 \\
\hline $1.5 ”$ & 100.0 & 100.0 & 37.5 \\
\hline $1 "$ & 100.0 & 100.0 & 25 \\
\hline $3 / 4 "$ & 87.9 & 100.0 & 19 \\
\hline $1 / 2 "$ & 41.0 & 100.0 & 12.5 \\
\hline $3 / 8 "$ & 13.6 & 100.0 & 9.5 \\
\hline$\# 4$ & 4.1 & 96.0 & 4.75 \\
\hline$\# 8$ & 4.0 & 73.9 & 2.36 \\
\hline$\# 16$ & 0.0 & 57.6 & 1.18 \\
\hline$\# 30$ & 0.0 & 40.3 & 0.6 \\
\hline$\# 50$ & 0.0 & 25.4 & 0.3 \\
\hline$\# 200$ & 0.0 & 10.6 & 0.075 \\
\hline Pan & 0 & 0 & 0 \\
\hline
\end{tabular}


Table 5.2 Calculated Steel Slag Specific Gravity and Absorption Values

\begin{tabular}{|c|c|c|c|c|c|}
\hline & $\mathbf{3 / 4}$ & $\mathbf{1 / 2}$ & $\mathbf{3 / 8}$ & $\mathbf{\# 4}$ & Fines \\
\cline { 2 - 6 } & \multicolumn{5}{|l|}{} \\
\hline Bulk Specific Gravity & 3.367 & 3.345 & 3.296 & 3.206 & 2.880 \\
\hline (Oven Dry Basis) & \multicolumn{5}{|l}{} \\
\hline Bulk Specific Gravity & 3.417 & 3.400 & 3.363 & 3.298 & 3.087 \\
\hline (Saturated-Surface-Dry Basis) & \multicolumn{5}{|l}{} \\
\hline Apparent Specific Gravity & 3.543 & 3.540 & 3.532 & 3.531 & 3.634 \\
\hline & & & \\
\hline Absorption, percent & $1.48 \%$ & $1.65 \%$ & $2.02 \%$ & $2.87 \%$ & $7.21 \%$ \\
\hline
\end{tabular}

\subsection{INITIAL MIX DESIGN TRIALS USING STEEL SLAG}

After obtaining the required steel slag aggregate from IMS, and performing the necessary preparations, the Superpave Calculator was used to determine the initial asphalt content. Previous research has demonstrated that, for limestone mixes, an absorption value of 0.6-0.8 can be used to perform the necessary binder estimation calculations (Harman, et al., 1999). Since the effect of asphalt cement on the IMS steel slag was unknown, an assumption that the absorption behavior matched limestone was used. The first tests were considered asphalt absorption trials, to further understand the nature of the aggregate in order to more accurately predict an initial asphalt estimate. The first trial aggregate blend consisted of 64\% \#57 and 36\% \#10 slag, which is displayed in Figure C.1, and the software estimated a binder percentage of $6.5 \%$. All necessary testing was performed to determine the volumetrics of this mix with the full results presented in Appendix C and a summary in Table 5.3.

Table 5.3 Trial 1Volumetric Summary

\begin{tabular}{|c|c|c|c|}
\hline \multicolumn{4}{|c|}{ Trial 1 - Volumetrics } \\
\hline \multicolumn{4}{|c|}{ 64\% \#57 Slag \& 36\% \#10 Slag 6.5\% AC } \\
\hline Category & Tolerance & Values & Passing \\
\hline VTM & $\sim 4 \%$ & $0.27 \%$ & NO \\
\hline VMA & $13 \%$ min & $10.41 \%$ & NO \\
\hline VFA & $65 \%-75 \%$ & $97.45 \%$ & NO \\
\hline D/B & $0.60-1.20$ & 1.09 & YES \\
\hline
\end{tabular}


From the summary in Table 5.3, it is obvious that the main criterion in determining mix acceptability, the Voids in the Total Mix (VTM) value does not approach the required value of $4.0 \%$. This lack of air voids in the mix is indicative of an excessive amount of binder. The binder was reduced by $1.0 \%$ for the next trial.

\subsection{DAS \#1}

For the next three trials, the binder percent was adjusted from $6.5 \%$ to $5.5 \%$, to $5.0 \%$ then to $4.5 \%$, in order to increase the value of VTM to $4.0 \%$. The design aggregate structure from trial one was used for all three trials, with volumetric analysis performed on each blend. The full results of these tests are presented in Appendix $\mathrm{C}$ and a summary is shown in Table 5.4.

Table 5.4 Trials 2,3 \& 4 Volumetric Summary

\begin{tabular}{|c|c|c|c|c|c|c|c|}
\hline \multicolumn{8}{|c|}{$64 \%$ \#57 Slag \& 36\% \#10 Slag } \\
\hline \multirow[b]{2}{*}{ Category } & \multirow[b]{2}{*}{ Tolerance } & \multicolumn{2}{|c|}{ Trial $25.5 \% \mathrm{AC}$} & \multicolumn{2}{|c|}{ Trial $35.0 \%$ AC } & \multicolumn{2}{|c|}{ Trial $44.5 \%$ AC } \\
\hline & & Values & Passing & Values & Passing & Values & Passing \\
\hline VTM & $\sim 4 \%$ & $1.08 \%$ & NO & $1.61 \%$ & NO & $3.57 \%$ & YES \\
\hline VMA & $13 \% \min$ & $8.44 \%$ & NO & $7.52 \%$ & NO & $7.81 \%$ & NO \\
\hline VFA & $65 \%-75 \%$ & $87.26 \%$ & $\mathrm{NO}$ & $78.56 \%$ & $\mathrm{NO}$ & $54.29 \%$ & $\mathrm{NO}$ \\
\hline $\mathrm{D} / \mathrm{B}$ & $0.60-1.20$ & 1.52 & NO & 1.91 & NO & 2.63 & $\mathrm{NO}$ \\
\hline
\end{tabular}

This iterative decrease in the binder percentage yielded an acceptable air content, but none of the other criteria were close to being within the tolerances. The binder percentage was approaching the proper value, but the aggregate structure was producing an extremely high dust to binder ratio and low VFA and VMA values. Graphs of the volumetrics for the first design aggregate structures at the three asphalt contents were created, in order to linearly interpolate if a theoretical asphalt content would result in all volumetric criteria being satisfied. These graphs are presented in Figures 5.1-5.3. 


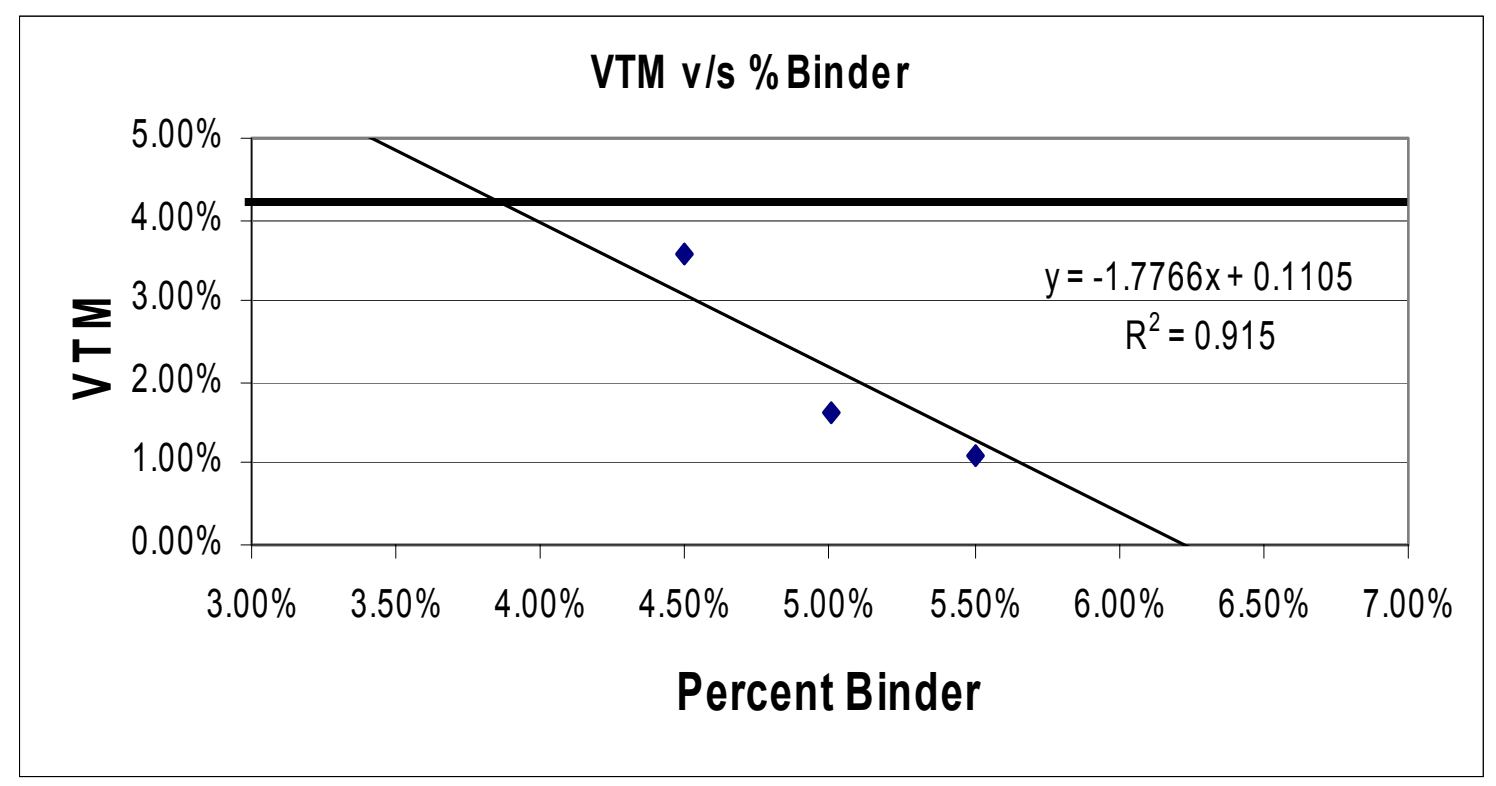

Figure 5.1 Interpolation of VTM v/s Percent Binder

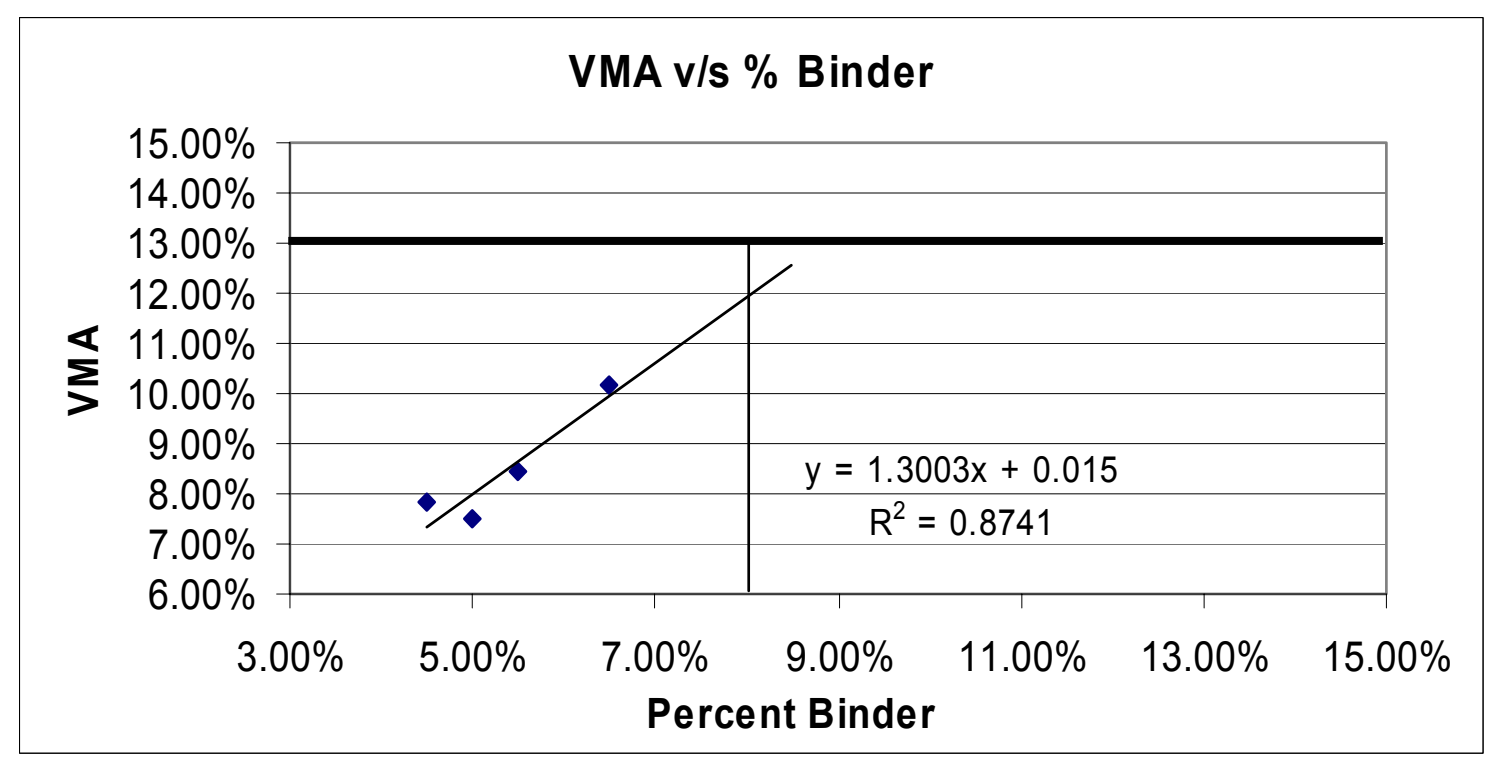

Figure 5.2 Interpolation of VMA v/s Percent Binder 


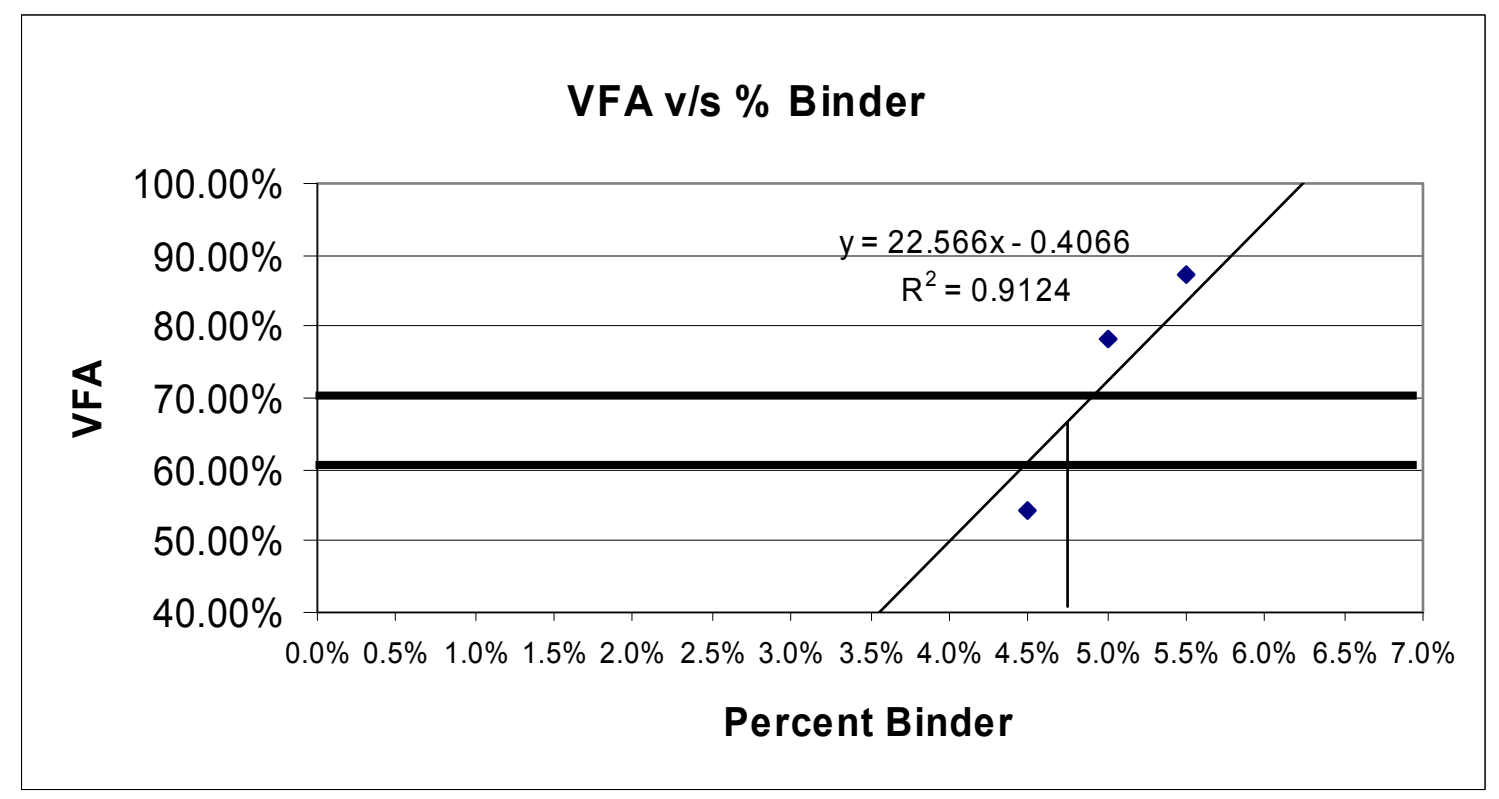

Figure 5.3 Interpolation of VFA v/s Percent Binder

From an examination of the three linear interpolations, the binder content for VTM is $4.0 \%-4.5 \%$, for VMA is $>8 \%$ and for VFA is $4.5 \%-5.0 \%$. From these values, it was determined that the minimum VMA value would never be satisfied if the VTM and VFA tolerances were met. Based on this inference, along with the fact that the $\mathrm{D} / \mathrm{b}$ value was double the highest limit, a decision was made to adjust the design aggregate structure.

\subsection{DAS \#2}

To reduce the $\mathrm{D} / \mathrm{b}$ value, the aggregate structure was made coarser to reduce the amount of dust in the mix, but the binder percentage was held constant at $4.5 \%$. The new blend consisted of 72\% \#57 and 28\% \#10 slag, presented in Figure C.2, which still met all criteria, but was much nearer the lower limits of acceptability. The necessary tests were performed on this new DAS and the volumetrics were calculated. The full results of these tests are presented in Appendix $\mathrm{C}$ and a summary is shown in Table 5.5. 
Table 5.5 Trial 5 Volumetric Summary

\begin{tabular}{|c|c|c|c|}
\hline \multicolumn{4}{|c|}{ Trial 5 - Volumetrics } \\
\hline \multicolumn{4}{|c|}{$\mathbf{7 2 \%}$ \#57 Slag \& 28\% \#10 Slag 4.5\% AC } \\
\hline Category & Tolerance & Values & Passing \\
\hline VTM & $\sim 4 \%$ & $4.84 \%$ & YES \\
\hline VMA & $13 \%$ min & $9.43 \%$ & NO \\
\hline VFA & $65 \%-75 \%$ & $48.62 \%$ & NO \\
\hline D/B & $0.60-1.20$ & 1.88 & NO \\
\hline
\end{tabular}

The increase in the coarse aggregate in the mix reduced the $\mathrm{D} / \mathrm{b}$ and increased the VTM and VMA percentages, but reduced the VFA. Realizing that the necessary air content was achievable, the challenge was increasing VMA and VFA, while decreasing $\mathrm{D} / \mathrm{b}$. The asphalt content would require further reduction to meet the criteria. Another issue arose with all of the binder and aggregate adjustments; there was a noticeable increase in mixing difficulty with the decreasing binder percentages. Mixing a sample with only $4.0 \%$ asphalt content would have been nearly impossible, thus a new approach was decided to achieve the optimum air content.

\subsection{DAS FROM LITERATURE TO DETERMINE OPTIMUM BINDER PERCENTAGE}

A new aggregate structure was needed if the criteria were to be met. After reviewing various articles on steel slag hot mix asphalt design, a possible gradation and binder percentage, used in South Carolina, which yielded 4.2\% VTM and acceptable volumetric criteria was selected (Hanson and Lynn, 1995). The aggregates used in the literature had nearly the same specific gravities as the IMS slag and the absorption percentages were comparable. The gradation is presented in Table 5.6 
Table 5.6 Steel Slag Gradation from Literature Review

\begin{tabular}{|c|c|c|}
\hline \multicolumn{2}{|c|}{ Percent Passing (\%) } & \\
\hline Sieve No. & IMS Slag & $\begin{array}{c}\text { Sieve Size } \\
(\mathrm{mm})\end{array}$ \\
\hline 2 " & 100.0 & 50 \\
\hline $1.5 ”$ & 100.0 & 37.5 \\
\hline $1 "$ & 100.0 & 25 \\
\hline $3 / 4 "$ & 97.0 & 19 \\
\hline $1 / 2 "$ & 89.4 & 12.5 \\
\hline $3 / 8 "$ & 73.0 & 9.5 \\
\hline$\# 4$ & 53.0 & 4.75 \\
\hline$\# 8$ & 37.0 & 2.36 \\
\hline$\# 16$ & 28.0 & 1.18 \\
\hline$\# 30$ & 23.0 & 0.6 \\
\hline$\# 50$ & 17.0 & 0.3 \\
\hline$\# 200$ & 6.0 & 0.075 \\
\hline Pan & 0 & 0 \\
\hline
\end{tabular}

Two samples were made using the gradations in Table 5.6. This gradation could not be created by blending the IMS coarse and fine aggregate, but it was evaluated to determine if a slag mix could be found which meets the Superpave criteria. The literature recommended using $7.0 \%$ asphalt content with the above gradation. The necessary tests were performed and the volumetrics were calculated. The full results of both tests are presented in Appendix C and a summary of averages is shown in Table 5.7.

Table 5.7 Trial 6 Average Volumetric Summary

\begin{tabular}{|c|c|c|c|}
\hline \multicolumn{4}{|c|}{ Trial 6 - Volumetrics } \\
\hline \multicolumn{4}{|c|}{ Gradation from Literature 7.0\% AC } \\
\hline Category & Tolerance & Values & Passing \\
\hline VTM & $\sim 4 \%$ & $0.39 \%$ & NO \\
\hline VMA & $13 \%$ min & $16.45 \%$ & YES \\
\hline VFA & $65 \%-75 \%$ & $97.61 \%$ & NO \\
\hline D/B & $0.60-1.20$ & 1.12 & YES \\
\hline
\end{tabular}

After examining the three design aggregate structures and the varying binder percentages tried, a conclusion was reached that a mix design cannot be created using only IMS steel slag as the aggregate. The slag used in the research, although having 
similar properties to the slag in the literature review, did not behave in the same manner. It was hypothesized that a reduction in binder percentage would increase the VTM to $4.0 \%$, but decrease the VMA and increase the $\mathrm{D} / \mathrm{b}$ values. The literature gradation was then abandoned and DAS \#2 was again tried, at $4.5 \%$ to evaluate rut susceptibility.

\subsection{EVALUATION OF RUT SUSCEPTIBILITY AND CONCLUSIONS}

Six compaction samples were created with 7.0\% VTM and subjected to 8000 wheel passes in the Asphalt Pavement Analyzer (APA). The pavement deformation was then measured and compared with acceptable limits. The full results of the rut testing are presented in Appendix $\mathrm{C}$ and a summary is presented in Table 5.8.

Table 5.8 Average Rut Deformation

\begin{tabular}{|c|c|c|c|}
\hline Criteria & $\mathbf{G}_{\mathbf{m b}}$ & \%Air & Rut Depth (mm) \\
\hline Averages & 2.948 & $7.22 \%$ & 7.69 \\
\hline
\end{tabular}

The average rut deformation of $7.69 \mathrm{~mm}$ is high when compared to the acceptable high limit of $6.0 \mathrm{~mm}$. The high rut susceptibility, combined with not meeting all four volumetric criteria at any time, make an asphalt mixture created with only IMS steel slag as the aggregate an unfeasible task. An acceptable mix design requires the addition of other aggregate types in order to meet volumetric limits and minimize rutting. 


\section{CHAPTER 6 CONCLUSIONS/RECOMMENDATIONS}

\subsection{CONCLUSIONS}

Based on the laboratory effort and computer program creation, the following conclusions were made:

- The Superpave mix design is a complex process, best suited for computer analysis.

- The Superpave Calculator software program is an excellent tool for predicting design aggregate structure initial binder percentages.

- The software streamlines volumetric analysis and combines all necessary charts and graphs along with the limits and restrictions.

- Using the Visual Basic for Applications approach to software development, it is easy to modify and keep the limits and specifications current.

- The software is freely available to anyone and the West Virginia Division of Transportation may use it as needed. It can be accessed either electronically through WVU Asphalt Technology website, [http://www2.cemr.wvu.edu/ wwwasph/]

- An automated Superpave mix design process will provide a uniform submittal format and will be able to be transmitted and stored electronically.

- A mix design consisting entirely of IMS steel slag as the aggregate does not meet all necessary volumetric criteria or provide adequate rut resistance.

- A functional IMS steel slag asphalt mix design must include some mineral filler or bag house fines to meet the $\mathrm{D} / \mathrm{b}$ criteria.

\subsection{RECOMMENDATIONS}

After developing the Superpave Calculator and performing the mix design research on steel slag, the following recommendations are suggested:

- The software may be utilized for all future mix designs created in the West Virginia University Asphalt Technology Laboratory.

- The Superpave Calculator can be used to demonstrate the mix design steps for a university class or a Superpave workshop. 
- After the software is distributed around the state, mix design data may be submitted to the DOH electronically in Excel format.

- Superpave is an evolving technology and it will be necessary to monitor and maintain the Superpave calculator to keep pace with these developments.

- The evaluation of the steel slag aggregate performed during this research did not produce an acceptable Superpave mix design. However, this material, when blended with other aggregates, has been used for Marshall mix designs. Therefore, potential for developing a Superpave mix design exists, but further research is needed. 


\section{REFERENCES}

AASHTO T 209-99, “Theoretical Maximum Specific Gravity and Density of Bituminous Paving Mixtures". Standard Specifications for Transportation Materials and Methods of Sampling and Testing $28^{\text {th }}$ Edition, Washington D.C.: AASHTO, 2000.

AASHTO T P4, "Method for Preparing and Determining the Density of HMA Specimens by Means of the Superpave Gyratory Compactor". Standard Specifications for Transportation Materials and Methods of Sampling and Testing $28^{\text {th }}$ Edition, Washington D.C.: AASHTO, 2000.

AASHTO, AASHTO Ware Catalog July 1, 2002- June 30, 2003.

[http://www.aashtoware.org/aashtoware/downloads/catalog_2003.pdf] Accessed December 3, 2002

Ali, N.A., Chan, J.S.S, Papagiannakis, T., Theriault, E.G., and Bergan, A.T., "The Use of Steel Slag in Asphaltic Concrete", Effects of Aggregates and Mineral Fillers on Asphalt Mixture Performance, ASTM STP 1147, R. C. Meininger, editor, American Society for Testing and Materials, Philadelphia, PA 1992.

Baird, R. R. Ancient Routes. 2000 [http://www.ancientroute.com/resource/Asphalt.htm]. Accessed Nov. 10, 2002.

Ciesielski, S. K., Case Histories of Solid Waste Industrial Slags Used in Hot Mix Asphalt Concrete Pavements, Villanova University. Villanova, PA 1996.

Emery, John, “Steel Slag Utilization in Asphalt Mixes”. Canadian Technical Asphalt Association Proceedings. Toronto, Ontario 1984.

Federal Highway Administration. Implementation Survey IV, 1999-2000. July 2000 [http://ce.ecn.purdue.edu/ spave/Technical\%20Info/Meetings/Imp99-00.htm]. Accessed Nov. 10, 2002.

Harman, T., D’Angelo, J., Bukowski, J. Superpave Asphalt Mixture Design Workshop. Federal Highway Administration. 1999. [http://www.tfhrc.gov/pavement/asphalt/prodrsrch/mixturedesign/mixdsgn.pdf]. Accessed Nov. 10, 2002. 
Hanson, D. I., Lynn, C. R., "Study to Improve Asphalt Mixes in South Carolina”, Volume 2- A Study of Crushed Slag Aggregates in Hot Mix Asphalt, National Center for Asphalt Technology, Auburn University, Auburn, AL 1995.

Hegmon, R.R., Ryan, P.F., “The Polishing Resistance of Selected Slag Aggregates”, Report No. S37. The Pennsylvania State University. University Park, PA 1984.

Jacobson, R. Microsoft Excel 97 Visual Basic Step by Step. Redmond, WA 1997.

Lee, A.R., Blast Furnace and Steel Slag, New York, NY 1974.

Masters, G. Visual Basic 6 Complete. Sybex, San Francisco, CA 1999.

McGannon, H. E., editor The Making, Shaping and Treating of Steel. "Slags in Iron and Steelmaking”, Ninth Ed. United States Steel Corporation. Herbick and Held:

Pittsburgh, PA 1971.

Noureldin, A.S., "Evaluation of Surface Mixtures of Steel and Slag Asphalt".

Transportation Research Record 1269, National Research Council, Washington, D.C 1990.

Pine Instrument Company, AFGC125X Gyratory Compactor Operation Manual. "PinePave User's Guide Version 4.00” Grove City, PA. 1998.

Ramirez, T. L., "Research Project No. 79-012”, Steel Slag Aggregates in Bituminous Mixtures Final Report, Commonwealth of Pennsylvania Department of Transportation, Harrisburg, PA. 1992.

Roberts, F. L., Kandhal, Prithvi, S., Brown, E.Ray, Lee, Dah-Yinn, Kennedy, Thomas W. Hot Mix Asphalt Materials, Mixture Design and Construction. NAPA Education Foundation, Lanham, MD. 1996.

Rock Binder's Inc., Asphalt Origins [http://www.rockbinders.com/asphalt.html]. Accessed Nov. 10, 2002.

Schneider, D. I., An Introduction to Programming Using Visual Basic 6.0 Fourth Edition. Prentice Hall, Upper Saddle River, NJ. 1999.

WVDOT Materials Procedure 401.02.28. Guide to Designing Hot-Mix Asphalt Using the Superpave Volumetric Design System. Charleston, WV. 2000. 
West Virginia Division of Highways Standard Specifications for Roads and Bridges. Division 400- Bituminous Mixes, Section 401.4.2 Plant Mix Formula. Charleston, WV. 2000.

Zaniewski, J. P., Superpave Mix Design Workshop West Virginia University, Morgantown, WV. 2002. 


\section{APPENDIX A}

\section{SCREEN SHOTS FROM SUPERPAVE CALCULATOR}




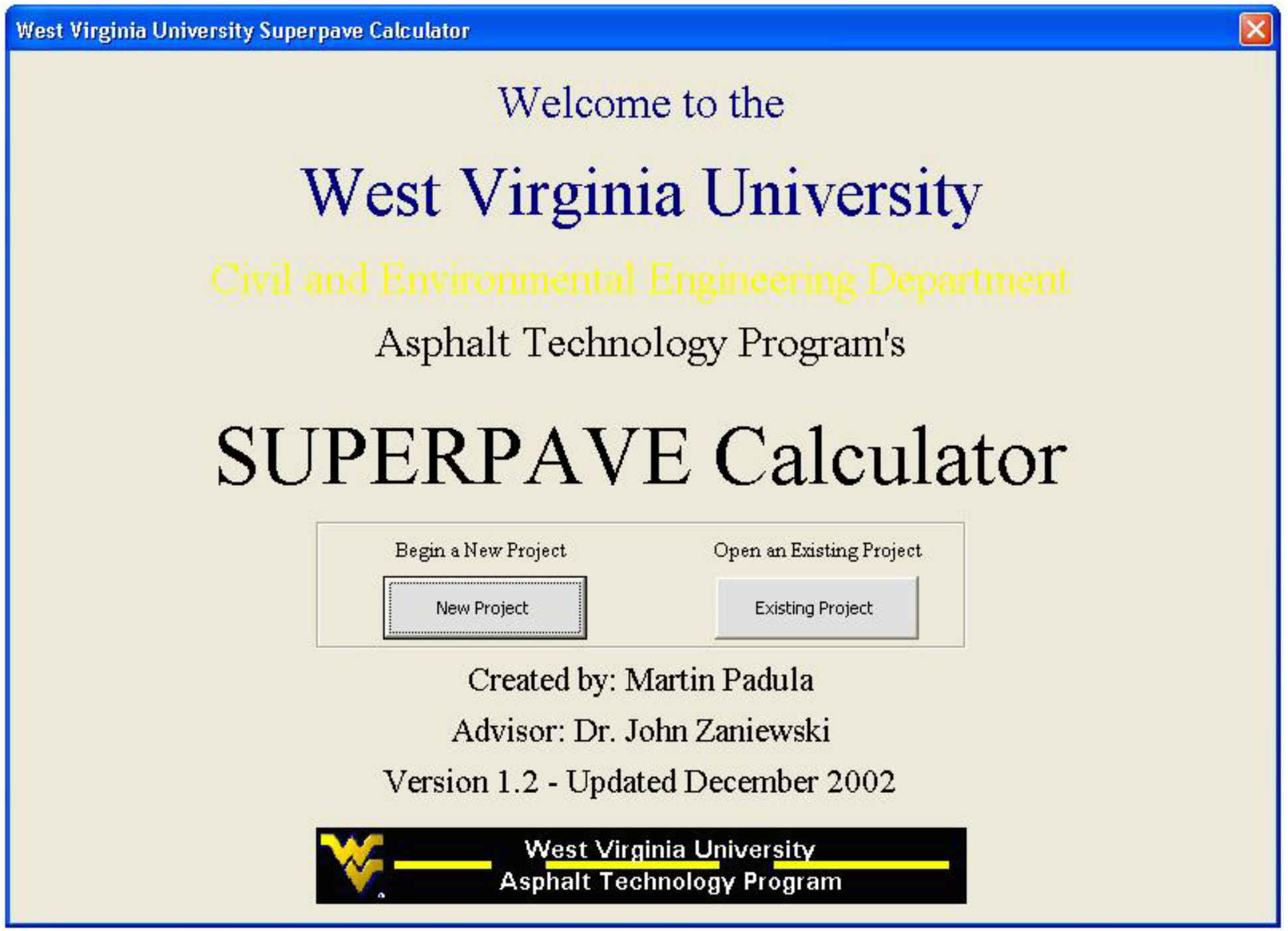

Figure A.1 Introduction to Superpave Calculator 


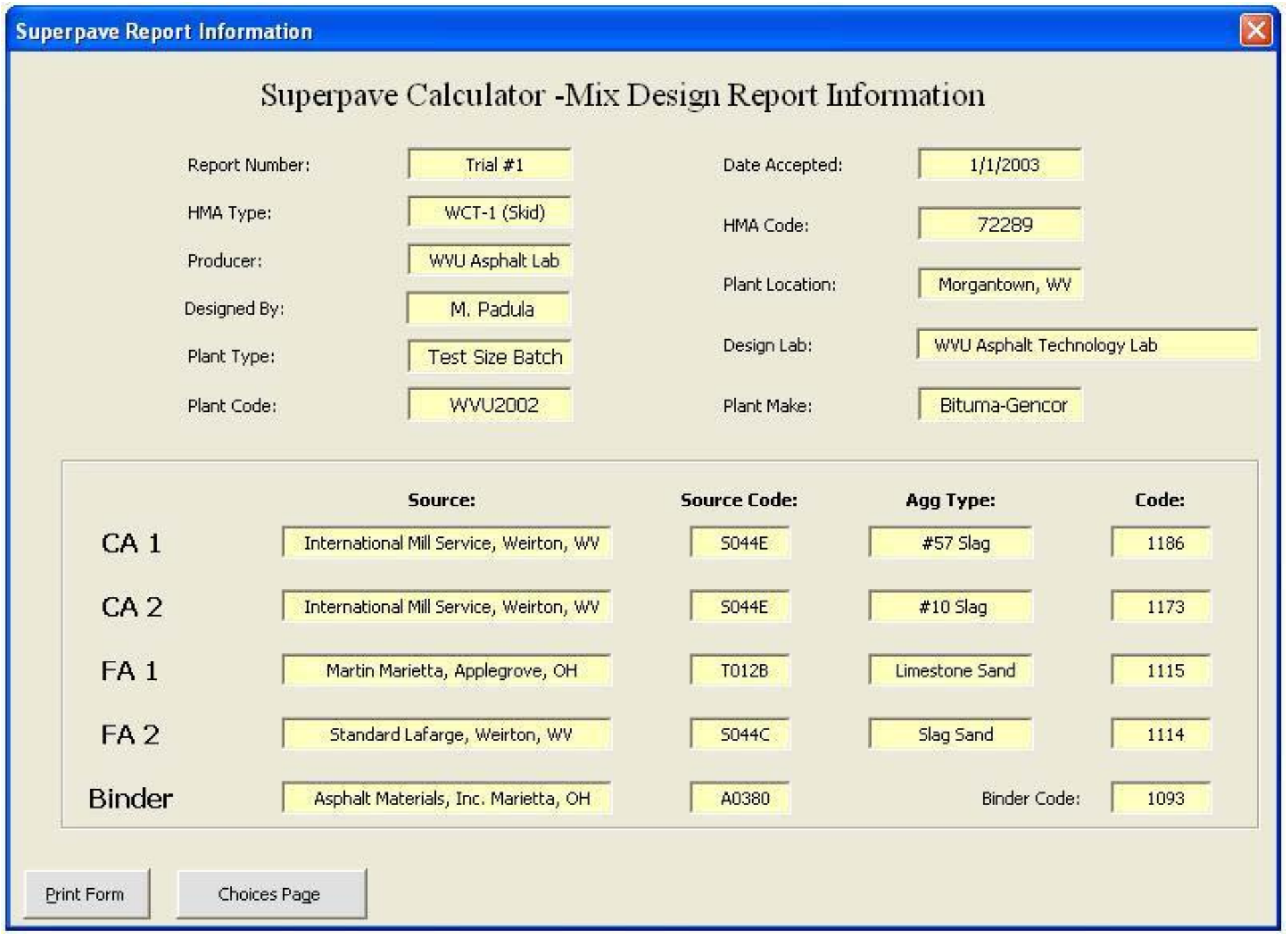

Figure A.2 Superpave Report Information 


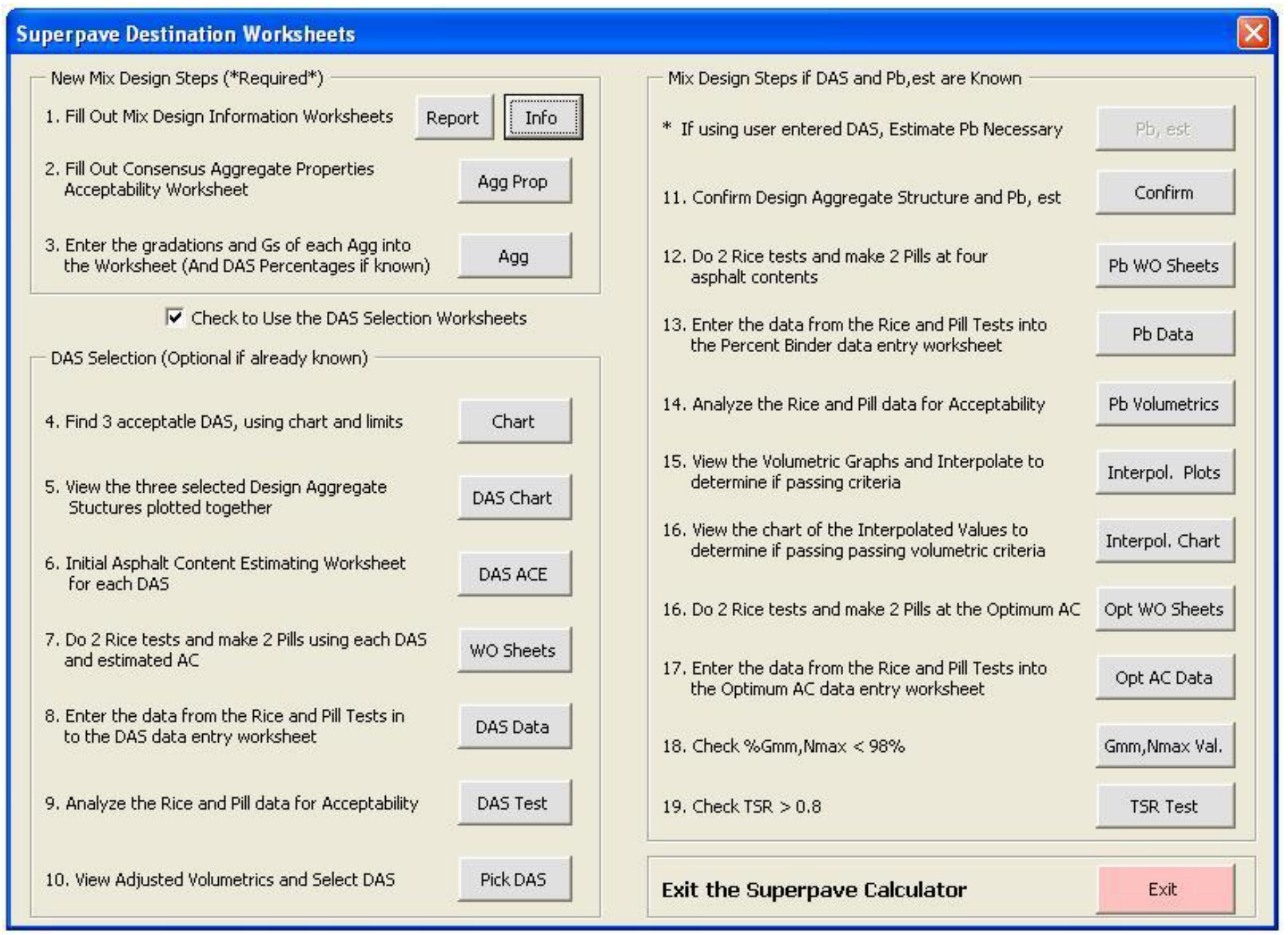

Figure A.3 Superpave Calculator Worksheet Choices 
Superpave Information Sheet

Superpave Calculator -Mix Composition Information

\begin{tabular}{|c|c|c|c|c|c|c|}
\hline Skid Design: & & - Yes & & No & & \\
\hline Binder Grade: & C PG & & (- PG 64-22 & C PG 70-2 & & PG 76-22 \\
\hline Depth from Surface: & & $C \leq 100$ & & $\geqslant 100 \mathrm{~mm}$ & & \\
\hline Traffic ESALs (Millions) & $r<0.3$ & $C 0.3$ to $<3$ & $r 3$ to $<10$ & $C[10$ to $<20]$ & C. 10 to $<30$ & $C \geq 30$ \\
\hline Mix Type (NMAS) & $37.5 \mathrm{~mm}$ & C $25 \mathrm{~mm}$ & C. $19 \mathrm{~mm}$ & C $12.5 \mathrm{~mm}$ & $9.5 \mathrm{~mm}$ & C $4.75 \mathrm{~mm}$ \\
\hline
\end{tabular}

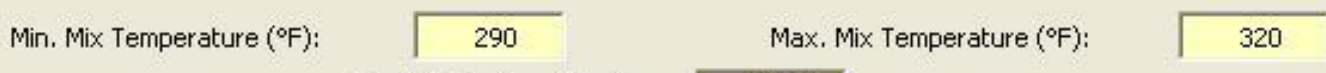 Specific Gravity of Binder: $\quad 1.033$

RAP Information (If Necessary)

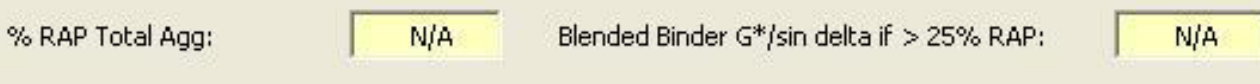

\% Binder in RAP Design: $\quad$ N/A

Print Form

Choices Page

Remarks: This is a trial to validate the software and demonstrate its utility

Figure A.4 Mix Information Worksheet 
Calculated Aggregate Properties

\section{Superpave Calculator - Calculated Aggregate Consensus Properties Worksheet}

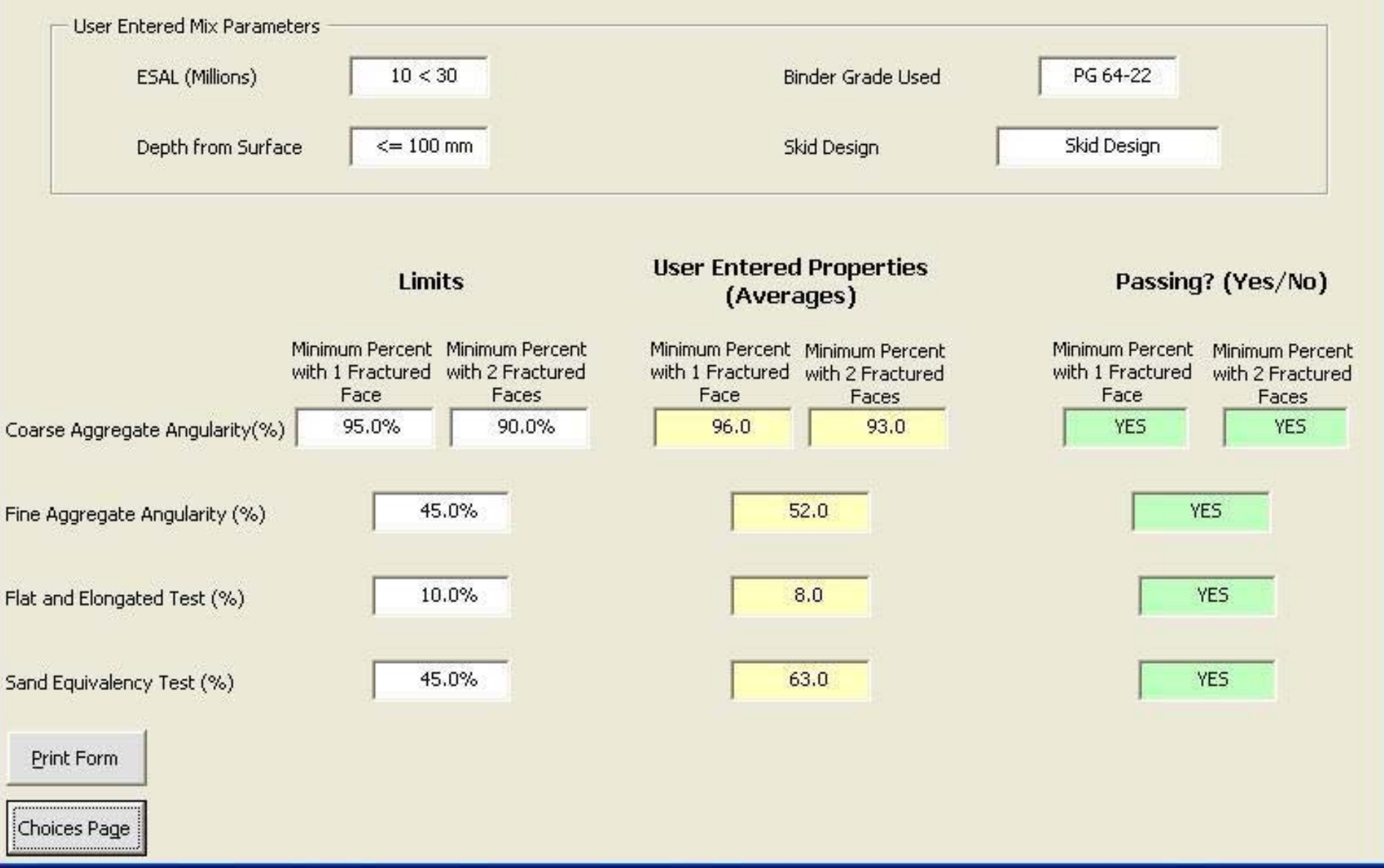

Figure A.5 Calculated Aggregate Consensus Properties Worksheet 


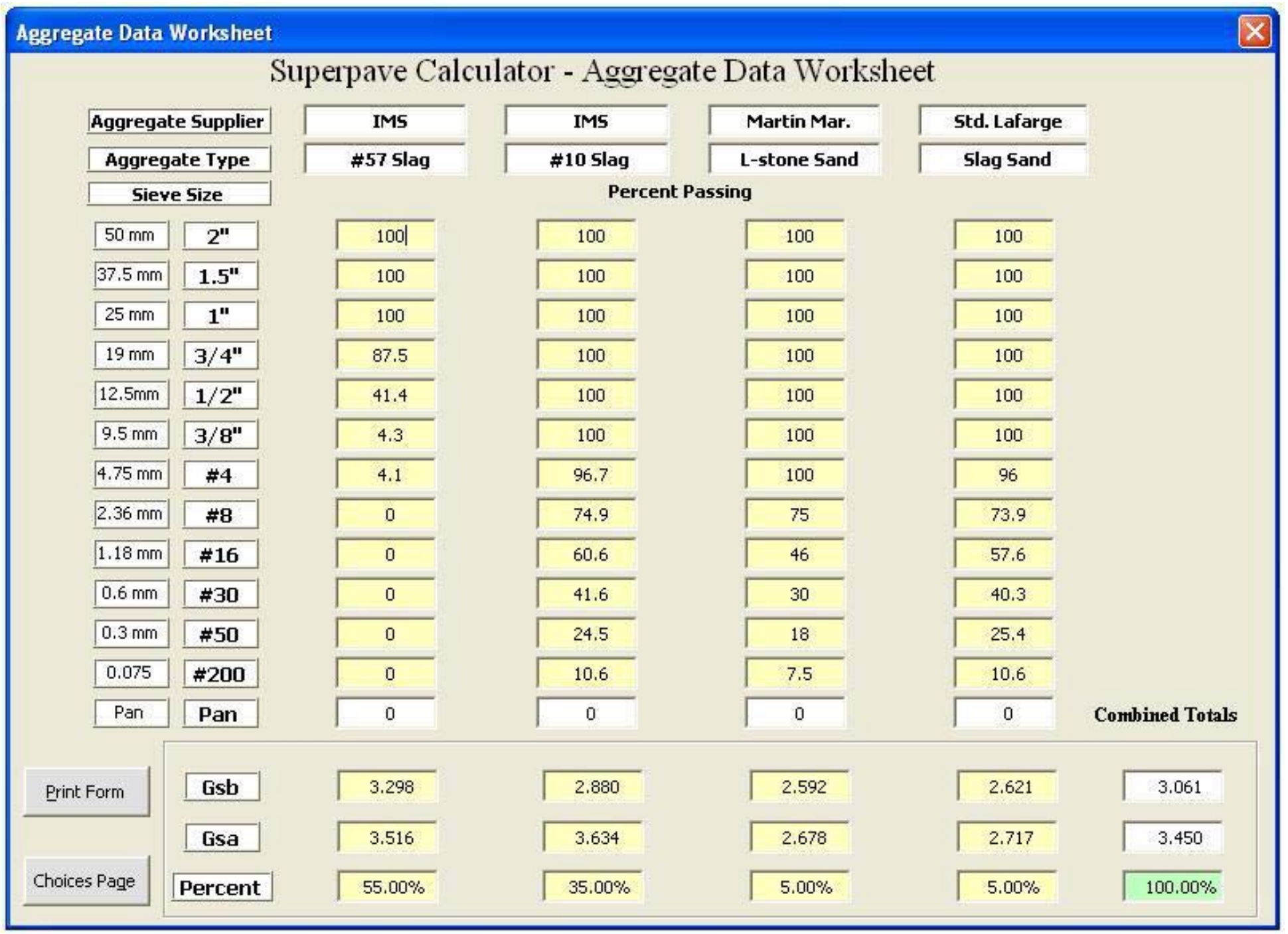

Figure A.6 Aggregate Data Worksheet 


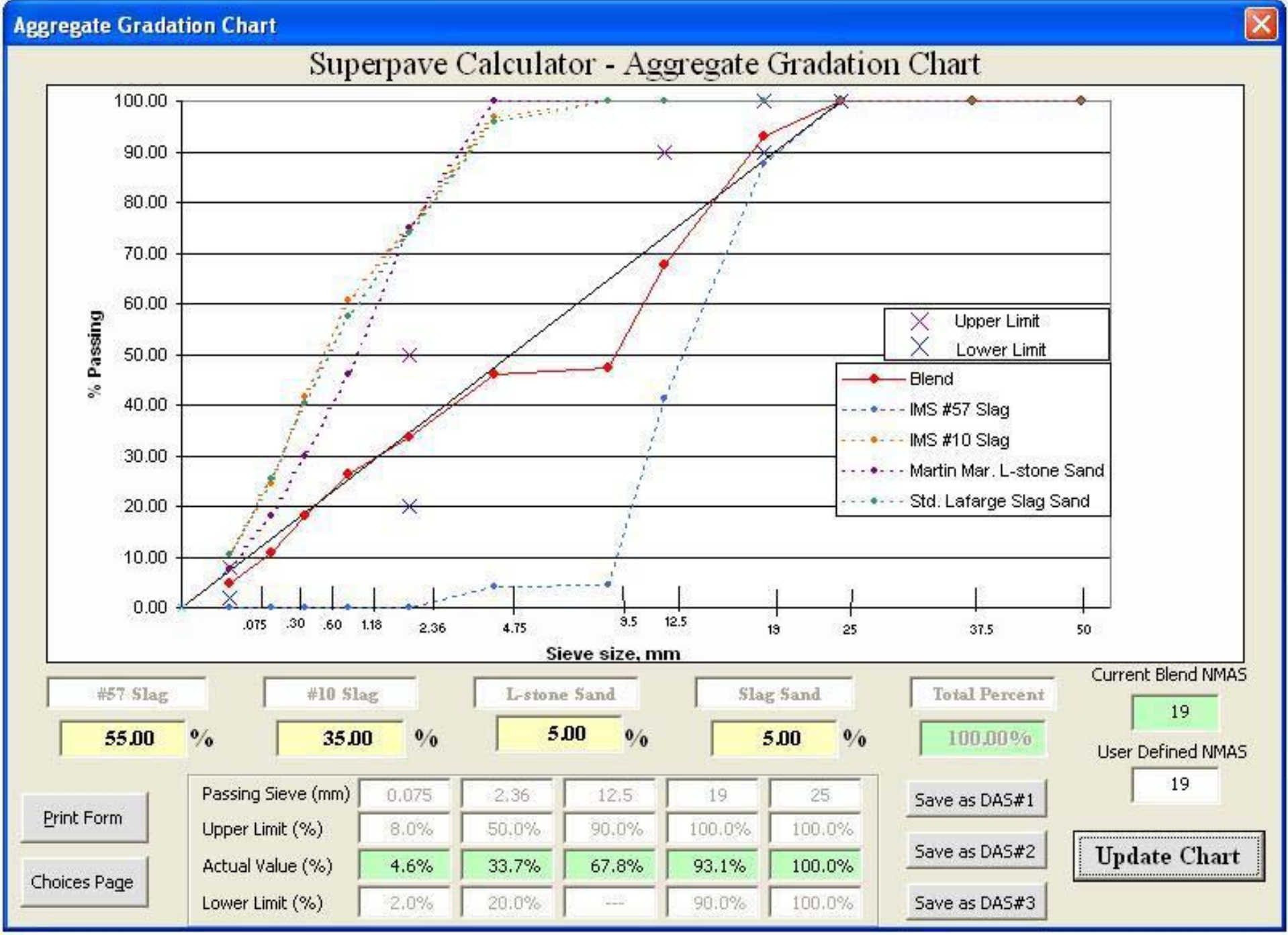

Figure A.7 Aggregate Gradation Chart 


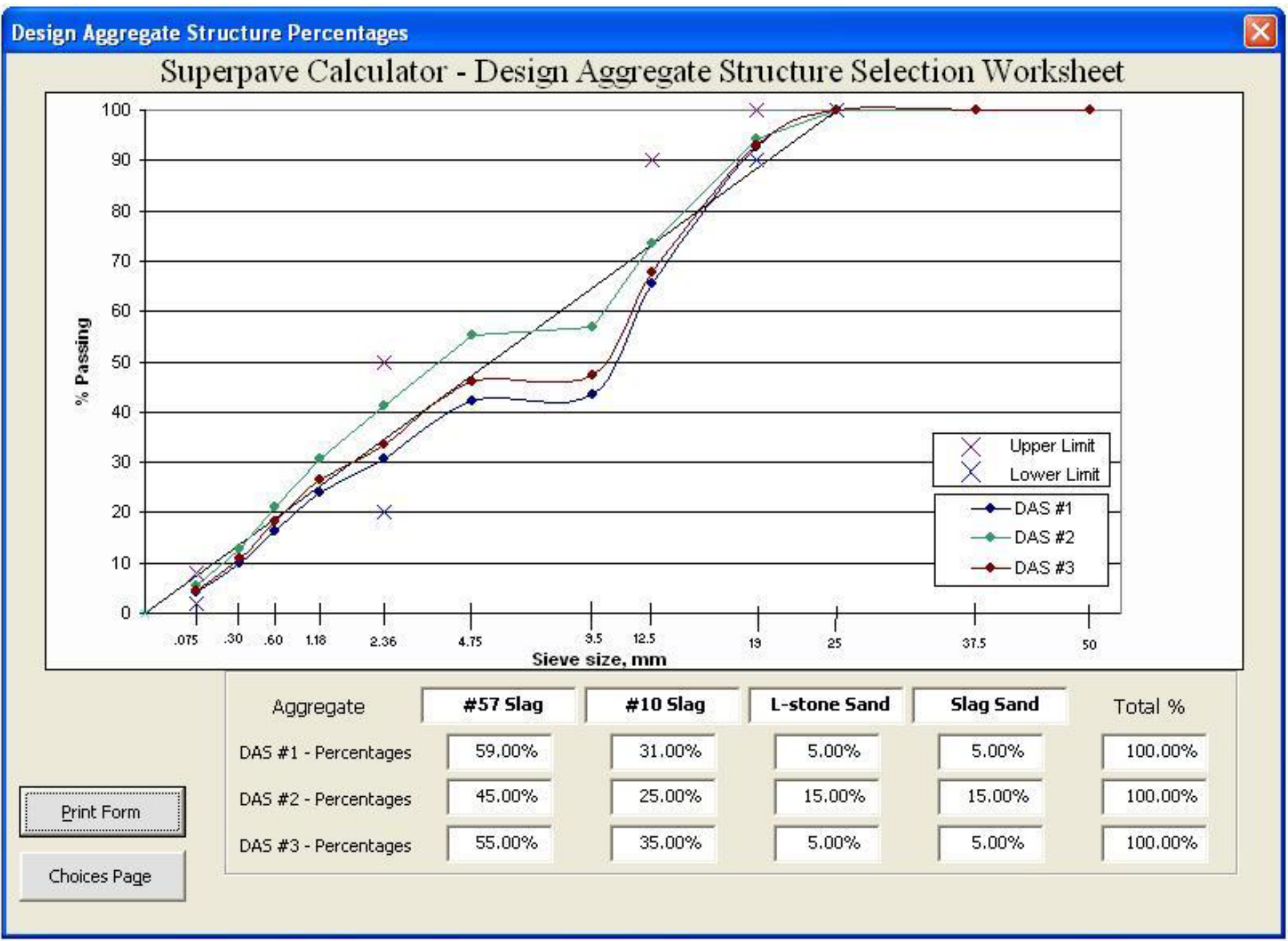

Figure A.8 Plot of 3 DAS Plotted Together 


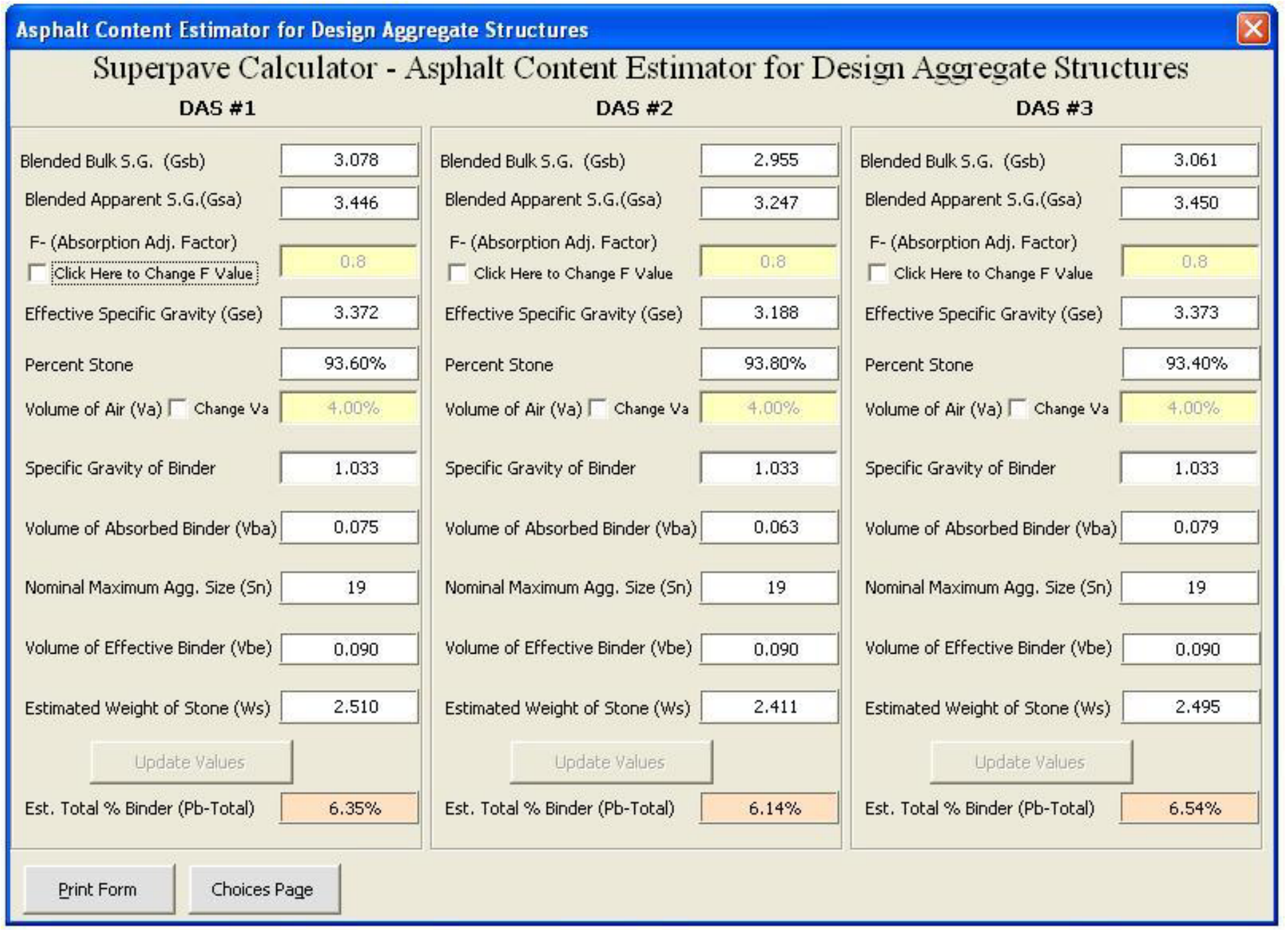

Figure A.9 Asphalt Content Estimator for Design Aggregate Structure 
Weigh-0ut Sheets for Design Aggregate Structure Volumetrics

\section{Aggregate Weigh Out Sheets DAS Volumetric Tests}

\section{Do 2 Rice tests and make 2 Pills using each DAS and estimated AC} (Using Cumulative or Individual Seive Weigh-Out sheets below)

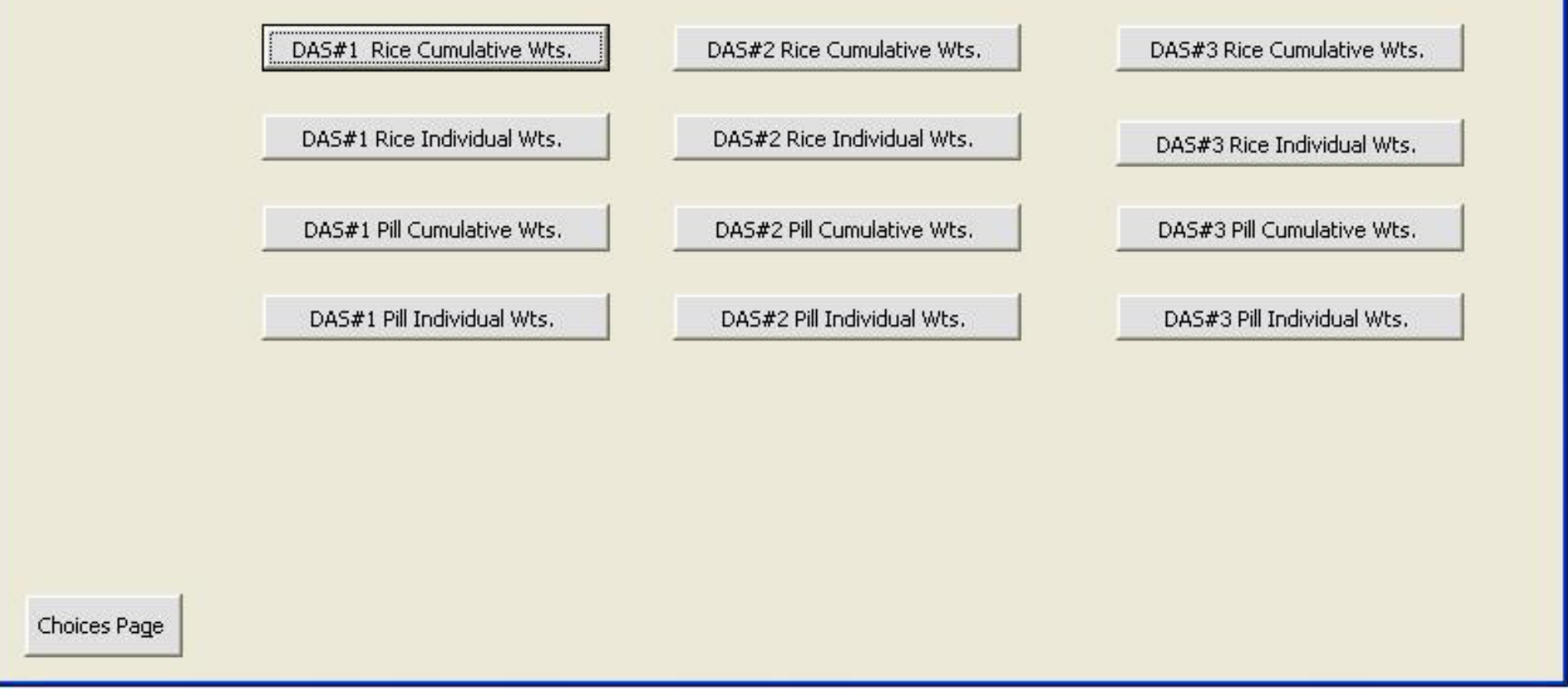

Figure A.10 Weigh-Out Sheets for Design Aggregate Structure Volumetrics 
Rice Weigh Out Sheet - Cumulative Sieve Weights for DAS \#1

Aggregate Weigh Out Sheet for Rice Test for DAS \#1 - (Cumulative Sieve Weights)

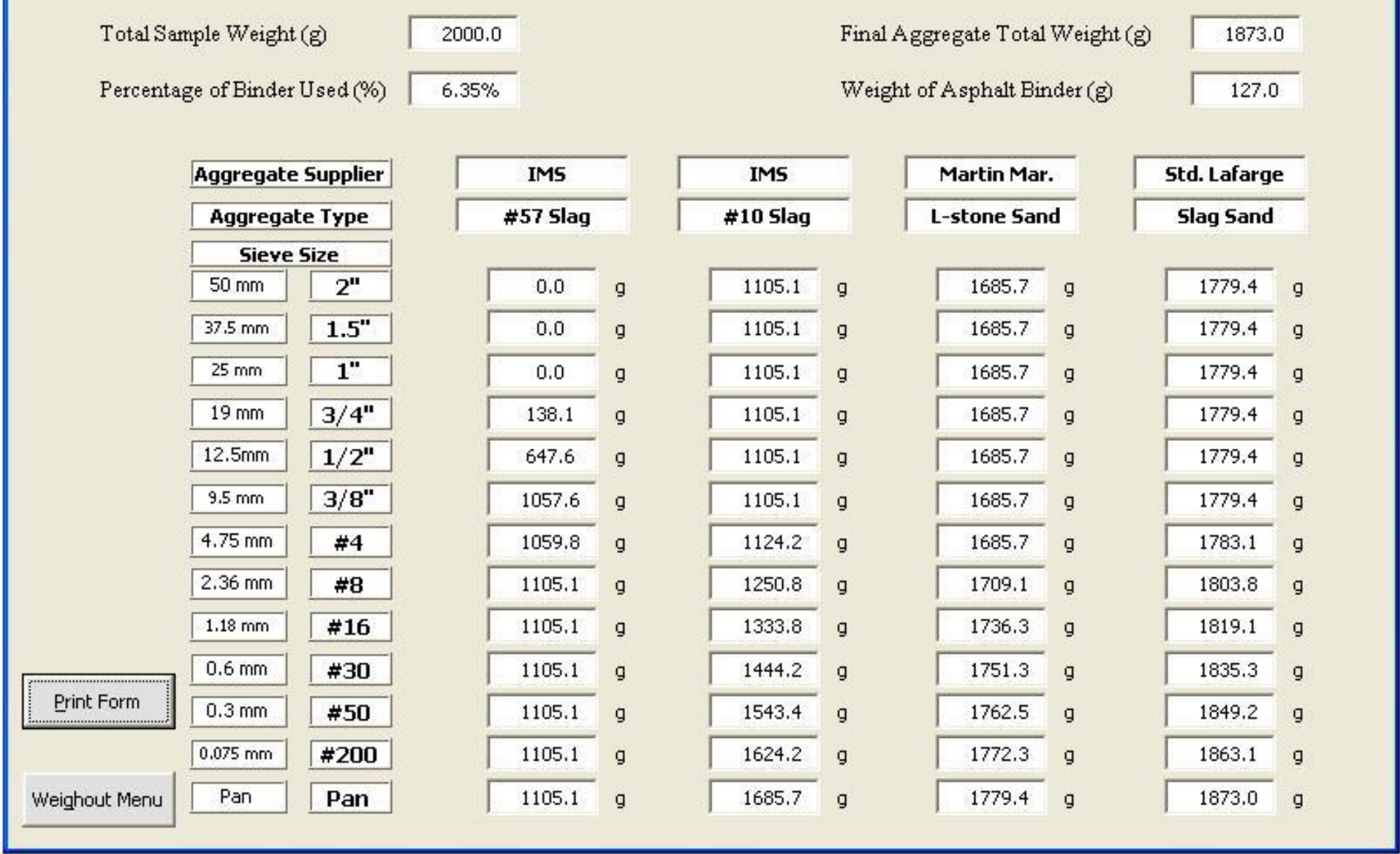

Figure A.11 Sample Rice Weigh-Out Sheet, Cumulative Sieve Weights 


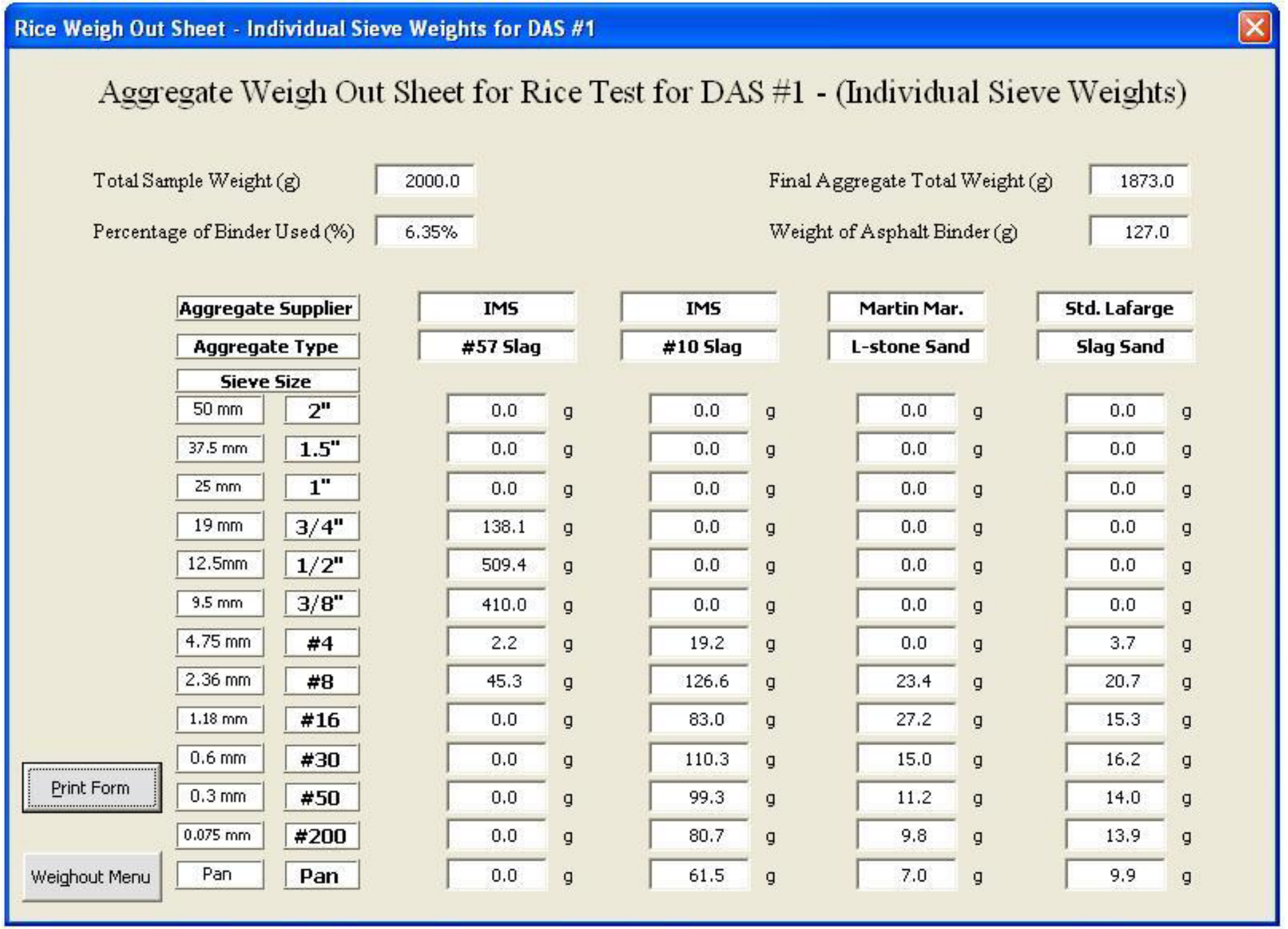

Figure A.12 Sample Rice Weigh-Out Sheet, Individual Sieve Weights 


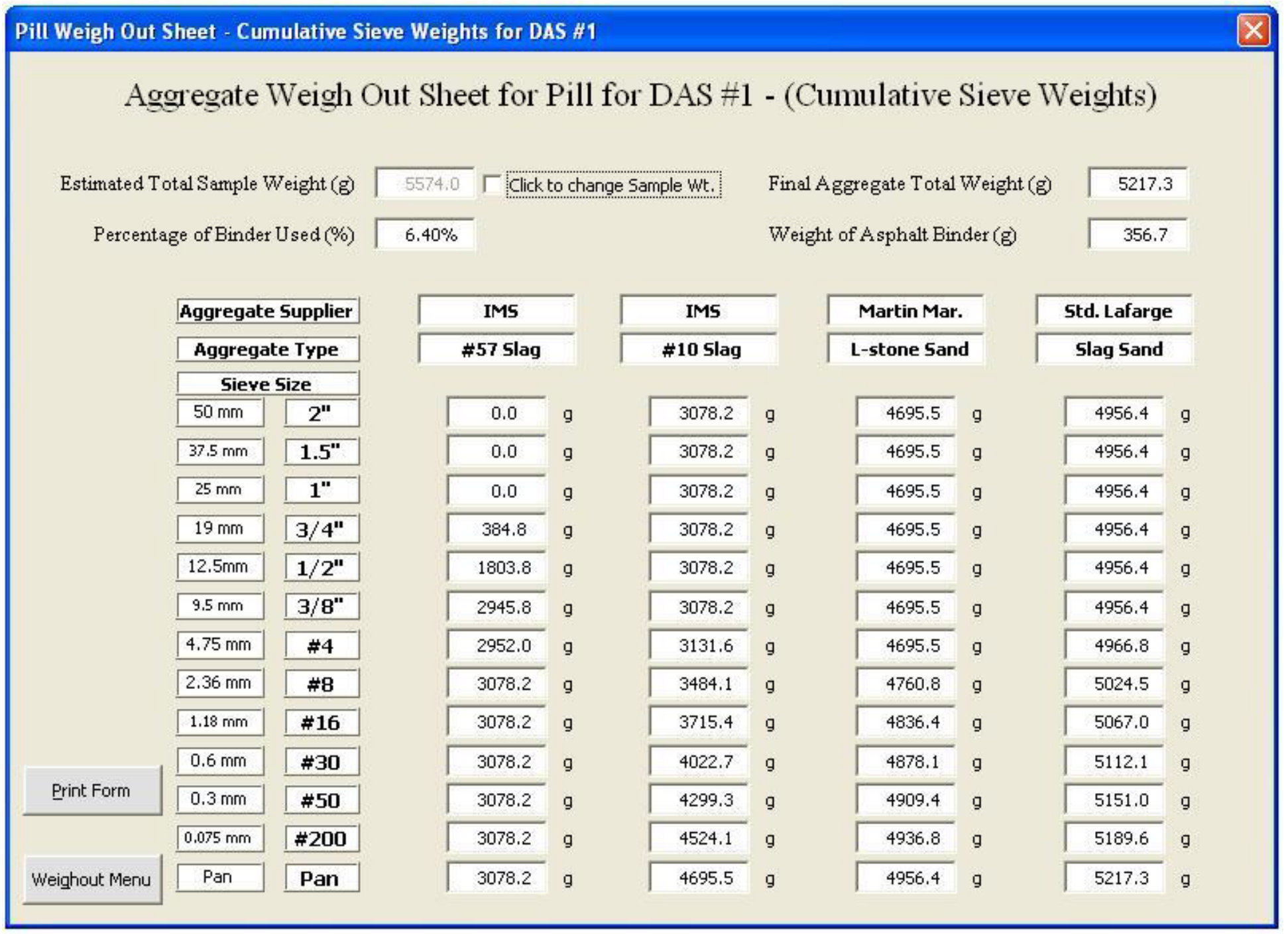

Figure A.13 Sample Pill Weigh-Out Sheet, Cumulative Sieve Weights1 


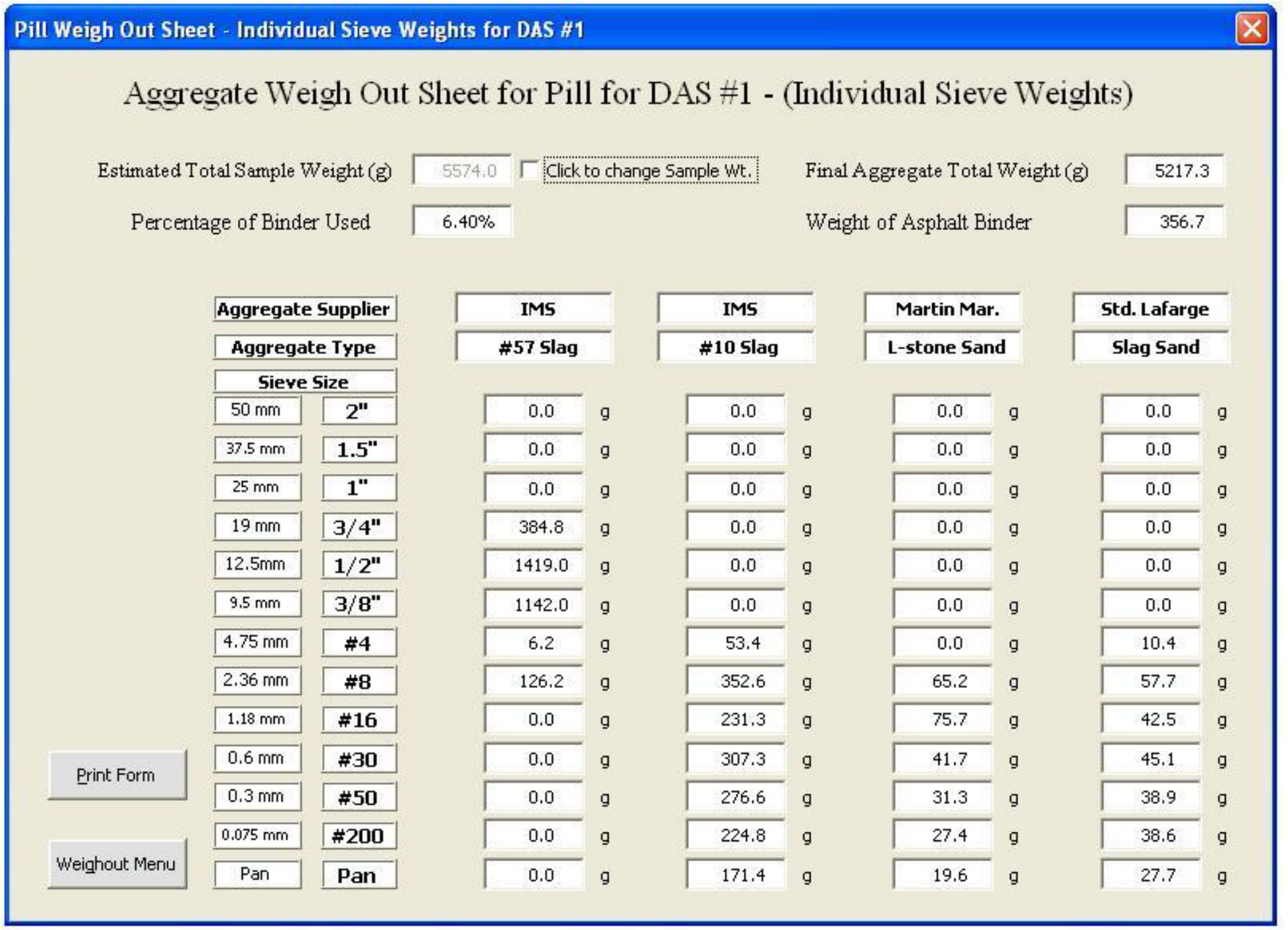

Figure A.14 Sample Pill Weigh-Out Sheet, Individual Sieve Weights 


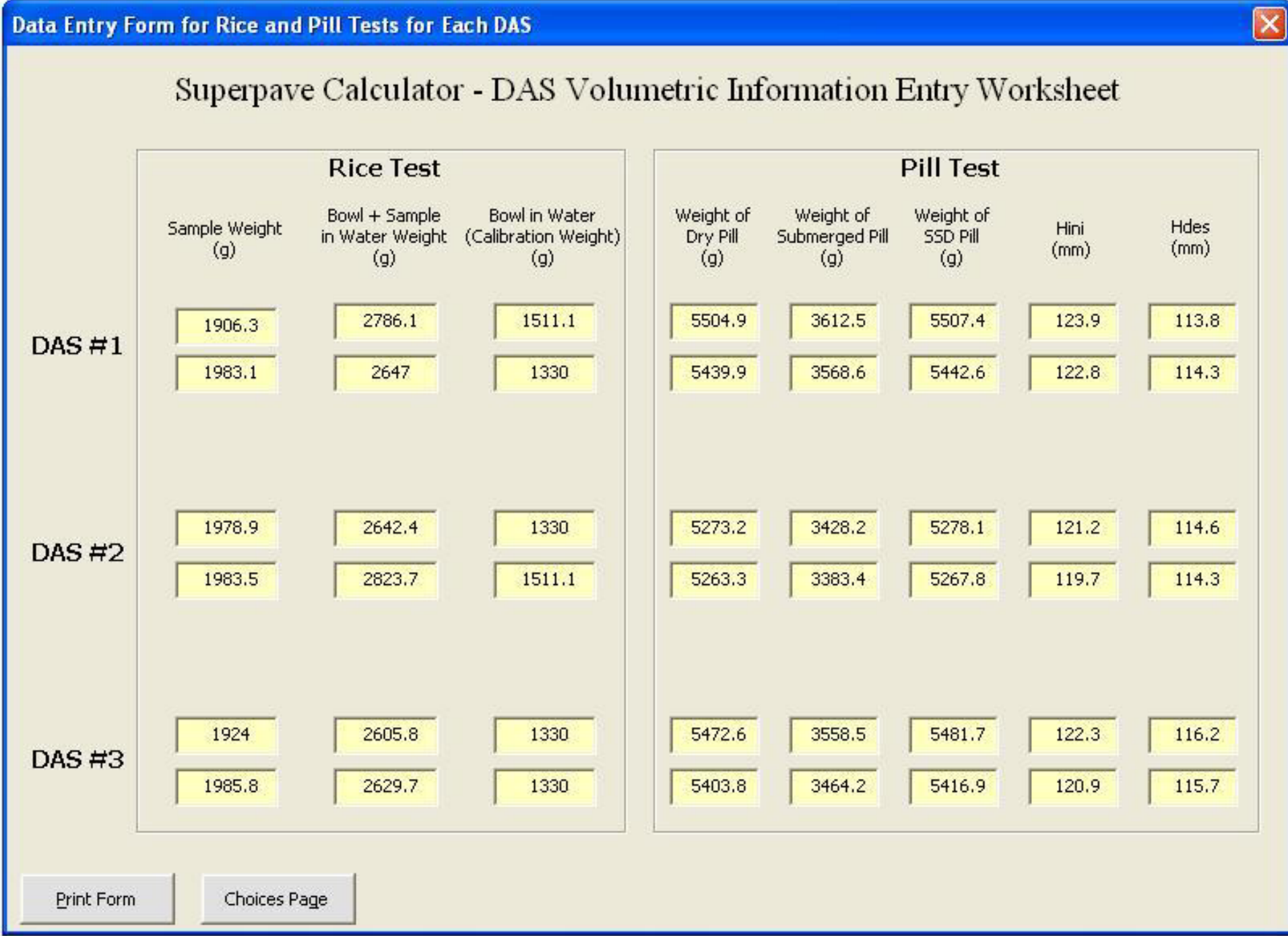

Figure A.15 Data Entry Form for Rice and Pill Tests for Each DAS 


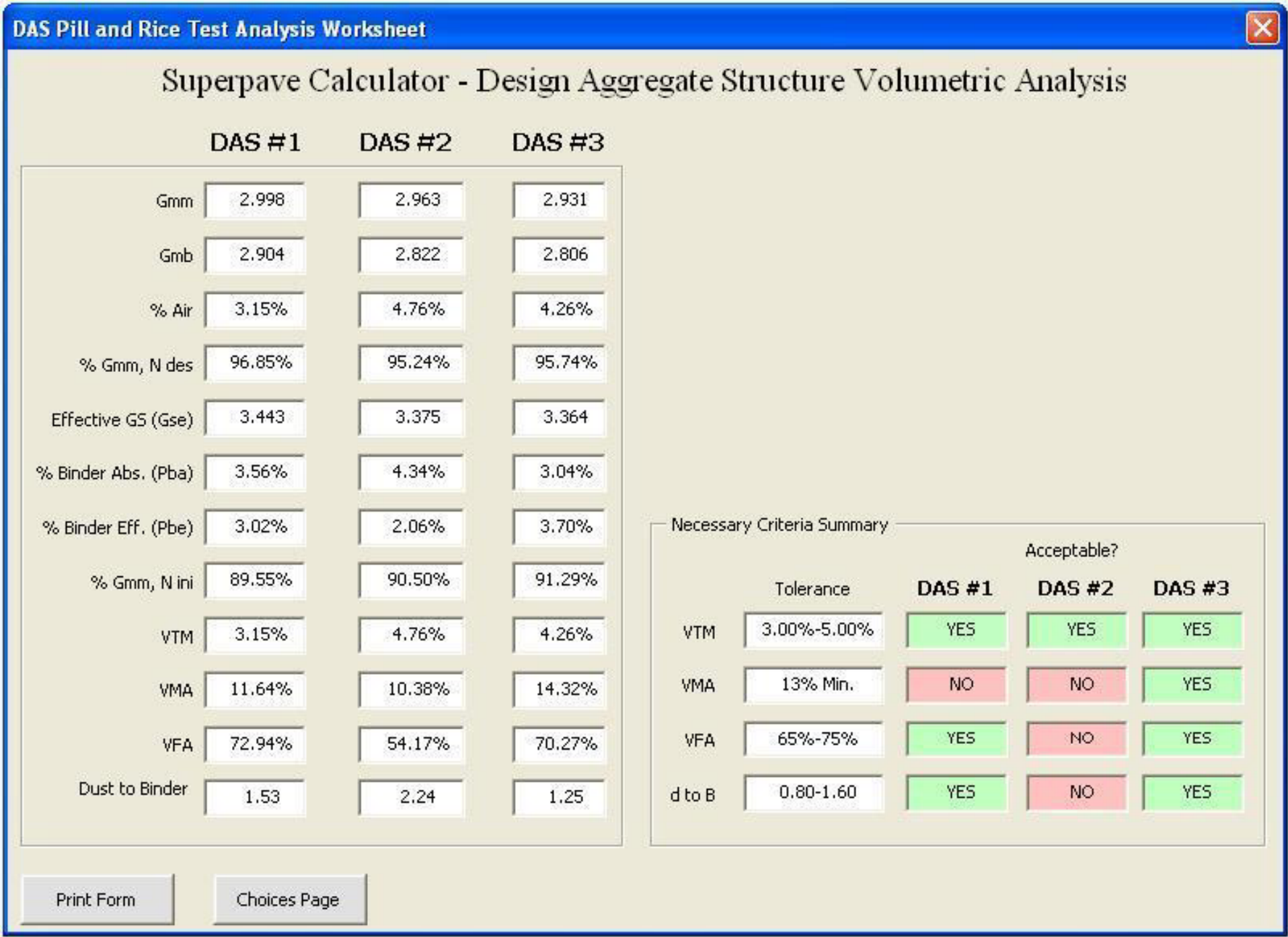

Figure A.16 DAS Pill and Rice Test Analysis Worksheet 


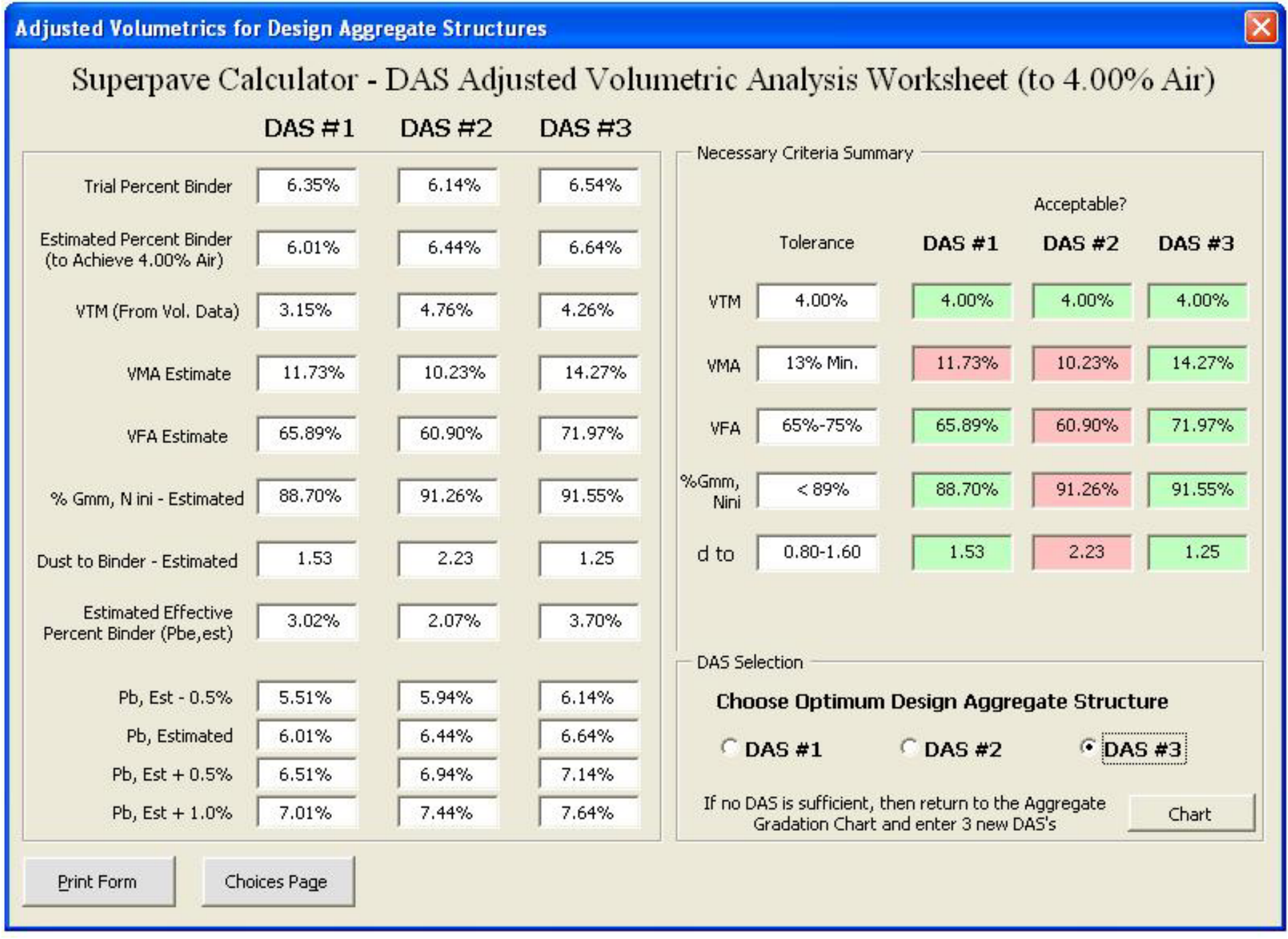

Figure A.17 Adjusted Volumetrics for Design Aggregate Structures 
Percent Binder Estimate for User Defined DAS

Superpave Calculator - Asphalt Content Estimator for User Entered DAS

\begin{tabular}{|c|c|}
\hline Blended Bulk S.G. (Gsb) & 3.061 \\
\hline Blended Apparent S.G.(Gsa) & 3.450 \\
\hline F- (Absorption Adj. Factor) & \\
\hline$\Gamma$ Click Here to Change $F$ Value & 0.8 \\
\hline Effective Specific Gravity (Gse) & 3.373 \\
\hline Percent Stone & $93.40 \%$ \\
\hline Volume of Air ( $\mathrm{Va}) \Gamma$ Change $\mathrm{Va}$ & $4,00 \%$ \\
\hline Percent Binder Initial Value(\%) & $6.60 \%$ \\
\hline Specific Gravity of Binder & 1.033 \\
\hline Volume of Absorbed Binder (Vba) & 0.079 \\
\hline Nominal Maximum Agg. Size (Sn) & 19 \\
\hline Volume of Effective Binder (Vbe) & $8.97 \%$ \\
\hline Estimated Weight of Stone (Ws) & 2.495 \\
\hline Update Yalues & \\
\hline st. Total \% Binder (Pb-Total) & $6.54 \%$ \\
\hline
\end{tabular}

Choices Page

Figure A.18 Percent Binder Estimates for User Defined DAS (If Needed) 


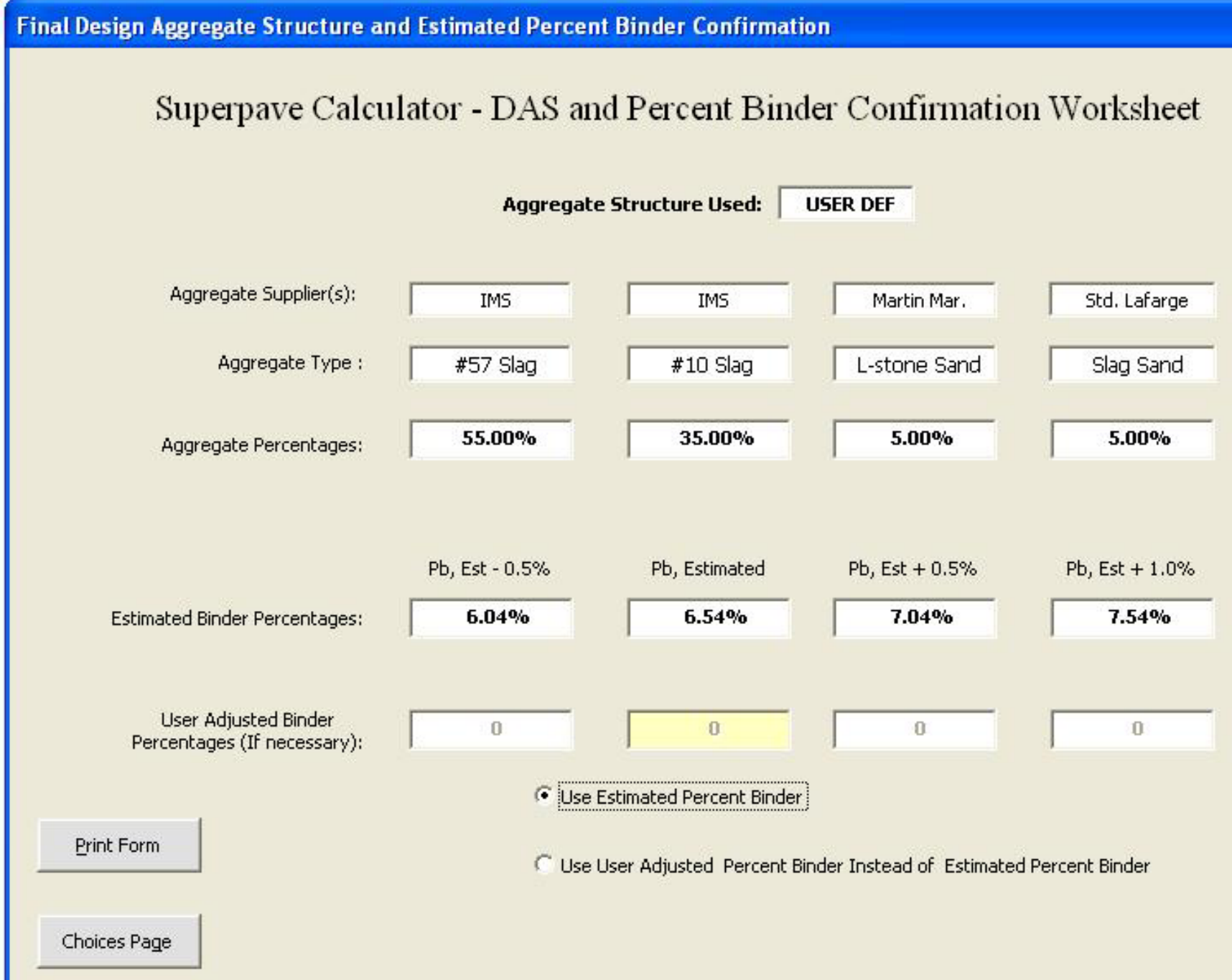

Figure A.19 Final DAS and Percent Binder Estimate Confirmation 


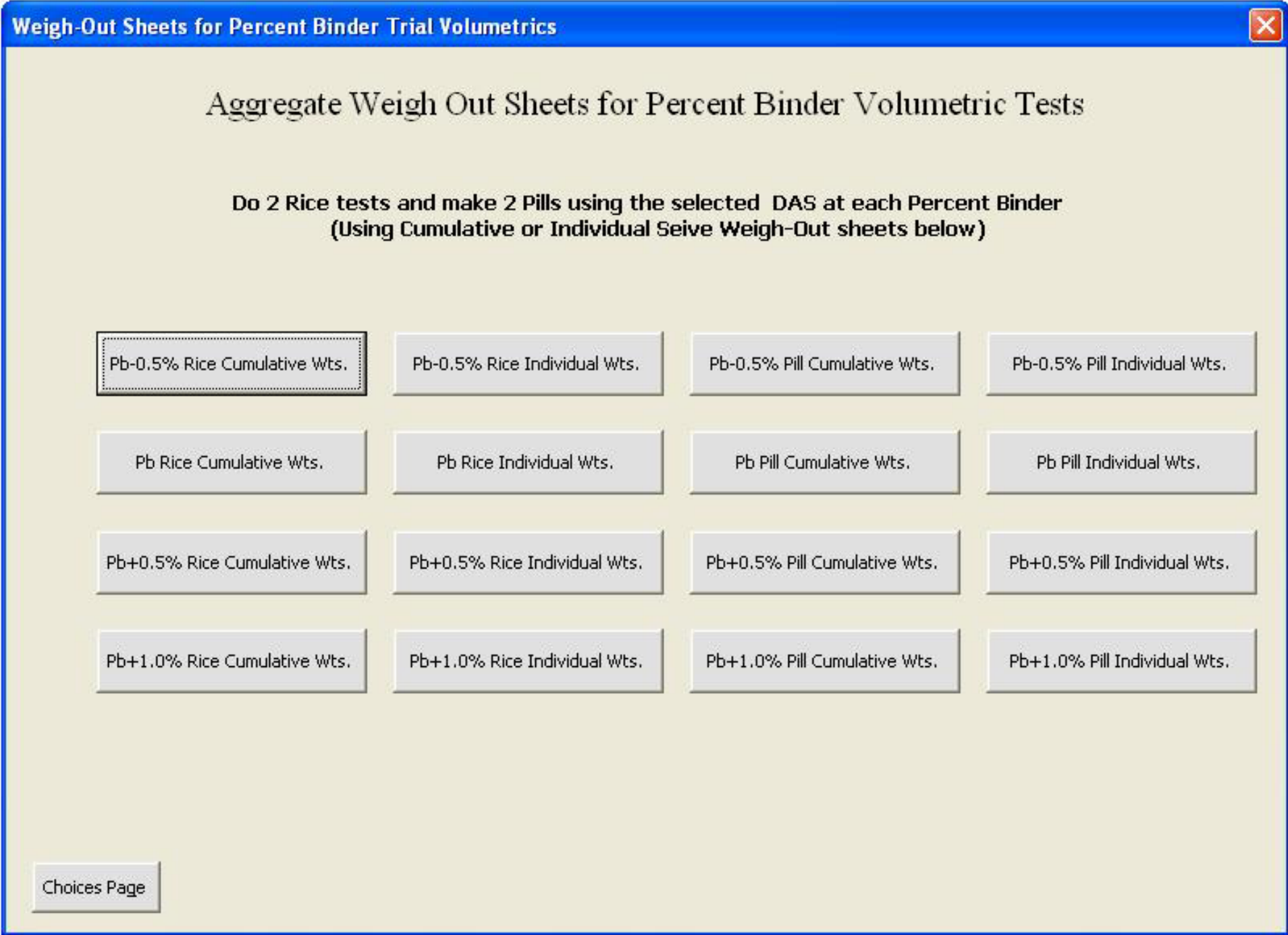

Figure A.20 Weigh-Out Sheets for Percent Binder Trial Volumetrics 
Rice Weigh Out Sheet - Cumulative Sieve Weights for Pb

Aggregate Weigh Out Sheet for Rice Test for $\mathrm{Pb}$ - (Cumulative Sieve Weights)

Total Sample Weight (g)

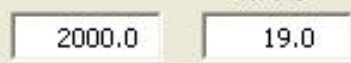

Final Aggregate Total Weight (g)

1869.2

Percentage of Binder Used (\%)

$6.54 \%$

Weight of A sphalt Binder (g)

130.8

Percent of Antistrip Added (\%)

Weight of Antistrip Added (g)

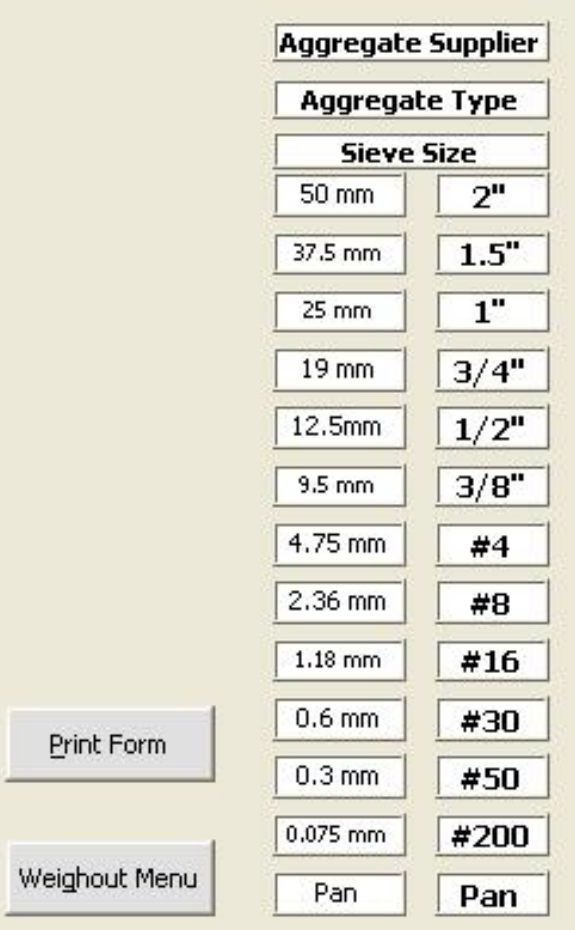

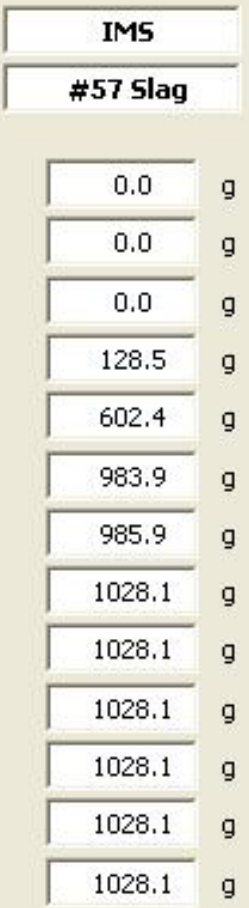

\begin{tabular}{|c|c|}
\hline IMS & \\
\hline \#10 Slag & \\
\hline 1028.1 & $g$ \\
\hline 1028.1 & $g$ \\
\hline 1028.1 & $g$ \\
\hline 1028.1 & $g$ \\
\hline 1028.1 & $g$ \\
\hline 1028.1 & $g$ \\
\hline 1049.6 & $g$ \\
\hline 1192.3 & g \\
\hline 1285.8 & $g$ \\
\hline 1410.1 & g \\
\hline 1522.0 & g \\
\hline 1612.9 & $g$ \\
\hline 1682.3 & g \\
\hline
\end{tabular}

\begin{tabular}{|c|c|}
\hline \multicolumn{2}{|l|}{ Martin Mar. } \\
\hline L-stone Sand & \\
\hline 1682.3 & 9 \\
\hline 1682.3 & 9 \\
\hline 1682.3 & 9 \\
\hline 1682.3 & 9 \\
\hline 1682.3 & 9 \\
\hline 1682.3 & 9 \\
\hline 1682.3 & g \\
\hline 1705.6 & 9 \\
\hline 1732.7 & g \\
\hline 1747.7 & 9 \\
\hline 1758.9 & 9 \\
\hline 1768.7 & 9 \\
\hline 1775.7 & $g$ \\
\hline
\end{tabular}

\begin{tabular}{|c|c|}
\hline \multicolumn{2}{|l|}{ Std. Lafarge } \\
\hline Slag Sand & \\
\hline 1775.7 & 9 \\
\hline 1775.7 & $g$ \\
\hline 1775.7 & $g$ \\
\hline 1775.7 & $g$ \\
\hline 1775.7 & $g$ \\
\hline 1775.7 & g \\
\hline 1779.5 & $g$ \\
\hline 1800.1 & g \\
\hline 1815.4 & $g$ \\
\hline 1831.5 & $g$ \\
\hline 1845.5 & $g$ \\
\hline 1859.3 & $g$ \\
\hline 1869.2 & \\
\hline
\end{tabular}

Figure A.21 Sample Rice Weigh-Out Sheet for Cumulative Sieve Weights 


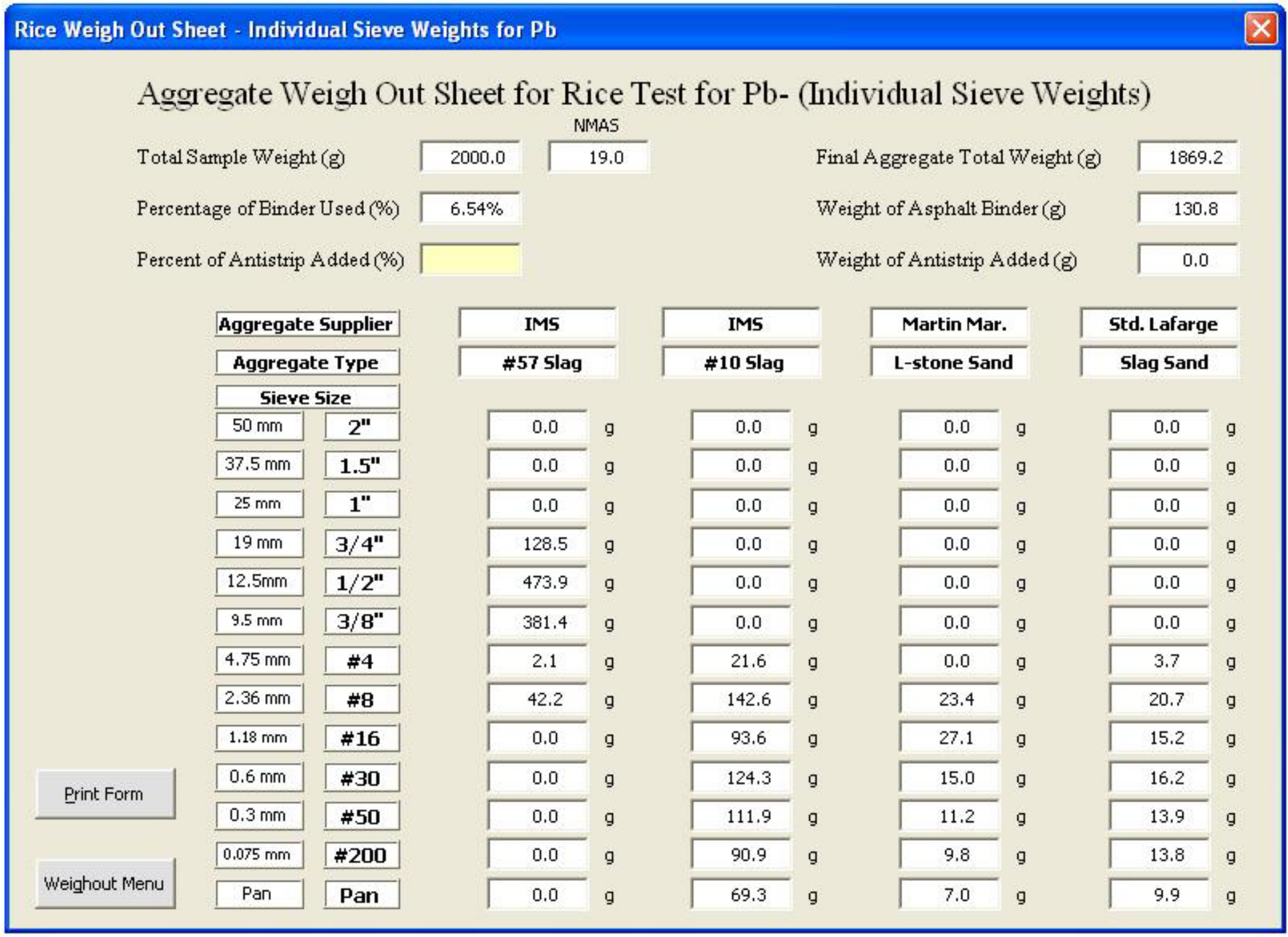

Figure A.22 Sample Rice Weigh-Out Sheet for Individual Sieve Weights 


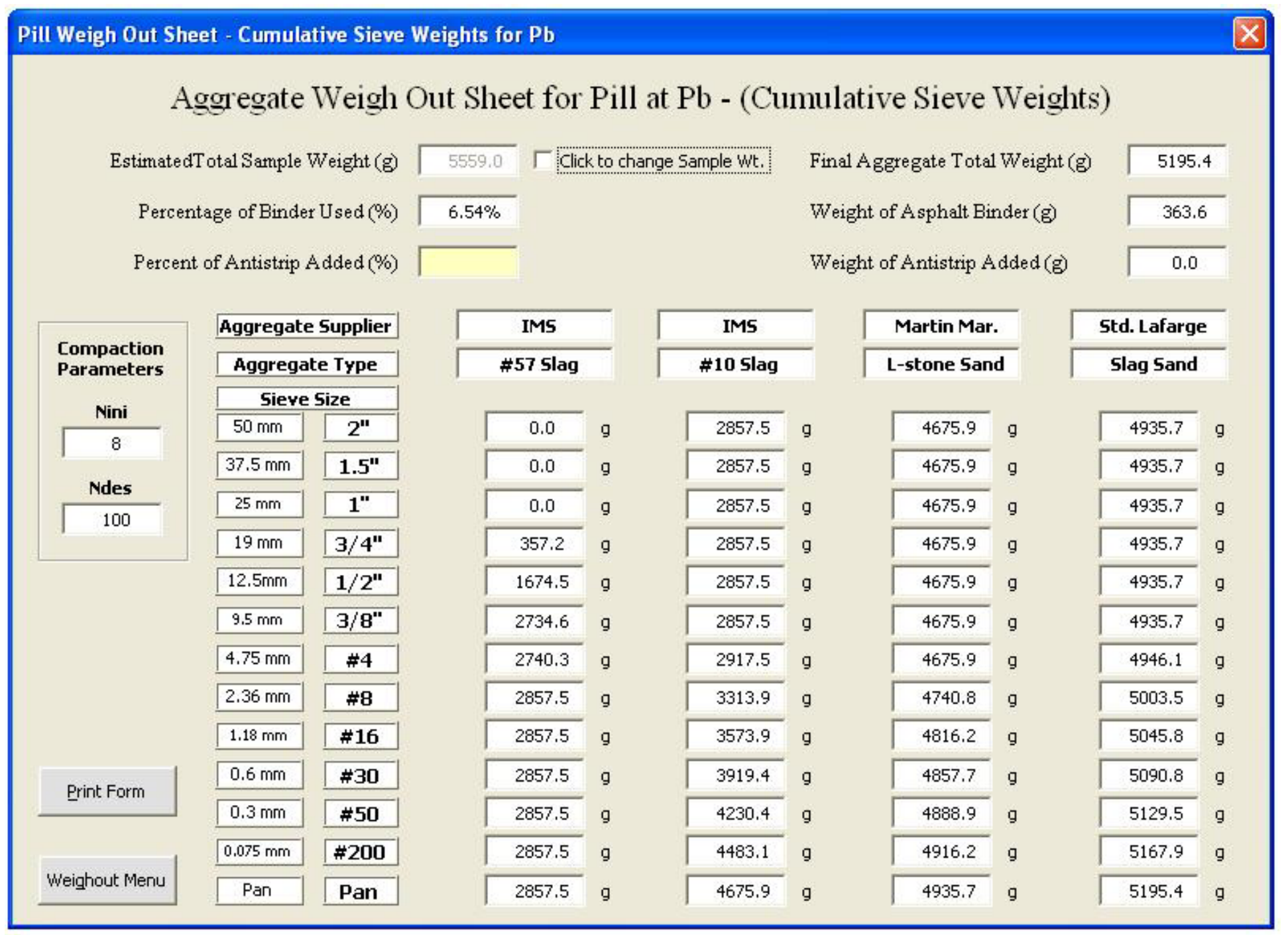

Figure A.23 Sample Pill Weigh-Out Sheet for Cumulative Sieve Weights 


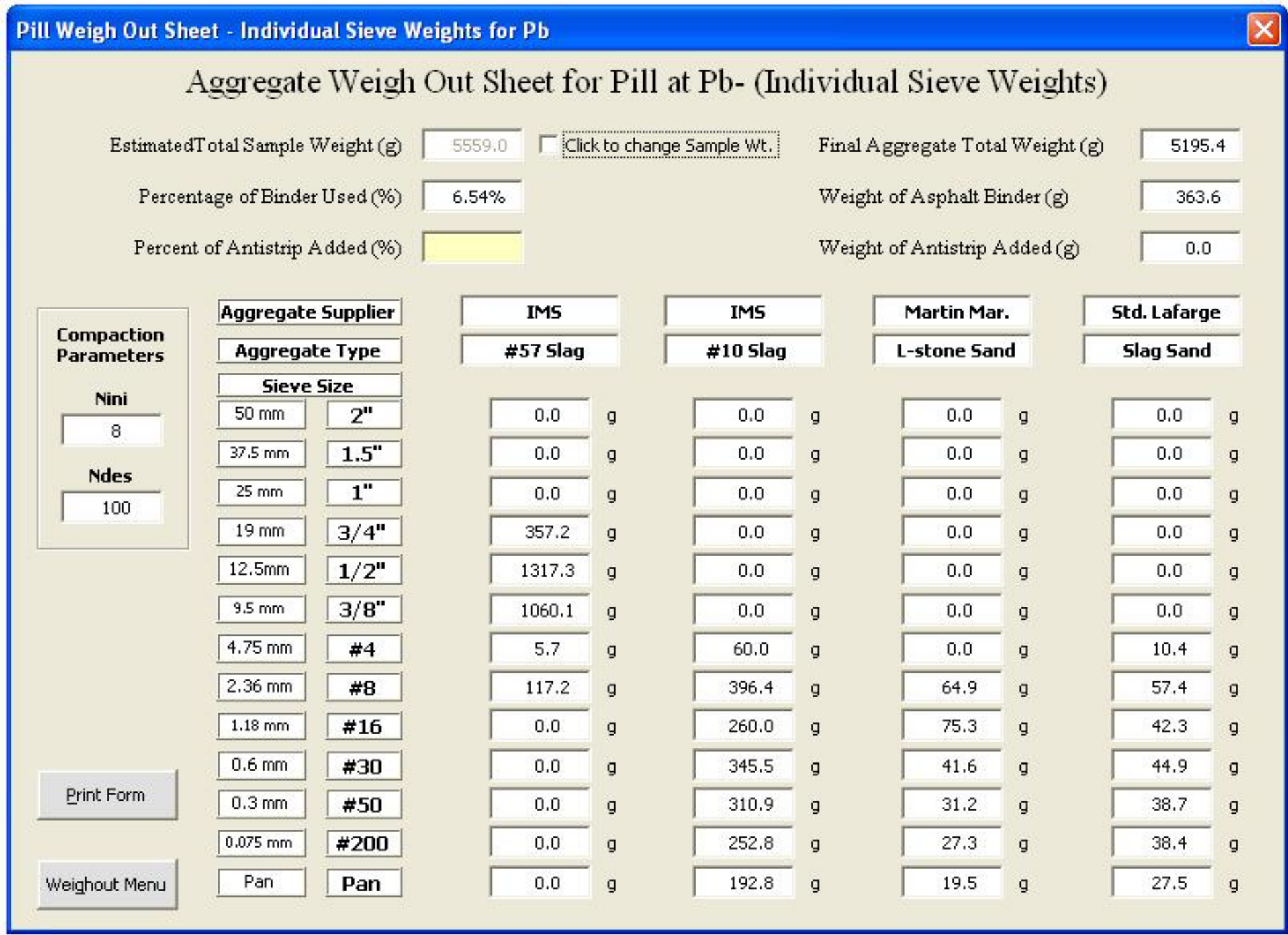

Figure A.24 Sample Pill Weigh-Out Sheet for Individual Sieve Weights 


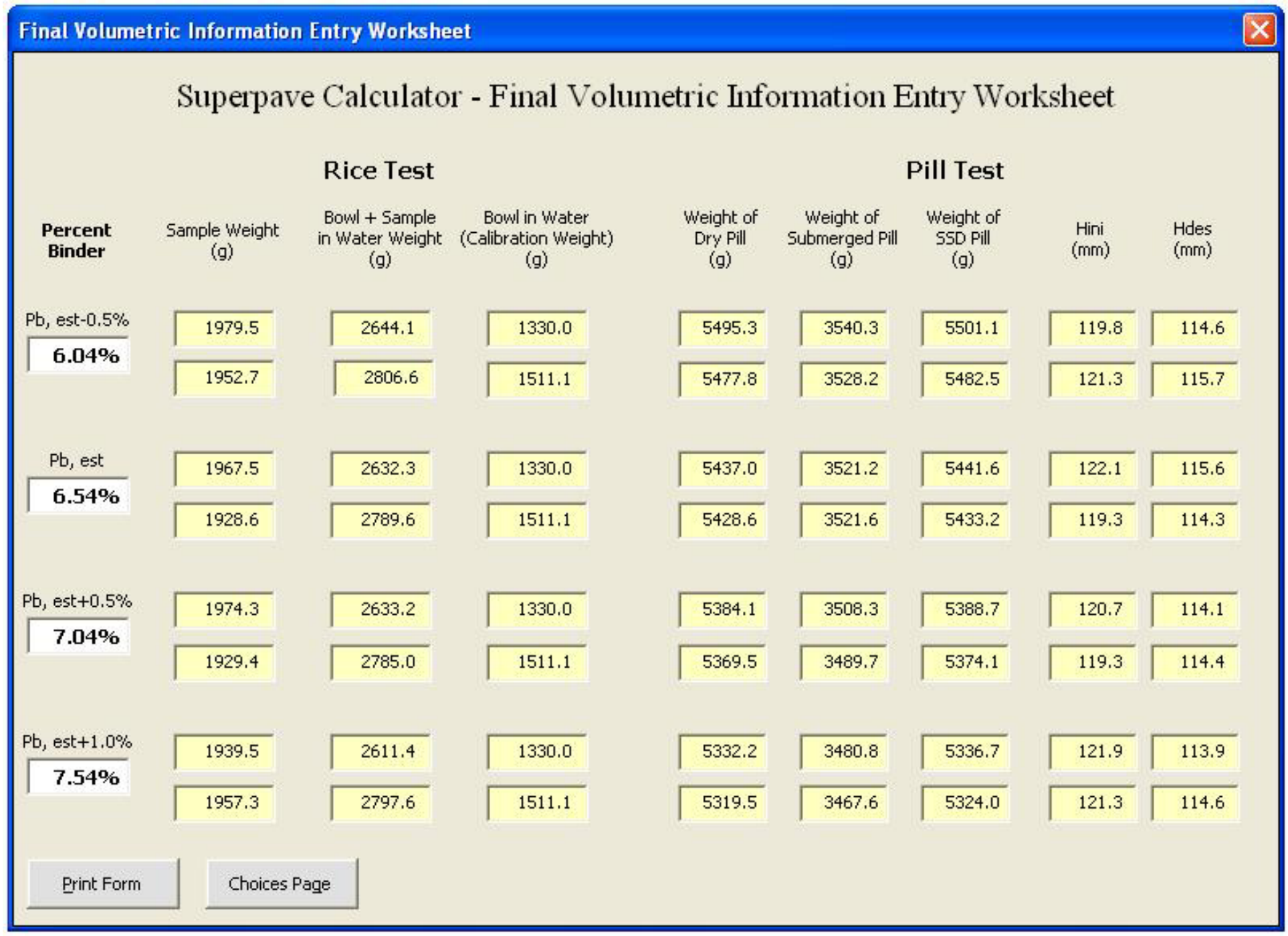

Figure A.25 Final Volumetric Information Entry Worksheet 


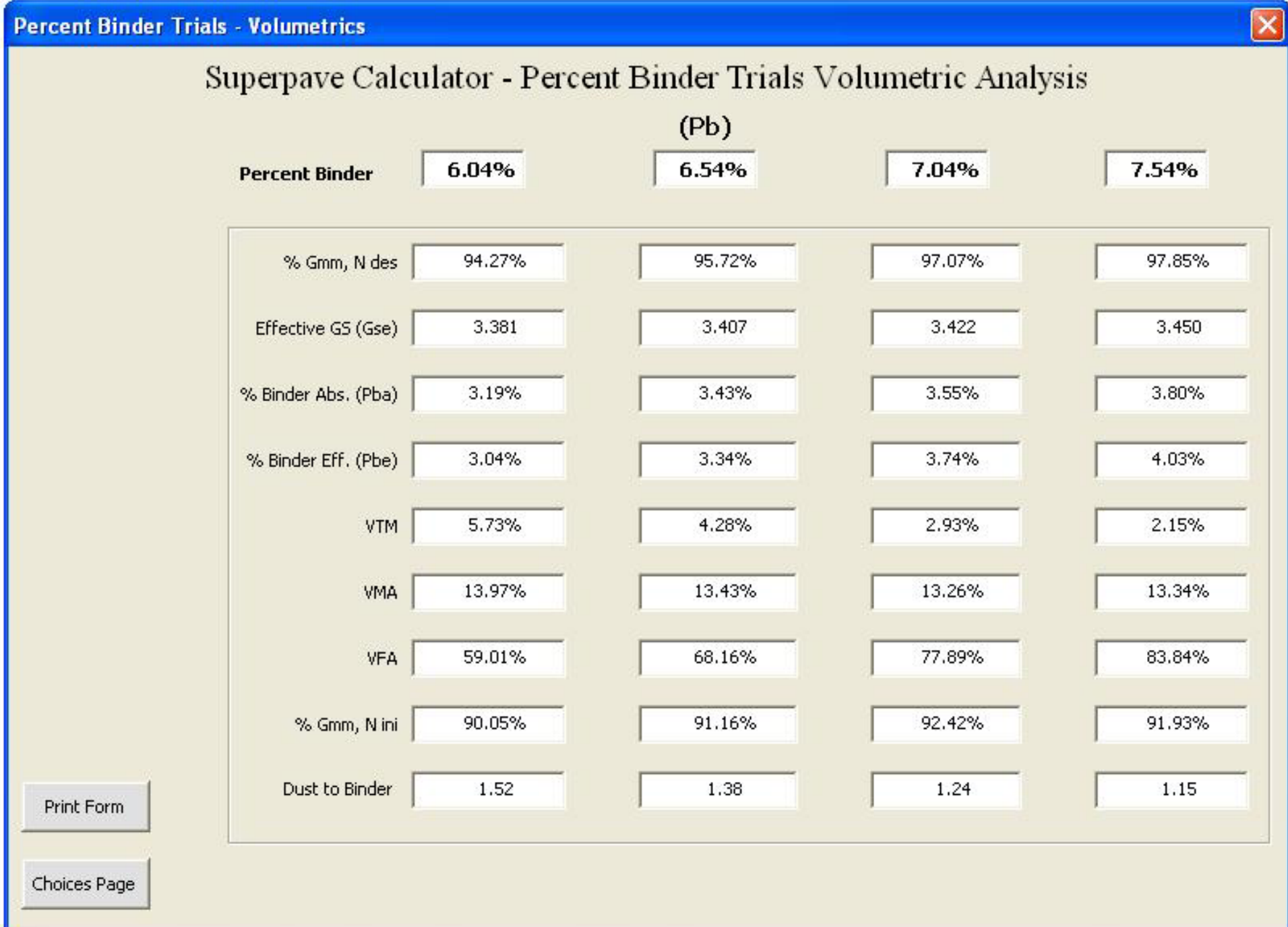

Figure A.26 Percent Binder Trials Volumetric Analysis 


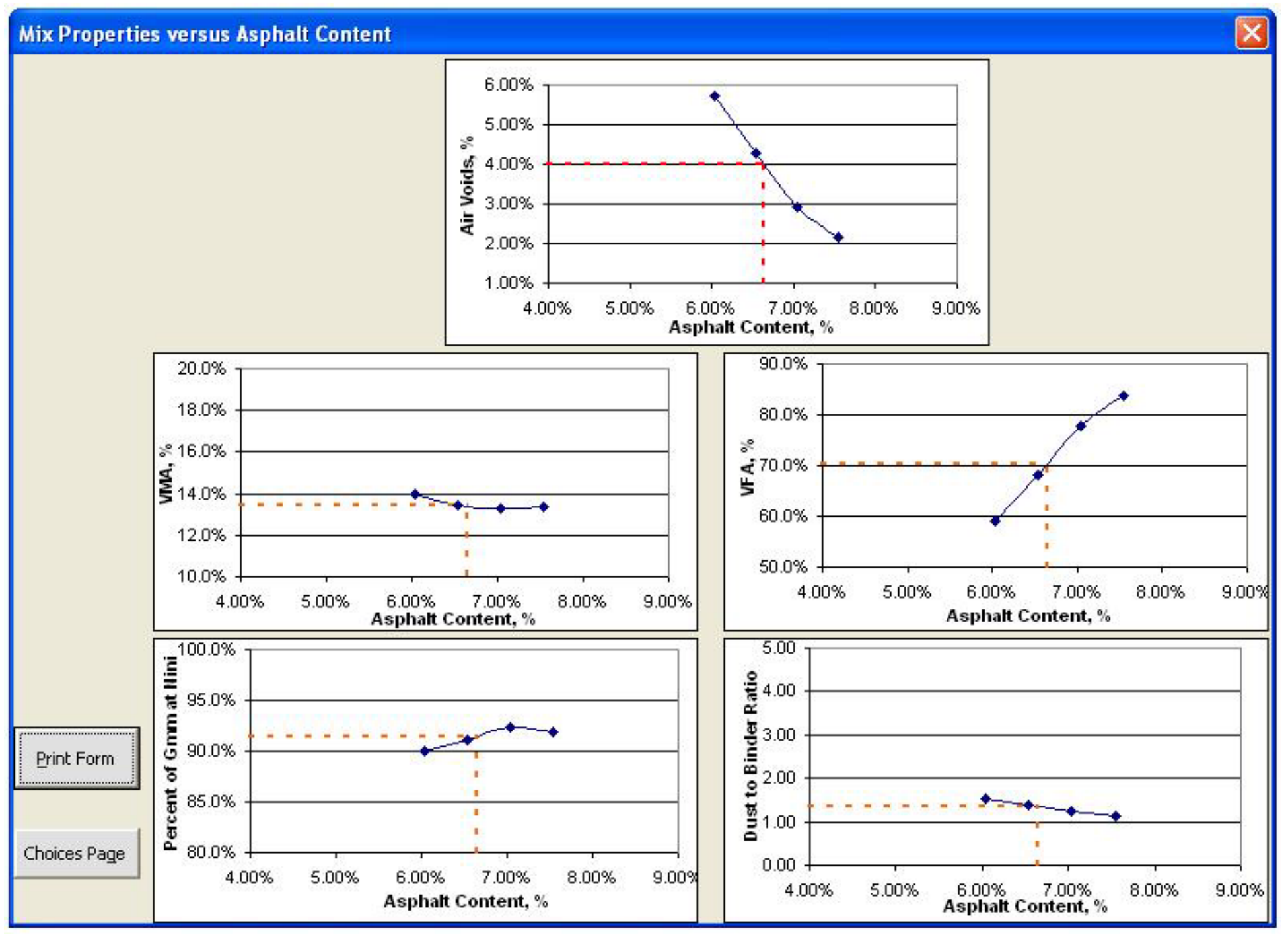

Figure A.27 Graphs of Mix Properties v/s Asphalt Content 


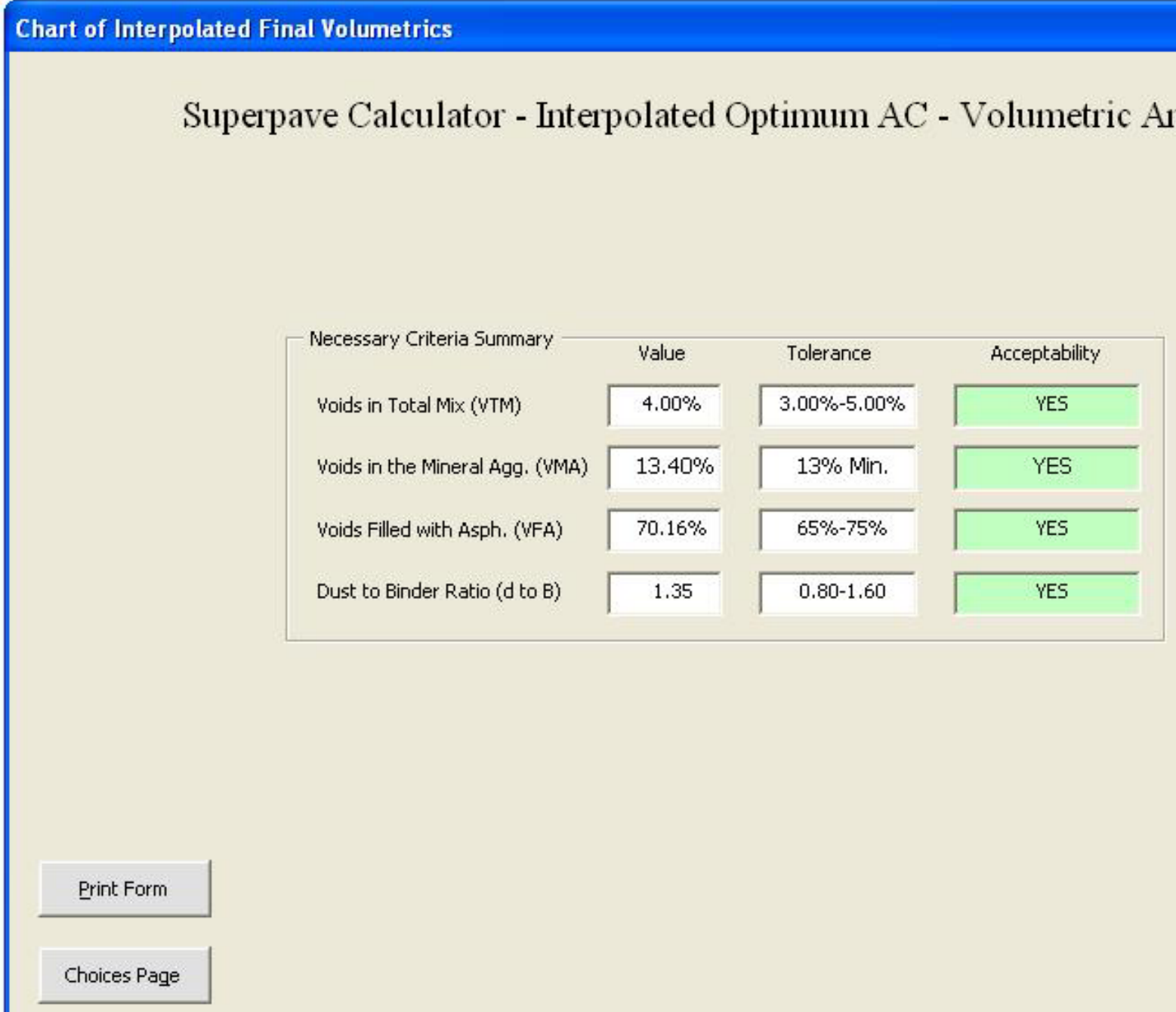

Superpave Calculator - Interpolated Optimum AC - Volumetric Analysis

Figure A.28 Chart of Interpolated Final Volumetrics 


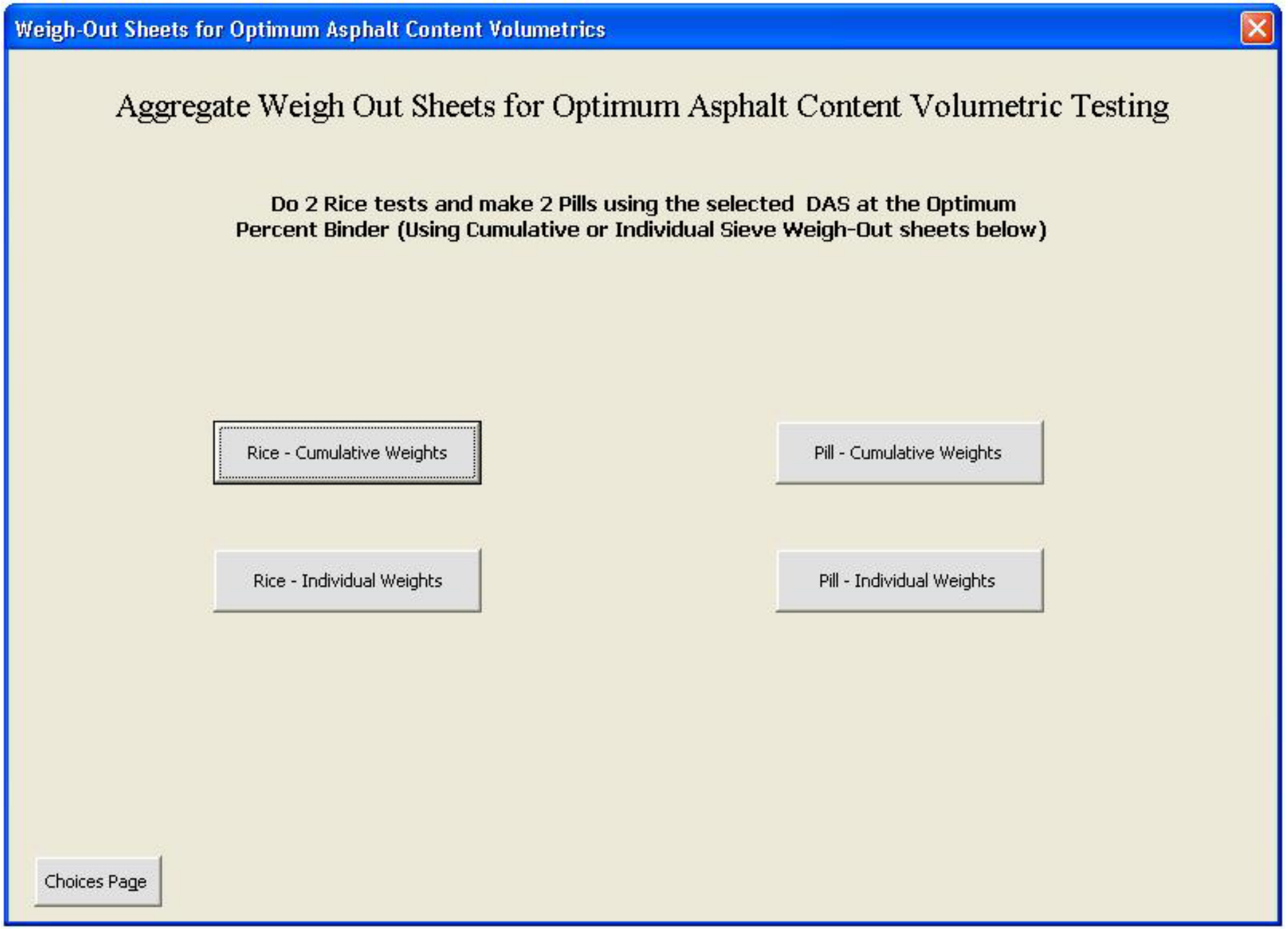

Figure A.29 Weigh-Out Sheets for Optimum Asphalt Content Volumetrics 


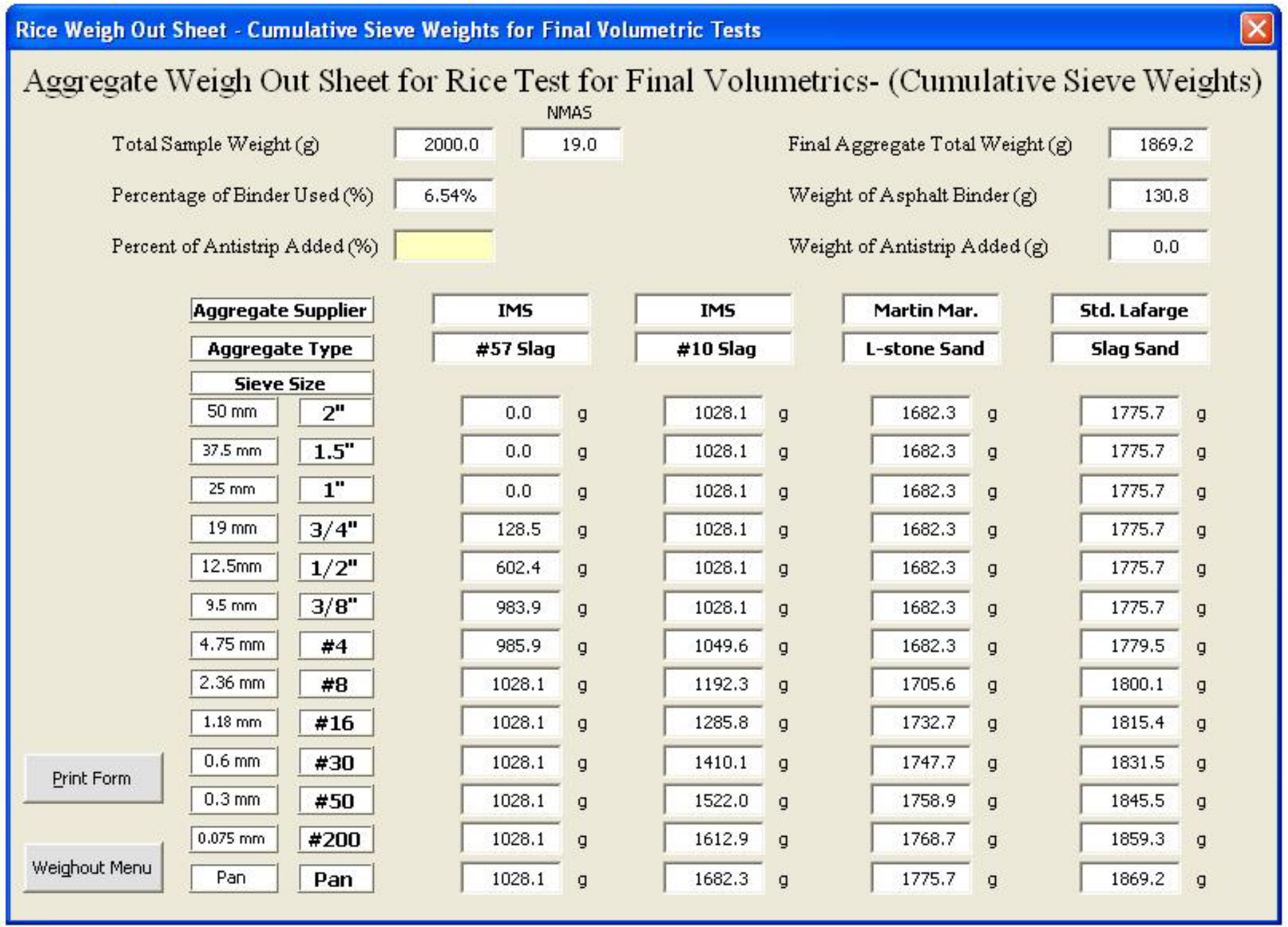

Figure A.30 Rice Weigh-Out Sheet - Cum. Sieve Weights for Final Volumetrics 


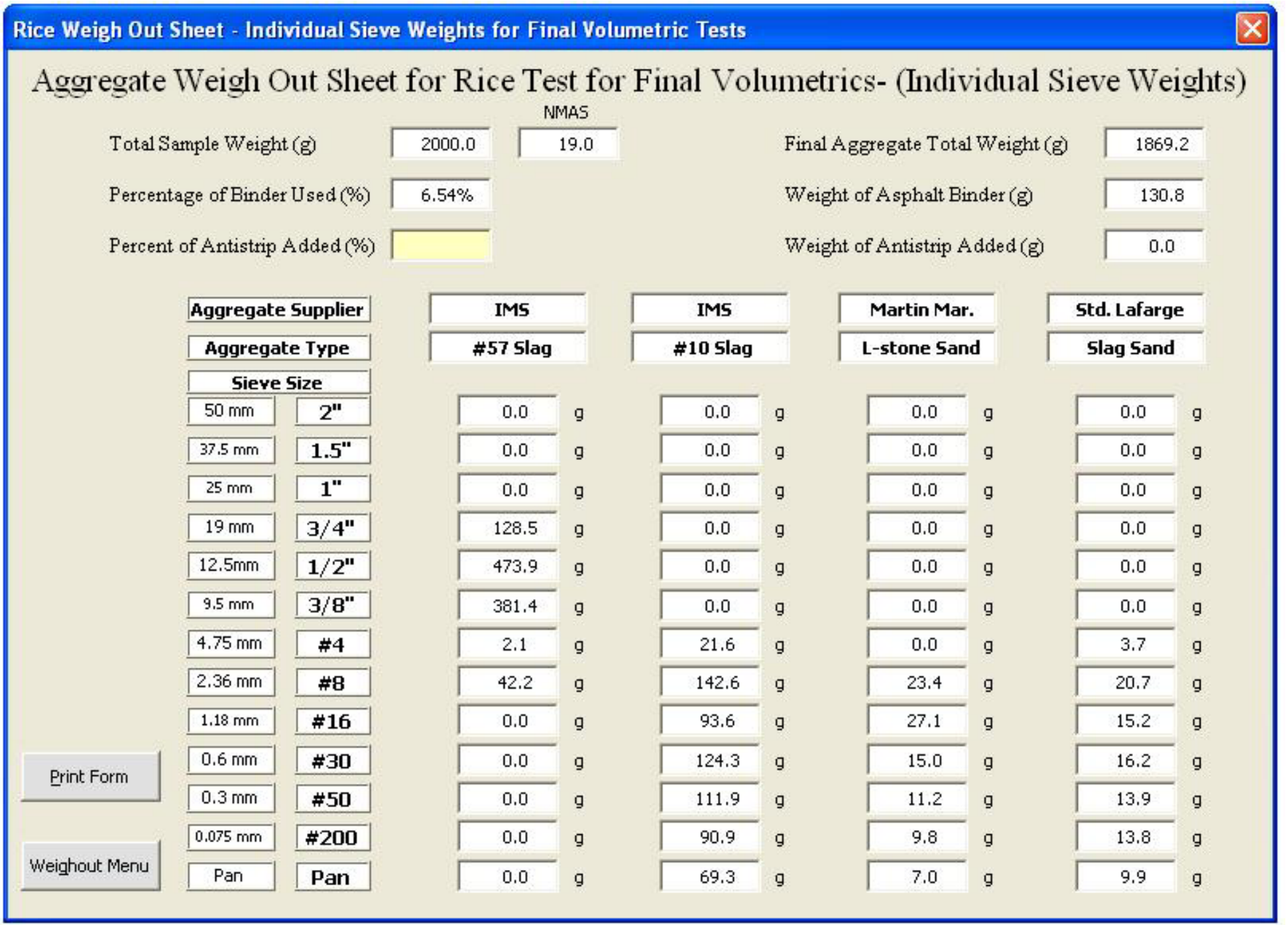

Figure A.31 Rice Weigh-Out Sheet - Individual Sieve Weights for Final Volumetrics 


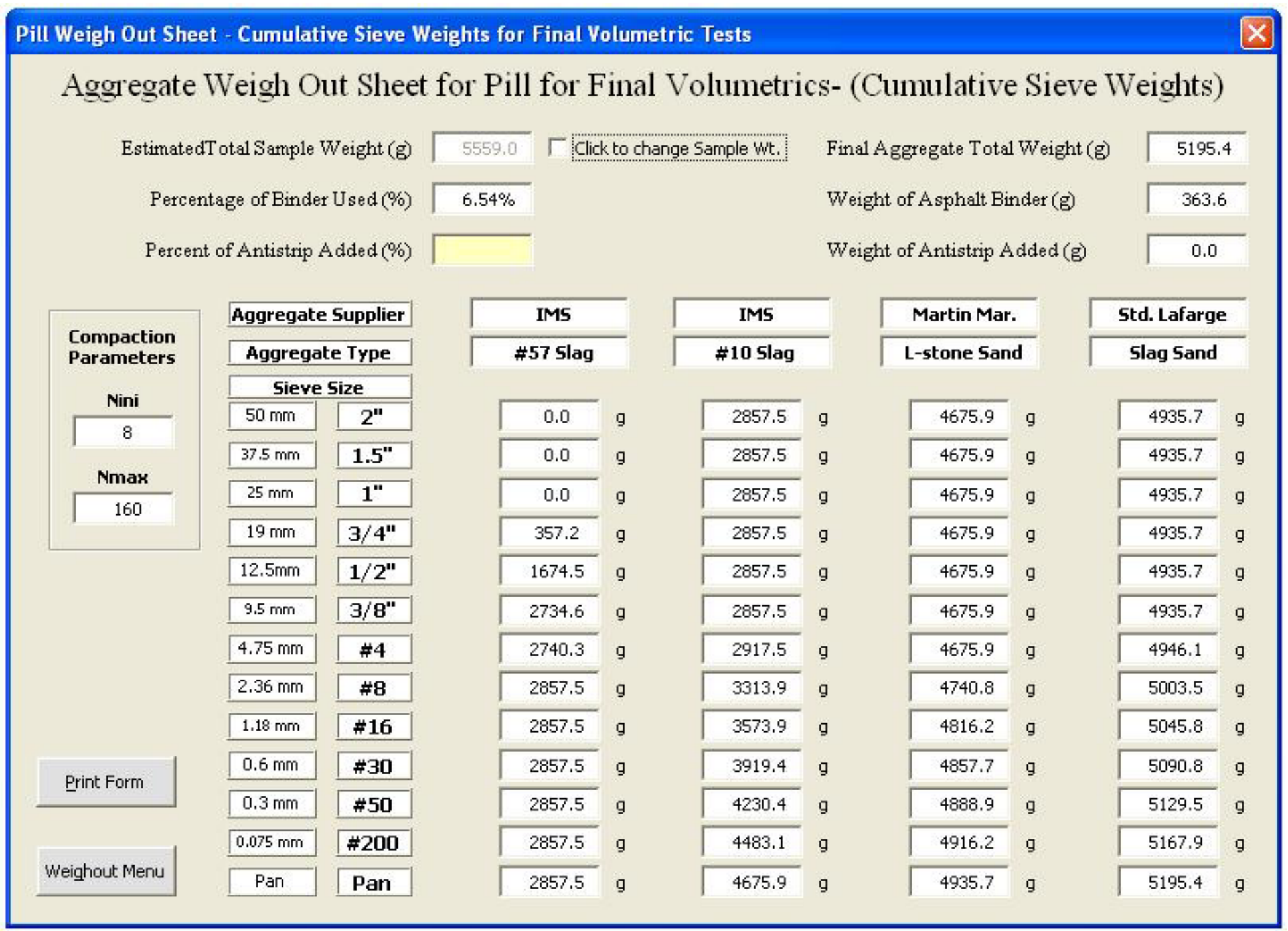

Figure A.32 Pill Weigh-Out Sheet - Cumulative Sieve Weights for Final Volumetrics 


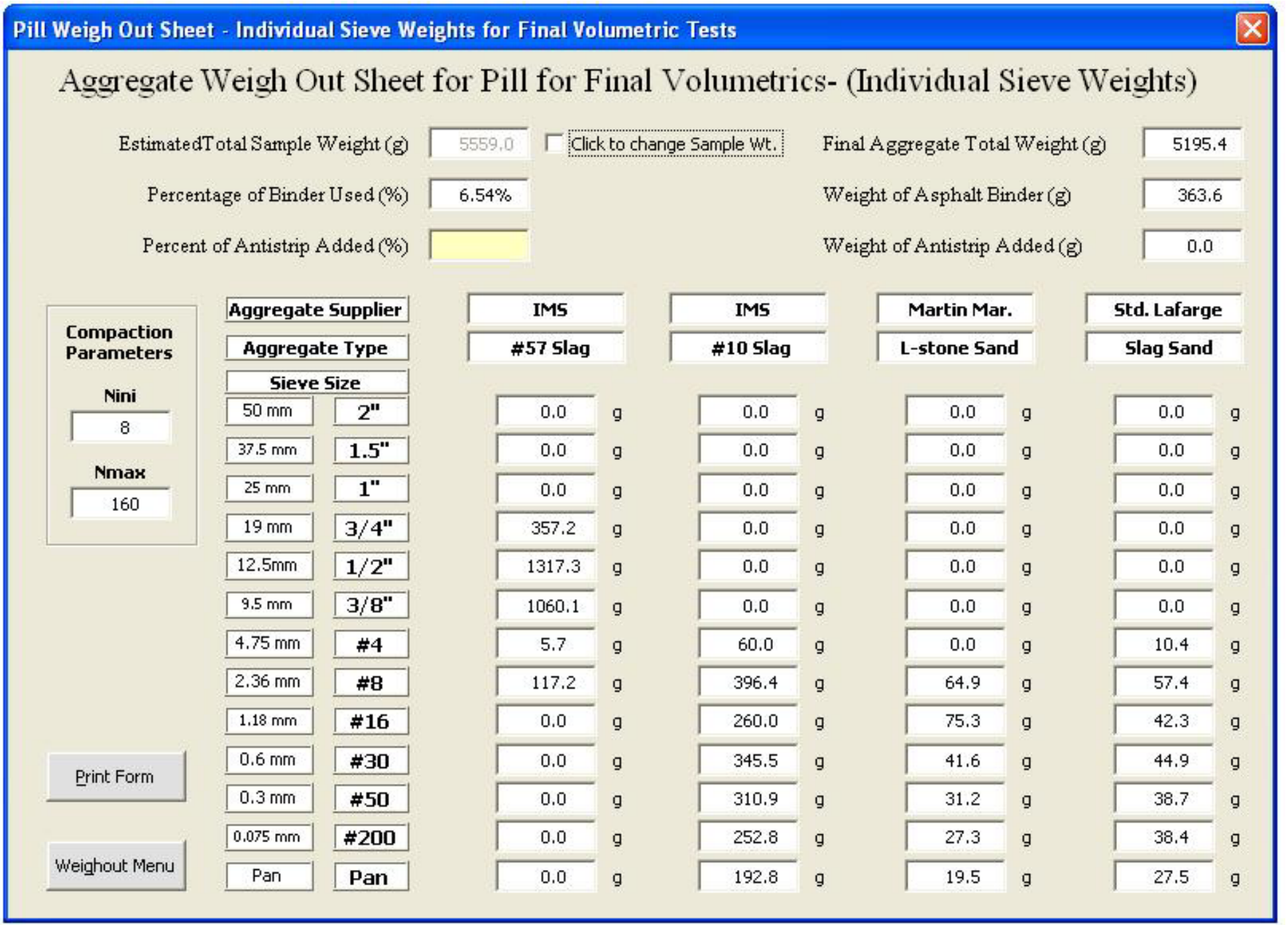

Figure A.33 Pill Weigh-Out Sheet - Individual Sieve Weights for Final Volumetrics 


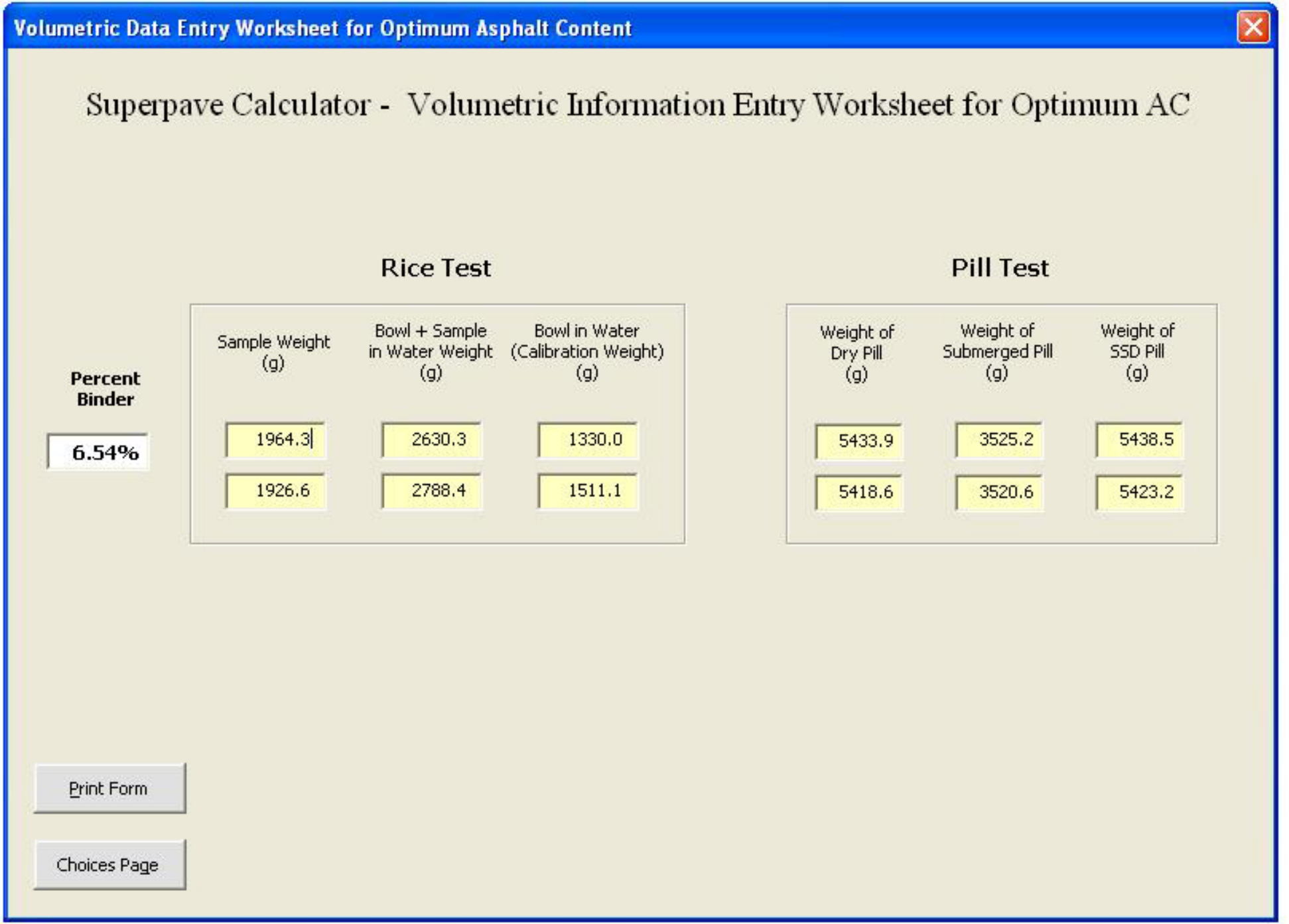

Figure A.34 Volumetric Data Entry Worksheet for Optimum Asphalt Content 


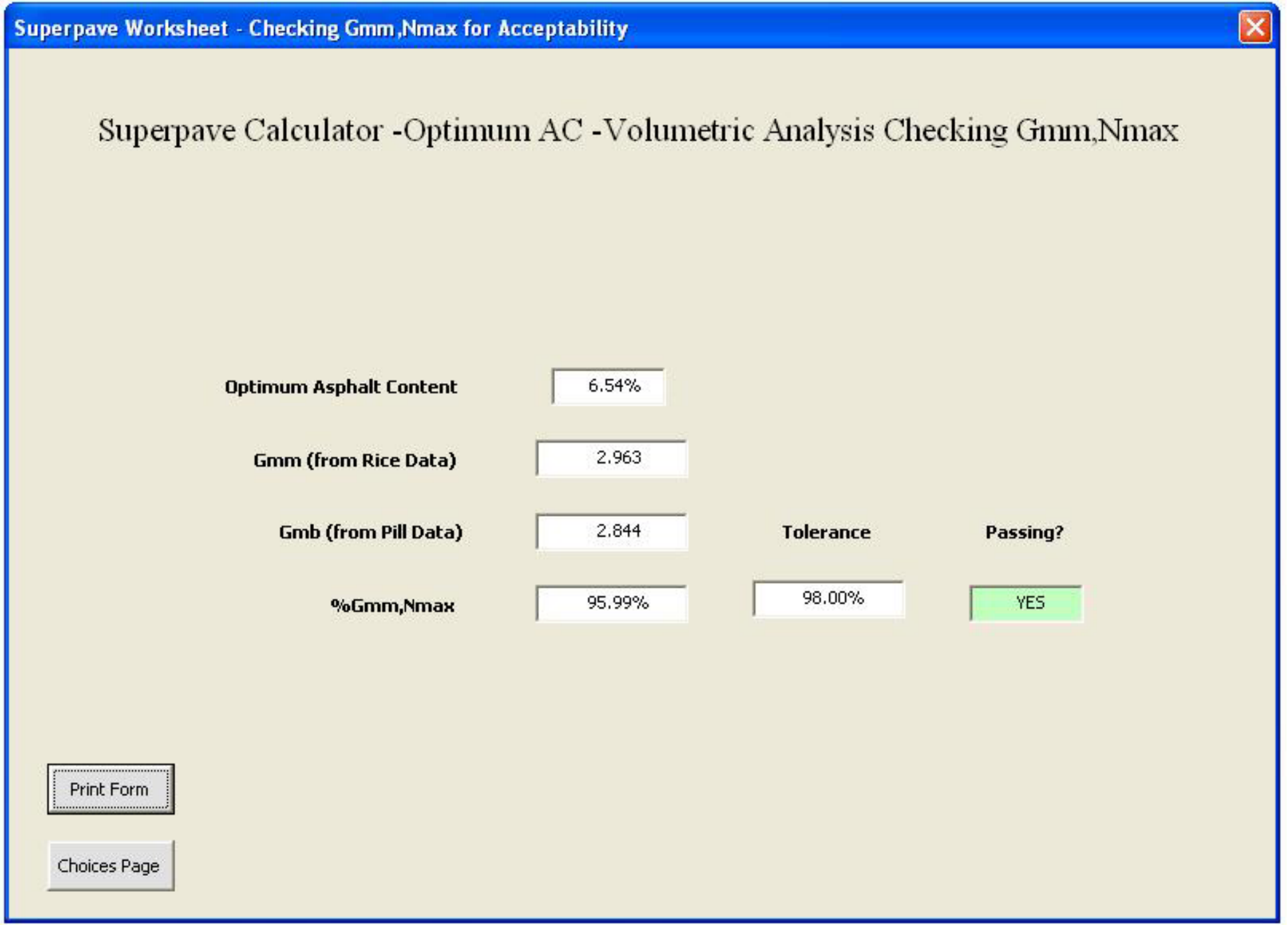

Figure A.35 Volumetric Data Analysis for Optimum Asphalt Content 
TSR Weighout Sheets and Data Entry Worksheets

\section{Aggregate Weigh Out Sheets for TSR Testing}

$$
\text { TSR Pill - Cumulative Weights }
$$

TSR Pill - Individual Weights

TSR Input

Sample 1

Wet Tensile Strength
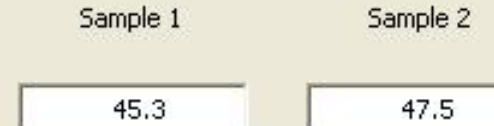

47.5

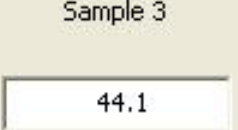

Dry Tensile Strength

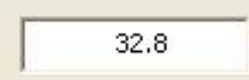

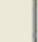

36.8

35.2

Acceptable?

Tensile Strength Ratio

1.31

YES

\section{Print Form}

Choices Page

Figure A.36 Agg. Weigh-Out and Data Entry Worksheets for Tensile Strength Ratio 


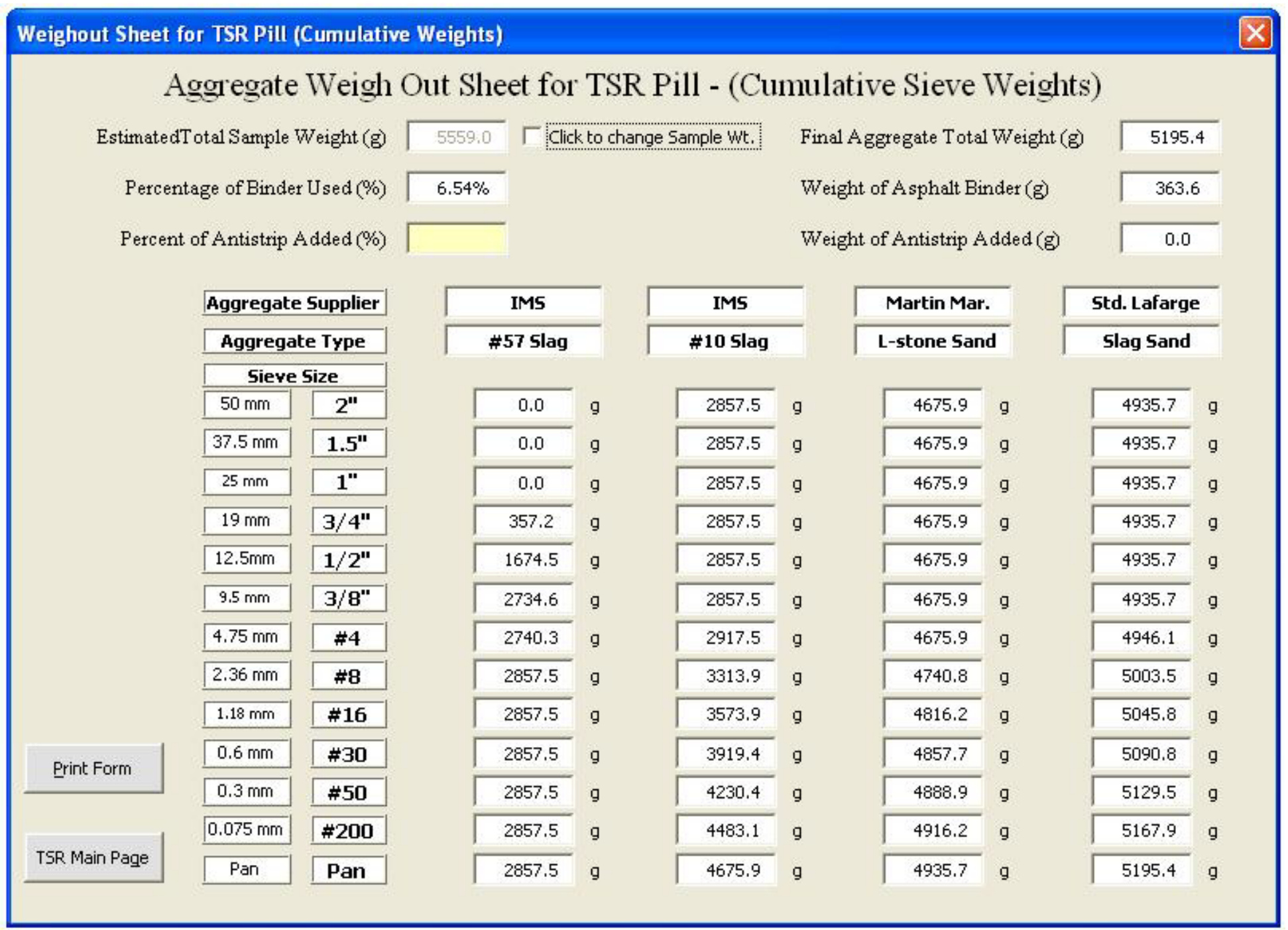

Figure A.37 Aggregate Weigh-Out Sheet for TSR Pill, Cumulative Sieve Weights 


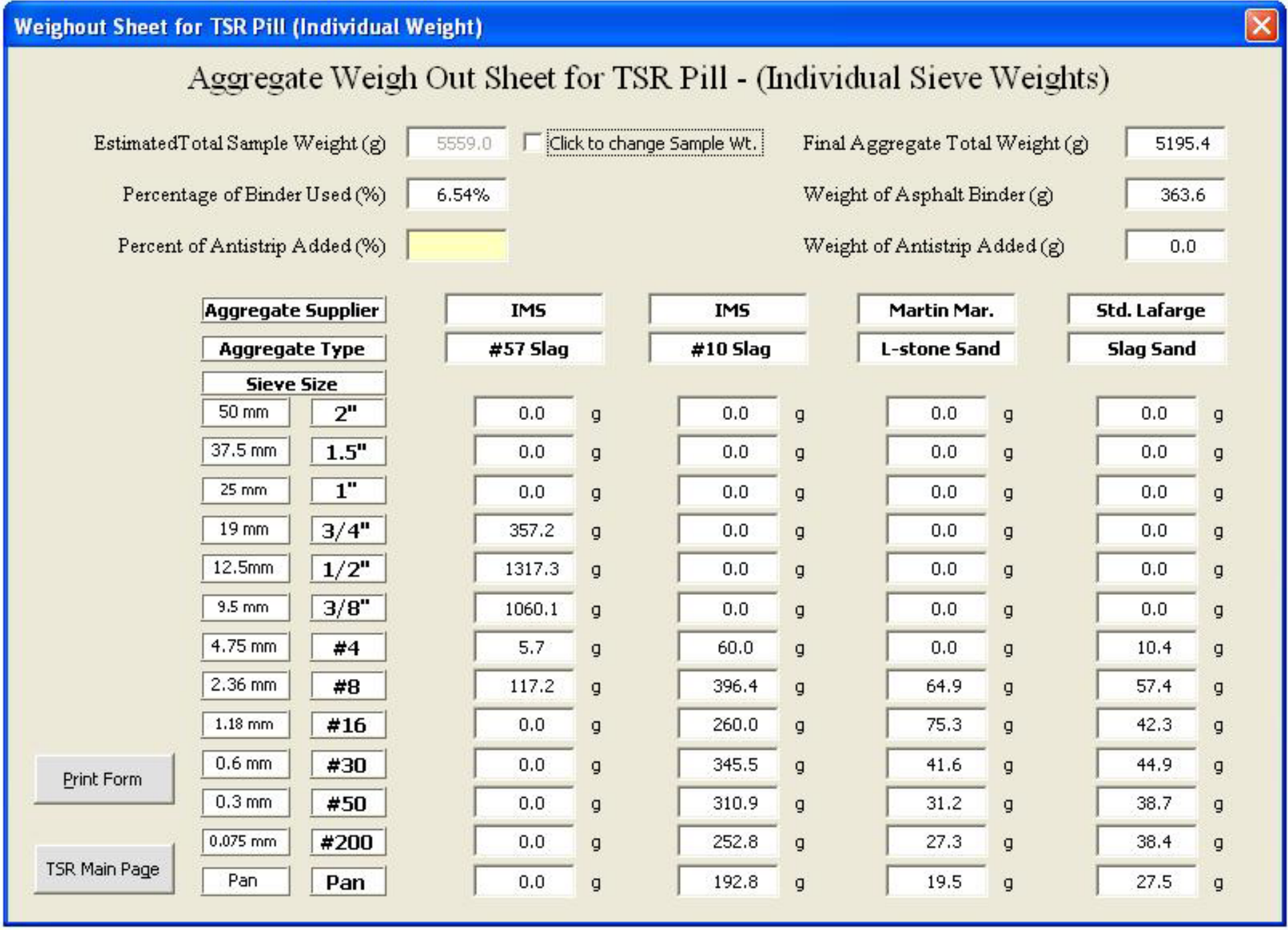

Figure A.38 Aggregate Weigh-Out Sheet for TSR Pill, Individual Sieve Weights 


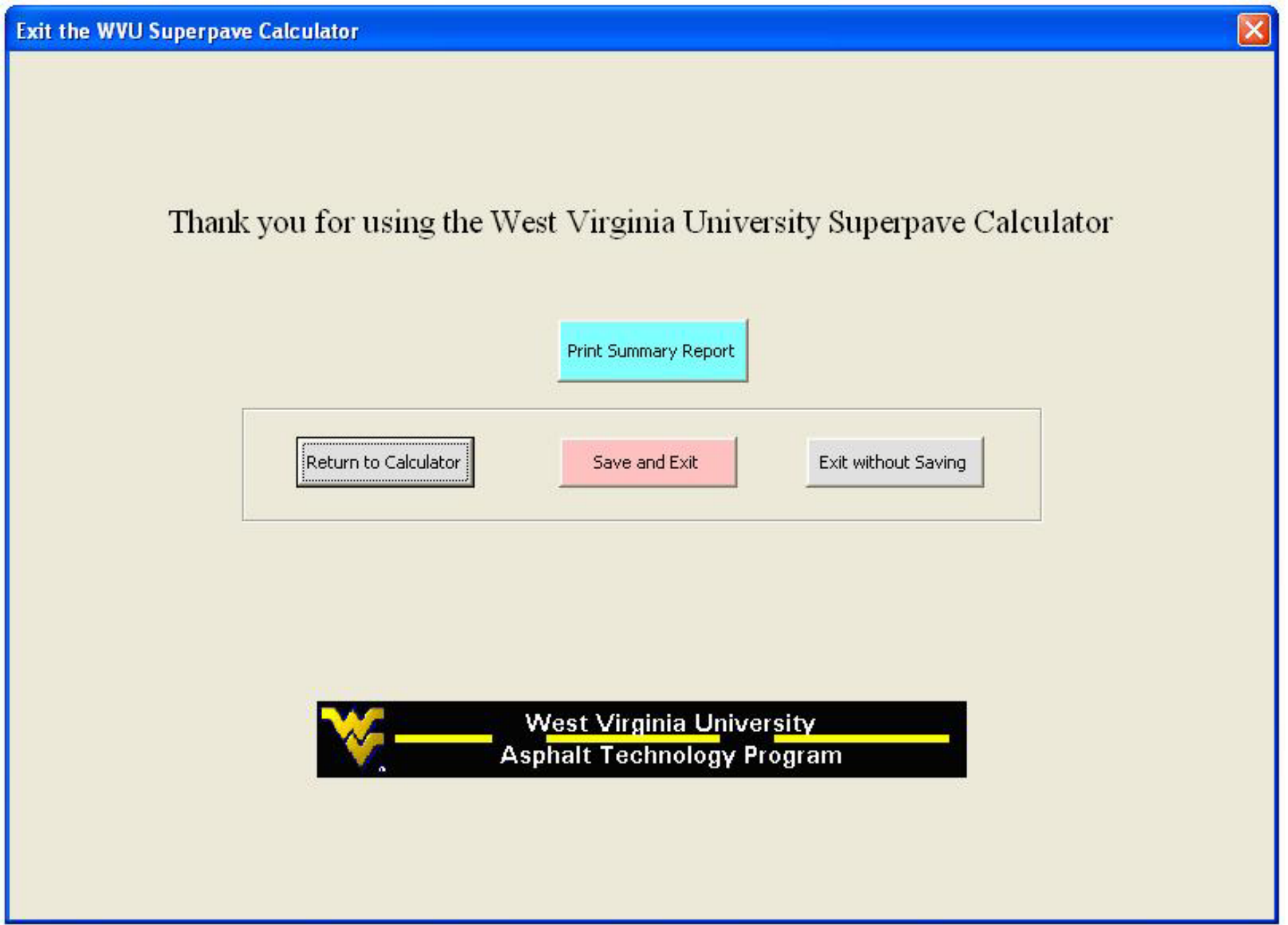

Figure A.39 Exit Screen for Superpave Calculator 
$1400 \mathrm{SP}$

$03-00$

WEST VIRGINIA DIVISION OF HIGHWAYS JOB MIX FORMULA FOR SUPERPAVE HOT-MIX ASPHALT

\begin{tabular}{lc|lc|}
\hline Report Number: & Trial \#1 & Date Accepted: & January 1,2003 \\
\hline HMA Type: & WCT-1 (Skid) & HMA Code: & 72289 \\
\hline Producer: & MV Asphalt Lab & Plant Location: & Morgantown, WV \\
\hline Designed By: & Test Size Batch & Plant Make: & WVU Asphalt Technology Lab \\
\hline Plant Type: & WVU2002 & Design ESALs (Millions): & $10<30$ \\
\hline Plant Code: & & &
\end{tabular}

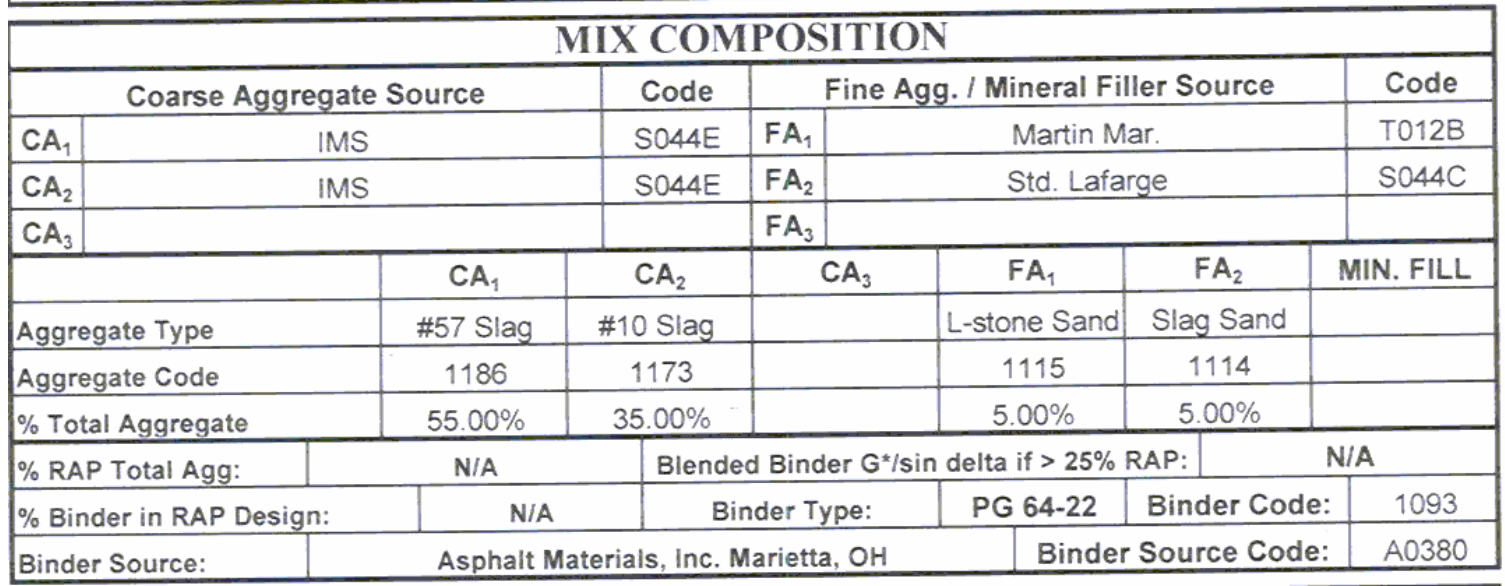

\begin{tabular}{|c|c|c|c|c|c|c|c|c|c|c|}
\hline & & & Sieve & raction & & & & \multirow{2}{*}{$\begin{array}{l}\text { Fines/Effective } \\
\text { Asphalt Ratio }\end{array}$} & \multirow{2}{*}{\multicolumn{2}{|c|}{$\begin{array}{c}\text { Tensile } \\
\text { Strn. Ratio }\end{array}$}} \\
\hline \multirow{2}{*}{$\begin{array}{c}\text { Sieve } \\
\text { Size }\end{array}$} & \multirow[b]{2}{*}{ Target } & \multicolumn{2}{|c|}{ Allowable } & \multirow{2}{*}{$\begin{array}{l}\text { Sieve } \\
\text { Size }\end{array}$} & \multirow[b]{2}{*}{ Target } & \multicolumn{2}{|c|}{ Allowable } & & & \\
\hline & & Min. & Max. & & & Min. & Max. & 1.35 & & 31 \\
\hline $2 "(50 \mathrm{~mm})$ & & & & $\# 4(4.75 \mathrm{~mm})$ & & & & \multirow{2}{*}{\multicolumn{3}{|c|}{$\begin{array}{c}\text { Temperature Range } \\
\text { Completed Mixture }\left({ }^{\circ} \mathrm{F}\right)\end{array}$}} \\
\hline $1.5^{\prime \prime}(37.5 \mathrm{~mm})$ & & & & \#8" $(2.36 \mathrm{~mm})$ & 35 & 20 & 50 & & & \\
\hline 1" $(25 \mathrm{~mm})$ & 100 & 100 & 100 & $\# 16(1.18 \mathrm{~mm})$ & & & & \multirow{2}{*}{$\begin{array}{c}\text { Desirable } \\
\text { Mean Temp. }\end{array}$} & \multicolumn{2}{|c|}{ Temp. Range } \\
\hline $3 / 4 "(19 \mathrm{~mm})$ & 95 & 90 & 100 & $\# 30(600 \mu \mathrm{m})$ & & & & & Min. & Max. \\
\hline $1 / 2 "(12.5 \mathrm{~mm})$ & 90 & & 90 & $\# 50(300 \mu \mathrm{m})$ & & & & & & \\
\hline $3 / 8^{\prime \prime}(9.5 \mathrm{~mm})$ & & & & $\# 200(75 \mu \mathrm{m})$ & 5 & 2 & 8 & 305 & 290 & 320 \\
\hline
\end{tabular}

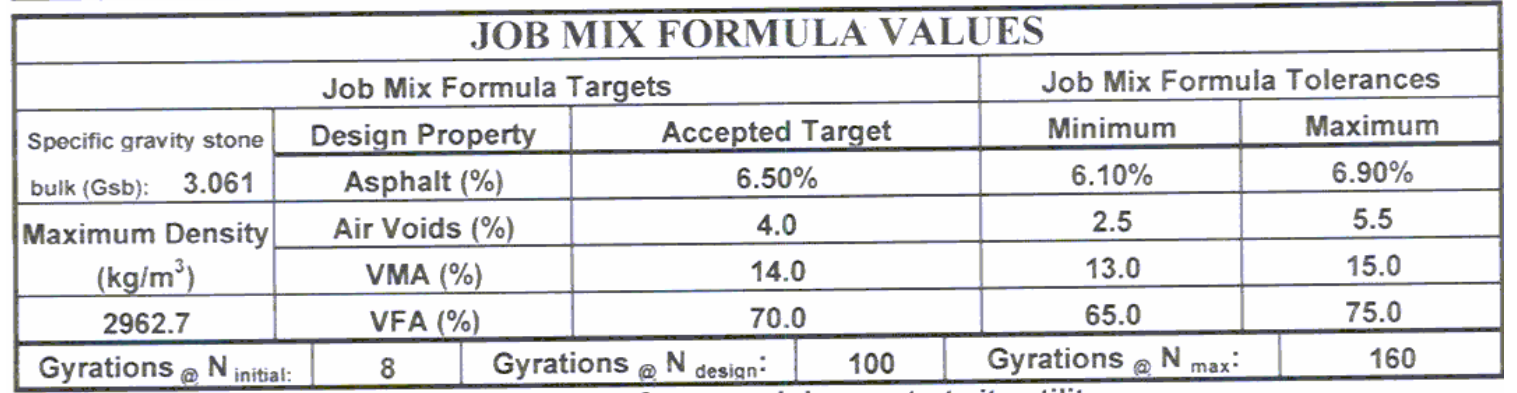

Remarks: This is a trial to validate the software and demonstrate its utility

Figure A.40 Sample Job Mix Formula Print Out (Produced Using Trial Data) 


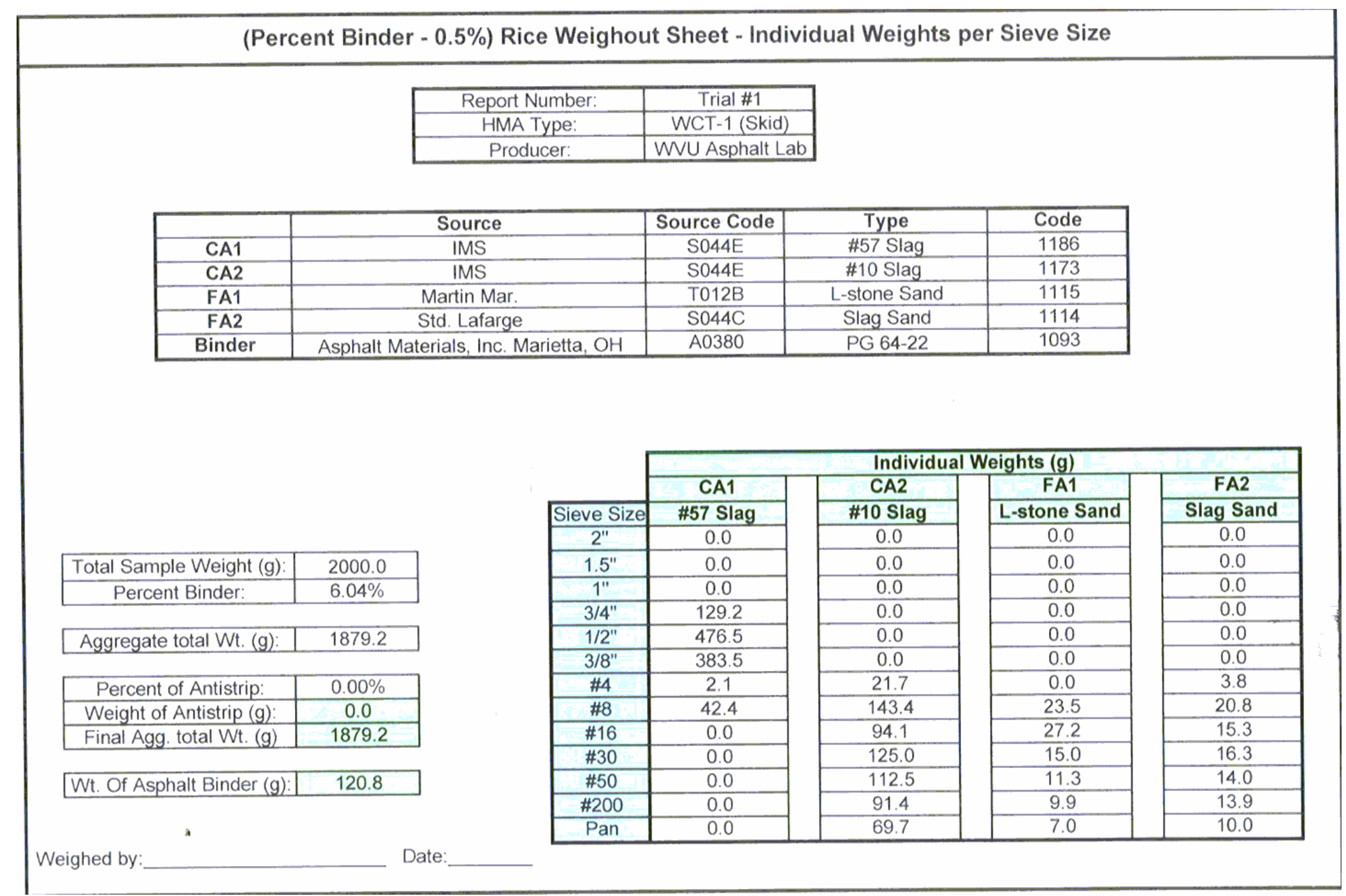

Figure A.41Sample Weigh-Out Sheet Print-Out (Using Trial Data) 


\section{APPENDIX B}

\section{SUPERPPAVE CALCULATOR USER'S MANUAL}


Structure of User Interface for Superpave Calculator

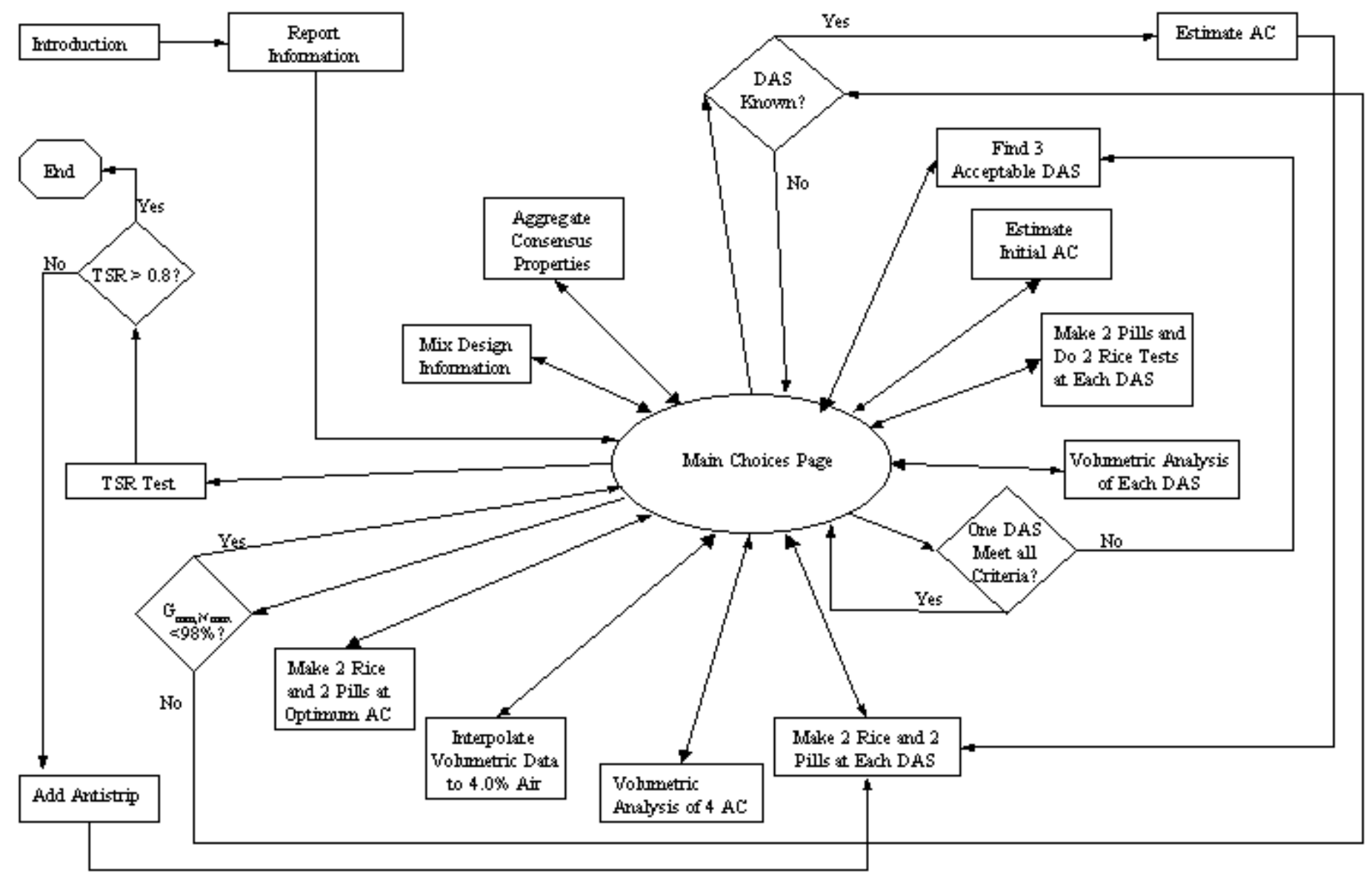

Figure B.1 Structure of User Interface for Superpave Calculator 


\section{USER'S MANUAL}

Welcome to the West Virginia University Department of Civil and Environmental Engineering Asphalt Technology Program's Superpave Calculator. The program is designed for all levels of asphalt mix design knowledge, from a practicing asphalt contractor to a student in an introductory bituminous pavement course. Each step in the Superpave Calculator mix design process is detailed, from the introduction to the exit page and all necessary processes in between. This manual describes the types of values that should be entered in each data entry text box, ensuring proper performance of the software and minimizing error messages. A screen capture of each user form is included in Appendix A, and may be helpful in identifying proper data types and acceptable values.

\section{Section I Installing the Software Computer.}

After obtaining a copy of the Superpave Calculator program, which is about 3.5MB, the user must install it on the host computer, create a shortcut in Microsoft Excel, and link the shortcut for future easy access.

1. Create a new folder on the desktop named "Superpave".

2. Copy the program into the "Superpave" folder.

3. Open the program in Microsoft Excel, enable macros, and right click on the toolbars at the top of the screen.

4. Click "Customize" on the menu, and then select the "New" button.

5. Name the new toolbar "Superpave", click "OK".

6. Select the "Commands" tab and highlight the "Macros" option.

7. Left-click "Custom Menu Item" and drag it onto the newly created "Superpave" toolbar. 
8. Right-click this newly created button. In the white field, rename the button "\&Superpave", and at the bottom of the menu select "Assign Macro".

9. Select the "Superpave" macro and click "OK".

10. Close the Customize menu and drag the newly created button to the top of the screen and "peg" it in an empty space.

After completing this process, the user only needs to click this "Superpave" button to launch the software.

\section{Section II Running the Superpave Calculator}

After completing Step I and installing the software and shortcut onto the host computer, the program is ready to run at the click of the "Superpave" button.

To use the program, launch the software by clicking the newly created "Superpave" button. An introduction screen will appear welcoming the user and identifying the developers, origin, version, and latest update. Two choices are presented: begin a new mix design project or open an existing file. New mix design steps are detailed in Section II; saving and opening files for modification are discussed in Section III. Screen captures of every step in the new mix design process are presented in Appendix A and may be referenced to compare acceptable values. After the "New Project" option is selected, the user is prompted to enter the mix design report information.

1. The Mix Design Report Information sheet is designed in tandem with the WV T400 SP Superpave Mix Design Summary sheet, which is required for each new mix design. All input fields are alphanumeric, created to assist the user throughout the process, but not used in calculations. The input fields for Report Number, HMA Type, Producer, etc. are directly linked to the T400 SP summary sheet and they also help to identify the mix if future modification is necessary. The aggregate data input on the bottom half of the screen is used to later identify gradations on graphs and aggregates for weigh out sheets. 
The source field requires data about the company supplying the aggregate, with the location of its city and state. The "Source Code" is a five digit alphanumeric code identifying each supplier and is standard for all designers in West Virginia. The "Aggregate Type" is an identifier of the specific type aggregate used, such as \#57 Slag, \#8 Limestone, or Natural Sand. "Aggregate Code" is the statewide four digit number code identifying each type of aggregate. The binder information is also entered on this sheet identifying the supplier, with city and state, source code and binder code. After entering all data, the user must go to the "Main Choices" page for further processing.

The "Main Choices" screen is the central hub of the entire program, allowing the user to return after every step, before continuing to the next part of the process. This page is linked to the program exit, which is the only method of quitting the application.

The "Mix Composition Information" page is the next step in the design process. The user inputs the required design parameters, which determine the tolerances and criteria that must be followed. The data for skid design, binder grade, depth from surface, traffic ESALs, NMAS and the binder specific gravity must be entered. The temperatures, RAP data and remarks field are for report information only. The required data entry includes:

- The skid design field, which identifies if the mix will be used as a skid or base design

- Binder type, the four types used in West Virginia are presented for selection

- The depth from surface is dependent on the skid design selection. If the mix will be used as a skid design, the only option is depth $<100 \mathrm{~mm}$

- The traffic ESALs, in millions, identifies the expected volume of roadway traffic

- The Nominal Maximum Aggregate Size (NMAS), identifying the size of the aggregates to be used for the mix design

- Specific gravity of the binder, which must be $0.900-1.100$ 
All of the required data must be entered, or else the program will return an error message prompting the user to completely fill in all information.

2. The Aggregate Consensus Properties page is designed simply as a tool to determine if laboratory generated aggregate data meets the set requirements. The user inputs the data for Coarse Aggregate Angularity (CAA), Fine Aggregate Angularity (FAA), Flat and Elongated Ratio (FE) and the Sand Equivalency Test (SE). The data are entered as percentages. Information from the Mix Composition page determines the acceptable range of values.

3. The Aggregate Data Worksheet allows the user to enter data on up to four different aggregate gradations. Bulk Specific Gravity (Gsb) and Apparent Specific Gravity (Gsa) for each aggregate type are also required. The data on the percent passing each sieve size for the individual aggregates is entered, with each value being equal or less than the previous passing percentage. If a percentage passing is entered that is greater than the value above, the program returns an error message warning the user of an invalid number that must be changed. The data on Gsb and Gsa is also required for the mix design process with Gsb always less than Gsa, otherwise an error message is displayed. Four different aggregates are not required for a mix design, but all of the necessary information on an aggregate must be completely entered, or an error message warns the user of empty input fields. If the design aggregate structure (DAS) is already known, the percentage of each aggregate to be used for a blend may be entered in the appropriate fields below the specific gravity data. If DAS is not yet determined, the percentages may be left blank.

On the Main Choices page, if the DAS is known, uncheck the "Determine DAS" box and proceed straight to estimating the necessary percent binder, with the button located at the top of the second column. If DAS must be determined, proceed to step four and create three individual DAS. 
4. The Aggregate Gradation Chart graphically displays the individual gradations for each aggregate used as well as the blended gradation. Below the plot are presented the restrictions for five control points, which are determined by the NMAS of the blend. Also presented is the overall blended NMAS of the current blend in either a red or green text box. When the aggregates are blended, the program calculates these six necessary values as well as the total blend percentage and returns the results in a colored box. If the box is green, the value is acceptable; if it is red, the limit is violated and the blend is unacceptable. The aggregates are blended so that the control points and the NMAS values are within the tolerances and all indicator boxes turn green. If the DAS is known, this is merely a visual tool to confirm acceptability; if DAS is unknown, then three blends are created and saved, using the "Save as DAS \#" buttons. The total percentage must equal 100\% to exit this page; otherwise an error message is displayed.

5. The DAS Chart page graphically displays the three determined design aggregate structures plotted on a single graph. There is no user input for this step, only a visual presentation of the three DASs.

6. The Initial Asphalt Content Estimator for each DAS uses a series of equations and limits based upon mix information and aggregate data to estimate the asphalt content for each DAS. This value is intended to only be an initial estimate, not the final value. Subsequent testing is needed for a definitive binder percentage as presented in Steps 7-10. This page automatically calculates the binder percentages on loading. If the absorption adjustment factor ( $\mathrm{F}$ Value) or the design air content $(\mathrm{Va})$ differ from the preset values, the new data must be entered and the binder percentage must be recalculated using the "Update Values" button. The calculated binder percentages are automatically passed to the weigh out sheets for Step 7.

7. Since two maximum specific gravity tests and two gyratory compaction samples are required for each DAS, the aggregates and binder must be weighed, blended and the tests performed. The weigh out sheets are provided to assist the user in determining the amount of material passing the sieves that 
must be weighed for each aggregate. Two formats are presented with this software: individual and cumulative sieve weights, both yielding the same final result. The "Print" button prints a form showing all required weights along with the necessary mix design information at the top of the sheet. No user input is necessary on any of these weigh out forms.

8. The Volumetric Data Entry Worksheet receives all of the weights obtained from the two Rice tests and two gyratory samples for each DAS. The Rice weight inputs are presented on the left of the screen; the pill data is entered on the right. All weights are in grams and must be positive numeric values. For the Rice test, the sample weight must be less than the submerged weight and the submerged weight must be greater than the calibration weight; any violation will return an error message. For the pills, the dry weight must be less than the SSD weight and greater than the submerged weight; an error box is displayed if otherwise. The pill heights, in millimeters, are also entered. The initial height must be greater than the design height, which must be between 110 and $120 \mathrm{~mm}$. An error message is displayed if these criteria are not met. The data entered on this worksheet is used to calculate the volumetric properties presented next in Step 9.

9. The Design Aggregate Structure Volumetric Analysis worksheet requires no user input; it displays all of the required volumetric values compared with the set tolerances. The four necessary criteria are presented in a summary on the right of the screen with acceptable values turning the display boxes green and invalid values turning red. The Voids in the Total Mix (VTM), Voids in the Mineral Aggregate (VMA), Voids Filled with Asphalt (VFA) and dust to binder ratio $(\mathrm{D} / \mathrm{b})$ values are presented along with the acceptable tolerances. No user input is necessary for this page, only an observation of the values for a comparison in Step 10.

10. The Design Aggregate Structure Volumetric Analysis Adjusted to 4.0\% Air worksheet presents all of the volumetric data mathematically adjusted to $4.0 \%$ VTM and presented with the tolerances. Upon examining the necessary criteria summary, with acceptable values presented in green boxes and 
unacceptable values in red, the user is required to pick the best DAS to continue with the procedure. If no DAS adjusted volumetric data meets all four criteria, the user is returned to the DAS selection plot and the process is repeated again until a valid structure is found. If a DAS meets all four criteria, it is selected and the user returns to the "Main Choices" page to continue the mix design with more volumetric analysis.

If the DAS is already known, as detailed before, the initial asphalt content is estimated for the future volumetric testing.

11. The DAS and Percent Binder Confirmation worksheet provides a summary of the mix design for the upcoming volumetric analysis procedures. The chosen DAS and calculated initial binder estimate are displayed for user verification. If the binder percentage must be adjusted, the new $\mathrm{P}_{\mathrm{b}, \text { sst }}$ can be inputted into the yellow box, which then automatically fills in the other necessary binder percentages. If the original binder percentage is to be used, check the designated box, otherwise check "Enter User Adjusted Value" and input the proper data. These values are passed into the weigh-out sheets for the volumetric analysis.

12. The next process is to make two maximum specific gravity and two gyratory compaction samples at each of four binder percentages. The weigh out sheets are provided to assist the user in weighing the material, the same as in Step 7. These sheets differ from those for DAS analysis because the user has the option of entering the percent of antistrip used for each mix and also entering a different weight for the gyratory compaction samples. When new data is entered, all values are immediately updated to reflect the changes. The sheets for the gyratory compaction samples also indicate the number of revolutions for gyratory compactor to achieve $\mathrm{N}_{\text {des }}$. The weigh out sheets are used to create the samples necessary for the volumetric analysis of Step 13.

13. The Volumetric Data Entry Worksheet receives all of the weights obtained from the two Rice tests and two gyratory samples for each binder percentage, the same as in Step 8 for DAS volumetric analysis. The Rice weight inputs 
are presented on the left of the screen and the pill data is entered on the right. All weights are in grams and must be positive numeric values. For the Rice test, the sample weight must be less than the submerged weight and the submerged weight must be greater than the calibration weight; any violation will return an error message. For the pills, the dry weight must be less than the SSD weight and greater than the submerged weight; an error box is displayed if otherwise. The pill heights, in millimeters, are also entered. The initial height must be greater than the design height, which must be between 110 and $120 \mathrm{~mm}$. An error message is displayed if these criteria are not met. The data entered on this worksheet is used to calculate the volumetric properties presented next in Step 14.

14. The Percent Binder Trials Volumetric Analysis worksheet requires no user input, it only displays the required volumetric values compared with the set tolerances, the same as in Step 9. The four necessary criteria for only the $\mathrm{P}_{\mathrm{b} \text {,est }}$ are presented in a summary at the bottom of the screen, with acceptable values turning the display boxes green and invalid values turning red. The Voids in the Total Mix (VTM), Voids in the Mineral Aggregate (VMA), Voids Filled with Asphalt (VFA) and dust to binder ratio (D/b) values are presented along with the acceptable tolerances. No user input is necessary for this page, only an observation of the values for the interpolation in Step 15.

15. The Mix Properties versus Asphalt Content worksheet graphically interpolates the binder percentage to $4.0 \% \mathrm{VTM}$, then adjusts the other four volumetric properties, VMA, VFA, $\% \mathrm{G}_{\mathrm{mm} \text {,Nini }}$ and $\mathrm{D} / \mathrm{b}$ to that calculated percent binder. The data is processed mathematically by Excel and then displayed visually for easy interpretation of the results. No user input is needed for this worksheet, only a viewing of the results for acceptability. The numerical results are presented in Step 16 for more precise determination of values.

16. The Interpolated Optimum AC-Volumetric Analysis worksheet is the numerical version of the interpolated results from Step 15. If the display boxes are green, the values are acceptable; red boxes signal an unacceptable 
result. No user interaction for this worksheet is allowed; it is only intended to notify the user if any value does not meet the necessary criteria.

17. Once the optimum binder percentage is determined by volumetric interpolation, volumetric analysis to determine $\% \mathrm{G}_{\mathrm{mm}, \mathrm{Nmax}}$ must be performed at this final asphalt content. Two more Rice tests and gyratory samples must be weighed out and the tests must be run in order to calculate the final volumetric properties. The weigh out sheets are of the same fashion as in step 12 , allowing the user to enter the amount of antistrip and change the weight of the compaction sample. The sheets indicate the number of revolutions necessary for $\mathrm{N}_{\max }$ for the gyratory compaction samples. The data from the samples is entered into the volumetric analysis data entry sheet in Step 18.

18. The Volumetric Information Entry Worksheet for Optimum AC is the same as the data entry worksheet for step 13, except no compaction sample heights are required. The Rice weight inputs are presented on the left of the screen and the pill data is entered on the right. All weights are in grams and must be positive numeric values. For the Rice test, the sample weight must be less than the submerged weight and the submerged weight must be greater than the calibration weight; any violation will return an error message. For the pills, the dry weight must be less than the SSD weight and greater than the submerged weight; an error box is displayed if otherwise. This data is used to determine if the value of $\% \mathrm{G}_{\mathrm{mm}, \mathrm{Nmax}}$ is acceptable in Step 19.

19. The Optimum AC Volumetric Analysis- Checking $\% \mathrm{G}_{\mathrm{mm} \text {,Nmax }}$ worksheet uses the values from Step 18 and returns the calculated volumetric analysis for $\% \mathrm{G}_{\mathrm{mm}, \mathrm{Nmax}}$, which must be less than $98.0 \%$. If the value is acceptable, the display box is green; an unacceptable value will return a red box. If the mix is unacceptable, a new DAS is required and the process begins again at Step 4. The last check of mix design acceptability is the evaluation of moisture susceptibility using the TSR test as detailed in Step 20.

20. The Tensile Strength Ratio (TSR) Test is performed by using the provided weigh out sheets to create six gyratory compaction samples for tensile strength testing. Three conditioned and three unconditioned samples are 
tested in the laboratory and their results are entered into the designated input boxes. After all values are inputted, the tensile strength ratio is displayed and the acceptability is noted with a red or green result. If the minimum allowable value for TSR, which is 0.8 , is not met, anitstripping is added and the process returns to Step 12 where two more Rice tests and gyratory compaction samples are created at each binder percentage. The process is then continued until an acceptable mix design is found, completing the entire procedure.

Once a mix design meets all volumetric criteria and has a $\% \mathrm{G}_{\mathrm{mm}, \mathrm{Nmax}}<98.0 \%$ and a TSR $>0.8$, the Superpave mix design is completed and the mix is deemed acceptable for use on the roadway.

All of the data, in a one-page summary, may be obtained by clicking the "Exit Superpave Calculator" button on the Main Choices page. At this point of the mix design process, the user has the option of printing the report, returning to the calculator or exiting the software. Printing the report only requires clicking the designated button, as does returning to the Superpave Calculator. The user has two other choices, which involve quitting the program by either saving or not saving the data. Quitting without saving loses all of the calculated data and exits Microsoft Excel, but saving the data involves another step, which is detailed in Section III.

\section{Section III Saving and Opening Mix Design Files}

At the introduction page, the user has the option of opening an existing project or starting a new project. If an existing mix design project is to be modified, select the appropriate button, which then displays the "Open" box. Choose the previously saved file for modification and click the "Open" button; the data is now loaded into the program and every step is ready for modification.

To save a mix design upon exiting the Superpave Calculator, choose the "Save and Exit" option. A "Save As" box will appear, prompting the user to give the mix design a unique name. Name the data something other than "Superpave" and click the "Save" button. The mix design data will be saved and the workbook will automatically close. 


\section{APPENDIX C}

\section{SLAG AGGREGATE EVALUATION LABORATORY RESULTS}




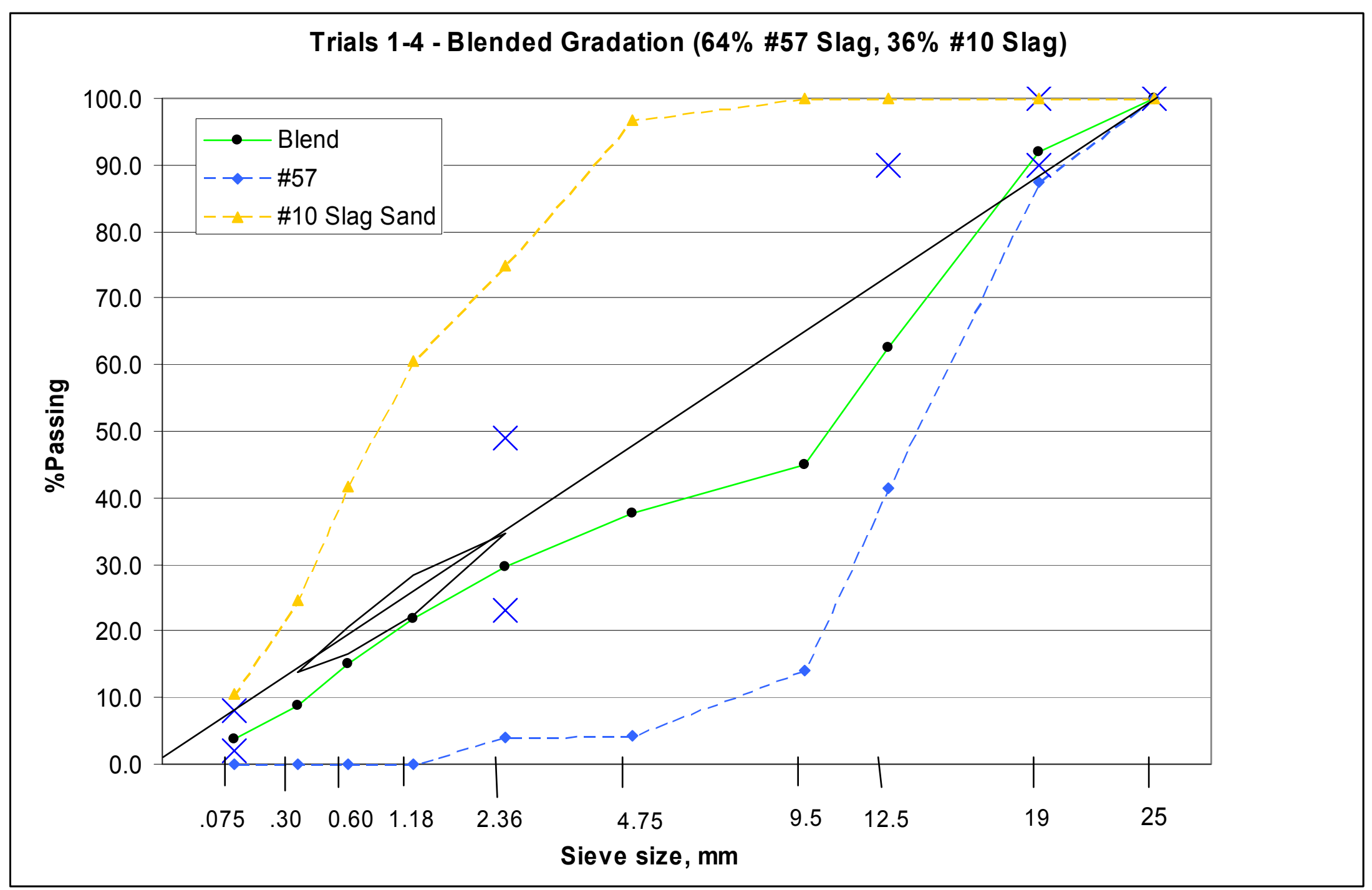

Figure C.1 Blended Gradation for Trials 1-4 (64\% \#57 Slag \& 36\% \#10 Slag) 


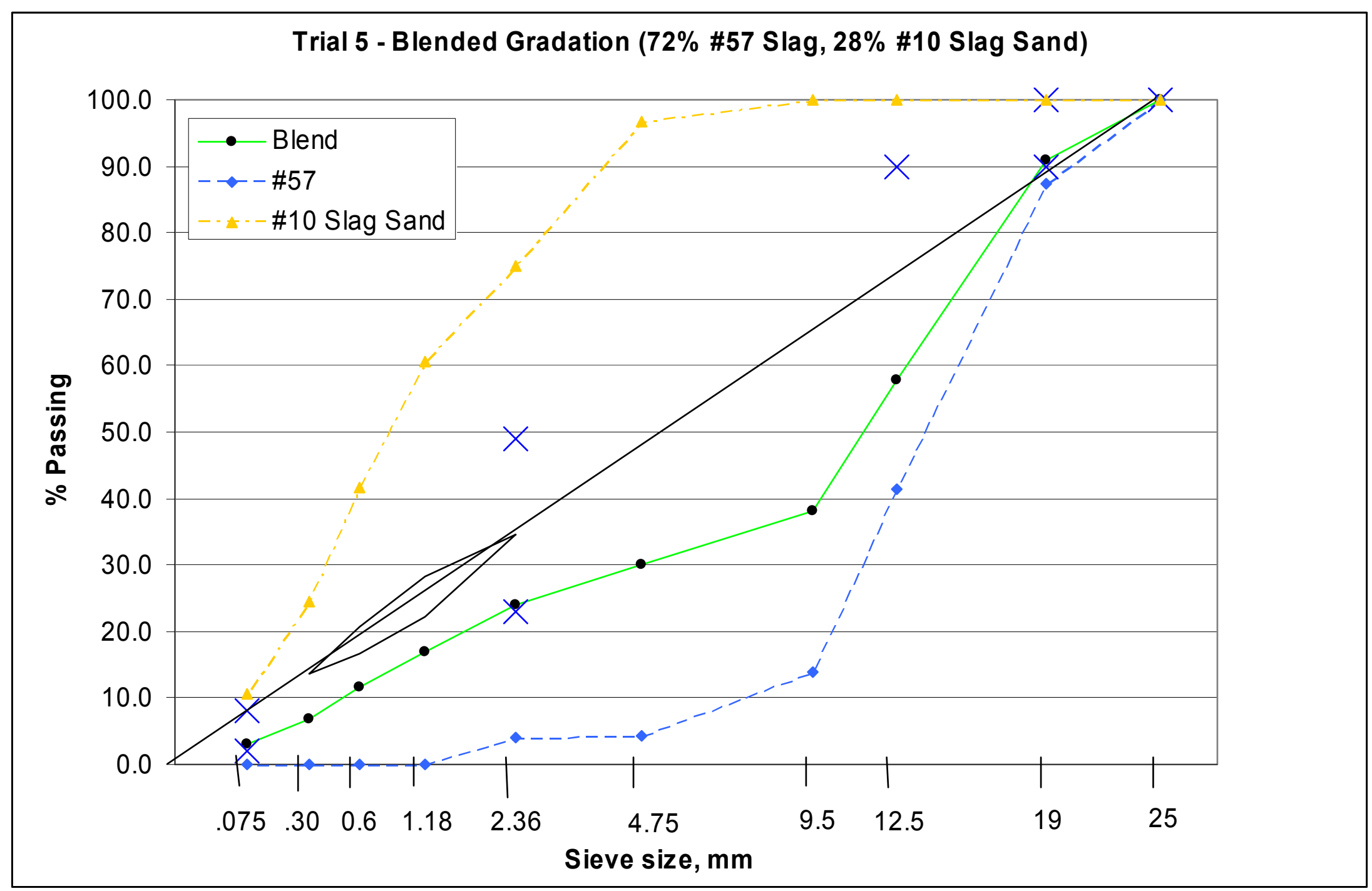

Figure C.2 Blended Gradation for Trial 5 (72\% \#57 Slag \& 28\% \#10 Slag) 


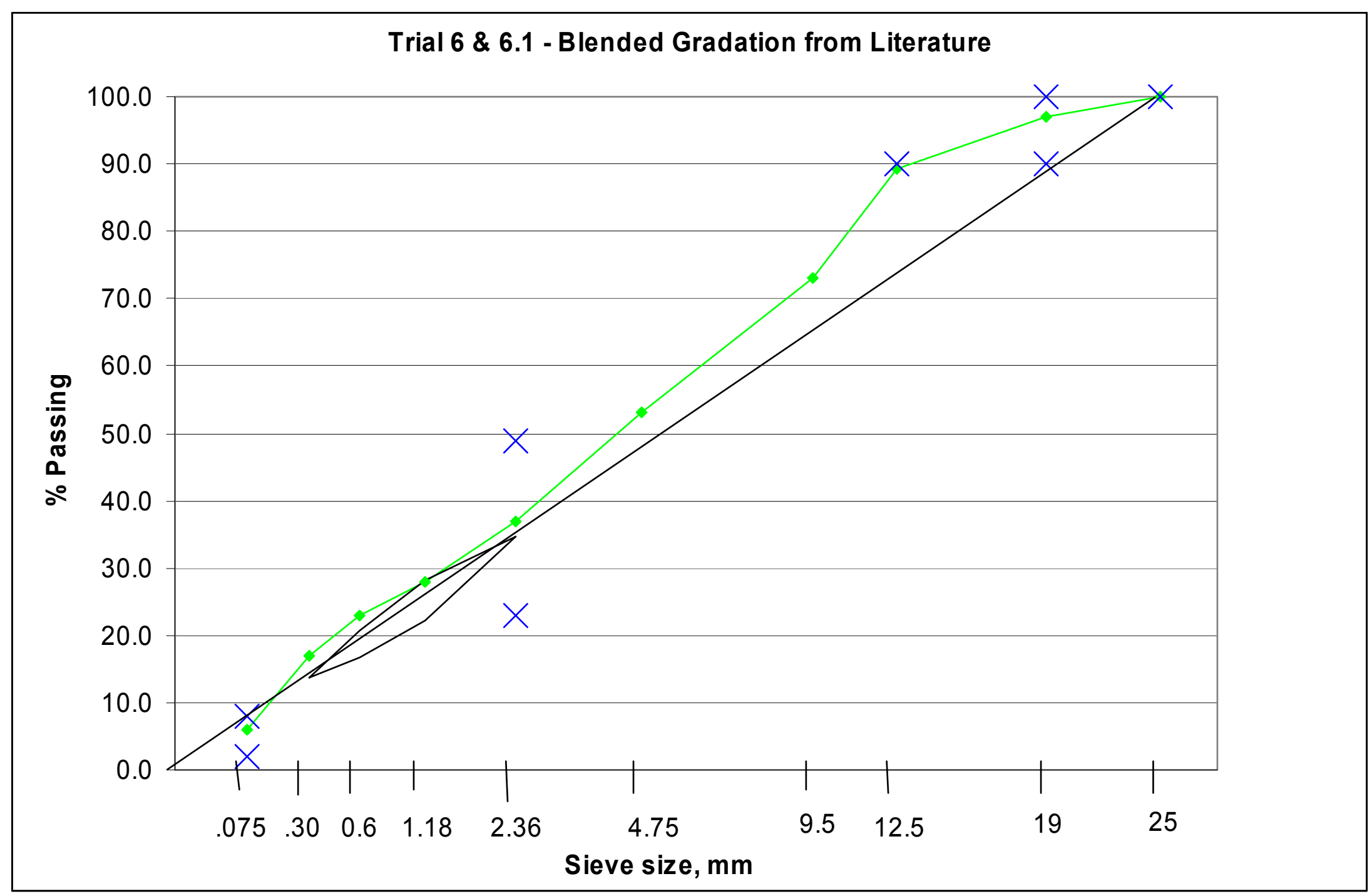

Figure C.3 Blended Gradation for Trials $6 \& 6.1$ (Gradation from Literature) 


\begin{tabular}{|c|c|}
\hline \multicolumn{2}{|c|}{$\begin{array}{c}\text { Trials 1-4 Estimated } \\
\text { Binder Percentage from } \\
\text { Aggregate Data }\end{array}$} \\
\hline \multicolumn{2}{|c|}{ Effective Gs } \\
\hline Blended $\mathrm{Gs}_{\mathrm{b}}$ & 3.134 \\
\hline Blended $\mathrm{Gs}_{\mathrm{a}}$ & 3.558 \\
\hline $\mathrm{F}$ & 0.8 \\
\hline $\mathrm{Gs}_{\mathrm{E}}$ & 3.473 \\
\hline \multicolumn{2}{|c|}{ Vol. absorbed binder (asphalt) } \\
\hline Percent Stone & $93.40 \%$ \\
\hline $\mathrm{V}_{\mathrm{a}}$ (air) & $4.00 \%$ \\
\hline Percent Binder & $6.60 \%$ \\
\hline $\mathrm{G}_{\mathrm{b}}$ & 1.033 \\
\hline $\mathrm{V}_{\mathrm{ba}}$ & 0.084 \\
\hline \multicolumn{2}{|c|}{ Est. of Vol of Effective Binder } \\
\hline $\mathrm{Sn}(\mathrm{mm})$ & 19 \\
\hline$V_{b e}$ & 0.090 \\
\hline \multicolumn{2}{|c|}{ Est. weight of stone } \\
\hline $\mathrm{W}_{\mathrm{s}}$ & 2.555 \\
\hline \multicolumn{2}{|c|}{ Percent Binder Estimate } \\
\hline $\mathrm{Pb}_{\text {Total }}$ & $6.56 \%$ \\
\hline
\end{tabular}

Table C.1 Estimated Binder Percentages from Aggregate Data

\begin{tabular}{|c|c|c|c|}
\hline \multicolumn{2}{|c|}{$\begin{array}{l}\text { Trial } 5 \text { Estimated Binder } \\
\text { Percentage from Aggregate Data }\end{array}$} & \multicolumn{2}{|c|}{$\begin{array}{l}\text { Trial } 6 \text { Estimated Binder } \\
\text { Percentage from Aggregate Data }\end{array}$} \\
\hline \multicolumn{2}{|c|}{ Effective Gs } & \multicolumn{2}{|c|}{ Effective Gs } \\
\hline Blended $\mathrm{Gs}_{\mathrm{b}}$ & 3.169 & Blended $\mathrm{Gs}_{\mathrm{b}}$ & 3.298 \\
\hline Blended $\mathrm{Gs}_{\mathrm{a}}$ & 3.548 & Blended $\mathrm{Gs}_{\mathrm{a}}$ & 3.516 \\
\hline $\mathrm{F}$ & 0.8 & $\mathrm{~F}$ & 0.8 \\
\hline & $\mathrm{Gs}_{\mathrm{E}}$ & 3.472 \\
\hline \multicolumn{2}{|c|}{ Vol. absorbed binder (asphalt) } & \multicolumn{2}{|c|}{ Vol. absorbed binder (asphalt) } \\
\hline Percent Stone & $93.87 \%$ & Percent Stone & $95.15 \%$ \\
\hline $\mathrm{V}_{\mathrm{a}}$ (air) & $4.00 \%$ & $\mathrm{~V}_{\mathrm{a}}$ (air) & $4.00 \%$ \\
\hline Percent Binder & $6.13 \%$ & Percent Binder & $4.85 \%$ \\
\hline $\mathrm{G}_{\mathrm{b}}$ & 1.033 & $\mathrm{G}_{\mathrm{b}}$ & 1.033 \\
\hline $\mathrm{V}_{\mathrm{ba}}$ & 0.075 & $\mathrm{~V}_{\mathrm{ba}}$ & 0.043 \\
\hline \multicolumn{2}{|c|}{ Est. of Vol of Effective Binder } & \multicolumn{2}{|c|}{ Est. of Vol of Effective Binder } \\
\hline $\mathrm{Sn}(\mathrm{mm})$ & 19 & $\mathrm{Sn}(\mathrm{mm})$ & 19 \\
\hline $\mathrm{V}_{\mathrm{be}}$ & 0.090 & $\mathrm{~V}_{\mathrm{be}}$ & 0.090 \\
\hline & \multicolumn{2}{|c|}{ Est. weight of stone } \\
\hline \multicolumn{2}{|c|}{ Est. weight of stone } & & \\
\hline $\mathrm{W}_{\mathrm{s}}$ & 2.592 & $\mathrm{~W}_{\mathrm{s}}$ & 2.699 \\
\hline \multicolumn{2}{|c|}{ Percent Binder Estimate } & \multicolumn{2}{|c|}{ Percent Binder Estimate } \\
\hline$\overline{\mathrm{Pb}_{\text {Total }}}$ & $6.17 \%$ & $\mathrm{~Pb}_{\text {Total }}$ & $4.85 \%$ \\
\hline
\end{tabular}


Table C. 2 Bulk Specific Gravity and Absorption of 3/4" Slag

WVU ASPHALT LAB

Bulk Specific Gravity and Absorption Coarse Aggregate

Aggregate

Date

Source

Tested By
3/4" Steel Slag

March 5-6, 2002

IMS Steel Slag

M. Padula, D. Diaz \& A. Kincell

(Record masses to $1 \mathrm{~g}$ )

$A=$ Mass of oven-dry sample in air, grams

\begin{tabular}{|c|c|}
\multicolumn{1}{c}{ A } & B \\
\hline 2497.1 & 2495.1 \\
\hline
\end{tabular}

$\mathrm{B}=$ Mass of saturated-surface-dry sample in air, grams

\begin{tabular}{|l|l|}
\hline 2532.2 & 2533.8 \\
\hline
\end{tabular}

$\mathrm{C}=$ Mass of saturated sample in water, grams

\begin{tabular}{|l|l|}
1793.1 & 1790.1 \\
\hline
\end{tabular}
Bulk Specific Gravity

(Oven Dry Basis)

Bulk Specific Gravity

(Saturated-Surface-Dry Basis)

Apparent Specific Gravity

Absorption, percent

$$
=\mathrm{A} /(\mathrm{B}-\mathrm{C})=
$$$$
=\mathrm{B} /(\mathrm{B}-\mathrm{C})=
$$$$
\mathrm{B} /(\mathrm{B}-\mathrm{C})
$$

\begin{tabular}{|c|c|c|}
\hline \multicolumn{1}{|c}{ A } & B & Average \\
\hline 3.379 & 3.355 & 3.367 \\
\hline \multicolumn{2}{|c|}{ Acceptable Range } & 0.038 \\
Actual Range & 0.024
\end{tabular}

OK

\begin{tabular}{|c|c|c|}
\hline 3.426 & 3.407 & 3.417 \\
\hline Acceptable Range & 0.032 \\
Actual Range & 0.019
\end{tabular} OK

$=\mathrm{A} /(\mathrm{A}-\mathrm{C})=$

\begin{tabular}{|l|r|r|}
\hline 3.547 & 3.539 & 3.543 \\
\hline Acceptable Range & 0.032 \\
Actual Range & 0.008
\end{tabular}

OK

$=(\mathrm{B}-\mathrm{A}) / \mathrm{A} * 100=$\begin{tabular}{|c|r|r|}
\hline $1.41 \%$ & $1.55 \%$ & $1.48 \%$ \\
\hline Acceptable Range & $0.41 \%$ \\
Actual Range & $0.15 \%$ & OK
\end{tabular}


Table C.3 Bulk Specific Gravity and Absorption of 1/2" Slag

WVU ASPHALT LAB

Bulk Specific Gravity and Absorption Coarse Aggregate

Aggregate

Date

Source

Tested By
1/2" Steel Slag

March 5-6, 2002

IMS Steel Slag

M. Padula, D. Diaz \& A. Kincell

(Record masses to $1 \mathrm{~g}$ )

$\mathrm{A}=$ Mass of oven-dry sample in air, grams

B = Mass of saturated-surface-dry sample in air, grams

$\mathrm{C}=$ Mass of saturated sample in water, grams

\begin{tabular}{l|l}
1435.8 & 1430.3 \\
\hline
\end{tabular}
Bulk Specific Gravity

(Oven Dry Basis)

Bulk Specific Gravity

(Saturated-Surface-Dry Basis)

Apparent Specific Gravity

Absorption, percent

$$
=\mathrm{A} /(\mathrm{B}-\mathrm{C})=
$$

\begin{tabular}{|c|c|r|}
\hline A & B & Average \\
\hline 3.358 & 3.332 & 3.345 \\
\hline \multicolumn{2}{|c|}{ Acceptable Range } & 0.038 \\
Actual Range & 0.025
\end{tabular}

$$
=\mathrm{B} /(\mathrm{B}-\mathrm{C})=
$$

3.414

Acceptable Range Actual Range

\begin{tabular}{|l|r|r|}
\hline 3.557 & 3.524 & 3.540 \\
\hline \multicolumn{2}{|c|}{ Acceptable Range } \\
Actual Range
\end{tabular}

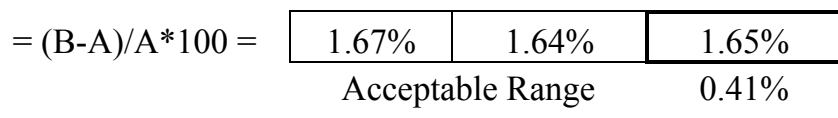

$$
\begin{aligned}
& \text { Actual Range }
\end{aligned}
$$

$\mathrm{OK}$

OK

$\mathrm{OK}$

$\mathrm{OK}$ 
Table C.4 Bulk Specific Gravity and Absorption of 3/8" Slag

\section{WVU ASPHALT LAB}

Bulk Specific Gravity and Absorption Coarse Aggregate

Aggregate

Date

Source

Tested By
3/8" Steel Slag

March 5-6, 2002

IMS Steel Slag

M. Padula, D. Diaz \& A. Kincell

(Record masses to 1g)

$\mathrm{A}=$ Mass of oven-dry sample in air, grams

$\mathrm{B}=$ Mass of saturated-surface-dry sample in air, grams

$\mathrm{C}=$ Mass of saturated sample in water, grams

\begin{tabular}{|c|c|}
\hline \multicolumn{1}{|c|}{ A } & B \\
\hline 1998.2 & 1997.6 \\
\hline
\end{tabular}

\begin{tabular}{|l|l|}
\hline 2039.1 & 2037.6 \\
\hline
\end{tabular}

\begin{tabular}{|l|l|}
\hline 1434.2 & 1430.3 \\
\hline
\end{tabular}
Bulk Specific Gravity

(Oven Dry Basis)

Bulk Specific Gravity

(Saturated-Surface-Dry Basis)

Apparent Specific Gravity

Absorption, percent

$$
=\mathrm{A} /(\mathrm{B}-\mathrm{C})=
$$

\begin{tabular}{|c|c|c|}
\hline A & B & Average \\
\hline 3.303 & 3.289 & 3.296 \\
\hline Acceptable Range & 0.038 \\
Actual Range & 0.014 & OK
\end{tabular}

$$
=\mathrm{B} /(\mathrm{B}-\mathrm{C})=
$$

\begin{tabular}{|c|c|c|}
\hline 3.371 & 3.355 & 3.363 \\
\hline Acceptable Range & 0.032 \\
Actual Range & 0.016
\end{tabular}

$$
=\mathrm{A} /(\mathrm{A}-\mathrm{C})=
$$

$$
3.543
$$

3.521

3.532

Acceptable Range Actual Range

0.032 $0.022 \quad$ OK

$$
=(\mathrm{B}-\mathrm{A}) / \mathrm{A} * 100=
$$


Table C.5 Bulk Specific Gravity and Absorption of \#4 Slag

WVU ASPHALT LAB

Bulk Specific Gravity and Absorption Coarse Aggregate

\begin{tabular}{|c|c|c|c|c|c|}
\hline Aggregate & \multicolumn{5}{|c|}{ \#4 Steel Slag } \\
\hline Date & \multicolumn{5}{|c|}{ March 5-6, 2002} \\
\hline Source & \multicolumn{5}{|c|}{ IMS Steel Slag } \\
\hline Tested By & \multicolumn{5}{|c|}{ M. Padula, D. Diaz \& A. Kincell } \\
\hline \multicolumn{6}{|c|}{ (Record masses to $1 \mathrm{~g}$ ) } \\
\hline \multicolumn{3}{|c|}{$A=$ Mass of oven-dry sample in air, grams } & 1994.6 & 1992.9 & \\
\hline \multicolumn{3}{|c|}{$\mathrm{B}=$ Mass of saturated-surface-dry sample in air, grams } & 2053.4 & 2048.5 & \\
\hline \multicolumn{3}{|c|}{$\mathrm{C}=$ Mass of saturated sample in water, grams } & 1428.2 & 1429.9 & \\
\hline & \multirow{3}{*}{$=\mathrm{A} /(\mathrm{B}-\mathrm{C})=$} & A & $\mathrm{B}$ & Average & \multirow{4}{*}{$\mathrm{OK}$} \\
\hline \multirow{2}{*}{$\begin{array}{l}\text { Bulk Specific Gravity } \\
\text { (Oven Dry Basis) }\end{array}$} & & 3.190 & 3.222 & 3.206 & \\
\hline & & $\begin{array}{r}\text { Accep } \\
\text { Act }\end{array}$ & $\begin{array}{l}\text { le Range } \\
\text { Range }\end{array}$ & $\begin{array}{l}0.038 \\
0.031\end{array}$ & \\
\hline \multirow{2}{*}{$\begin{array}{l}\text { Bulk Specific Gravity } \\
\text { (Saturated-Surface-Dry Basis) }\end{array}$} & \multirow[t]{2}{*}{$=\mathrm{B} /(\mathrm{B}-\mathrm{C})=$} & 3.284 & 3.312 & 3.298 & \\
\hline & & $\begin{array}{r}\text { Accep } \\
\text { Act }\end{array}$ & $\begin{array}{l}\text { le Range } \\
\text { Range }\end{array}$ & $\begin{array}{l}0.032 \\
0.027\end{array}$ & $\mathrm{OK}$ \\
\hline \multirow[t]{2}{*}{ Apparent Specific Gravity } & \multirow[t]{2}{*}{$=\mathrm{A} /(\mathrm{A}-\mathrm{C})=$} & 3.522 & 3.540 & 3.531 & \multirow{3}{*}{ OK } \\
\hline & & $\begin{array}{r}\text { Accep } \\
\text { Act }\end{array}$ & $\begin{array}{l}\text { le Range } \\
\text { Range }\end{array}$ & $\begin{array}{l}0.032 \\
0.018\end{array}$ & \\
\hline \multirow[t]{2}{*}{ Absorption, percent } & \multirow[t]{2}{*}{$=(\mathrm{B}-\mathrm{A}) / \mathrm{A} * 100=$} & $2.95 \%$ & $2.79 \%$ & $2.87 \%$ & \\
\hline & & $\begin{array}{r}\text { Accep } \\
\text { Act }\end{array}$ & $\begin{array}{l}\text { le Range } \\
\text { Range }\end{array}$ & $\begin{array}{l}0.41 \% \\
0.16 \%\end{array}$ & OK \\
\hline
\end{tabular}

Report Specific Gravity to the nearest 0.01

Report Absorption to the nearest $0.1 \%$ 
Table C.6 Summary of Bulk Specific Gravity and Absorption for Coarse Steel Slag WVU ASPHALT LAB

Bulk Specific Gravity and Absorption Coarse Aggregate

Aggregate

Date

Source

Tested By

Bulk Specific Gravity

(Oven Dry Basis)

Bulk Specific Gravity

(Saturated-Surface-Dry Basis)

Apparent Specific Gravity

Absorption, percent
Steel Slag Summary

March 5-6, 2002

IMS Steel Slag

M. Padula, D. Diaz \& A. Kincell

\begin{tabular}{|l|c|c|c|c|}
\hline 3/4" & $\mathbf{1 / 2}$ & $\mathbf{3 / 8}$ & \#4 & Fines \\
\hline \multicolumn{5}{|l|}{} \\
\hline 3.367 & 3.345 & 3.296 & 3.206 & 2.880 \\
\hline \multicolumn{5}{|l|}{} \\
\hline 3.417 & 3.400 & 3.363 & 3.298 & 3.087 \\
\hline \multicolumn{5}{|l}{} \\
\hline 3.543 & 3.540 & 3.532 & 3.531 & 3.634 \\
\hline \multicolumn{5}{|l}{} \\
\hline $1.48 \%$ & $1.65 \%$ & $2.02 \%$ & $2.87 \%$ & $7.21 \%$ \\
\hline
\end{tabular}




\section{Table C.7 Fine Steel Slag Aggregate Bulk Specific Gravity and Absorption}

\section{WVU ASPHALT LAB}

Bulk Specific Gravity and Absorption

Fine Aggregate

\begin{tabular}{ll} 
Field Sample No. & Steel Slag Fines \\
\cline { 2 - 2 } Date & March 6-7, 2002 \\
\cline { 2 - 2 } Source & IMS Steel Slag \\
\cline { 2 - 2 } Tested by & M. Padula, D. Diaz \& A. Kincell
\end{tabular}

(Recorded masses to $0.1 \mathrm{~g}$ )

$\mathrm{A}=$ Mass of oven-dry sample in air, grams (a-b)

\begin{tabular}{lll} 
A & B Average \\
\hline
\end{tabular}

\begin{tabular}{|l|l|}
\hline 464.7 & 468.5 \\
\hline
\end{tabular}

$\mathrm{a}=$ Mass of oven-dry sample and drying pan in air, grams

$b=$ Mass of drying pan, grams $----$

$\mathrm{B}=$ Mass of pycnometer filled to calibration mark

\begin{tabular}{l|l|}
658.8 & 679.8 \\
\hline
\end{tabular}
with distilled water, grams

$\mathrm{C}=$ Mass of pycnometer, sample, and water to calibration marks, grams

$\mathrm{D}=$ Mass of sturated-surface-dry sample in air, grams

Bulk Specific Gravity

$=\mathrm{A} /(\mathrm{B}+\mathrm{D}-\mathrm{C})=$

2.842

2.917

2.880

(oven dry basis)

Bulk Specific Gravity

$=\mathrm{D} /(\mathrm{B}+\mathrm{D}-\mathrm{C})=$

\begin{tabular}{l|l}
3.058 & 3.116 \\
\hline
\end{tabular}

3.087

(saturated-surface-dry basis)

Apparent Specific gravity

$$
=\mathrm{A} /(\mathrm{B}+\mathrm{A}-\mathrm{C})=
$$

3.625

Absorption, percent

$$
=(\mathrm{D}-\mathrm{A}) / \mathrm{A} * 100=
$$

\begin{tabular}{|l|l|l|}
\hline $7.60 \%$ & $6.83 \%$ & $7.21 \%$ \\
\hline
\end{tabular}

Report Specific Gravities to the nearest 0.001 Report Absorption to the nearest $0.01 \%$ 
Table C.8 Trial 1 Volumetric Data

\begin{tabular}{|c|c|}
\hline \multicolumn{2}{|c|}{$\begin{array}{l}\text { Trial } 1 \text { - Volumetrics } \\
\text { 64\% \#57 Slag \& 36\% \#10 Slag }\end{array}$} \\
\hline $\mathrm{P}_{\mathrm{b}}$ Used & $6.50 \%$ \\
\hline $\mathrm{h}_{\mathrm{des}}$ & 105.5 \\
\hline $\mathrm{h}_{\text {ini }}$ & 114.3 \\
\hline $\mathrm{G}_{\mathrm{mb}}$ & 3.003 \\
\hline $\mathrm{G}_{\mathrm{mm}}$ & 3.011 \\
\hline \multicolumn{2}{|c|}{$\% \mathrm{G}_{\mathrm{mm}, \mathrm{N} \text { des }}$} \\
\hline$\% \mathrm{G}_{\mathrm{mm}, \mathrm{N} \text { des }}$ & $99.73 \%$ \\
\hline \multicolumn{2}{|c|}{ Effective Specific Gravity $\left(\mathrm{G}_{\mathrm{SE}}\right)$} \\
\hline $\mathrm{G}_{\mathrm{SE}}$ & 3.473 \\
\hline \multicolumn{2}{|c|}{ Percent Binder Absorbed } \\
\hline $\mathrm{P}_{\mathrm{ba}}$ & $3.22 \%$ \\
\hline \multicolumn{2}{|c|}{ Percent Binder Effective } \\
\hline $\mathrm{P}_{\mathrm{bE}}$ & $3.49 \%$ \\
\hline \multicolumn{2}{|c|}{ Dust to Binder Ratio } \\
\hline $\mathrm{D}$ to $\mathrm{B}$ & 1.09 \\
\hline \multicolumn{2}{|c|}{$\% \mathrm{G}_{\mathrm{mm}, \mathrm{N} \text { ini }}$} \\
\hline$\% \mathrm{G}_{\mathrm{mm}, \mathrm{N} \text { ini }}$ & $92.01 \%$ \\
\hline \multicolumn{2}{|c|}{ Voids in Total Mix (VTM) } \\
\hline VTM & $0.27 \%$ \\
\hline \multicolumn{2}{|c|}{ Voids in the Mineral Agg. (VMA) } \\
\hline VMA & $10.41 \%$ \\
\hline \multicolumn{2}{|c|}{ Voids Filled with Asph. (VFA) } \\
\hline VFA & $97.45 \%$ \\
\hline
\end{tabular}

\begin{tabular}{|c|c|}
\hline \multicolumn{2}{|c|}{$\begin{array}{c}\text { Trial } 1 \text { - Volumetrics } \\
\text { Adjusted to 4\% Air } \\
64 \% \text { \#57 Slag \& 36\% \#10 Slag }\end{array}$} \\
\hline $\mathrm{P}_{\mathrm{b} \text { trial }}$ & $6.50 \%$ \\
\hline \multicolumn{2}{|c|}{ Percent Binder } \\
\hline $\mathrm{P}_{\mathrm{best}}$ & $5.00 \%$ \\
\hline \multicolumn{2}{|c|}{ VMA Estimate } \\
\hline VTM & $2.66 \%$ \\
\hline $\mathrm{C}$ & 0.1 \\
\hline $\mathrm{VMA}_{\text {est }}$ & $10.78 \%$ \\
\hline \multicolumn{2}{|c|}{ VFA Estimate } \\
\hline $\mathrm{VFA}_{\text {est }}$ & $62.89 \%$ \\
\hline \multicolumn{2}{|c|}{$\% \mathrm{G}_{\mathrm{mm} \text { est, Nini }}$} \\
\hline$\% \mathrm{G}_{\mathrm{mm} \text { est, Nini }}$ & $88.28 \%$ \\
\hline \multicolumn{2}{|c|}{ Dust to Binder Estimate } \\
\hline $\mathrm{D} / \mathrm{b}_{\text {est }}$ & 1.09 \\
\hline \multicolumn{2}{|c|}{ Estimated Effective \% Binder } \\
\hline $\mathrm{P}_{\mathrm{be}, \text { est }}$ & $3.50 \%$ \\
\hline \multicolumn{2}{|c|}{ Percent Binder Trials } \\
\hline$P_{b, \text { est }}-0.5 \%$ & $4.50 \%$ \\
\hline $\mathrm{Pb}$,est & $5.00 \%$ \\
\hline $\mathrm{P}_{\mathrm{b}, \mathrm{est}}+0.5 \%$ & $5.50 \%$ \\
\hline $\mathrm{P}_{\mathrm{b}, \mathrm{est}}+1.0 \%$ & $6.00 \%$ \\
\hline
\end{tabular}

\begin{tabular}{|c|c|c|c|}
\hline \multicolumn{4}{|c|}{ Superpave Criteria } \\
\hline \multicolumn{4}{|c|}{ Actual Values } \\
\hline Category & Tolerance & Values & Passing \\
\hline VTM & $\sim 4 \%$ & $0.27 \%$ & NO \\
\hline VMA & $13 \%$ min & $10.41 \%$ & NO \\
\hline VFA & $65 \%-75 \%$ & $97.45 \%$ & NO \\
\hline D/B & $0.60-1.20$ & 1.09 & YES \\
\hline
\end{tabular}

\begin{tabular}{|c|c|c|c|}
\hline \multicolumn{4}{|c|}{ Superpave Criteria } \\
\hline \multicolumn{4}{|c|}{ Theoretical Values } \\
\hline Category & Tolerance & Values & Passing \\
\hline VTM & $\sim 4 \%$ & $4.00 \%$ & YES \\
\hline VMA & $13 \% \min$ & $10.78 \%$ & NO \\
\hline VFA & $65 \%-75 \%$ & $62.89 \%$ & NO \\
\hline D/B & $0.60-1.20$ & 1.09 & YES \\
\hline
\end{tabular}


Table C.9 Trial 2 Volumetric Data

\begin{tabular}{|c|c|}
\hline \multicolumn{2}{|c|}{$\begin{array}{c}\text { Trial } 2 \text { - Volumetrics } \\
64 \% \text { \#57 Slag \& } 36 \% \text { \#10 Slag }\end{array}$} \\
\hline $\mathrm{P}_{\mathrm{b}} \mathrm{U}$ & $5.50 \%$ \\
\hline 108.8 & 108.8 \\
\hline \multicolumn{2}{|r|}{119.1} \\
\hline \multicolumn{2}{|r|}{3.036} \\
\hline \multicolumn{2}{|c|}{$\mathrm{G}_{\mathrm{mm}}$} \\
\hline \multicolumn{2}{|c|}{$\% \mathrm{G}_{\mathrm{mm}, \mathrm{N} \text { des }}$} \\
\hline$\% \mathrm{G}_{\mathrm{mm}, \mathrm{N} \text { des }}$ & $98.92 \%$ \\
\hline \multicolumn{2}{|c|}{ Effective Specific Gravity $\left(\mathrm{G}_{\mathrm{SE}}\right)$} \\
\hline $\mathrm{G}_{\mathrm{SE}}$ & 3.467 \\
\hline \multicolumn{2}{|c|}{ Percent Binder Absorbed } \\
\hline $\mathrm{P}_{\mathrm{ba}}$ & $3.17 \%$ \\
\hline \multicolumn{2}{|c|}{ Percent Binder Effective } \\
\hline $\mathrm{P}_{\mathrm{bE}}$ & $2.50 \%$ \\
\hline \multicolumn{2}{|c|}{ Dust to Binder Ratio } \\
\hline $\mathrm{D}$ to $\mathrm{B}$ & 1.52 \\
\hline \multicolumn{2}{|c|}{$\% \mathrm{G}_{\mathrm{mm}, \mathrm{N} \text { ini }}$} \\
\hline$\% \mathrm{G}_{\mathrm{mm}, \mathrm{N} \text { ini }}$ & $90.37 \%$ \\
\hline \multicolumn{2}{|c|}{ Voids in Total Mix (VTM) } \\
\hline VTM & $1.08 \%$ \\
\hline \multicolumn{2}{|c|}{ Voids in the Mineral Agg. (VMA) } \\
\hline VMA & $8.44 \%$ \\
\hline \multicolumn{2}{|c|}{ Voids Filled with Asph. (VFA) } \\
\hline VFA & $87.26 \%$ \\
\hline
\end{tabular}

\begin{tabular}{|c|c|}
\hline \multicolumn{2}{|c|}{$\begin{array}{c}\text { Trial } 2 \text { - Volumetrics } \\
\text { Adjusted to 4\% Air } \\
\text { 64\% \#57 Slag \& 36\% \#10 Slag }\end{array}$} \\
\hline $\mathrm{P}_{\mathrm{b} \text { trial }}$ & $5.17 \%$ \\
\hline \multicolumn{2}{|c|}{ Percent Binder } \\
\hline$P_{b \text { est }}$ & $4.00 \%$ \\
\hline \multicolumn{2}{|c|}{ VMA Estimate } \\
\hline VTM & $1.08 \%$ \\
\hline $\mathrm{C}$ & 0.1 \\
\hline $\mathrm{VMA}_{\text {est }}$ & $8.73 \%$ \\
\hline \multicolumn{2}{|c|}{ VFA Estimate } \\
\hline VFA $_{\text {est }}$ & $54.18 \%$ \\
\hline \multicolumn{2}{|c|}{$\% \mathrm{G}_{\mathrm{mm} \text { est, Nini }}$} \\
\hline$\% \mathrm{G}_{\mathrm{mm} \text { est, Nini }}$ & $87.44 \%$ \\
\hline \multicolumn{2}{|c|}{ Dust to Binder Estimate } \\
\hline $\mathrm{D} / \mathrm{b}_{\text {est }}$ & 1.76 \\
\hline \multicolumn{2}{|c|}{ Estimated Effective \% Binder } \\
\hline $\mathrm{P}_{\text {be, est }}$ & $2.17 \%$ \\
\hline \multicolumn{2}{|c|}{ Percent Binder Trials } \\
\hline $\mathrm{P}_{\mathrm{b}, \mathrm{est}}-0.5 \%$ & $3.50 \%$ \\
\hline $\mathrm{Pb}, \mathrm{est}$ & $4.00 \%$ \\
\hline $\mathrm{P}_{\mathrm{b}, \mathrm{est}}+0.5 \%$ & $4.50 \%$ \\
\hline $\mathrm{P}_{\mathrm{b}, \mathrm{est}}+1.0 \%$ & $5.00 \%$ \\
\hline
\end{tabular}

\begin{tabular}{|c|c|c|c|}
\hline \multicolumn{4}{|c|}{ Superpave Criteria } \\
\hline \multicolumn{4}{|c|}{ Actual Values } \\
\hline Category & Tolerance & Values & Passing \\
\hline VTM & $\sim 4 \%$ & $1.08 \%$ & NO \\
\hline VMA & $13 \% \min$ & $8.44 \%$ & NO \\
\hline VFA & $65 \%-75 \%$ & $87.26 \%$ & NO \\
\hline D/B & $0.60-1.20$ & 1.52 & NO \\
\hline
\end{tabular}

\begin{tabular}{|c|c|c|c|}
\hline \multicolumn{4}{|c|}{ Superpave Criteria } \\
\hline \multicolumn{4}{|c|}{ Theoretical Values } \\
\hline Category & Tolerance & Values & Passing \\
\hline VTM & $\sim 4 \%$ & $4.00 \%$ & YES \\
\hline VMA & $13 \% \min$ & $8.73 \%$ & NO \\
\hline VFA & $65 \%-75 \%$ & $54.18 \%$ & NO \\
\hline D/B & $0.60-1.20$ & 1.76 & NO \\
\hline
\end{tabular}


Table C.10 Trial 3 Volumetric Data

\begin{tabular}{|c|c|}
\hline \multicolumn{2}{|c|}{$\begin{array}{c}\text { Trial } 3 \text { - Volumetrics } \\
64 \% \text { \#57 Slag \& } 36 \% \text { \#10 Slag }\end{array}$} \\
\hline $\mathrm{P}_{\mathrm{b}} \mathrm{U}$ & $5.00 \%$ \\
\hline 112.4 & 112.4 \\
\hline \multicolumn{2}{|r|}{123.4} \\
\hline 3.051 & 3.051 \\
\hline \multicolumn{2}{|c|}{$\mathrm{G}_{\mathrm{mm}}$} \\
\hline \multicolumn{2}{|c|}{$\% \mathrm{G}_{\mathrm{mm}, \mathrm{N} \text { des }}$} \\
\hline$\% \mathrm{G}_{\mathrm{mm}, \mathrm{N} \text { des }}$ & $98.39 \%$ \\
\hline \multicolumn{2}{|c|}{ Effective Specific Gravity $\left(\mathrm{G}_{\mathrm{SE}}\right)$} \\
\hline $\mathrm{G}_{\mathrm{SE}}$ & 3.466 \\
\hline \multicolumn{2}{|c|}{ Percent Binder Absorbed } \\
\hline $\mathrm{P}_{\mathrm{ba}}$ & $3.17 \%$ \\
\hline \multicolumn{2}{|c|}{ Percent Binder Effective } \\
\hline $\mathrm{P}_{\mathrm{bE}}$ & $1.99 \%$ \\
\hline \multicolumn{2}{|c|}{ Dust to Binder Ratio } \\
\hline D to $\mathrm{B}$ & 1.91 \\
\hline \multicolumn{2}{|c|}{$\% \mathrm{G}_{\mathrm{mm}, \mathrm{N} \text { ini }}$} \\
\hline$\% \mathrm{G}_{\mathrm{mm}, \mathrm{N} \text { ini }}$ & $89.62 \%$ \\
\hline \multicolumn{2}{|c|}{ Voids in Total Mix (VTM) } \\
\hline VTM & $1.61 \%$ \\
\hline \multicolumn{2}{|c|}{ Voids in the Mineral Agg. (VMA) } \\
\hline VMA & $7.52 \%$ \\
\hline \multicolumn{2}{|c|}{ Voids Filled with Asph. (VFA) } \\
\hline VFA & $78.56 \%$ \\
\hline
\end{tabular}

\begin{tabular}{|c|c|}
\hline \multicolumn{2}{|c|}{$\begin{array}{c}\text { Trial } 3 \text { - Volumetrics } \\
\text { Adjusted to 4\% Air } \\
\text { 64\% \#57 Slag \& 36\% \#10 Slag }\end{array}$} \\
\hline $\mathrm{P}_{\mathrm{b} \text { trial }}$ & $5.00 \%$ \\
\hline \multicolumn{2}{|c|}{ Percent Binder } \\
\hline$P_{b \text { est }}$ & $4.05 \%$ \\
\hline \multicolumn{2}{|c|}{ VMA Estimate } \\
\hline VTM & $1.62 \%$ \\
\hline $\mathrm{C}$ & 0.1 \\
\hline $\mathrm{VMA}_{\text {est }}$ & $7.76 \%$ \\
\hline \multicolumn{2}{|c|}{ VFA Estimate } \\
\hline VFA $_{\text {est }}$ & $48.45 \%$ \\
\hline \multicolumn{2}{|c|}{$\% \mathrm{G}_{\mathrm{mm} \text { est, Nini }}$} \\
\hline$\% \mathrm{G}_{\mathrm{mm} \text { est, Nini }}$ & $87.23 \%$ \\
\hline \multicolumn{2}{|c|}{ Dust to Binder Estimate } \\
\hline $\mathrm{D} / \mathrm{b}_{\text {est }}$ & 1.91 \\
\hline \multicolumn{2}{|c|}{ Estimated Effective \%Binder } \\
\hline$P_{\text {be, est }}$ & $2.00 \%$ \\
\hline \multicolumn{2}{|c|}{ Percent Binder Trials } \\
\hline$P_{b, \text { est }}-0.5 \%$ & $3.55 \%$ \\
\hline $\mathrm{Pb}$,est & $4.05 \%$ \\
\hline $\mathrm{P}_{\mathrm{b}, \mathrm{est}}+0.5 \%$ & $4.55 \%$ \\
\hline $\mathrm{P}_{\mathrm{b}, \mathrm{est}}+1.0 \%$ & $5.05 \%$ \\
\hline
\end{tabular}

\begin{tabular}{|c|c|c|c|}
\hline \multicolumn{4}{|c|}{ Superpave Criteria } \\
\hline \multicolumn{4}{|c|}{ Actual Values } \\
\hline Category & Tolerance & Values & Passing \\
\hline VTM & $\sim 4 \%$ & $1.61 \%$ & NO \\
\hline VMA & $13 \% \min$ & $7.52 \%$ & NO \\
\hline VFA & $65 \%-75 \%$ & $78.56 \%$ & NO \\
\hline D/B & $0.60-1.20$ & 1.91 & NO \\
\hline
\end{tabular}

\begin{tabular}{|c|c|c|c|}
\hline \multicolumn{4}{|c|}{ Superpave Criteria } \\
\hline \multicolumn{4}{|c|}{ Theoretical Values } \\
\hline Category & Tolerance & Values & Passing \\
\hline VTM & $\sim 4 \%$ & $4.00 \%$ & YES \\
\hline VMA & $13 \% \min$ & $7.76 \%$ & NO \\
\hline VFA & $65 \%-75 \%$ & $48.45 \%$ & NO \\
\hline D/B & $0.60-1.20$ & 1.91 & NO \\
\hline
\end{tabular}


Table C.11 Trial 4 Volumetric Data

\begin{tabular}{|c|c|}
\hline \multicolumn{2}{|c|}{$\begin{array}{c}\text { Trial } 4 \text { - Volumetrics } \\
64 \% \text { \#57 Slag \& 36\% \#10 Slag }\end{array}$} \\
\hline $\mathrm{P}_{\mathrm{b}} \mathrm{U}$ & $4.50 \%$ \\
\hline 115.4 & 115.4 \\
\hline \multicolumn{2}{|r|}{124.9} \\
\hline 3.025 & 3.025 \\
\hline \multicolumn{2}{|r|}{3.137} \\
\hline \multicolumn{2}{|c|}{$\% \mathrm{G}_{\mathrm{mm}, \mathrm{N} \text { des }}$} \\
\hline$\% \mathrm{G}_{\mathrm{mm}, \mathrm{N} \text { des }}$ & $96.43 \%$ \\
\hline \multicolumn{2}{|c|}{ Effective Specific Gravity $\left(\mathrm{G}_{\mathrm{SE}}\right)$} \\
\hline $\mathrm{G}_{\mathrm{SE}}$ & 3.470 \\
\hline \multicolumn{2}{|c|}{ Percent Binder Absorbed } \\
\hline $\mathrm{P}_{\mathrm{ba}}$ & $3.19 \%$ \\
\hline \multicolumn{2}{|c|}{ Percent Binder Effective } \\
\hline $\mathrm{P}_{\mathrm{bE}}$ & $1.45 \%$ \\
\hline \multicolumn{2}{|c|}{ Dust to Binder Ratio } \\
\hline $\mathrm{D}$ to $\mathrm{B}$ & 2.63 \\
\hline \multicolumn{2}{|c|}{$\% \mathrm{G}_{\mathrm{mm}, \mathrm{N} \text { ini }}$} \\
\hline$\% \mathrm{G}_{\mathrm{mm}, \mathrm{N} \text { ini }}$ & $89.10 \%$ \\
\hline \multicolumn{2}{|c|}{ Voids in Total Mix (VTM) } \\
\hline VTM & $3.57 \%$ \\
\hline \multicolumn{2}{|c|}{ Voids in the Mineral Agg. (VMA) } \\
\hline VMA & $7.81 \%$ \\
\hline \multicolumn{2}{|c|}{ Voids Filled with Asph. (VFA) } \\
\hline VFA & $54.29 \%$ \\
\hline
\end{tabular}

\begin{tabular}{|c|c|}
\hline \multicolumn{2}{|c|}{$\begin{array}{c}\text { Trial } 4 \text { - Volumetrics } \\
\text { Adjusted to 4\% Air } \\
64 \% \text { \#57 Slag \& } 36 \% \text { \#10 Slag }\end{array}$} \\
\hline $\mathrm{P}_{\mathrm{b} \text { trial }}$ & $4.50 \%$ \\
\hline \multicolumn{2}{|c|}{ Percent Binder } \\
\hline $\mathrm{P}_{\mathrm{b} \text { est }}$ & $4.33 \%$ \\
\hline \multicolumn{2}{|c|}{ VMA Estimate } \\
\hline VTM & $3.56 \%$ \\
\hline $\mathrm{C}$ & 0.1 \\
\hline $\mathrm{VMA}_{\text {est }}$ & $7.85 \%$ \\
\hline \multicolumn{2}{|c|}{ VFA Estimate } \\
\hline $\mathrm{VFA}_{\text {est }}$ & $49.04 \%$ \\
\hline \multicolumn{2}{|c|}{$\% \mathrm{G}_{\mathrm{mm} \text { est, Nini }}$} \\
\hline$\% \mathrm{G}_{\mathrm{mm} \text { est }, \mathrm{Nini}}$ & $88.66 \%$ \\
\hline \multicolumn{2}{|c|}{ Dust to Binder Estimate } \\
\hline $\mathrm{D} / \mathrm{b}_{\text {est }}$ & 2.58 \\
\hline \multicolumn{2}{|c|}{ Estimated Effective \% Binder } \\
\hline $\mathrm{P}_{\text {be, est }}$ & $1.48 \%$ \\
\hline \multicolumn{2}{|c|}{ Percent Binder Trials } \\
\hline $\mathrm{P}_{\mathrm{b}, \text { est }}-0.5 \%$ & $3.83 \%$ \\
\hline $\mathrm{Pb}, \mathrm{est}$ & $4.33 \%$ \\
\hline $\mathrm{P}_{\mathrm{b}, \mathrm{est}}+0.5 \%$ & $4.83 \%$ \\
\hline $\mathrm{P}_{\mathrm{b}, \mathrm{est}}+1.0 \%$ & $5.33 \%$ \\
\hline
\end{tabular}

\begin{tabular}{|c|c|c|c|}
\hline \multicolumn{4}{|c|}{ Superpave Criteria } \\
\hline \multicolumn{4}{|c|}{ Actual Values } \\
\hline Category & Tolerance & Values & Passing \\
\hline VTM & $\sim 4 \%$ & $3.57 \%$ & YES \\
\hline VMA & $13 \% \min$ & $7.81 \%$ & NO \\
\hline VFA & $65 \%-75 \%$ & $54.29 \%$ & NO \\
\hline D/B & $0.60-1.20$ & 2.63 & NO \\
\hline
\end{tabular}

\begin{tabular}{|c|c|c|c|}
\hline \multicolumn{4}{|c|}{ Superpave Criteria } \\
\hline \multicolumn{4}{|c|}{ Theoretical Values } \\
\hline Category & Tolerance & Values & Passing \\
\hline VTM & $\sim 4 \%$ & $4.00 \%$ & YES \\
\hline VMA & $13 \% \min$ & $7.85 \%$ & NO \\
\hline VFA & $65 \%-75 \%$ & $49.04 \%$ & NO \\
\hline D/B & $0.60-1.20$ & 2.58 & NO \\
\hline
\end{tabular}


Table C.12 Trial 5 Volumetric Data

\begin{tabular}{|c|c|}
\hline \multicolumn{2}{|c|}{$\begin{array}{c}\text { Trial } 5 \text { - Volumetrics } \\
72 \% \text { \#57 Slag \& } 28 \% \text { \#10 Slag }\end{array}$} \\
\hline $\mathrm{P}_{\mathrm{b}}$ Used & $4.50 \%$ \\
\hline $\mathrm{h}_{\mathrm{des}}$ & 115.7 \\
\hline $\mathrm{h}_{\text {ini }}$ & 125.6 \\
\hline $\mathrm{G}_{\mathrm{mb}}$ & 3.005 \\
\hline $\mathrm{G}_{\mathrm{mm}}$ & 3.158 \\
\hline \multicolumn{2}{|c|}{$\% \mathrm{G}_{\mathrm{mm}, \mathrm{N} \text { des }}$} \\
\hline$\% \mathrm{G}_{\mathrm{mm}, \mathrm{N} \text { des }}$ & $95.16 \%$ \\
\hline \multicolumn{2}{|c|}{ Effective Specific Gravity $\left(\mathrm{G}_{\mathrm{SE}}\right)$} \\
\hline $\mathrm{G}_{\mathrm{SE}}$ & 3.497 \\
\hline \multicolumn{2}{|c|}{ Percent Binder Absorbed } \\
\hline $\mathrm{P}_{\mathrm{ba}}$ & $3.06 \%$ \\
\hline \multicolumn{2}{|c|}{ Percent Binder Effective } \\
\hline $\mathrm{P}_{\mathrm{bE}}$ & $1.58 \%$ \\
\hline \multicolumn{2}{|c|}{ Dust to Binder Ratio } \\
\hline $\mathrm{D}$ to $\mathrm{B}$ & 1.88 \\
\hline \multicolumn{2}{|c|}{$\% \mathrm{G}_{\mathrm{mm}, \mathrm{N} \text { ini }}$} \\
\hline$\% \mathrm{G}_{\mathrm{mm}, \mathrm{N} \text { ini }}$ & $87.65 \%$ \\
\hline \multicolumn{2}{|c|}{ Voids in Total Mix (VTM) } \\
\hline VTM & $4.84 \%$ \\
\hline \multicolumn{2}{|c|}{ Voids in the Mineral Agg. (VMA) } \\
\hline VMA & $9.43 \%$ \\
\hline \multicolumn{2}{|c|}{ Voids Filled with Asph. (VFA) } \\
\hline VFA & $48.62 \%$ \\
\hline
\end{tabular}

\begin{tabular}{|c|c|}
\hline \multicolumn{2}{|c|}{$\begin{array}{c}\text { Trial } 5 \text { - Volumetrics } \\
\text { Adjusted to 4\% Air } \\
72 \% \text { \#57 Slag \& } 28 \% \text { \#10 Slag }\end{array}$} \\
\hline $\mathrm{P}_{\mathrm{b} \text { trial }}$ & $4.50 \%$ \\
\hline \multicolumn{2}{|c|}{ Percent Binder } \\
\hline $\mathrm{P}_{\mathrm{b} \text { est }}$ & $4.84 \%$ \\
\hline \multicolumn{2}{|c|}{ VMA Estimate } \\
\hline VTM & $4.84 \%$ \\
\hline $\mathrm{C}$ & 0.1 \\
\hline $\mathrm{VMA}_{\text {est }}$ & $9.27 \%$ \\
\hline \multicolumn{2}{|c|}{ VFA Estimate } \\
\hline VFA $_{\text {est }}$ & $56.85 \%$ \\
\hline \multicolumn{2}{|c|}{$\% \mathrm{G}_{\mathrm{mm} \text { est, Nini }}$} \\
\hline$\% \mathrm{G}_{\mathrm{mm} \text { est, Nini }}$ & $88.46 \%$ \\
\hline \multicolumn{2}{|c|}{ Dust to Binder Estimate } \\
\hline $\mathrm{D} / \mathrm{b}_{\text {est }}$ & 1.62 \\
\hline \multicolumn{2}{|c|}{ Estimated Effective \% Binder } \\
\hline $\mathrm{P}_{\text {be, est }}$ & $1.82 \%$ \\
\hline \multicolumn{2}{|c|}{ Percent Binder Trials } \\
\hline$P_{b, \text { est }}-0.5 \%$ & $4.34 \%$ \\
\hline $\mathrm{Pb}$,est & $4.84 \%$ \\
\hline $\mathrm{P}_{\mathrm{b}, \mathrm{est}}+0.5 \%$ & $5.34 \%$ \\
\hline $\mathrm{P}_{\mathrm{b}, \mathrm{est}}+1.0 \%$ & $5.84 \%$ \\
\hline
\end{tabular}

\begin{tabular}{|c|c|c|c|}
\hline \multicolumn{4}{|c|}{ Superpave Criteria } \\
\hline \multicolumn{4}{|c|}{ Actual Values } \\
\hline Category & Tolerance & Values & Passing \\
\hline VTM & $\sim 4 \%$ & $4.84 \%$ & YES \\
\hline VMA & $13 \% \min$ & $9.43 \%$ & NO \\
\hline VFA & $65 \%-75 \%$ & $48.62 \%$ & NO \\
\hline D/B & $0.60-1.20$ & 1.88 & NO \\
\hline
\end{tabular}

\begin{tabular}{|c|c|c|c|}
\hline \multicolumn{4}{|c|}{ Superpave Criteria } \\
\hline \multicolumn{4}{|c|}{ Theoretical Values } \\
\hline Category & Tolerance & Values & Passing \\
\hline VTM & $\sim 4 \%$ & $4.00 \%$ & YES \\
\hline VMA & $13 \% \min$ & $9.27 \%$ & NO \\
\hline VFA & $65 \%-75 \%$ & $56.85 \%$ & NO \\
\hline D/B & $0.60-1.20$ & 1.62 & NO \\
\hline
\end{tabular}


Table C.13 Trial 6 Volumetric Data

\begin{tabular}{|c|c|}
\hline \multicolumn{2}{|c|}{$\begin{array}{c}\text { Trial } 6 \text { - Volumetrics } \\
\text { Agg. Blend from Literature }\end{array}$} \\
\hline $\mathrm{P}_{\mathrm{b}}$ Used & $7.00 \%$ \\
\hline $\mathrm{h}_{\mathrm{des}}$ & 115.5 \\
\hline $\mathrm{h}_{\text {ini }}$ & 120.0 \\
\hline $\mathrm{G}_{\mathrm{mb}}$ & 2.946 \\
\hline $\mathrm{G}_{\mathrm{mm}}$ & 2.950 \\
\hline \multicolumn{2}{|c|}{$\% \mathrm{G}_{\mathrm{mm}, \mathrm{N} \text { des }}$} \\
\hline$\% \mathrm{G}_{\mathrm{mm}, \mathrm{N} \text { des }}$ & $99.86 \%$ \\
\hline \multicolumn{2}{|c|}{ Effective Specific Gravity $\left(\mathrm{G}_{\mathrm{SE}}\right)$} \\
\hline $\mathrm{G}_{\mathrm{SE}}$ & 3.429 \\
\hline \multicolumn{2}{|c|}{ Percent Binder Absorbed } \\
\hline $\mathrm{P}_{\mathrm{ba}}$ & $1.20 \%$ \\
\hline \multicolumn{2}{|c|}{ Percent Binder Effective } \\
\hline $\mathrm{P}_{\mathrm{bE}}$ & $5.88 \%$ \\
\hline \multicolumn{2}{|c|}{ Dust to Binder Ratio } \\
\hline $\mathrm{D}$ to $\mathrm{B}$ & 1.02 \\
\hline \multicolumn{2}{|c|}{$\% \mathrm{G}_{\mathrm{mm}, \mathrm{N} \text { ini }}$} \\
\hline$\% \mathrm{G}_{\mathrm{mm}, \mathrm{N} \text { ini }}$ & $96.12 \%$ \\
\hline \multicolumn{2}{|c|}{ Voids in Total Mix (VTM) } \\
\hline VTM & $0.14 \%$ \\
\hline \multicolumn{2}{|c|}{ Voids in the Mineral Agg. (VMA) } \\
\hline VMA & $16.90 \%$ \\
\hline \multicolumn{2}{|c|}{ Voids Filled with Asph. (VFA) } \\
\hline VFA & $99.20 \%$ \\
\hline
\end{tabular}

\begin{tabular}{|c|c|}
\hline \multicolumn{2}{|c|}{$\begin{array}{c}\text { Trial } 6 \text { - Volumetrics } \\
\text { Adjusted to 4\% Air } \\
\text { Agg. Blend from Literature }\end{array}$} \\
\hline $\mathrm{P}_{\mathrm{b} \text { trial }}$ & $7.00 \%$ \\
\hline \multicolumn{2}{|c|}{ Percent Binder } \\
\hline $\mathrm{P}_{\mathrm{b} \text { est }}$ & $5.46 \%$ \\
\hline \multicolumn{2}{|c|}{ VMA Estimate } \\
\hline VTM & $1.54 \%$ \\
\hline $\mathrm{C}$ & 0.1 \\
\hline $\mathrm{VMA}_{\text {est }}$ & $17.31 \%$ \\
\hline \multicolumn{2}{|c|}{ VFA Estimate } \\
\hline VFA $_{\text {est }}$ & $76.89 \%$ \\
\hline \multicolumn{2}{|c|}{$\% \mathrm{G}_{\mathrm{mm} \text { est, Nini }}$} \\
\hline$\% \mathrm{G}_{\mathrm{mm} \text { est, Nini }}$ & $92.26 \%$ \\
\hline \multicolumn{2}{|c|}{ Dust to Binder Estimate } \\
\hline $\mathrm{D} / \mathrm{b}_{\text {est }}$ & 1.09 \\
\hline \multicolumn{2}{|c|}{ Estimated Effective \% Binder } \\
\hline $\mathrm{P}_{\text {be, est }}$ & $5.50 \%$ \\
\hline \multicolumn{2}{|c|}{ Percent Binder Trials } \\
\hline$P_{b, \text { est }}-0.5 \%$ & $4.96 \%$ \\
\hline $\mathrm{Pb}$,est & $5.49 \%$ \\
\hline $\mathrm{P}_{\mathrm{b}, \mathrm{est}}+0.5 \%$ & $5.96 \%$ \\
\hline $\mathrm{P}_{\mathrm{b}, \mathrm{est}}+1.0 \%$ & $6.46 \%$ \\
\hline
\end{tabular}

\begin{tabular}{|c|c|c|c|}
\hline \multicolumn{4}{|c|}{ Superpave Criteria } \\
\hline \multicolumn{4}{|c|}{ Actual Values } \\
\hline Category & Tolerance & Values & Passing \\
\hline VTM & $\sim 4 \%$ & $0.14 \%$ & NO \\
\hline VMA & $13 \% \min$ & $16.90 \%$ & YES \\
\hline VFA & $65 \%-75 \%$ & $99.20 \%$ & NO \\
\hline D/B & $0.60-1.20$ & 1.02 & YES \\
\hline
\end{tabular}

\begin{tabular}{|c|c|c|c|}
\hline \multicolumn{4}{|c|}{ Superpave Criteria } \\
\hline \multicolumn{4}{|c|}{ Theoretical Values } \\
\hline Category & Tolerance & Values & Passing \\
\hline VTM & $\sim 4 \%$ & $4.00 \%$ & YES \\
\hline VMA & $13 \% \min$ & $17.31 \%$ & YES \\
\hline VFA & $65 \%-75 \%$ & $76.89 \%$ & NO \\
\hline D/B & $0.60-1.20$ & 1.09 & YES \\
\hline
\end{tabular}


Table C.14 Trial 6.1 Volumetric Data

\begin{tabular}{|c|c|}
\hline \multicolumn{2}{|c|}{$\begin{array}{c}\text { Trial 6.1 - Volumetrics (Retrial) } \\
\text { Agg. Blend from Literature }\end{array}$} \\
\hline $\mathrm{P}_{\mathrm{b}}$ Used & $6.50 \%$ \\
\hline $\mathrm{h}_{\mathrm{des}}$ & 115.3 \\
\hline $\mathrm{h}_{\mathrm{ini}}$ & 122.5 \\
\hline $\mathrm{G}_{\mathrm{mb}}$ & 2.963 \\
\hline $\mathrm{G}_{\mathrm{mm}}($ Estimated $)$ & 2.982 \\
\hline \multicolumn{2}{|c|}{$\% \mathrm{G}_{\mathrm{mm}, \mathrm{N} \text { des }}$} \\
\hline$\% \mathrm{G}_{\mathrm{mm}, \mathrm{N} \text { des }}$ & $99.36 \%$ \\
\hline \multicolumn{2}{|c|}{ Effective Specific Gravity $\left(\mathrm{G}_{\mathrm{SE}}\right)$} \\
\hline $\mathrm{G}_{\mathrm{SE}}$ & 3.432 \\
\hline \multicolumn{2}{|c|}{ Percent Binder Absorbed } \\
\hline $\mathrm{P}_{\mathrm{ba}}$ & $1.23 \%$ \\
\hline \multicolumn{2}{|c|}{ Percent Binder Effective } \\
\hline $\mathrm{P}_{\mathrm{bE}}$ & $5.35 \%$ \\
\hline \multicolumn{2}{|c|}{ Dust to Binder Ratio } \\
\hline $\mathrm{D}$ to $\mathrm{B}$ & 1.21 \\
\hline \multicolumn{2}{|c|}{$\% \mathrm{G}_{\mathrm{mm}, \mathrm{N} \text { ini }}$} \\
\hline$\% \mathrm{G}_{\mathrm{mm}, \mathrm{N} \text { ini }}$ & $93.52 \%$ \\
\hline \multicolumn{2}{|c|}{ Voids in Total Mix (VTM) } \\
\hline VTM & $0.64 \%$ \\
\hline \multicolumn{2}{|c|}{ Voids in the Mineral Agg. (VMA) } \\
\hline VMA & $16.00 \%$ \\
\hline \multicolumn{2}{|c|}{ Voids Filled with Asph. (VFA) } \\
\hline VFA & $96.02 \%$ \\
\hline
\end{tabular}

\begin{tabular}{|c|c|}
\hline \multicolumn{2}{|c|}{$\begin{array}{c}\text { Trial 6.1 - Volumetrics (Retrial) } \\
\text { Adjusted to 4\% Air } \\
\text { Agg. Blend from Literature }\end{array}$} \\
\hline $\mathrm{P}_{\mathrm{b} \text { trial }}$ & $6.50 \%$ \\
\hline \multicolumn{2}{|c|}{ Percent Binder } \\
\hline$P_{b \text { est }}$ & $5.15 \%$ \\
\hline \multicolumn{2}{|c|}{ VMA Estimate } \\
\hline VTM & $0.63 \%$ \\
\hline $\mathrm{C}$ & 0.1 \\
\hline $\mathrm{VMA}_{\mathrm{est}}$ & $16.31 \%$ \\
\hline \multicolumn{2}{|c|}{ VFA Estimate } \\
\hline VFA $_{\text {est }}$ & $75.48 \%$ \\
\hline \multicolumn{2}{|c|}{$\% \mathrm{G}_{\mathrm{mm} \text { est, Nini }}$} \\
\hline$\% \mathrm{G}_{\mathrm{mm} \text { est, Nini }}$ & $90.16 \%$ \\
\hline \multicolumn{2}{|c|}{ Dust to Binder Estimate } \\
\hline $\mathrm{D} / \mathrm{b}_{\text {est }}$ & 1.19 \\
\hline \multicolumn{2}{|c|}{ Estimated Effective \%t Binder } \\
\hline $\mathrm{P}_{\mathrm{be}, \text { est }}$ & $5.03 \%$ \\
\hline \multicolumn{2}{|c|}{ Percent Binder Trials } \\
\hline$P_{b, \text { est }}-0.5 \%$ & $4.65 \%$ \\
\hline $\mathrm{Pb}, \mathrm{est}$ & $5.15 \%$ \\
\hline $\mathrm{P}_{\mathrm{b}, \mathrm{est}}+0.5 \%$ & $5.65 \%$ \\
\hline $\mathrm{P}_{\mathrm{b}, \text { est }}+1.0 \%$ & $6.15 \%$ \\
\hline
\end{tabular}

\begin{tabular}{|c|c|c|c|}
\hline \multicolumn{4}{|c|}{ Superpave Criteria } \\
\hline \multicolumn{4}{|c|}{ Actual Values } \\
\hline Category & Tolerance & Values & Passing \\
\hline VTM & $\sim 4 \%$ & $0.64 \%$ & NO \\
\hline VMA & $13 \% \min$ & $16.00 \%$ & YES \\
\hline VFA & $65 \%-75 \%$ & $96.02 \%$ & NO \\
\hline D/B & $0.60-1.20$ & 1.21 & NO \\
\hline
\end{tabular}

\begin{tabular}{|c|c|c|c|}
\hline \multicolumn{4}{|c|}{ Superpave Criteria } \\
\hline \multicolumn{4}{|c|}{ Theoretical Values } \\
\hline Category & Tolerance & Values & Passing \\
\hline VTM & $\sim 4 \%$ & $4.00 \%$ & YES \\
\hline VMA & $13 \% \min$ & $16.31 \%$ & YES \\
\hline VFA & $65 \%-75 \%$ & $75.48 \%$ & NO \\
\hline D/B & $0.60-1.20$ & 1.19 & YES \\
\hline
\end{tabular}


Table C.15 Trial 1 Pill and Rice Test Data and Calculations

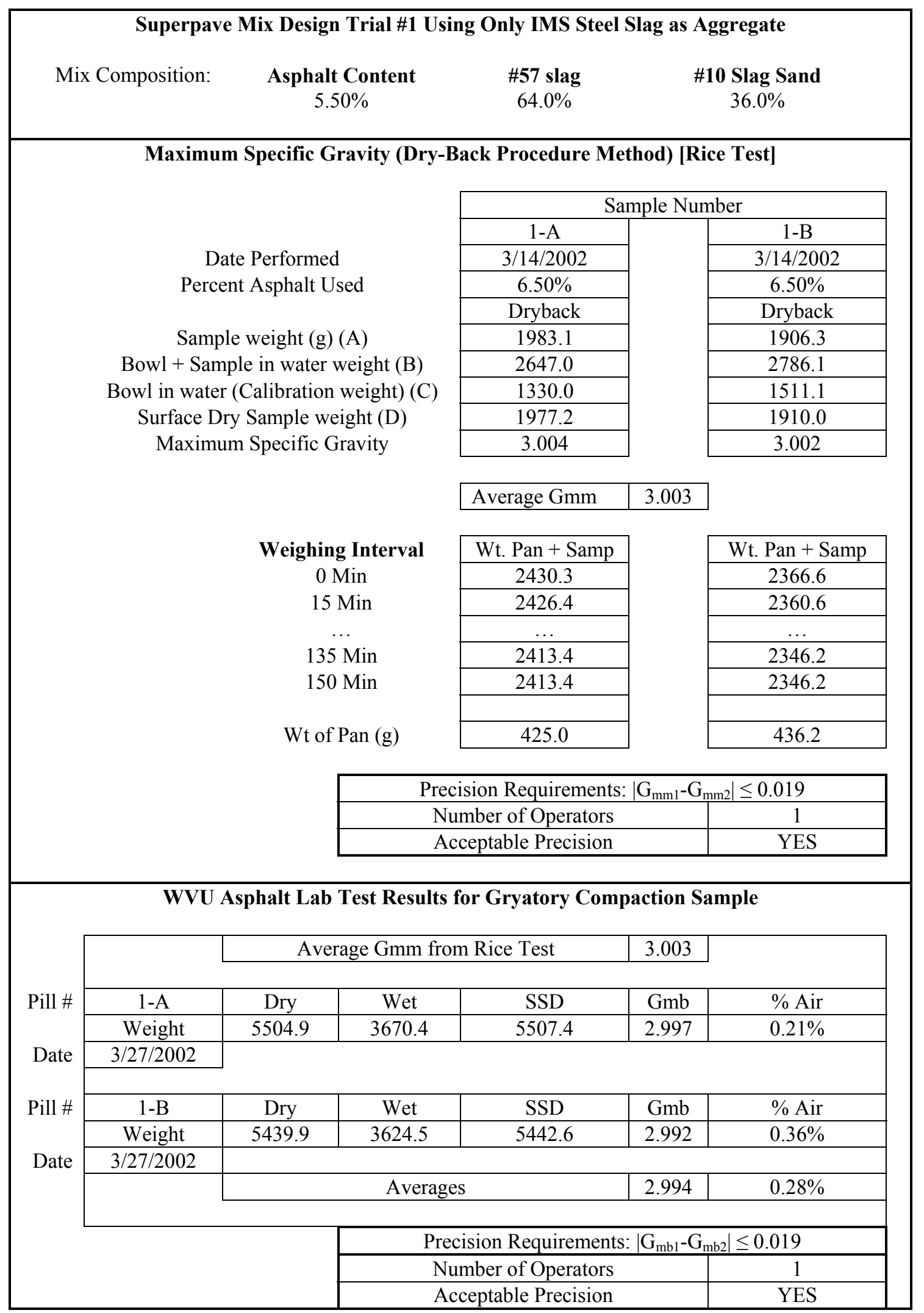


Table C.16 Trial 2 Pill and Rice Test Data and Calculations

Superpave Mix Design Trial \#2 Using Only IMS Steel Slag as Aggregate

Mix Composition:

Asphalt Content

$5.50 \%$

\#57 slag

\#10 Slag Sand

$64.0 \%$

$36.0 \%$

\section{Maximum Specific Gravity (Rice Test)}

Date Performed

Percent Asphalt Used

Sample weight (g) (A)

Bowl + Sample in water weight (B)

Bowl in water (Calibration weight) (C)

Maximum Specific Gravity

\begin{tabular}{|c|c|}
\hline \multicolumn{2}{|c|}{ Sample Number } \\
\hline 2 2-A & \\
\cline { 1 - 1 } $3 / 29 / 2002$ & $2-\mathrm{B}$ \\
\hline $5.50 \%$ & $3 / 29 / 2002$ \\
\cline { 1 - 1 } Non-dryback & $5.50 \%$ \\
\cline { 1 - 1 } 1947.7 & Non-dryback \\
2643.2 & 1926.0 \\
1330.0 & 2806.6 \\
3.070 & 1511.1 \\
& 3.055 \\
\end{tabular}

Average Gmm 3.062

Precision Requirements: $\left|\mathrm{G}_{\mathrm{mm} 1}-\mathrm{G}_{\mathrm{mm} 2}\right| \leq 0.019$

Number of Operators 1

Acceptable Precision YES

\section{WVU Asphalt Lab Test Results for Gryatory Compaction Sample}

\begin{tabular}{|c|c|c|c|c|c|c|}
\hline \multirow[b]{2}{*}{ Pill \# } & & \multicolumn{3}{|c|}{ Average Gmm from Rice Test } & 3.062 & \multirow[b]{2}{*}{$\%$ Air } \\
\hline & $2-\mathrm{A}$ & Dry & Wet & SSD & $\mathrm{Gmb}$ & \\
\hline \multirow[b]{2}{*}{ Date } & Weight & 5633.4 & 3780.1 & 5638.7 & 3.031 & $1.02 \%$ \\
\hline & $3 / 29 / 2002$ & & & & & \\
\hline \multirow[t]{2}{*}{ Pill \# } & $2-\mathrm{B}$ & Dry & Wet & SSD & $\mathrm{Gmb}$ & $\%$ Air \\
\hline & Weight & 5623.1 & 3779.1 & 5627.7 & 3.042 & $0.67 \%$ \\
\hline \multirow[t]{2}{*}{ Date } & $3 / 29 / 2002$ & & & & & \\
\hline & & \multicolumn{3}{|c|}{ Averages } & 3.036 & $0.84 \%$ \\
\hline
\end{tabular}

Precision Requirements: $\left|\mathrm{G}_{\mathrm{mb} 1}-\mathrm{G}_{\mathrm{mb} 2}\right| \leq 0.019$

Number of Operators

Acceptable Precision

YES


Table C.17 Trial 3 Pill and Rice Test Data and Calculations

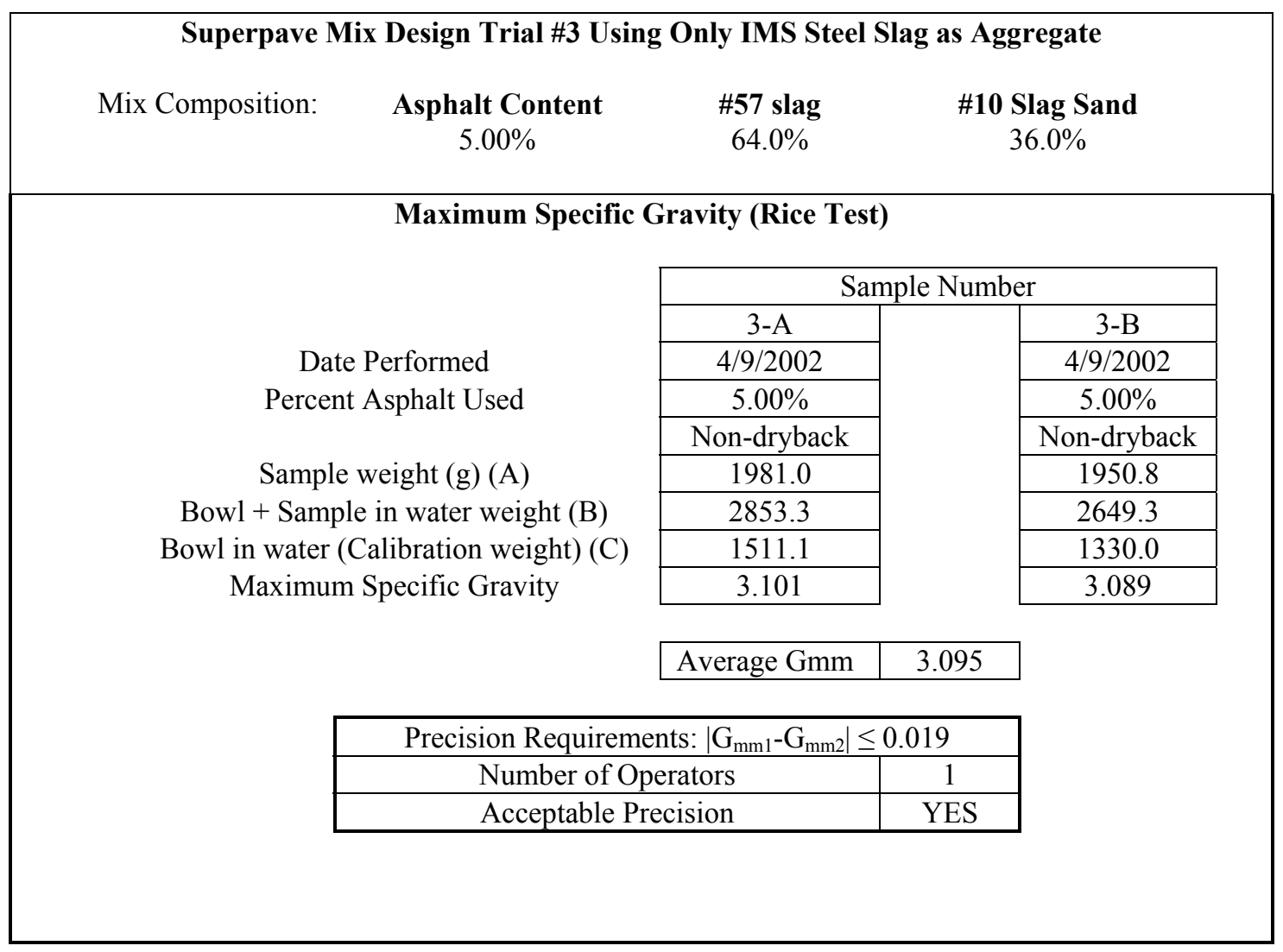

\begin{tabular}{|c|c|c|c|c|c|c|}
\hline \multicolumn{7}{|c|}{ WVU Asphalt Lab Test Results for Gryatory Compaction Sample } \\
\hline \multirow[b]{2}{*}{ Pill \# } & & \multicolumn{3}{|c|}{ Average Gmm from Rice Test } & 3.095 & \\
\hline & $3-\mathrm{A}$ & Dry & Wet & SSD & $\mathrm{Gmb}$ & $\%$ Air \\
\hline \multirow{3}{*}{$\begin{array}{l}\text { Date } \\
\text { Pill \# }\end{array}$} & Weight & 5804.9 & 3907.6 & 5815.2 & 3.043 & $1.68 \%$ \\
\hline & $4 / 9 / 2002$ & & & & & \\
\hline & 3-B & Dry & Wet & SSD & Gmb & $\%$ Air \\
\hline \multirow{6}{*}{ Date } & Weight & 5732.6 & 3873.8 & 5746.5 & 3.061 & $1.10 \%$ \\
\hline & $4 / 9 / 2002$ & & & & & \\
\hline & & \multicolumn{3}{|c|}{ Averages } & 3.052 & $1.39 \%$ \\
\hline & & \multicolumn{4}{|c|}{ Precision Requirements: $\left|\mathrm{G}_{\mathrm{mb} 1}-\mathrm{G}_{\mathrm{mb} 2}\right| \leq 0.019$} & \\
\hline & & \multicolumn{3}{|c|}{ Number of Operators } & 1 & \\
\hline & & \multicolumn{3}{|c|}{ Acceptable Precision } & YES & \\
\hline
\end{tabular}


Table C.18 Trial 4 Pill and Rice Test Data and Calculations

\begin{tabular}{|c|c|c|c|c|}
\hline \multicolumn{5}{|c|}{ Superpave Mix Design Trial \#4 Using Only IMS Steel Slag as Aggregate } \\
\hline Mix Composition: & $\begin{array}{c}\text { Asphalt Content } \\
4.50 \%\end{array}$ & $\begin{array}{c}\# 57 \text { slag } \\
64.0 \%\end{array}$ & \multicolumn{2}{|c|}{$\begin{array}{c}\text { \#10 Slag Sand } \\
36.0 \%\end{array}$} \\
\hline \multicolumn{5}{|c|}{ Maximum Specific Gravity (Rice Test) } \\
\hline \multirow{9}{*}{\multicolumn{2}{|c|}{$\begin{array}{c}\text { Date Performed } \\
\text { Percent Asphalt Used } \\
\text { Sample weight (g) (A) } \\
\text { Bowl + Sample in water weight (B) } \\
\text { Bowl in water (Calibration weight) (C) } \\
\text { Maximum Specific Gravity }\end{array}$}} & \multicolumn{3}{|c|}{ Sample Number } \\
\hline & & \multicolumn{3}{|c|}{ sample Number } \\
\hline & & $4 / 16 / 2002$ & & $4 / 16 / 2002$ \\
\hline & & $4.50 \%$ & & $4.50 \%$ \\
\hline & & Non-dryback & & Non-dryback \\
\hline & & 1972.4 & & 1965.2 \\
\hline & & 2855.7 & & 2667.9 \\
\hline & & 1511.1 & & 1330.0 \\
\hline & & 3.142 & & 3.133 \\
\hline & & Average Gmm & 3.137 & \\
\hline & Precision Requirem & ts: $\left|\mathrm{G}_{\mathrm{mm} 1}-\mathrm{G}_{\mathrm{mm} 2}\right| \leq$ & 019 & \\
\hline & Number of & erators & 1 & \\
\hline & Acceptable & ecision & YES & \\
\hline
\end{tabular}

\begin{tabular}{|c|c|c|c|c|c|c|}
\hline \multicolumn{7}{|c|}{ WVU Asphalt Lab Test Results for Gryatory Compaction Sample } \\
\hline \multirow{3}{*}{ Pill \# } & & \multicolumn{3}{|c|}{ Average Gmm from Rice Test } & 3.137 & \multirow[b]{2}{*}{$\%$ Air } \\
\hline & $4 \mathrm{~A}$ & Dry & Wet & SSD & $\mathrm{Gmb}$ & \\
\hline & Weight & 5813.5 & 3916.6 & 5834.5 & 3.031 & $3.38 \%$ \\
\hline \multirow{3}{*}{$\begin{array}{l}\text { Date } \\
\text { Pill \# }\end{array}$} & $4 / 16 / 2002$ & & & & & \\
\hline & $4 \mathrm{~B}$ & Dry & Wet & SSD & $\mathrm{Gmb}$ & $\%$ Air \\
\hline & Weight & 5815.5 & 3917.3 & 5843.1 & 3.020 & $3.75 \%$ \\
\hline \multirow[t]{5}{*}{ Date } & $4 / 16 / 2002$ & & & & & \\
\hline & & \multicolumn{3}{|c|}{ Averages } & 3.025 & $3.56 \%$ \\
\hline & & \multicolumn{4}{|c|}{ Precision Requirements: $\left|\mathrm{G}_{\mathrm{mb} 1}-\mathrm{G}_{\mathrm{mb} 2}\right| \leq 0.019$} & \\
\hline & & \multicolumn{3}{|c|}{ Number of Operators } & 1 & \\
\hline & & \multicolumn{3}{|c|}{ Acceptable Precision } & YES & \\
\hline
\end{tabular}


Table C.19 Trial 5 Pill and Rice Test Data and Calculations

Superpave Mix Design Trial \#5 Using Only IMS Steel Slag as Aggregate

Mix Composition:

Asphalt Content

\#57 slag

\#10 Slag Sand

$4.50 \%$

$72.0 \%$

$28.0 \%$

\section{Maximum Specific Gravity (Rice Test)}

Date Performed

Percent Asphalt Used

Sample weight (g) (A)

Bowl + Sample in water weight (B)

Bowl in water (Calibration weight) (C)

Maximum Specific Gravity

\begin{tabular}{|c|c|}
\hline \multicolumn{2}{|c|}{ Sample Number } \\
\hline $5-A$ & $5-B$ \\
\hline $5 / 8 / 2002$ & $5 / 8 / 2002$ \\
\hline $4.50 \%$ & $4.50 \%$ \\
\hline Non-dryback & Non-dryback \\
\hline 1973.4 & 1973.2 \\
\hline 2860.8 & 2857.9 \\
\hline 1511.1 & 1511.1 \\
\hline 3.164 & 3.150 \\
\hline
\end{tabular}

\section{\begin{tabular}{|l|l|}
\hline Average Gmm & 3.157 \\
\hline
\end{tabular}}

Precision Requirements: $\left|\mathrm{G}_{\mathrm{mm} 1}-\mathrm{G}_{\mathrm{mm} 2}\right| \leq 0.019$ Number of Operators

Acceptable Precision

1

YES

WVU Asphalt Lab Test Results for Gryatory Compaction Sample

\begin{tabular}{|c|c|c|c|c|c|c|}
\hline \multirow{3}{*}{ Pill \# } & & \multicolumn{3}{|c|}{ Average Gmm from Rice Test } & 3.157 & \multirow[b]{2}{*}{$\%$ Air } \\
\hline & $5 \mathrm{~A}$ & Dry & Wet & SSD & $\mathrm{Gmb}$ & \\
\hline & Weight & 5592.4 & 3755.8 & 5627.6 & 2.988 & $5.36 \%$ \\
\hline Date & $5 / 8 / 2002$ & & & & & \\
\hline \multirow[t]{2}{*}{ Pill \# } & $5 B$ & Dry & Wet & SSD & Gmb & $\%$ Air \\
\hline & Weight & 5635.3 & 3800.8 & 5665.3 & 3.022 & $4.26 \%$ \\
\hline \multirow[t]{2}{*}{ Date } & $5 / 8 / 2002$ & & & & & \\
\hline & & \multicolumn{3}{|c|}{ Averages } & 3.005 & $4.81 \%$ \\
\hline
\end{tabular}

Precision Requirements: $\left|\mathrm{G}_{\mathrm{mm} 1}-\mathrm{G}_{\mathrm{mm} 2}\right| \leq 0.019$ Number of Operators Acceptable Precision

1


Table C.20 Trial 6 Pill and Rice Test Data and Calculations

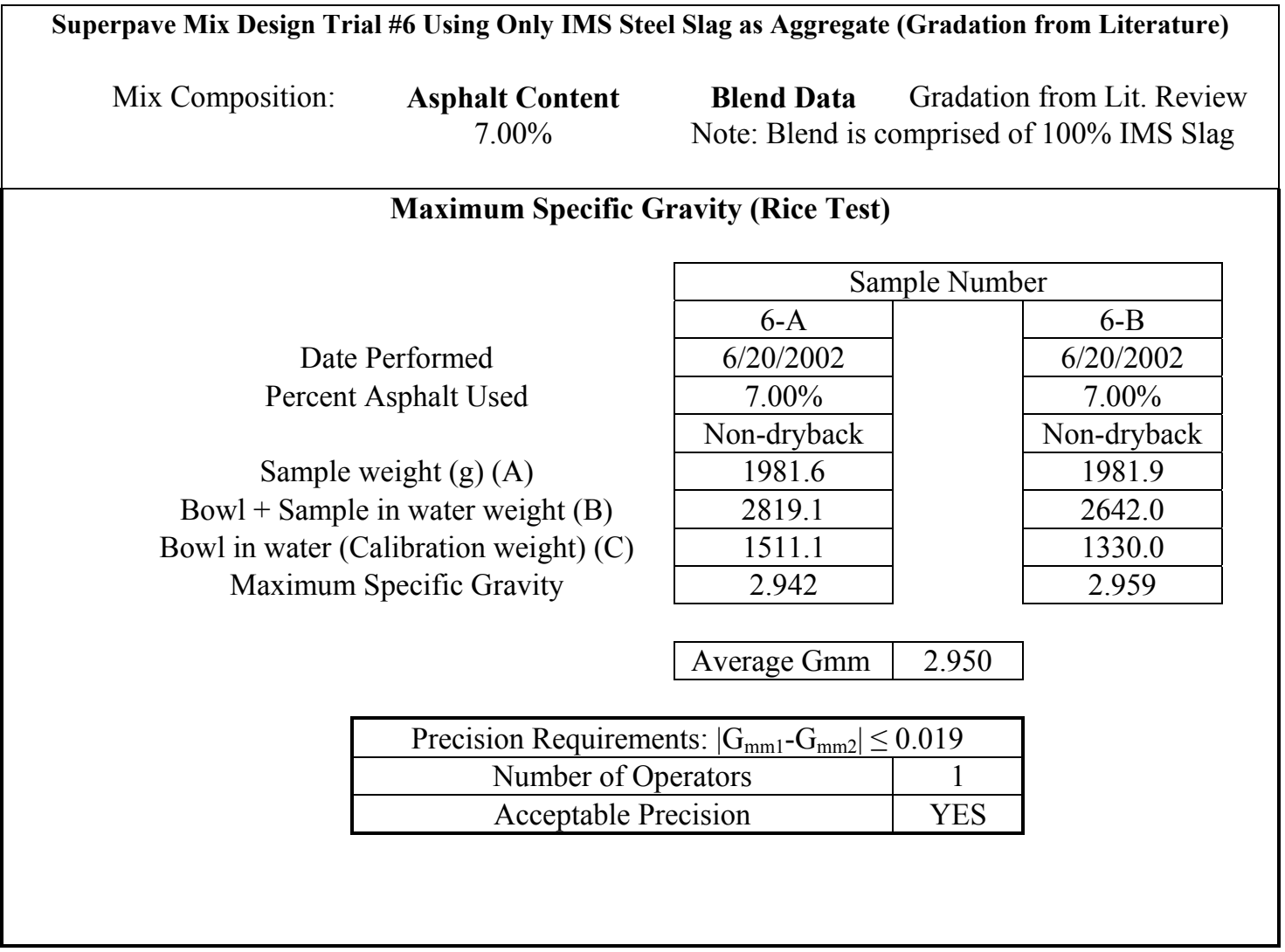

WVU Asphalt Lab Test Results for Gryatory Compaction Sample

\begin{tabular}{|c|c|c|c|c|c|c|}
\hline \multirow{3}{*}{ Pill \# } & \multirow[b]{2}{*}{$6 \mathrm{~A} 1$} & \multicolumn{3}{|c|}{ Average Gmm from Rice Test } & 2.950 & \multirow[b]{2}{*}{$\%$ Air } \\
\hline & & \multirow{2}{*}{$\frac{\text { Dry }}{5901.5}$} & \multirow{2}{*}{$\begin{array}{c}\text { Wet } \\
3904.8 \\
\end{array}$} & \multirow{2}{*}{$\begin{array}{c}\text { SSD } \\
5907.2 \\
\end{array}$} & \multirow{2}{*}{$\begin{array}{l}\text { Gmb } \\
2.947\end{array}$} & \\
\hline & Weight & & & & & $0.10 \%$ \\
\hline Date & $6 / 26 / 2002$ & & & & & \\
\hline \multirow{2}{*}{ Pill \# } & $6 \mathrm{~A} 2$ & Dry & Wet & SSD & $\mathrm{Gmb}$ & $\%$ Air \\
\hline & Weight & 5896.3 & 3898.6 & 5901.4 & 2.944 & $0.21 \%$ \\
\hline \multirow[t]{2}{*}{ Date } & $6 / 26 / 2002$ & & & & & \\
\hline & & \multicolumn{3}{|c|}{ Averages } & 2.946 & $0.15 \%$ \\
\hline
\end{tabular}

Precision Requirements: $\left|\mathrm{G}_{\mathrm{mm} 1}-\mathrm{G}_{\mathrm{mm} 2}\right| \leq 0.019$

Number of Operators

Acceptable Precision

1


Table C.21 Trial 6.1 Pill and Rice Test Data and Calculations

\section{Superpave Mix Design Trial \#6.1 Retrial of Trial 6 (To confirm data)}

Mix Composition: Asphalt Content

Blend Data Gradation from Lit. Review $7.00 \%$ Note: Blend is comprised of $100 \%$ IMS Slag

Maximum Specific Gravity (Rice Test)

Date Performed

Percent Asphalt Used

Sample weight (g) (A)

Bowl + Sample in water weight $(B)$

Bowl in water (Calibration weight) (C)

Maximum Specific Gravity

\begin{tabular}{|c|c|}
\hline \multicolumn{2}{|c|}{ Sample Number } \\
\hline & \\
\hline & \\
\hline & \\
\hline 0.0 & 0.0 \\
\hline 0.0 & 0.0 \\
\hline 0.0 & 0.0 \\
\hline 0.000 & 0.000 \\
\hline
\end{tabular}

\begin{tabular}{|l|l|}
\hline Average Gmm & 2.982 \\
\hline
\end{tabular}

Note: $\mathrm{G}_{\mathrm{mm}}$ value estimated

from aggregate data

\begin{tabular}{|c|c|}
\hline Precision Requirements: $\left|\mathrm{G}_{\mathrm{mm} 1}-\mathrm{G}_{\mathrm{mm} 2}\right| \leq 0.019$ \\
\hline Number of Operators & N/A \\
\hline Acceptable Precision & N/A \\
\hline
\end{tabular}

WVU Asphalt Lab Test Results for Gryatory Compaction Sample

\begin{tabular}{|c|c|c|c|c|c|c|}
\hline \multirow{3}{*}{ Pill \# } & & \multicolumn{3}{|c|}{ Average Gmm from Rice Test } & 2.982 & \multirow[b]{2}{*}{$\%$ Air } \\
\hline & $6.1 \mathrm{~A} 1$ & Dry & Wet & SSD & Gmb & \\
\hline & Weight & 5907.7 & 3924.7 & 5915.9 & 2.967 & $0.51 \%$ \\
\hline Date & $6 / 28 / 2002$ & & & & & \\
\hline \multirow{2}{*}{ Pill \# } & $6.1 \mathrm{~A} 2$ & Dry & Wet & SSD & $\mathrm{Gmb}$ & $\%$ Air \\
\hline & Weight & 5929.3 & 3932.9 & 5936.4 & 2.959 & $0.76 \%$ \\
\hline \multirow[t]{2}{*}{ Date } & $6 / 28 / 2002$ & & & & & \\
\hline & & \multicolumn{3}{|c|}{ Averages } & 2.963 & $0.63 \%$ \\
\hline
\end{tabular}

\begin{tabular}{|c|c|}
\hline Precision Requirements: $\left|\mathrm{G}_{\mathrm{mm} 1}-\mathrm{G}_{\mathrm{mm} 2}\right| \leq 0.019$ \\
\hline Number of Operators & 1 \\
\hline Acceptable Precision & YES \\
\hline
\end{tabular}


Table C.22 Rut Testing Results

WU Asphalt Lab Test Results for Creation of Samples for Rut Testing

\begin{tabular}{|c|c|c|c|}
\hline \multicolumn{4}{|c|}{ Maximum Specific Gravity (Rice Test) } \\
\hline \multirow{4}{*}{$\begin{array}{l}\text { Date Performed } \\
\text { Percent Asphalt Used }\end{array}$} & Rut Rice\#1 & & Rut Rice \#2 \\
\hline & $6 / 10 / 2002$ & & $6 / 10 / 2002$ \\
\hline & $4.50 \%$ & & $4.50 \%$ \\
\hline & Non-dryback & & Non-dryback \\
\hline \multirow{5}{*}{$\begin{array}{c}\text { Sample weight }(\mathrm{g})(\mathrm{A}) \\
\text { Bow + Sample in water weight }(\mathrm{B}) \\
\text { Bow in water (Calibration weight) }(\mathrm{C}) \\
\text { Maximum Specific Gravity }\end{array}$} & 1981.2 & & 1981.7 \\
\hline & 2870.4 & & 2686.5 \\
\hline & 1511.1 & & 1330.0 \\
\hline & 3.186 & & 3.170 \\
\hline & Average $\mathrm{Gmm}$ & 3.178 & \\
\hline
\end{tabular}

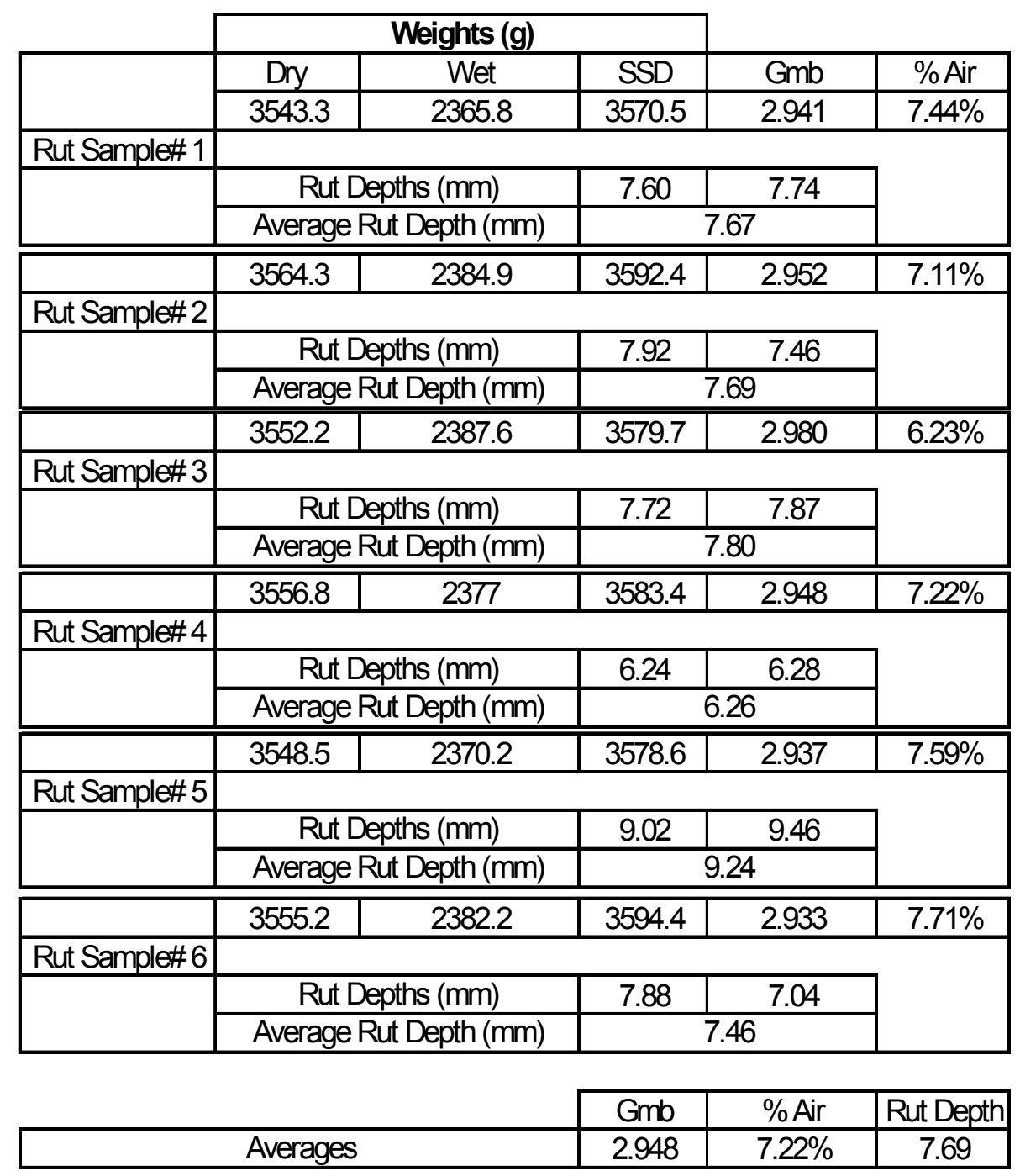




\section{VITA}

Martin Felix Padula was born on November 22, 1977 in Detroit, Michigan, the son of Donald and Ann Padula. In 1983 he moved with his family to Fairmont, West Virginia, where he received his primary and secondary education. After completing his work at East Fairmont High School in 1996, he studied Physics and Business at West Virginia Wesleyan College. He earned a Bachelor of Science degree with honors in Business Administration from WVWC in 2000, with minors in Physics, Mathematics, and Economics. Upon graduation, he enrolled in the B.S. program in Civil Engineering at West Virginia University, completing the degree in May 2002, graduating Magna Cum Laude. After 8 months of intense graduate work, he finished his Master of Science degree from WVU in December 2002. He plans to pursue a career as a professional civil engineer.

Permanent Address: Rt. 4 Box 576B

Fairmont, WV 26554

This thesis was created and typed by Martin Padula. 